\title{
KINETIC SHEAR STRENGTH OF THREE ROCK TYPES
}

\author{
by \\ John Q. Ehrgott \\ Structures Laboratory \\ U. S. Army Engineer Waterways Experiment Station \\ P. O. Box 631, Vicksburg, Miss. 39180
}

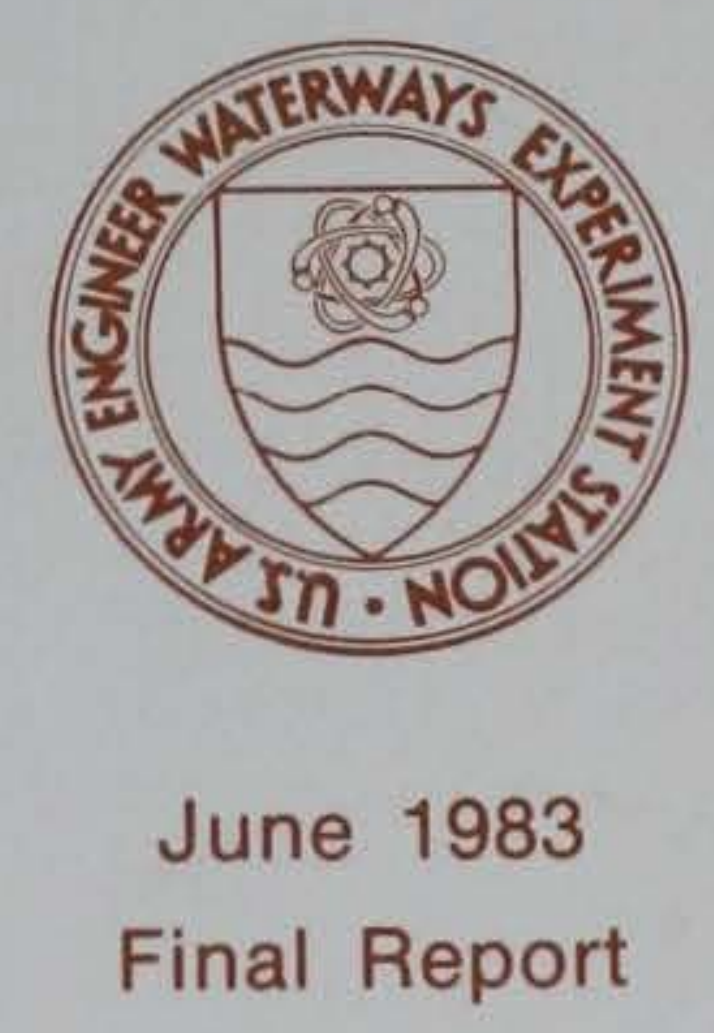

Approved For Public Release; Distribution Unlimited

\section{LUBRAM BRANCW}

TECHNICAL INFORMATION CENTER

US ARMY ENGINEER WATERWAYS EXPERIMENT STATIOF

VICKSBURG, MUISSISSIPPI

Prepared for Office, Chief of Engineers, U. S. Army Washington, D. C. 20314 
Unclassified

SECURITY CLASSIFICATION OF THIS PAGE (Whon Date Entored)

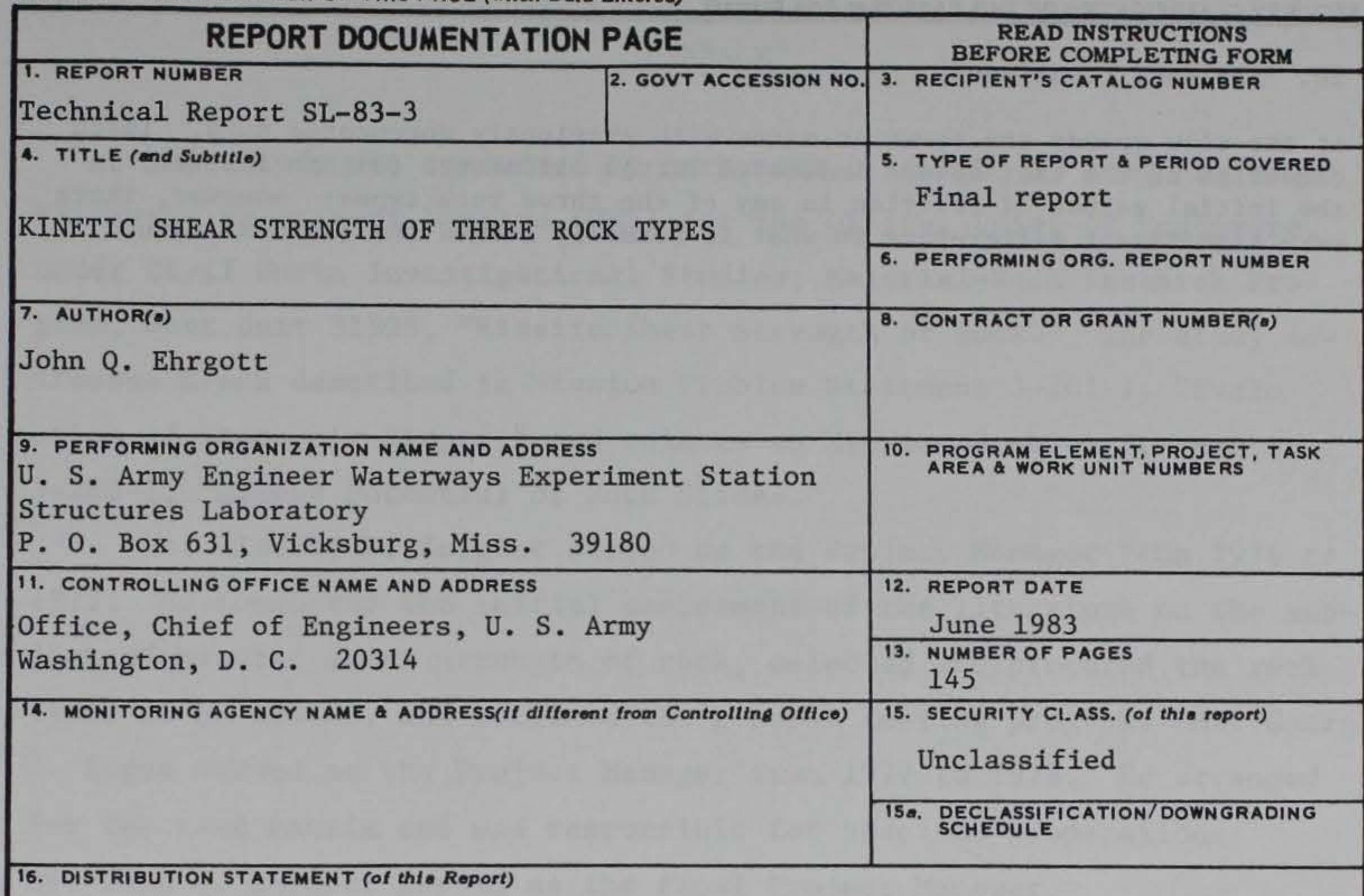

Approved for public release; distribution unlimited.

17. DISTRIBUTION STATEMENT (of the abotract antered in Block 20, if different from Report)

18. SUPPLEMENTARY NOTES

Available from National Technical Information Service, 5285 Port Royal Road, Springfield, Va. 22161.

19. KEY WORDS (Continue on reveree alde If necesaary and Idontlly by block number)

Kinetics Shear strength (Soils)

Geology Surface roughness

Rocks

20. AESTRACT (Continue an roverae of if if mecoatery and Identily by block number)

There has been little research into the kinetic friction developed between surfaces of rapidly moving geologic materials. This report documents the results of laboratory friction tests conducted on prepared surfaces of a limestone, a dolomite, and a sandstone. The laboratory tests were conducted in a dynamic friction device in which one hollow cylindrical specimen was rotated while another specimen was pushed into it. The rate of rotation could be varied from $0.15 \mathrm{in.} / \mathrm{min}$ to greater than $40,000 \mathrm{in.} / \mathrm{min}$. The data from tests conducted

(Continued) 


\section{ABSTRACT (Continued)}

at the slow speeds are shown to agree with previously documented data. Tests conducted at the fast speeds indicated little difference (within scatter) in the initial values of friction in any of the three rock types; however, there were significant differences in what is normally termed the residual value. 


\section{PREFACE}

This study was conducted by personnel of the U. S. Army Engineer Waterways Experiment Station (WES) for the Office, Chief of Engineers, under Civil Works Investigational Studies; Material-Rock Research Program, Work Unit 31525, "Kinetic Shear Strength of Rock." The study addresses needs described in Mission Problem Statement 3-201-1, "Evaluation of Reservoir Slopes," and relates to Mission Problem Statement 3-200-1, "Damage Potential of Rock Slides."

Mr. Timothy W. Zeigler served as the Project Manager from 1976 to 1977. He conducted the initial assessment of the literature on the subject of kinetic shear strength of rock, selected and procured the rock types to be tested, and outlined the general testing program. Mr. George L. Regan served as the Project Manager from 1977 to 1978. He arranged for the test matrix and was responsible for specimen preparation. Mr. John Q. Ehrgott served as the final Project Manager.

Mr. John 0. Curtis was the Project Engineer and was responsible for the conduct of tests and data reduction. He also prepared Appendices $\mathrm{A}$ and B. The laboratory friction tests were conducted by personnel of the Geomechanics Division, Structures Laboratory (SL). The mineralogical examination was conducted by personnel of the Concrete Technology Division, SL.

The work was performed under the general supervision of $\mathrm{Dr}$. Don C. Banks, Chief, Engineering Geology and Rock Mechanics Division, Geotechnical Laboratory. COL John L. Cannon, CE, COL Nelson P. Conover, CE, and COL Tilford C. Creel, CE, were Commanders and Directors of WES. Mr. F. R. Brown was WES Technical Director. 
PREFACE . . . . . . . . . . . . . . . . . . . . . . . . 1

CONVERSION FACTORS, NON-SI TO SI (METRIC) UNITS

OF MEASUREMENT ... . . . . . . . . . . . . . . . 3

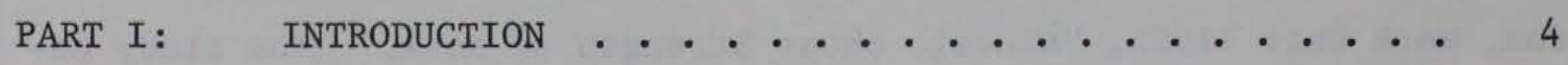

PART II: DESCRIPTION OF APPARATUS AND TEST PROCEDURES $\cdot \cdot \cdot \cdot \cdot 7$

R-Type Test . . . . . . . . . . . . . . . 7

N-Type Test ................... 13

Measurement Systems . . . . . . . . . . . . 18

Recording Systems . . . . . . . . . . . . . 20

PART III: ROCK DESCRIPTION AND SPECIMEN PREPARATION . . • . . . 21

Rock Description .................. 21

Specimen Preparation .............. . . . 23

PART IV: EXPERIMENTAL RESULTS . . . . . . . . . . . . . 29

Berea Sandstone .. . . . . . . . . . . . 31

Oneota Dolomite................... . 33

Bedford Limestone ... . . . . . . . . . . . 44

Summary of Data................ . . 73

PART V: DISCUSSION AND CONCLUSIONS . . . . . . . . . . 83

Comparison of Slow Test Results . . . . . . . . . 83

Comparison of Static to Dynamic Test Results . . . . . 87

Conclusions . . . . . . . . . . . . . . . 98

REFERENCES . . . . . . . . . . . . . . . . . . 103

APPENDIX A: COMMENTS CONCERNING SURFACE ROUGHNESS . . . . . . . A1

APPENDIX B: SURFACE PROFILES . . . . . . . . . . . . . . . B1 


\section{CONVERSION FACTORS, NON-SI TO SI (METRIC) \\ UNITS OF MEASUREMENT}

Non-SI units of measurement used in this report can be converted to SI (metric) units as follows:

$\frac{c}{\text { Multiply }}$
feet
feet per second
inches
inches
inches per minute
inches per second
inch-pounds (force)
microinches
pounds (force)
pounds (force) per
square inch
pounds (mass) per
cubic foot

\begin{tabular}{l}
\multicolumn{1}{c}{ By } \\
\hline 0.3048 \\
0.3048 \\
2.54 \\
0.0254 \\
1.524 \\
0.0254 \\
0.1129848 \\
0.0254 \\
4.448222 \\
0.006894757 \\
16.01846
\end{tabular}

To Obtain

metres

metres per second

centimetres

metres

metres per second

metres per second

newton-metres

micrometres

newtons

megapascals

kilograms per

cubic metre 


\section{KINETIC SHEAR STRENGTH OF THREE ROCK TYPES}

\section{PART I: INTRODUCTION}

1. The stability of slopes during the life of an engineering work is crucial to the usefulness and safety of the project, be it a lock and dam, a dam and reservoir, or a highway or railroad cut. Slope failures or slides occurring during the initial stages of construction generally are more a nuisance in nature and impact the project through cleanup costs and delays. Slides occurring several years after construction and during the operational life of the project tend to be catastrophic. This effect is especially likely if the project has been operational and there have been no warning signs of possible slope failure. For example, the slide at Vaiont, Italy, involved a large mass of rock, without apparent warning, moving at high speeds into a reservoir, resulting in a large wave overtopping a dam and devastating a vast region downstream.

2. However, detection of the potential slide zone with wel1defined boundary conditions may not be sufficient to predict the danger of the slide. At the Vaiont Dam prior to the actual slide, on 9 October 1963, there were indications of a slope movement or creep (Kiersch 1964). In fact, measurements of the slope movement were constantly being monitored (Kusnacht 1973). Then the unexpected happened. In less than $30 \mathrm{sec}$ the entire side of the mountain, $2 \mathrm{~km}$ long by $1.6 \mathrm{~km}$ wide, moved into the reservoir. Surface speed along the failure plane was estimated at 36,000 to $72,000 \mathrm{in./min.*} \mathrm{Factors} \mathrm{such} \mathrm{as} \mathrm{rock} \mathrm{shear}$ strength, rock asperities along the slide zone, and groundwater elevations in the side mass all had an important influence on the slide formation. These factors are usually true in all slides.

3. The influences of these factors are understood and can be accounted for in most engineering analyses if they are detected in the field. Other factors are yet to be understood. For example, in the

* A table of factors for converting non-SI units of measurement to SI (metric) units is presented on page 3. 
Vaiont slide and in retrospect, given all known boundary conditions, what value of friction would the design engineer use to analyze a slide moving at 36,000 to 72,000 in./min?

4. The U. S. Army Engineer Waterways Experiment Station (WES) was requested to analyze a potential landslide along the side of Lake Koocanusa at Libby Dam (Banks and DeAngelo 1972). Although the slide zone and many of the various factors were defined, there was a great deal of uncertainty regarding the velocity of the slide should it start to actually move. There was concern if the large mass of slide moved fast enough, it could strike the reservoir water with a momentum that would create huge waves. Waves of sufficient height could damage and/or overtop the dam itself. It was concluded that the factor which would affect the slide velocity was the kinetic shear strength of the rock.

5. The coefficient of friction which is commonly used in slope stability analyses relates only to the limiting equilibrium case--whether the rock will or will not move. However, the study undertaken by WES at Lake Koocanusa indicated little was known about the kinetic shear strength; i.e., the shear strength existing along moving rock surfaces. There was a lack of experimental data on the friction between rocks at rates in excess of $1 \mathrm{in./sec.}$

6. The study described herein was sponsored by the office, Chief of Engineers (OCE), to provide an experimental data base of the kinetic friction between several rock types. Previous experimental studies concerning friction between rocks were surveyed, and one was selected as a starting point--the work by Coulson (1970) performed at the University of Illinois. In his program, Coulson examined five rock types prepared with four different surface textures at a conventional rate of speed 0.1 in./ min. In the study reported here, a specially designed laboratory test device, which is described in Part II, was used to determine friction of geologic material at various rates of speed. Three of the same rock types and one of the four surface textures used in Coulson's study were selected and prepared as described in Part III. Tests were initially conducted in the WES friction device at rates similar to those used by Coulson, and results indicated a reasonable duplication of experimental 
data. Then, the rocks were tested at heretofore unattainable rates approaching $4000 \mathrm{in./min.} \mathrm{All} \mathrm{the} \mathrm{results} \mathrm{are} \mathrm{presented} \mathrm{in} \mathrm{Part} \mathrm{IV,} \mathrm{and}$ discussions and conclusions are presented in Part V. Appendices A and B contain data regarding the surface roughness measurements. 


\section{PART II: DESCRIPTION OF APPARATUS AND TEST PROCEDURES}

7. In FY 76 and 77, WES received OCE RDT\&E Special Purpose Equipment funds for the development of a test device capable of measuring the kinetic friction between various structural, earth, and rock materials. A contract was awarded to SECO-DYN, Inc., of Pomona, Calif., for the design and fabrication of a dynamic rotary shear test device with the ability to (a) accommodate unlimited shear displacements, (b) attain high velocities, (c) apply high normal loads, (d) handle specimen sizes compatible with 5- and 6-in.-diam core sizes, and (e) provide for phased future modifications for controlled static testing as well as controlled intermediate velocities. The device underwent successful demonstration tests in the fall of 1977.

8. The test device was designed to permit friction testing of hollow, cylindrical shaped specimens. Two types of loading tests can be conducted, as illustrated in Figure 1. In the first type test, the Rtype shown in Figure la, the specimen is first rotated up to a given speed, then a normal load as high as $50 \mathrm{MPa}$ is applied as fast as $1 \mathrm{msec}$. In the second type test, the $\mathrm{N}$-type in Figure $1 \mathrm{~b}$, one specimen is first forced into the other specimen under a given normal force, then, while the normal force is held constant, the second specimen is rotated at

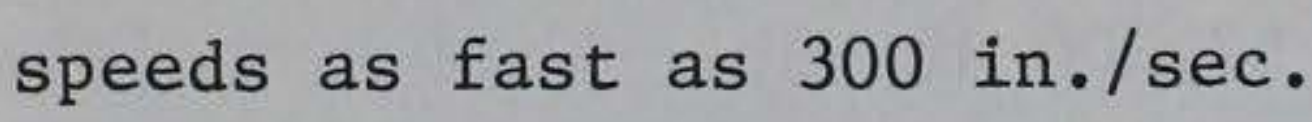

\section{R-Type Test}

9. Velocities up to $1100 \mathrm{in./sec}$ are attainable under a full normal pressure of approximately $50 \mathrm{MPa}$ (7250 psi); velocities up to 2300 in./sec are attainable under a reduced normal pressure of approximately $10 \mathrm{MPa}$ (1450 psi). In addition, even at the fastest velocities, the velocity does not reduce by more than 5 percent during the first $50 \mathrm{msec}$ after specimen contact. During the 50-msec time window, shear load developed between the specimens is measured, while the normal load and relative velocity are maintained essentially constant. However, the device takes hundreds of milliseconds to slow down and stop, and the 

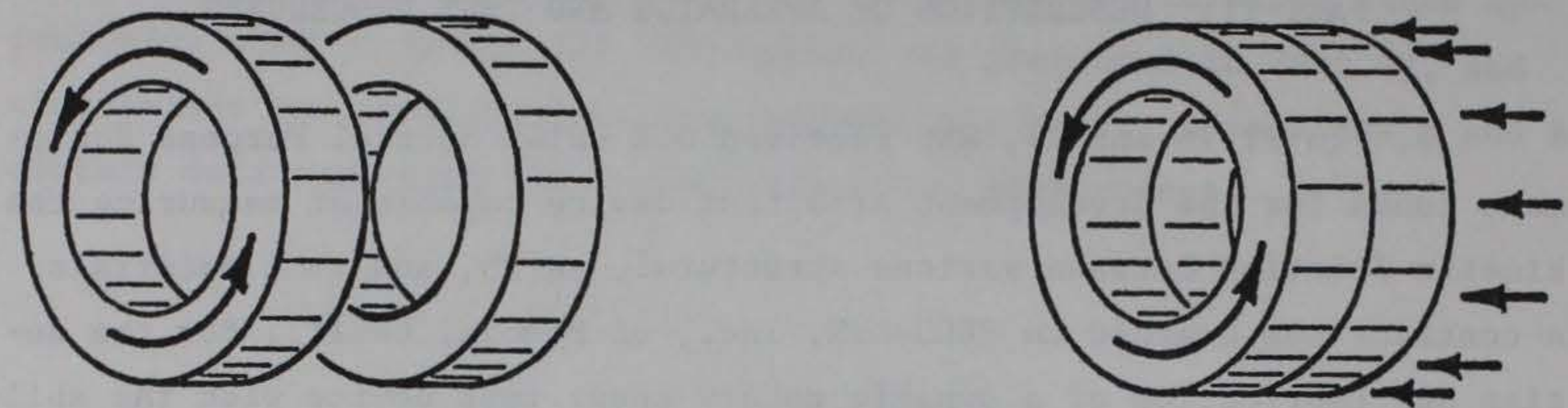

a. R-type test: one specimen is first rotated to a desired speed and then a normal force is applied
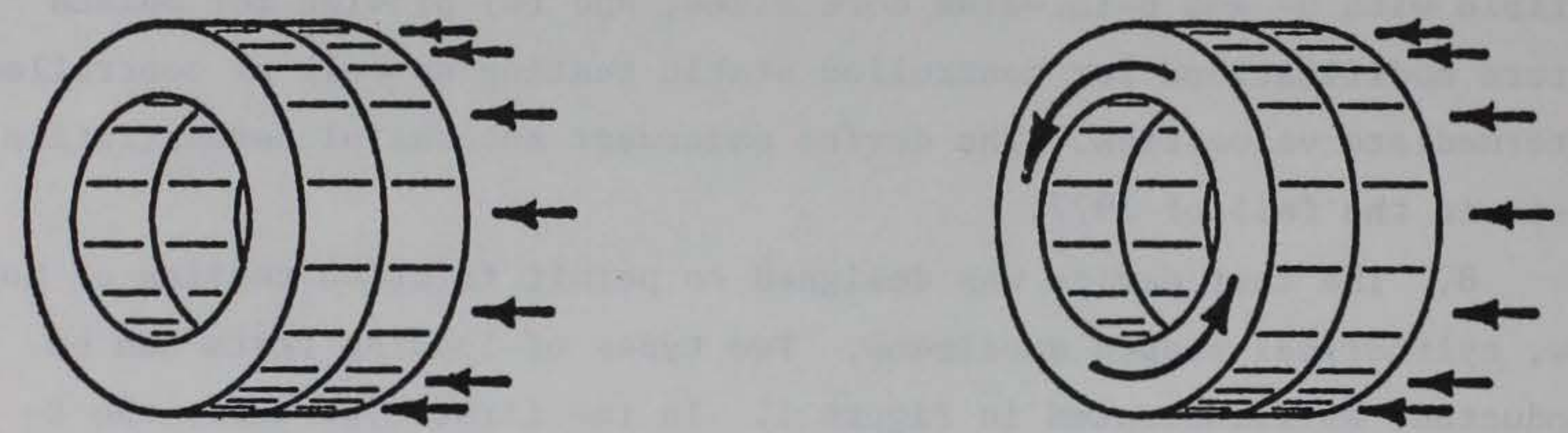

b. N-type test: the specimens are first loaded by a normal force and then one is rotated

Figure 1. The two types of loading tests

data are continuously recorded throughout the test. The maximum reaction torque which was specified was limited to 57,000 in.-1b. This translates into a maximum measurable coefficient of friction of 0.4 or less at a full normal surface stress of $50 \mathrm{MPa}$ (7250 psi). Surfaces with greater than 0.4 coefficient of friction must be tested at slightly reduced normal stress.

10. Figure 2 shows the basic dynamic friction test device as it would be configured for the R-type test. Various components such as the electric drive motor, flywheel, specimen containers, normal pressure rise valve, and normal gas reservoir are identified. The device can be divided into two sections: the rotational system and the normal force system. The rotational system contains the drive motor, main shaft, flywheel, and rotating specimen container. These are also shown on the left side in Figure 3. Speeds of up to $2300 \mathrm{in./sec}$ are 


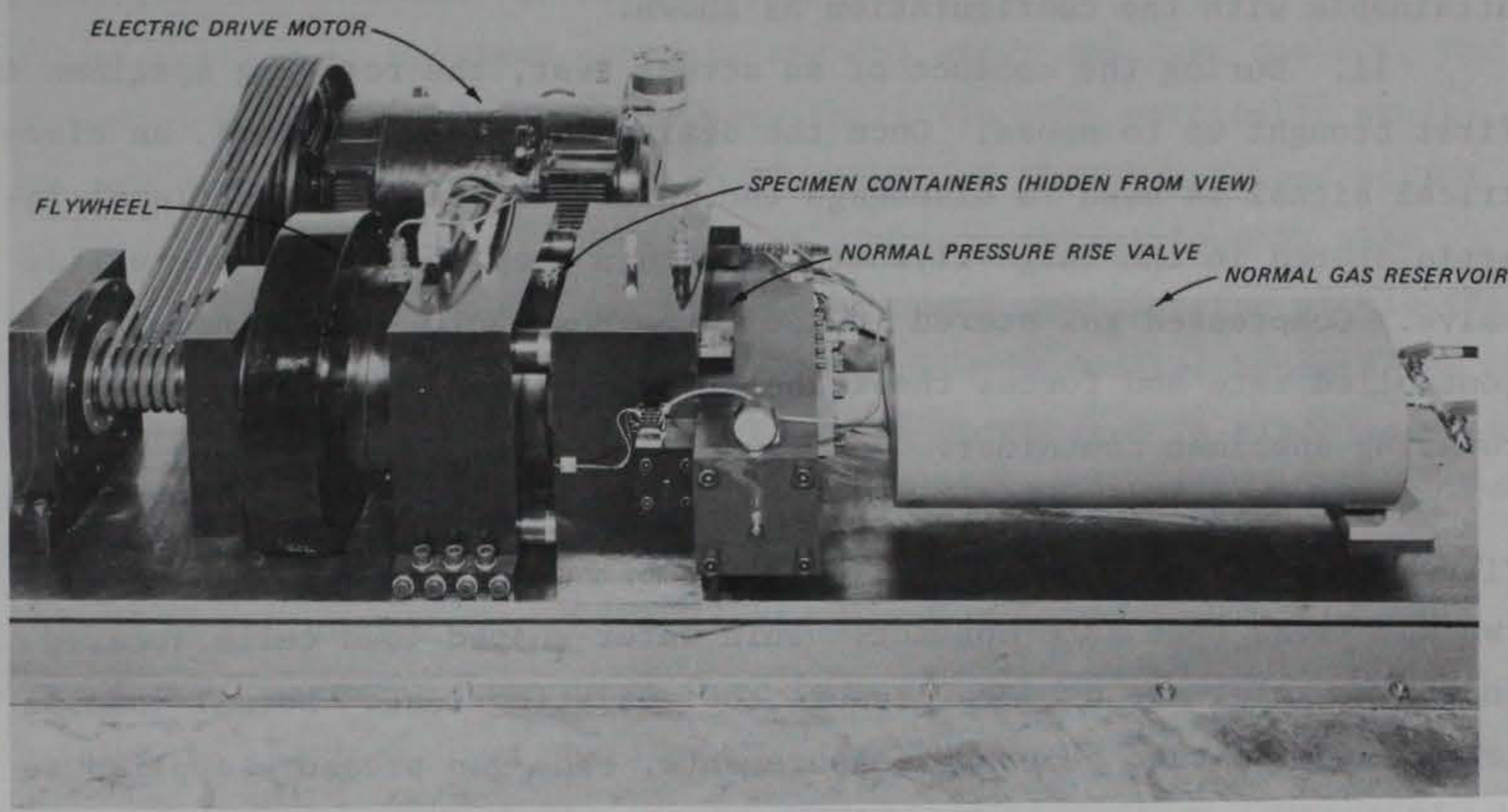

Figure 2. Dynamic friction test device assembled and ready for test initiation

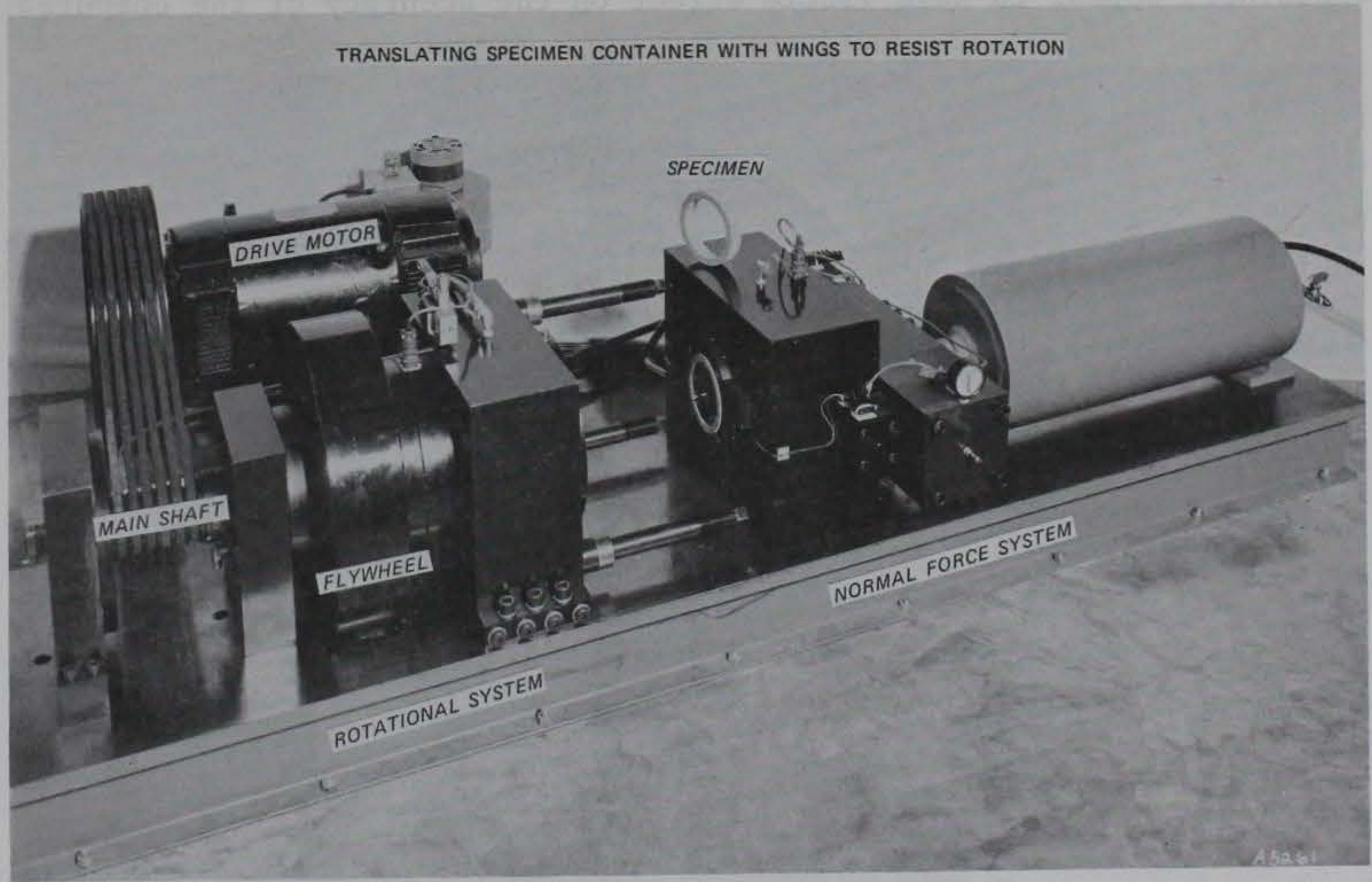

Figure 3. Dynamic friction test device disassembled to permit access to specimen containers 
attainable with the configuration as shown.

11. During the conduct of an actual test, the rotating specimen is first brought up to speed. Once the desired speed is attained, an electrical signal is used to disengage the motor, leaving all rotational inertia stored in the large flywheel, and then open the normal force rise valve. Compressed gas stored in the large reservoir is released at a controlled rate and forces the translating specimen container into the rotating specimen container.

12. Large wings on the translating specimen container, shown in Figure 4 , resist the torque caused by specimen surface friction as the two specimens come into contact. Thin wafer-shaped load cells located under each wing are used to measure the resisting load. Normal load is determined from two separate measurements. The gas pressure applied to the back side of the container is measured, and the normal load is computed from the pressure applied to the area. 0-rings, which seal the container, appear to have little effect on the accuracy of the computed

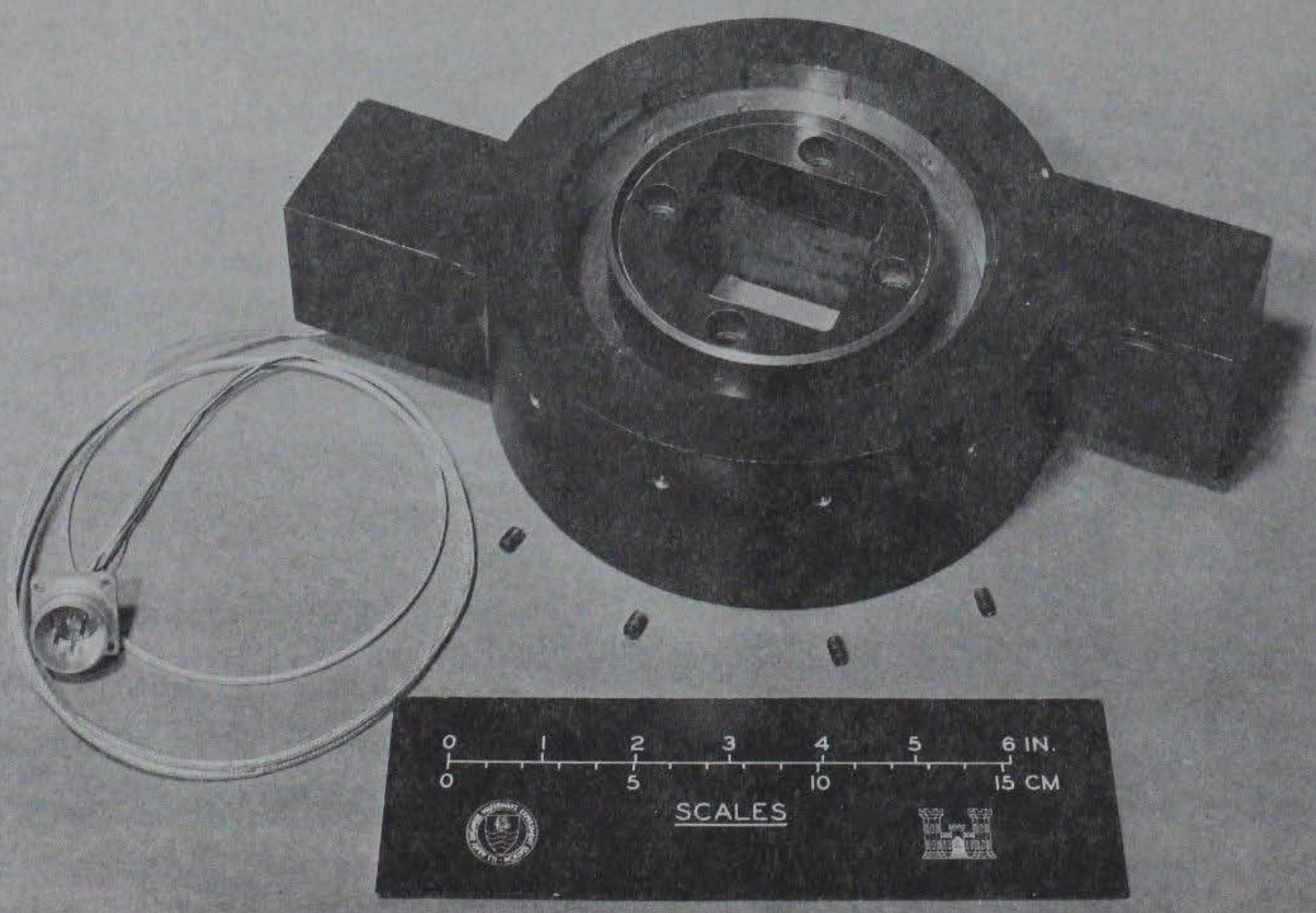

Figure 4. Translating specimen container 
load, probably because (a) breakaway friction of the 0-rings has already occurred prior to specimen contact, and (b) after specimen contact, the amount of specimen deflection is very small (in this particular study). The gas pressure is therefore a good measure of the normal load acting on the specimen surfaces. However, as a check, normal load is also measured directly by a special ring-shaped load cell located within the translating specimen container. The load cell is located beneath the specimen and serves as the base. It can be calibrated in place using a steel specimen to load its surface. Different ranges of load cells are available. Figure 5 shows a close-up of the translating specimen container in the device immediately following a test. A portion of the specimen it contains appears to have been ripped off during the test, resulting in the irregular surface. At the center of the container is a cone which forms part of the linear variable differential transducer (LVDT) system used to measure continually the deflection between the translating and rotating containers. The LVDT also provides a monitor

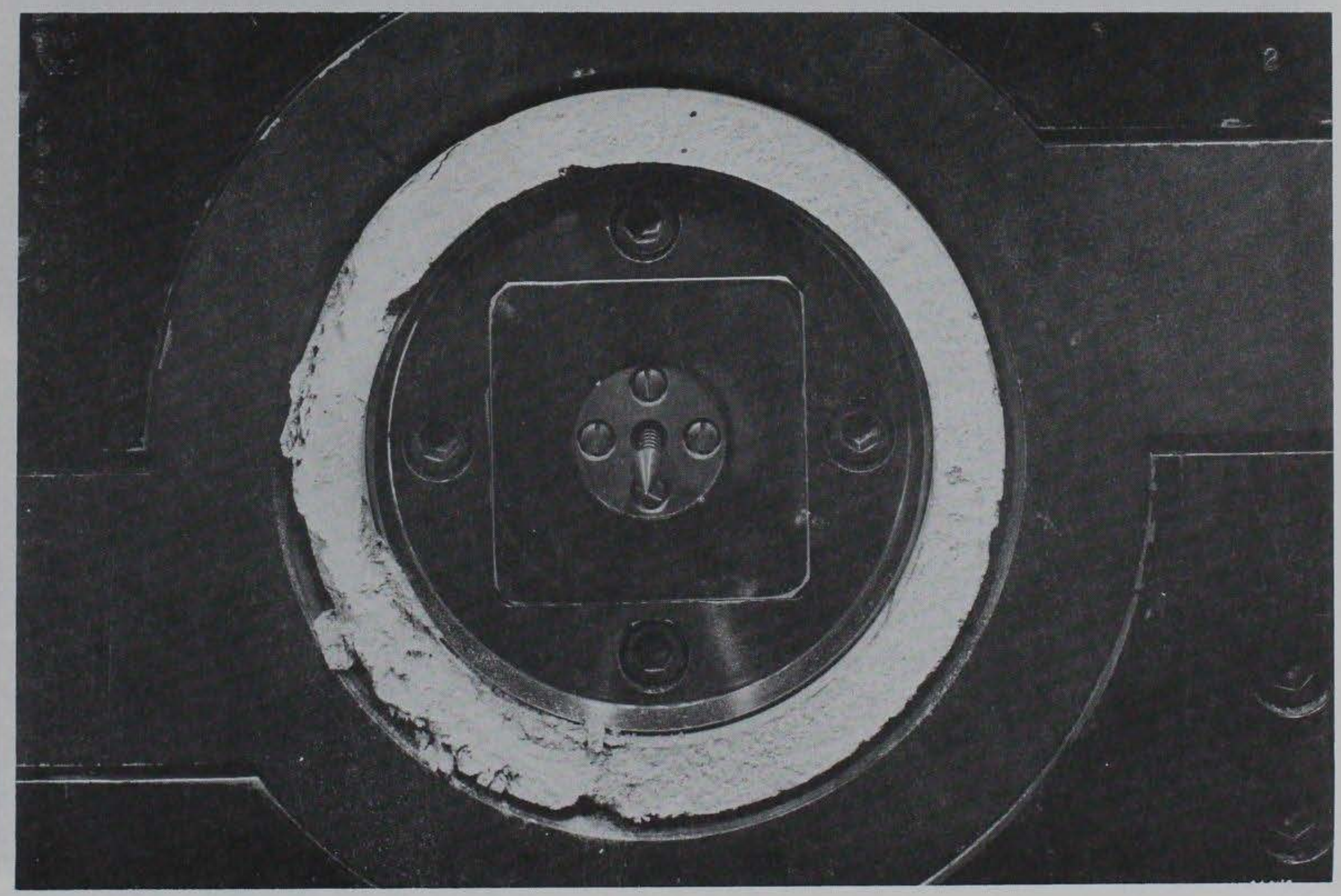

Figure 5. Close-up of translating specimen container 
on specimen conditions during the test. For example, should a particle from a specimen become dislodged during a test, causing a spreading apart of the specimens, then the movement between the containers is evident in the test record.

13. Figure 6 shows a close-up of the rotating specimen container in place just after testing. It contains the other half of the test specimen (previously mentioned). Although the rotating specimen container does not translate, there is an extremely small oil reservoir located directly behind the container. A flush-mounted pressure transducer is used to measure the oil pressure as the translating container comes into contact with the rotating specimen. Although the pressure is not as accurate an indication of normal force, it nevertheless indicates specimen contact and is generally a reliable guide to the normal forcetime history.

14. The grooves located around the periphery of the rotating container operate in conjunction with the optical tracking system used to

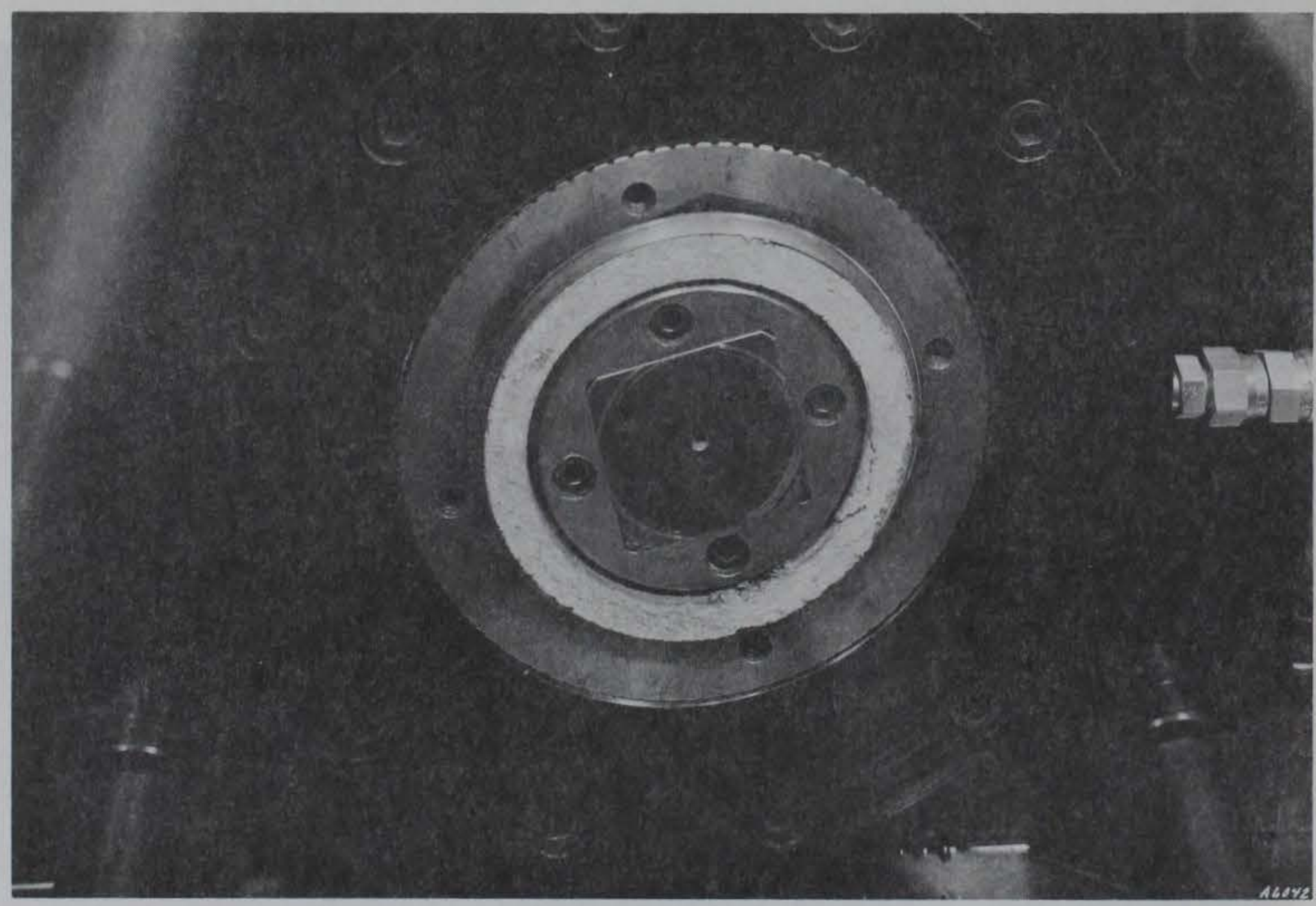

Figure 6. Close-up of rotating specimen container 
measure the rotational speed of the container.

15. The rotating specimen container itself is shown in Figure 7 . The bolts are used to attach the container to the main rotational shaft. A specimen is first placed in the container; then the assembly is placed onto the shaft. Close tolerances are maintained in the machinery of the device, and therefore there is virtually no play in the container or the shaft. The bolts are tightened, but some very minor adjustments are possible to more perfectly align the rotating specimen's surface with the translating specimen's surface. In addition, the entire normal force system containing the translating specimen can be aligned by a system of four large bolts and spacers attached to the rotating system.

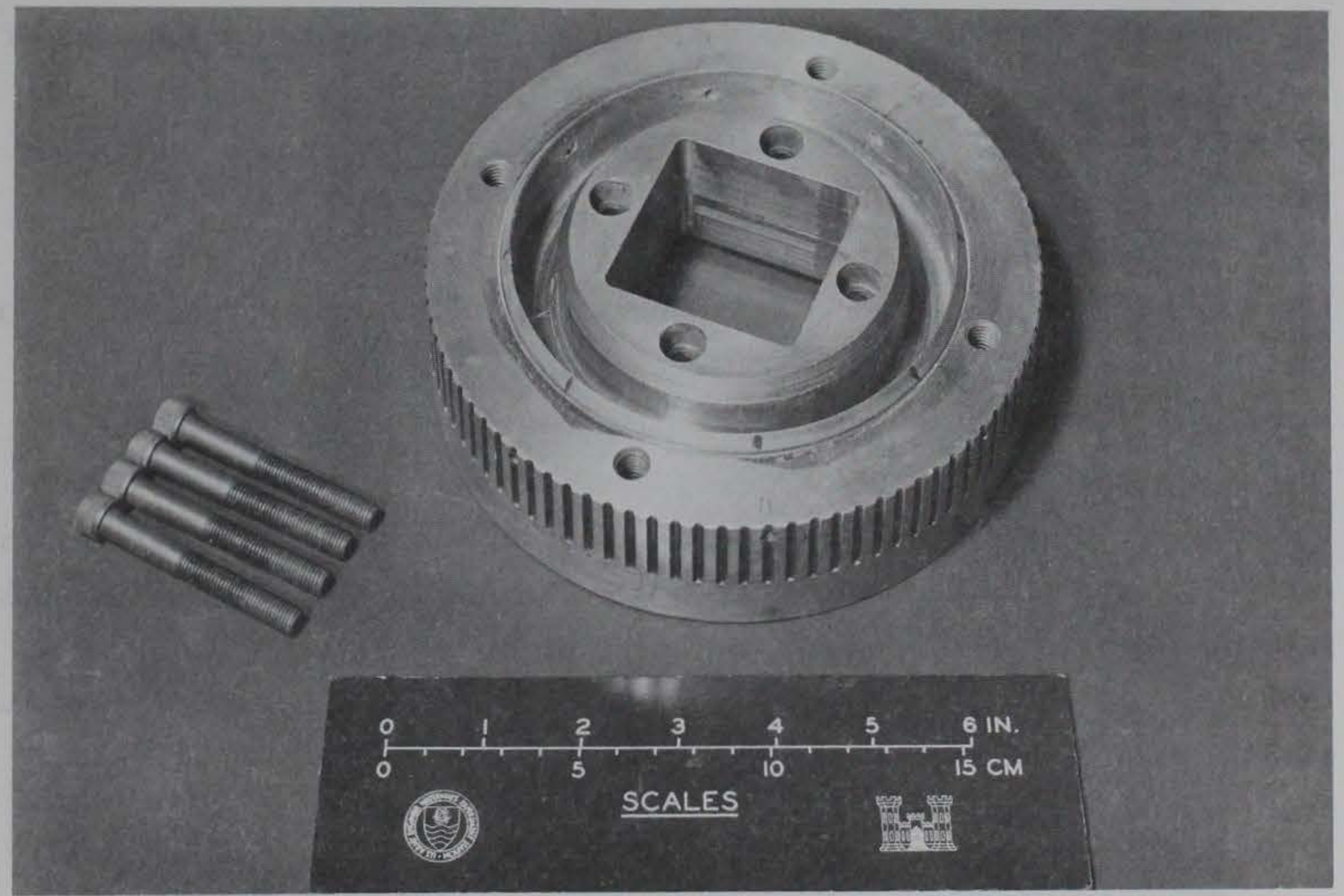

Figure 7. Rotating specimen container

\section{N-Type Test}

16. During an N-type loading test, the specimens are first brought together at a controlled application of normal force. One specimen is 
then rotated at a controlled rate ranging from less than $0.003 \mathrm{in} . / \mathrm{sec}$ to speeds of up to $300 \mathrm{in./sec.} \mathrm{As} \mathrm{with} \mathrm{the} \mathrm{R-type} \mathrm{test,} \mathrm{measurements} \mathrm{are}$ continually made of the applied normal load, the resisting torque load, and the rotating specimen speed.

17. N-type tests are conducted with the device configuration shown in Figure 8. The drive motor and associated sheaves are removed and replaced with a rack drive system. The rack, shown in Figure 8 in a pretest position, is pushed through the drive gear by a large piston on a guide rail. The drive gear turns the flywheel-rotational specimen container assembly. A shock absorber at the far end of the rack guide slows and stops the rack.

18. A view from the opposite side of the testing area is shown in Figure 9. The piston assembly is visible. This assembly consists of two long cylindrical reservoirs. The lower unit houses the piston; the upper unit contains either a fluid (for slow tests) or a gas (for rapid tests).

19. Prior to a test, a fast-opening valve located at the rear of the reservoir is closed and permits pressurizing the upper reservoir. On test command, the valve opens and the gas or the fluid is channelled through a preset orifice and acts on the piston. The piston in turn pushes the rack.

20. During operation in the rapid mode, the piston accelerates the rack to produce flywheel rotations approaching $1500 \mathrm{rpm}$ in less than two revolutions. In the slow mode, movement of the rack is barely perceptible, and therefore the rotation of the flywheel must be carefully measured. Such measurements usually are made manually with a $0.01-$ in. scale and stopwatch.

21. The control cables and hydraulic lines which are visible in both Figures 8 and 9 are run directly to a control console located in an adjoining room. The console is pictured in Figure 10. It contains all the necessary valves and electrical switches required for test device operation. In addition, the console also houses various other components required for device operation such as pressurized air oilers which ensure proper lubrication of all bearings during operation. The controls on the 


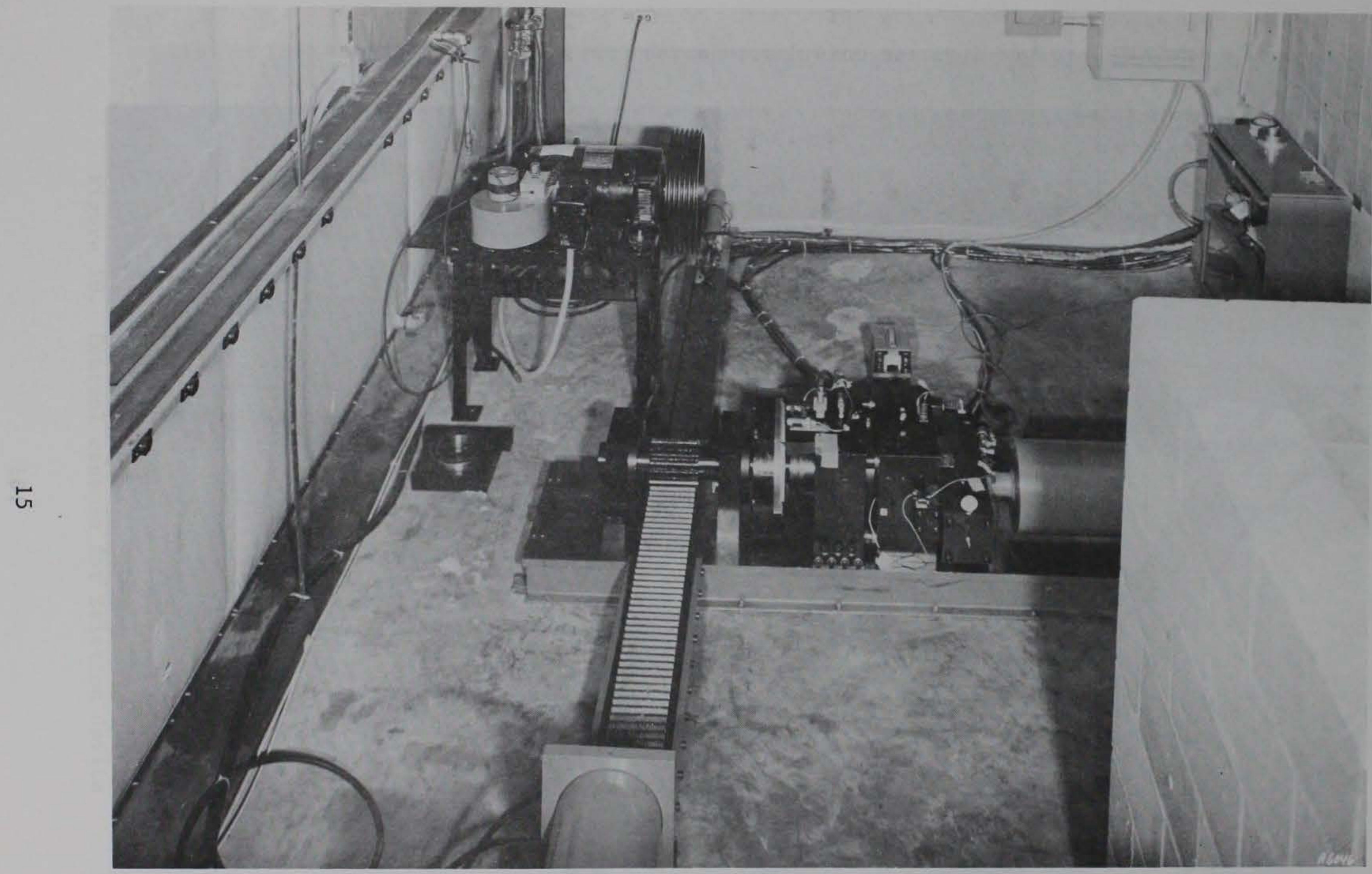

Figure 8. Friction device with rack drive system 


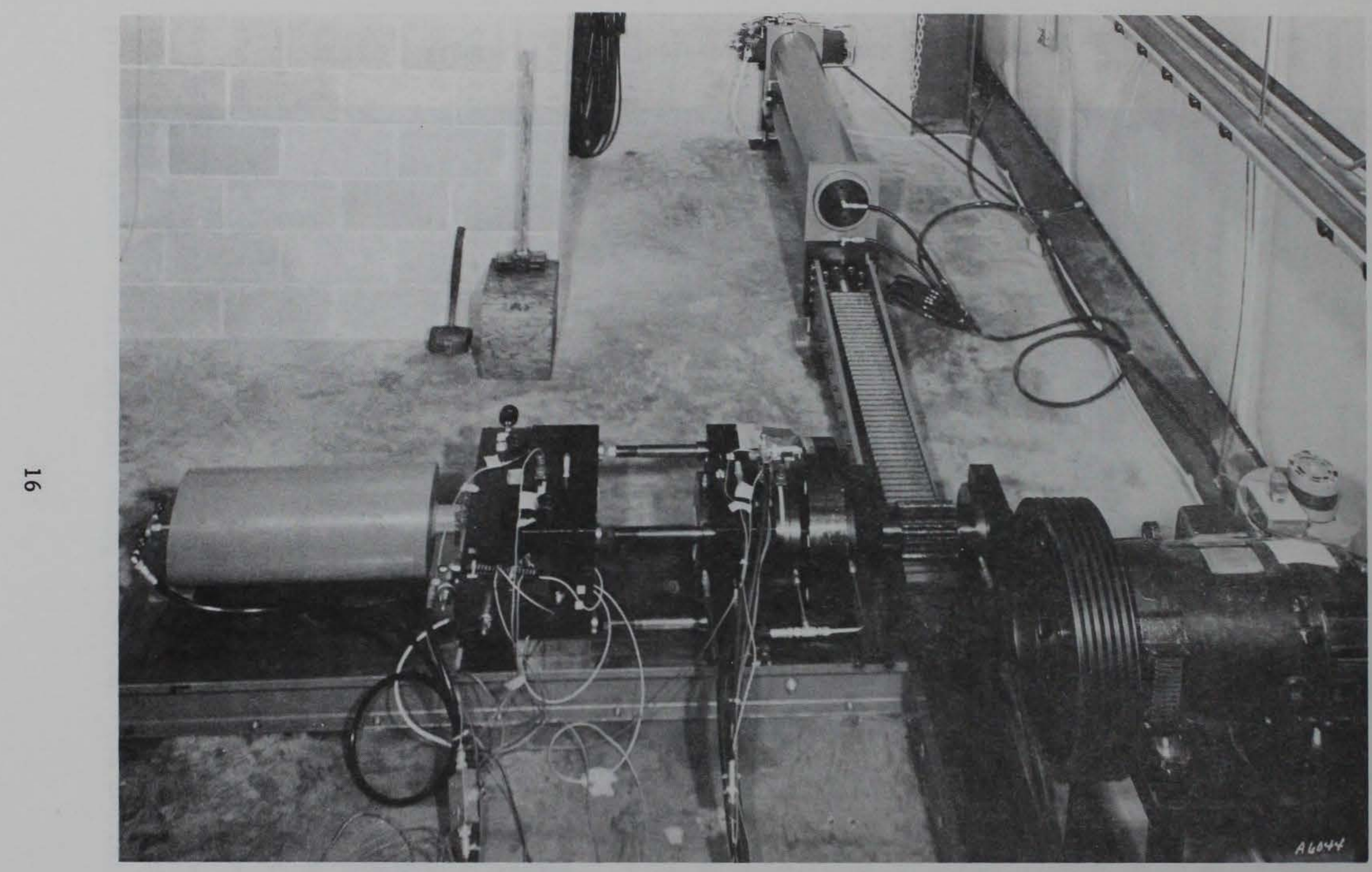

Figure 9. Friction device with piston assembly visible 


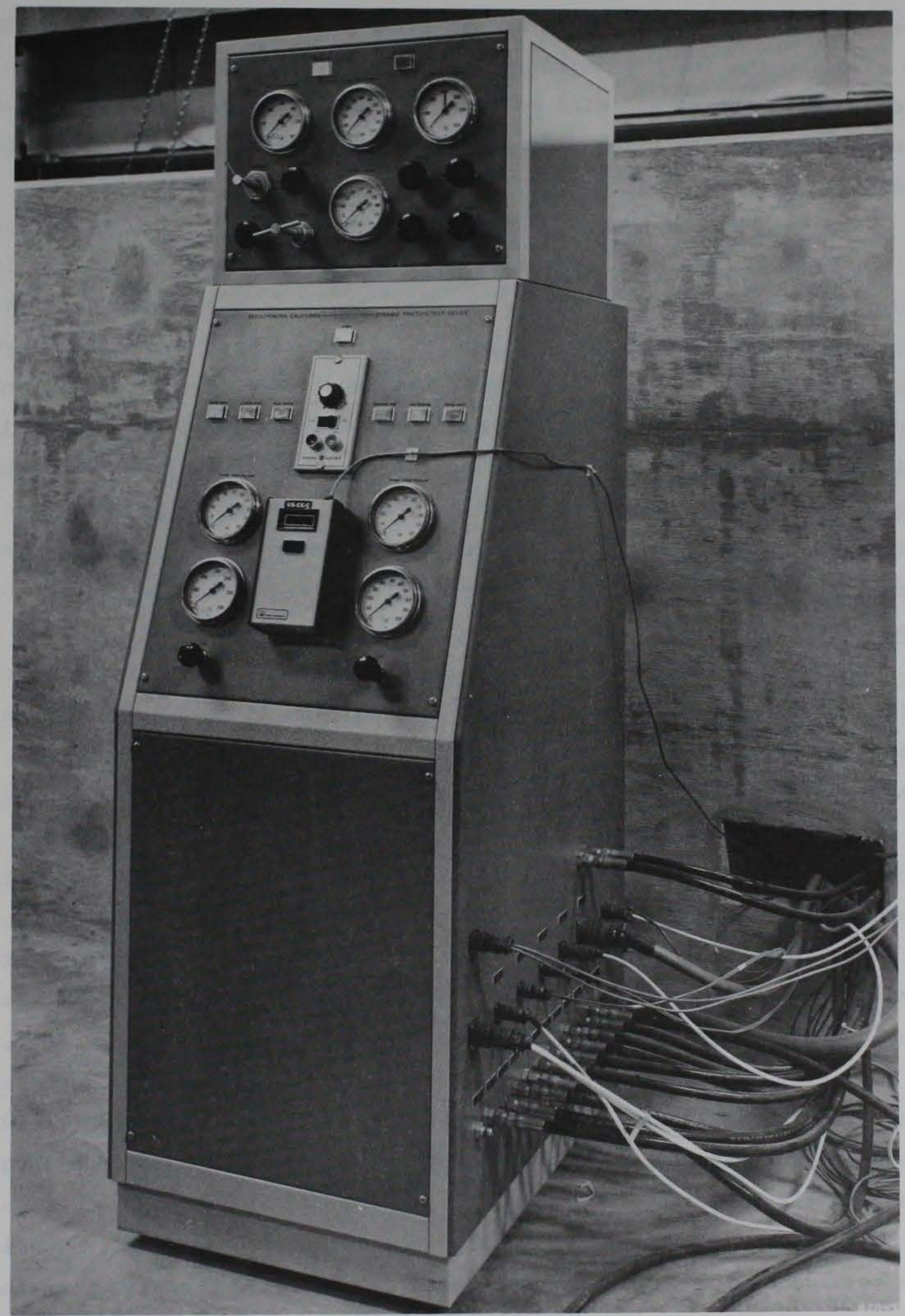

Figure 10. Control console for friction device 
face of the upper portion are for the rack drive system. The switches and gages on the lower portion face control the application of normal force. The switches and dial on the small center plate control the motor. Programmable timers are used for proper timing of controlled events.

\section{Measurement Systems}

22. Mention has been made earlier of the various measurement systems used throughout the test device. All the systems were designed not only to obtain the necessary data but more importantly to permit in-place calibration through the same instrumentation systems used to record the data. Each transducer was selected to provide optimum output over an anticipated range. In those cases where several ranges were to be examined, interchangeable transducers were obtained.

Normal force

23. A WES-designed, ring-shaped load cell was used to measure the applied normal force. The load cell is strain-gaged in a full compensating bridge, slips into the bottom of the translating specimen container, and serves as the bottom for the test specimen. Electrical wires are brought out through the container and out the front of the normal force system. Several ranges of load cell are available. The range is determined by the thickness of the center section of the ring.

24. Calibration of the cell was accomplished by placing the entire translating specimen container in a loading frame. All electrical wires were left connected to the actual recording system. A steel specimen, the same size as the rock specimens, was placed in the specimen container, and known loading increments were added to the assembly. As with all instrumentation signal conditioning systems used, multiple calibration resistive steps were used.

25. In general, the load cell was sensitive to nonuniform loadings such as a point loading over one portion of the cell. Complicating the matter was the fact that in many tests the specimens were tightly held in the specimen container. Load applied to the specimen surface was 
transferred to the side wall rather than the base load cell. Therefore, the load cell data were used very carefully and only after reasonable comparison with the normal pressure cell data.

Normal pressure

26. A commercial pressure transducer is located behind the translating specimen container to record the pressure used to produce the normal force. The pressure was calibrated through the same signal conditioning instrumentation employed for the tests. Dead loading calibration tests were also conducted with the transducer in place. Pressure was applied to the container which was held in place by a load cell. The pressure recorded by the transducer (when multiplied by the area) compared favorably to the load cell output.

27. A similar pressure transducer is also located in an extremely small hydraulic chamber behind the rotating specimen container. However, due to rotational inertia of the container, the transducer only registers gross loading of the specimen container and is only used as a check on the applied load.

Torque load

28. Thin disc-shaped load cell washers are located on either side of the translating specimen container. The cells are sandwiched between discs of a commercially produced friction reducer. The translating container moves across the load cells, and the friction reducer minimizes the loading effect due to drag forces. The load washers were calibrated individually against a prediction load cell held within a loading frame. Each washer was, however, calibrated through the same signal conditioning instrumentation circuit.

Movement

29. Movement between the two specimen containers is monitored by an LVDT system. The coil portion of the unit is held in a recessed hole located in the center of the translating specimen container. A springloaded core rod is used whose arrow-shaped point contacts the center of the rotating specimen container. The unit is used mostly for test control and as an indicator of gross specimen movement and general test performance. 
Speed

30. A fiber optical probe is mounted in the housing around the rotating container. The fibers are divided into two sections, 1ight transmitters and light receivers. Light is shown into the transmitters which reflect light off the grooves of the container; the receivers are connected to a photo cell which senses the reflected light. The grooves alternately cause more or less light to be reflected, which is converted into an electrical output by the photo cells and when amplified is recorded as a series of blips on the magnetic tape and/or oscillograph. This signal is also fed into an integrating circuit which can be precalibrated and recorded directly as a velocity at rotational speeds greater than $400 \mathrm{rpm}$. WES-designed and -built amplifiers were used to condition the transducer signals, except for those of the LVDT. These amplifiers and transducers had a frequency response of greater than $1500 \mathrm{~Hz}$. The LVDT employed a commercial carrier amplifier; this system had a system response slightly better than $600 \mathrm{~Hz}$.

\section{$\underline{\text { Recording Systems }}$}

31. All signals were recorded on magnetic tape and on light beam oscillographs. The purpose of the oscillograph was to serve as a backup recording system as well as to provide a quick look at the test data.

32. The magnetic analog tape was digitized on a system at WES specially designed for that purpose. The system permitted data processing in the course of digitizing, and thus the raw analog data on tape were processed into tabulated data and plots in one step.

33. The oscillograph records were hand-reduced, and the raw data processed through a computer program on time-sharing. The output was obtained in the form of $\mathrm{X}-\mathrm{Y}$ plots. The data reduced from oscillograph records were marginal in resolution, especially in the case of the R-type tests, and therefore only used if the magnetic tape system failed. 


\section{$\underline{\text { Rock Description }}$}

34. Three types of rock taken from quarry blocks were used in this study: Oneota dolomite from Kasota, Minn.; Bedford limestone from Bedford, Ind.; and Berea sandstone from Amherst, Ohio. They were selected mainly because of their documented properties and uniformity.

35. Oneota dolomite is a grayish-orange (10YR7/4), * fine-grained, massive, porous calcitic dolomite that contains some quartz and feldspar. The quartz was more common than the feldspar. The grain size based on thin sections examined with a polarized microscope (Figure 11) ranged

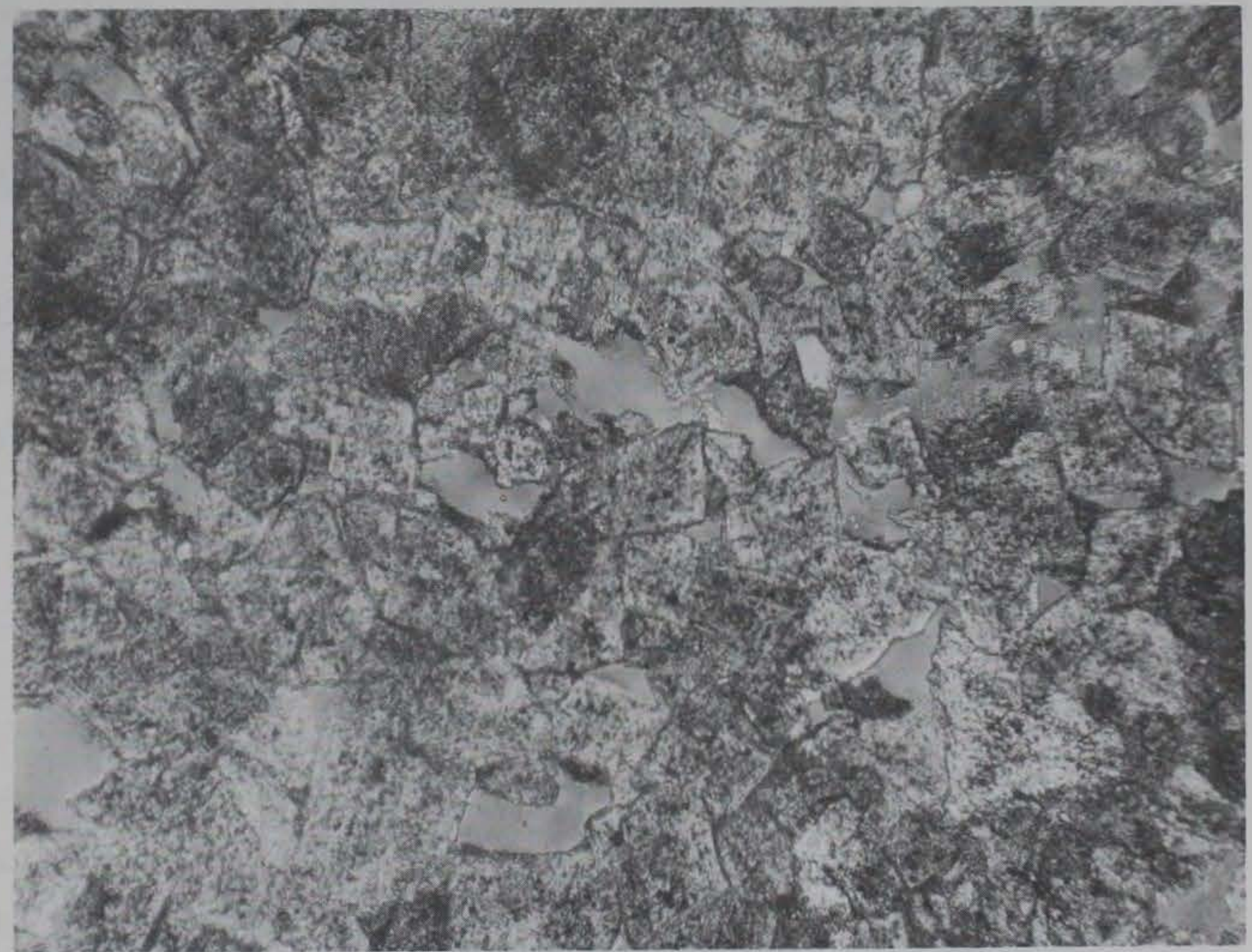

Figure 11. Photomicrograph of dolomite specimen, crossed nicols

* This system is according to the Rock-Color Chart Committee, E. N. Goddard, Chairman (1975). 
from 15 to $220 \mu \mathrm{m}$ for the carbonate rhombs to 15 to $85 \mu \mathrm{m}$ for the detrital grains of quartz and feldspar. The dolomite is clouded with opaque dust which in some grains has migrated to the boundaries. Bedford limestone is a yellowish-gray $(5 Y 7 / 2)$ slightly porous oolitic limestone which contains small amounts of quartz and possibly some amphibole. Grain size ranged from 300 to $450 \mu \mathrm{m}$. A photograph taken of a thin section is shown In Figure 12. Foraminifera (up to $860 \mu \mathrm{m}$ ), brachiopod shells, fragments of bryozoans, ostracods, and oolites of carbonate material (1000 $\mathrm{m}$ in diameter) lie in a cement of optically continuous calcite.

36. Berea sandstone is a light olive-gray (5Y5/2), fine-grained, massive, slightly porous sandstone consisting of mostly quartz with minor amounts of feldspar, siderite, and kaolinite. Some calcite and clay mica were also detected. Grain size ranged from 40 to $310 \mu \mathrm{m}$ with the average size of approximately $190 \mu \mathrm{m}$ as determined from the thin section shown in Figure 13. Secondary quartz growth serves as the predominate cementing material; however, in places, a fine-grained calcite cement holds the

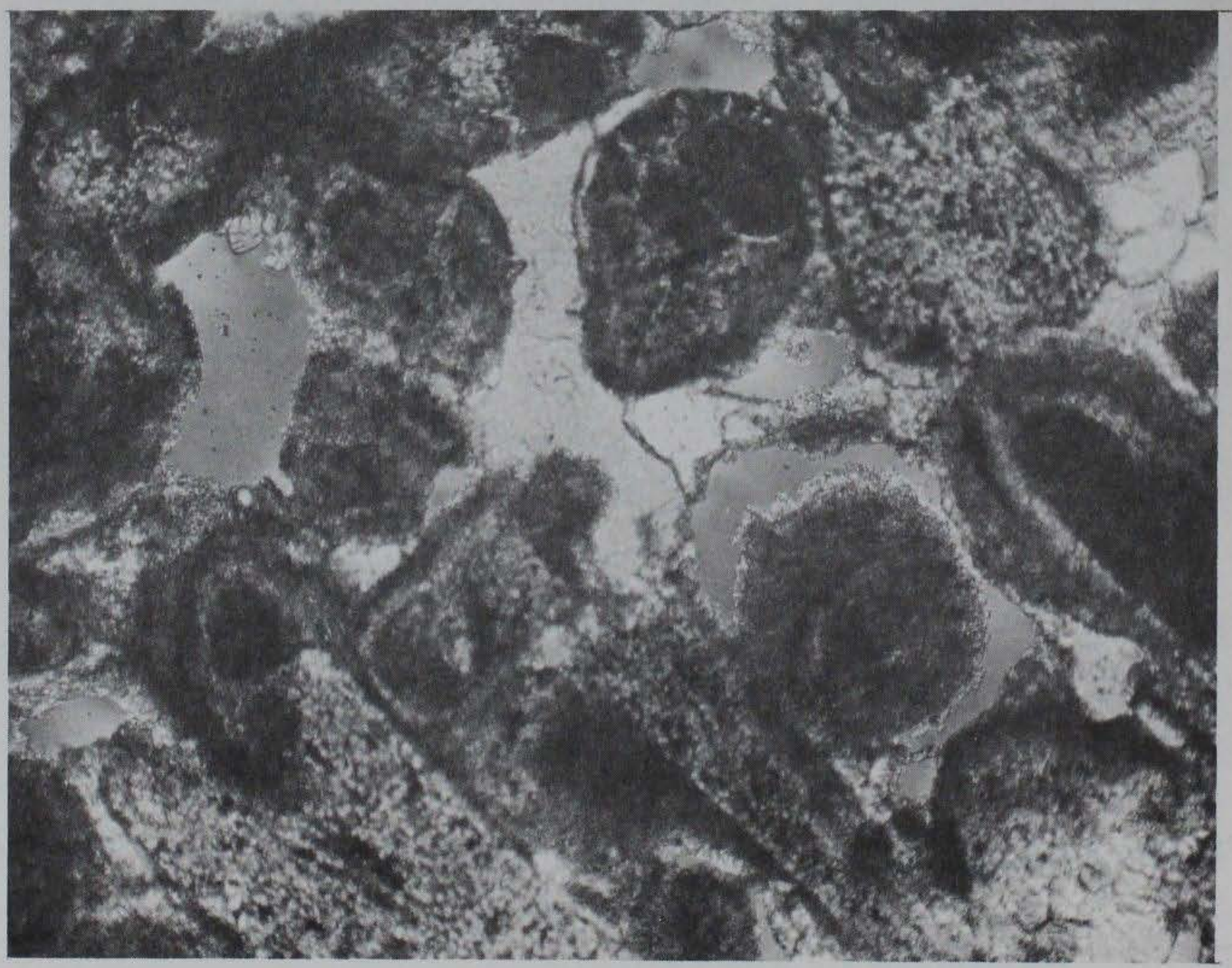

Figure 12. Photomicrograph of limestone specimen, crossed nicols 


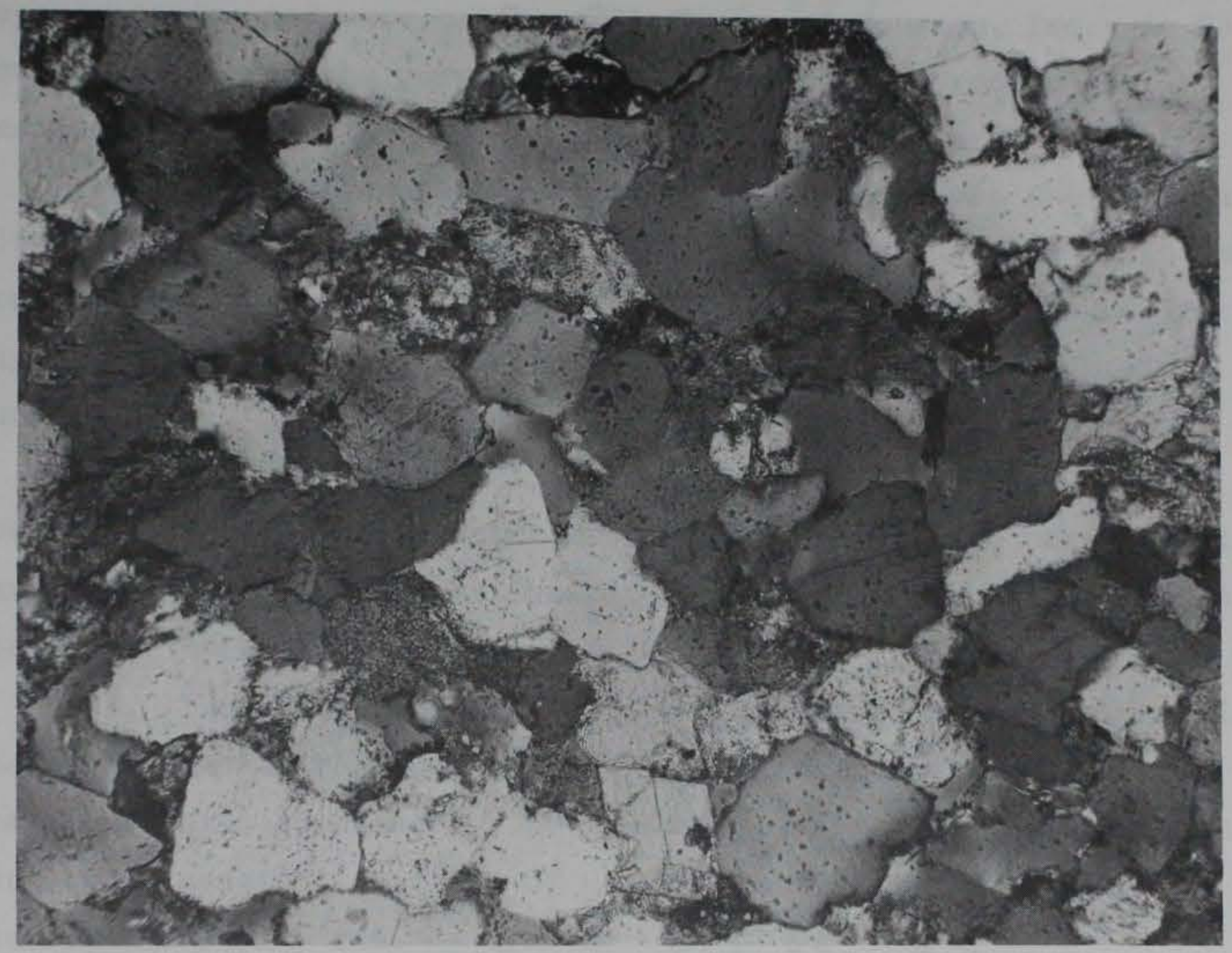

Figure 13. Photomicrograph of sandstone, crossed nicols detrital quartz grains in place. A summary of the various engineering properties is presented in Table 1 . Values are taken directly from Miller (1966).

\section{Specimen Preparation}

37. As was noted, each type of rock was received at WES as a quarry block. Each material was initially cored in 12-in. lengths with a 5-1/4-in. outside diameter. Specimens were then machined to be 4.000 in. in inside diameter by $1.000 \mathrm{in.} \mathrm{thick.} \mathrm{Tolerances} \mathrm{of} \pm 0.003$ in. were acceptable. Many potential specimens were broken during the final stages of machining.

38. Following machining, the specimen surfaces were prepared by vibratory lapping in clean tap water. They were first ground with a No. $3 F$ silicon carbide grit, and then a No. 600 alumina grit was used. 39. Seven specimens of each rock type were selected as being 
Table 1

Index Engineering Types (Miller 1966)

\begin{tabular}{|c|c|c|c|c|c|c|c|c|c|}
\hline Rock Type & $\begin{array}{l}\text { Unit } \\
\text { Weight } \\
\text { pcf }\end{array}$ & $\begin{array}{l}\text { Unconfined } \\
\text { Compressive } \\
\text { Strength } \\
\text { psi } \\
\end{array}$ & $\begin{array}{l}\text { Tangent } \\
\text { Modulus of } \\
\text { Elasticity } \\
10^{6} \text { psi }\end{array}$ & $\begin{array}{l}\text { Schmidt } \\
\text { Rebound } \\
\text { Hardness } \\
\quad \text { R } \\
\end{array}$ & $\begin{array}{c}\text { Abrasion } \\
\text { Hardness } \\
\mathrm{H}_{\mathrm{a}} \\
\end{array}$ & $\begin{array}{l}\text { Sonic } \\
\text { Velocity, fps, } \\
\text { at } 5000 \text { psi } \\
\text { Axial Stress } \\
\end{array}$ & $\begin{array}{l}\text { Sonic } \\
\text { Velocity, fps, } \\
\text { at } 100 \text { psi } \\
\text { Axial Stress } \\
\end{array}$ & $\begin{array}{c}\text { Absorption } \\
\% \\
\end{array}$ & $\begin{array}{c}\text { Total } \\
\text { Hardness } \\
\mathrm{H}_{\mathrm{T}} \\
\end{array}$ \\
\hline $\begin{array}{l}\text { Berea } \\
\text { sandstone }\end{array}$ & 136.2 & 10,700 & 2.80 & 42 & 0.47 & 12,540 & 8,665 & 8.27 & 28.8 \\
\hline $\begin{array}{l}\text { Oneota } \\
\text { dolomite }\end{array}$ & 153.0 & 12,600 & 6.38 & 43 & 1.00 & 17,070 & 16,305 & 5.39 & 43.0 \\
\hline $\begin{array}{l}\text { Bedford } \\
\text { limestone }\end{array}$ & 137.7 & 7,400 & 4.14 & 33 & 0.43 & 13,925 & 12,825 & 8.14 & 20.3 \\
\hline
\end{tabular}


representative and were taken to Clarkson and Foreman, Inc., in Bound Brook, N. J., for the purpose of obtaining surface roughness measurements.

40. The device used at Clarkson and Foreman was the Surfanalyzer 136 system which can be used for making surface roughness measurements of round objects. The object is placed on a flat table which can rotate at any rate from about $1 / 4$ to $8 \mathrm{rpm}$ while the stylus is held against the surface.

41. The Surfanalyzer 136 system is capable of measuring at least four basic quantities associated with surface texture: true profile, waviness, roughness, and arithmetic average or roughness height (American Society of Mechanical Engineers (ASME) 1962).

42. The true profile is a record of actual up-and-down motions of the stylus and is recorded on a strip chart recorder. Within the physical constraints imposed by the stylus tip, the true profile is an accurate two-dimensional picture of what any surface looks like along the path of the stylus tip.

43. Waviness is the low-frequency component of a profile which may also be recorded on a strip chart and can be taken as a measure of flatness of a whole surface. Roughness, on the other hand, is the highfrequency component of a profile and may be superposed on waviness to yield the true profile. Information concerning the cutoff frequency for these two quantities was not available.

44. Finally, there is the arithmetic average deviation (or average roughness height), which is most often used as a quantitative measure of surface roughness. Presumably, the rougher the surface, the higher the arithmetic average. One must be cautioned that this is not a sufficient measure of surface roughness (see Appendix A). The arithmetic average may be recorded in two ways on the instruments made available by Clarkson and Foreman: one is on a strip chart and the other is by a dial reading.

45. Surface roughness recordings are very sensitive to a quantity called roughness-width cutoff (ASME 1962), which is defined as the greatest spacing of irregularities to be included in the measurement of average roughness height. Roughness-width cutoff acts as a filter in 
that it does not allow spacings between asperities greater than its value to be used in computing average roughness height. Roughness-width cutoff for these tests was $30,000 \mu \mathrm{in}$. The true profiles of the specimens are presented in Appendix B.

46. Table 2 presents roughness numbers for all of the stones compiled from the strip chart recordings. Furthermore, an average for each stone was determined, and, finally, an average for each rock type was established. There was a great deal of data scatter within each rock

Table 2

Roughness Numbers from Strip Chart Recordings

\begin{tabular}{|c|c|c|c|c|c|}
\hline \multirow[b]{2}{*}{ Rock Type } & \multirow[b]{2}{*}{$\begin{array}{l}\text { Sample } \\
\text { No. }\end{array}$} & \multicolumn{4}{|c|}{ Roughness Number } \\
\hline & & $\begin{array}{c}\text { 1st } \\
\text { Measurement }\end{array}$ & $\begin{array}{c}\text { 2nd } \\
\text { Measurement }\end{array}$ & $\begin{array}{c}\text { Average } \\
\text { for Sample }\end{array}$ & $\begin{array}{l}\text { Overall } \\
\text { Average }\end{array}$ \\
\hline $\begin{array}{l}\text { Berea } \\
\text { Sandstone }\end{array}$ & $\begin{array}{l}1 \\
2 \\
3 \\
4 \\
5 \\
5 \\
6 \\
7 \\
7\end{array}$ & $\begin{array}{c}515 \\
553 \\
268 \\
650 \\
334 \\
\text { (Entire } \\
347 \\
525 \\
\text { Entire }\end{array}$ & $\begin{array}{c}412 \\
694 \\
308 \\
345 \\
208 \\
\text { Circumference) } \\
351 \\
396 \\
\text { Circumference) }\end{array}$ & $\begin{array}{l}464 \\
624 \\
288 \\
498 \\
271 \\
343 \\
394 \\
460 \\
455\end{array}$ & 417 \\
\hline $\begin{array}{l}\text { Oneota } \\
\text { Dolomite }\end{array}$ & $\begin{array}{l}1 \\
2 \\
3 \\
4 \\
5 \\
6 \\
7\end{array}$ & $\begin{array}{l}285 \\
278 \\
270 \\
293 \\
183 \\
108 \\
201\end{array}$ & $\begin{array}{l}365 \\
163 \\
278 \\
315 \\
169 \\
306 \\
210\end{array}$ & $\begin{array}{l}325 \\
221 \\
274 \\
304 \\
176 \\
207 \\
206\end{array}$ & 245 \\
\hline $\begin{array}{l}\text { Bedford } \\
\text { Limestone }\end{array}$ & $\begin{array}{l}1 \\
2 \\
3 \\
4 \\
5 \\
6 \\
7\end{array}$ & $\begin{array}{l}199 \\
211 \\
218 \\
265 \\
144 \\
274 \\
208\end{array}$ & $\begin{array}{l}224 \\
236 \\
241 \\
241 \\
173 \\
259 \\
254\end{array}$ & $\begin{array}{l}212 \\
224 \\
229 \\
253 \\
158 \\
267 \\
231\end{array}$ & 225 \\
\hline
\end{tabular}


type; however, the sandstone was rougher than either limestone or dolomite, and there was little difference between limestone and dolomite.

47. As discussed earlier, dial readings of average roughness numbers were also taken by "eyeballing" an average over the length of the traverse. The same individual from Clarkson and Foreman made all of the readings. Four measurements were made for each stone, and the results are given in Table 3 . Once again, an average for each stone and an average for each type of rock were recorded. These latter numbers follow a pattern similar to those from the strip chart measurements,

Table 3

$\underline{\text { Roughness Numbers from Dial Readings }}$

\begin{tabular}{|c|c|c|c|c|c|c|c|}
\hline \multirow{3}{*}{ Rock Type } & \multirow{3}{*}{$\begin{array}{l}\text { Sample } \\
\text { No. }\end{array}$} & \multicolumn{6}{|c|}{ Roughness Number } \\
\hline & & \multicolumn{4}{|c|}{ Section } & \multirow{2}{*}{$\begin{array}{c}\text { Average } \\
\text { for Sample }\end{array}$} & \multirow{2}{*}{$\begin{array}{l}\text { Overal1 } \\
\text { Average }\end{array}$} \\
\hline & & a & $\mathrm{b}$ & c & $\mathrm{d}$ & & \\
\hline \multirow{7}{*}{$\begin{array}{l}\text { Berea } \\
\text { Sandstone }\end{array}$} & 1 & 400 & 300 & 300 & 400 & 350 & \multirow{7}{*}{419} \\
\hline & 2 & 200 & 320 & 640 & 200 & 340 & \\
\hline & 3 & 440 & 280 & 280 & 460 & 365 & \\
\hline & 4 & 240 & 200 & 400 & 480 & 330 & \\
\hline & 5 & 200 & 480 & 580 & 560 & 455 & \\
\hline & 6 & 520 & 400 & 540 & 800 & 565 & \\
\hline & 7 & 700 & 360 & 425 & 640 & 531 & \\
\hline \multirow{7}{*}{$\begin{array}{l}\text { Oneota } \\
\text { Dolomite }\end{array}$} & 1 & -- & 134 & 220 & 120 & 158 & \multirow{7}{*}{172} \\
\hline & 2 & 240 & 200 & 120 & 80 & 160 & \\
\hline & 3 & 190 & -- & 200 & 180 & 190 & \\
\hline & 4 & 80 & 120 & 200 & 120 & 130 & \\
\hline & 5 & 200 & 120 & 80 & 80 & 120 & \\
\hline & 6 & 120 & 400 & 300 & 200 & 255 & \\
\hline & 7 & 220 & 200 & 160 & 180 & 190 & \\
\hline \multirow{7}{*}{$\begin{array}{l}\text { Bedford } \\
\text { Limestone }\end{array}$} & 1 & 120 & 280 & 370 & 300 & 268 & \multirow{7}{*}{211} \\
\hline & 2 & 300 & 300 & 160 & 327 & 272 & \\
\hline & 3 & 240 & -- & 80 & -- & 160 & \\
\hline & 4 & 280 & 120 & 280 & 200 & 220 & \\
\hline & 5 & 170 & 210 & 120 & 200 & 175 & \\
\hline & 6 & 200 & 240 & 200 & -- & 213 & \\
\hline & 7 & 200 & 160 & 120 & 187 & 167 & \\
\hline
\end{tabular}


although dial readings show a greater difference between limestone and dolomite.

48. Table 4 contains a summary of average roughness numbers for each rock type as measured from strip chart recordings and from dial readings as well as a listing of Coulson's (1970) results for the same rock types and lapping process.

Table 4

Comparison of Average Roughness Numbers

\begin{tabular}{|l|c|c|c|}
\hline \multirow{2}{*}{ Rock Type } & \multicolumn{3}{|c|}{ Average } \\
\cline { 2 - 4 } & $\begin{array}{c}\text { Strip Chart } \\
\text { Recordings }\end{array}$ & $\begin{array}{c}\text { Dial } \\
\text { Readings }\end{array}$ & $\begin{array}{r}\text { Coulson } \\
(1970)\end{array}$ \\
\hline Berea Sandstone & 417 & 419 & 380 \\
Oneota Dolomite & 245 & 172 & 150 \\
Bedford Limestone & 225 & 211 & 330 \\
\hline
\end{tabular}

* All stones lapped with No. 600 silicon carbide grit.

49. Unfortunately, it appears that obtaining a particular surface roughness for these stones is not an easily repeatable task. Not only is there a great deal of data scatter for each rock type but also, with the exception of Berea sandstone (strip chart averages only), average roughness numbers for these three rock types do not fall within 10 percent of Coulson's values, as desired. However, Coulson* has pointed out that he found that the properties of these rocks, including relative weakness, low abrasion resistance, and high absorptivity, cause a fairly large amount of surface roughness data scatter. The numbers indicate the surfaces of the dolomite and sandstone to be slightly rougher than the surfaces Coulson tested. The limestone surface in this study was smoother.

* Telephone Conversation Record, Subject: "Surface Roughness of Polished Rock Specimens," John 0. Curtis, 19 January 1979, File EGRMD/2. 


\section{PART IV: EXPERIMENTAL RESULTS}

50. Approximately 72 rock specimens were prepared for the planned experimental test program which was to have consisted of some 35 tests. of the 72 specimens, only 64 were usable after final preparation and assembly of the test device. The total number of tests conducted was 31. Of the 31 tests, only 25 were considered successful; i.e., al1 transducers functioned properly and the data were properly recorded. The 25 tests included 2 on the Berea sandstone, 6 on the Oneota dolomite, and 17 on the Bedford limestone.

51. The Berea sandstone was the most difficult to prepare; a large number of specimens were broken during the final stages of preparation. The Oneota dolomite was not quite as difficult to prepare, although some specimens were broken during preparation and some were broken during assembly of the test device. The Bedford limestone specimens were by far the easiest to prepare and work with throughout the test assembly process.

52. A list of all the tests reported herein is included in Table 5. The test number is coded to include the following information:

Type specimen: SS Berea sandstone

DD Oneota dolomite

LL Bedford limestone

Test identification: $11.2,10.2$, etc.

Nominal rotation speed in $\mathrm{rpm}$ :

$$
\begin{array}{rl}
0 & \mathrm{rpm}(0.15 \mathrm{in.} / \mathrm{min}) \\
300 \mathrm{rpm}(4,000 \mathrm{in.} / \mathrm{min}) \\
1,000 \mathrm{rpm}(14,000 \mathrm{in./min}) \\
3,000 \mathrm{rpm}(40,000 \mathrm{in./min})
\end{array}
$$

Type test: $\mathrm{N}$ normal stress applied first, then specimen rotated

$\mathrm{R}$ specimen rotated to speed, then normal stress applied

Target normal load: 50 psi - low level

175 psi - medium leve1

300 psi - high level

$\underline{W}$ is used to indicate if the specimens were wet 
Table 5

Summary of Laboratory Test Data

\begin{tabular}{|c|c|c|c|c|c|c|}
\hline \multirow[b]{2}{*}{ Test No. } & \multirow[b]{2}{*}{ Material } & \multirow{2}{*}{$\begin{array}{l}\text { Type } \\
\text { Test } \\
\end{array}$} & \multirow{2}{*}{$\begin{array}{c}\text { Speed } \\
\text { in./min }\end{array}$} & \multirow{2}{*}{$\begin{array}{c}\text { Normal Stress } \\
\text { psi } \\
\end{array}$} & \multicolumn{2}{|c|}{ Dry Density, pcf } \\
\hline & & & & & Rotating & Translating \\
\hline SS $11 \cdot 7 \cdot 0 . \mathrm{N} .300 \mathrm{~W}$ & Berea sandstone & $\mathrm{N}$ & 0.25 & 575 & 131.1 & 130.9 \\
\hline SS $12.5 .1000 . \mathrm{N} .300 \mathrm{~W}$ & Berea sandstone & $\mathrm{N}$ & 13,713 & 275 & 132.6 & 131.8 \\
\hline DD $11 \cdot 3 \cdot 0 \cdot N \cdot 300$ & Oneota dolomite & $\mathrm{N}$ & 0.13 & 415 & 150.3 & 151.5 \\
\hline DD $11 \cdot 13 \cdot 300 \cdot N \cdot 300$ & Oneota dolomite & $\mathrm{N}$ & 4,948 & 500 & 150.7 & 151.1 \\
\hline DD $11.29 .1000 \cdot$ N. 300 & Oneota dolomite & $\mathrm{N}$ & 13,700 & 470 & 149.7 & 150.8 \\
\hline DD $11.14 \cdot 300 \cdot R \cdot 300$ & Oneota dolomite & R & 5,650 & $200-500 * *$ & 150.0 & 150.7 \\
\hline DD $11 \cdot 6 \cdot 0 \cdot \mathrm{N} \cdot 300 \mathrm{~W}$ & Oneota dolomite & $\mathrm{N}$ & 0.16 & 340 & 151.8 & 149.1 \\
\hline DD $11.30 .1000 . \mathrm{N} .300 \mathrm{~W}$ & Oneota dolomite & $\mathrm{N}$ & 13,700 & 300 & 147.5 & 150.9 \\
\hline LL $10.19 \cdot 0 \cdot N \cdot 50$ & Bedford limestone & $\mathrm{N}$ & 0.21 & $100 \pm$ & 136.6 & 137.0 \\
\hline LL $10.20 .0 \cdot$ N. 175 & Bedford limestone & $\mathrm{N}$ & 0.15 & 480 & 136.7 & 136.9 \\
\hline LL $11.2 \cdot 0 \cdot$ N. 300 & Bedford limestone & N & 0.094 & 1050 & 135.6 & 136.7 \\
\hline LL $10.25 .300 . N .50$ & Bedford limestone & $\mathrm{N}$ & 5,370 & 128 & 137.1 & $137.1 *$ \\
\hline LL $10.26 .300 . \mathrm{N} .175$ & Bedford limestone & $\mathrm{N}$ & 41 & 740 & 136.0 & 137.1 \\
\hline LL $11 \cdot 7 \cdot 300 \cdot$ N. 300 & Bedford limestone & $\mathrm{N}$ & 3,960 & 1160 & 137.3 & 136.2 \\
\hline LL 11.28 .1000$. N. 300 & Bedford limestone & $\mathrm{N}$ & 13,700 & 500 & 136.8 & 137.1 \\
\hline LL $10 \cdot 30.300 \cdot$ R. 50 & Bedford limestone & R & 3,750 & 175 & 136.0 & 136.9 \\
\hline LL $11.17 \cdot 300 \cdot$ R. 300 & Bedford limestone & $\mathrm{R}$ & 6,220 & $450 / 550 * *$ & 137.7 & 137.3 \\
\hline LL $9.20 .3000 . R .50$ & Bedford limestone & $\mathrm{R}$ & 43,400 & 50 & 137.1 & $137.1 *$ \\
\hline LL $9.20 \cdot 3000 \cdot R \cdot 150$ & Bedford limestone & $\mathrm{R}$ & 57,900 & 150 & 137.1 & $137.1 *$ \\
\hline LL $9.20 .3000 . R \cdot 300$ & Bedford limestone & R & 43,900 & 150 & 137.1 & $137.1 *$ \\
\hline LL $10.23 \cdot 0 . \mathrm{N} .175 \mathrm{~W}$ & Bedford limestone & $\mathrm{N}$ & 0.18 & 490 & 137.1 & $137.1 *$ \\
\hline LL $11 \cdot 3 \cdot 0 \cdot \mathrm{N} \cdot 300 \mathrm{~W}$ & Bedford limestone & $\mathrm{N}$ & 0.17 & 580 & 136.1 & 136.8 \\
\hline LL 12.4 .1000$. N. $300 \mathrm{~W}$ & Bedford limestone & $\mathrm{N}$ & 12,700 & 215 & 136.8 & 136.8 \\
\hline LL $11.17 \cdot 300 \cdot$ R. $300 \mathrm{~W}$ & Bedford limestone & R & 6,640 & 550 & 135.4 & 138.4 \\
\hline LL 9.21 .3000$. R. $300 \mathrm{~W}$ & Bedford limestone & $\mathbf{R}$ & 42,400 & 300 & 137.1 & $137.1 *$ \\
\hline
\end{tabular}

* Average value based on 12 specimens (range 136.0 to $138.2 \mathrm{pcf}$ ).

** Variation of normal stress. 


\section{Berea Sandstone}

53. Two tests were conducted on sandstone specimens with wet surfaces. The specimens were soaked underwater for approximately 3 to 4 hr prior to testing. Assembly of specimens into the holders took about $1 \mathrm{hr}$; i.e., care had to be taken to ensure that each contact surface was perfectly normal to the holder. During this time, a damp cloth was used to prevent drying of the specimens. The holders were then placed into the device, and the device was assembled. The transducers were connected, and the electric calibration steps were placed on the record prior to the test. It was only during this final phase, which took approximately 30 min, that the specimens could not be kept moist and were subject to air-drying.

54. The specimens used in test SS 11.7.0.N.300W had dry densities of 131.1 pcf (rotating specimen) and 130.9 pcf (translating specimen). The test notes indicate that the translating specimen cracked in two places during the test. Two surface areas, approximately 1 in. long on both specimens, showed powder, while the remainder of the contact surfaces were slick and shiny. The grooves placed in the side of each specimen prior to the test indicate that the two specimens moved approximately $1 / 8 \mathrm{in}$. within the holders. The data plotted as (a) shear stress versus normal stress, (b) coefficient of friction versus normal stress, and (c) coefficient of friction versus time are shown in Figure 14. The normal stress assumes full contact between the surfaces. The coefficient of friction is defined as the ratio of shear stress to normal stress. The rotational deflection during the test may be calculated using the time at the point of interest and the rate of 0.25 in./min. The data indicate a maximum friction value of approximately 0.55 .

55. The specimens for test SS 12.5.1000.N.300W had dry densities of 132.6 pcf (rotating specimen) and 131.8 pcf (translating specimen). The test procedure with regard to soaking and device assembly was the same as that for the previously reported test. The test notes indicate that the rotating specimen could not be placed perfectly flat in the 

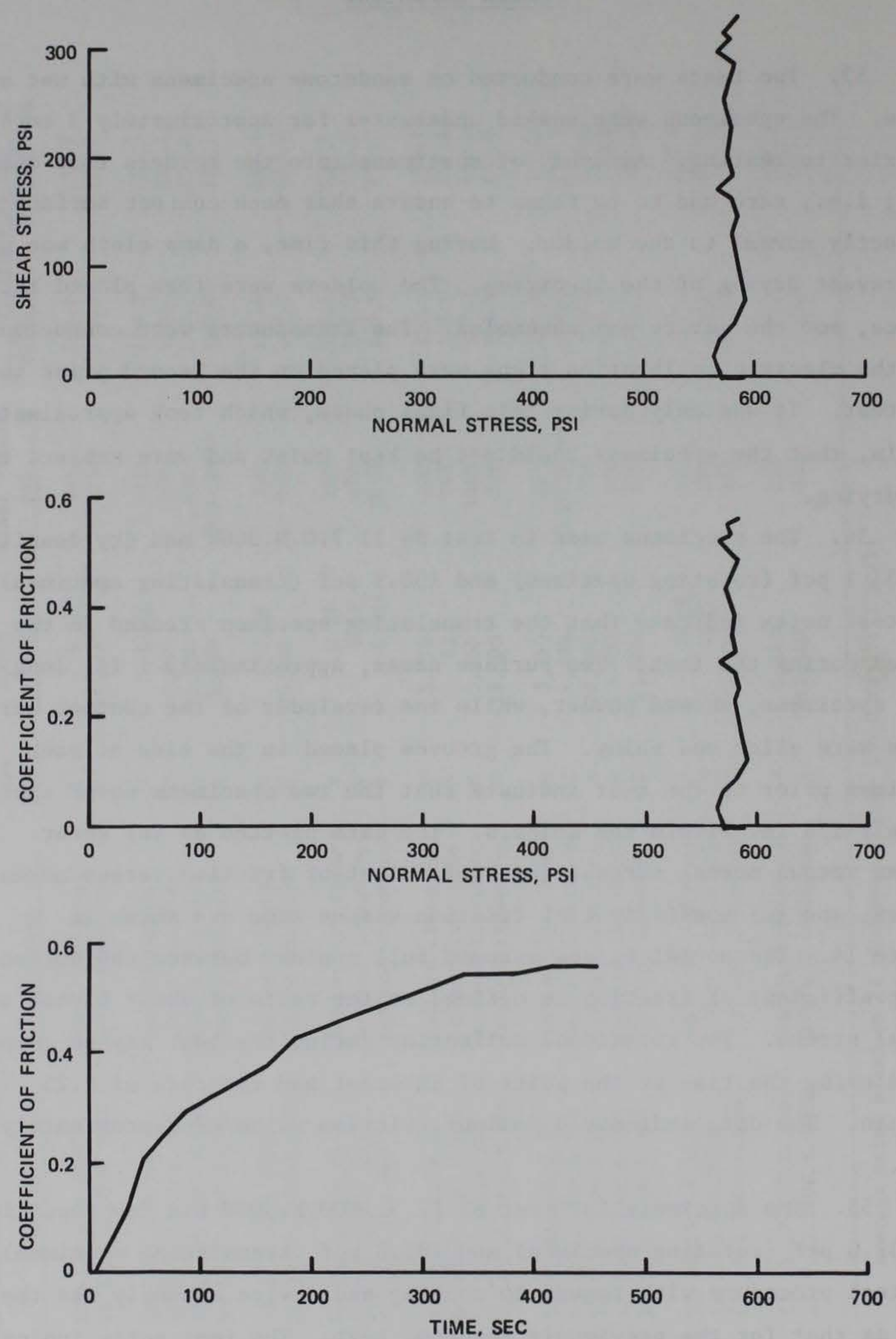

Figure 14. Results of static test SS 11.7.0.N.300W on sandstone 
container, resulting in an angle of 0.05 deg across the specimen. During the test, the surfaces showed considerable wear; they appeared yellowish-green after the test. There was nothing unusual to indicate nonuniform contact between the specimens.

56. The data are plotted in Figure 15. The maximum coefficient of friction value was 0.78 although breaks at 0.3 and 0.6 are evident in the data. The value of 0.3 appears to be related to a fluctuation in the loading rate, whereas the 0.6 value appears related to the material response.

57. After the peak value was reached, the coefficient decreased to a much lower range (between 0.2 and 0.3 ). The rate of loading was not constant throughout the entire time represented in the data plot. The rotating specimen reached a speed of $13,713 \mathrm{in.} / \mathrm{min}$ prior to peak and slowed by some 20 percent over the $300 \mathrm{msec}$ plotted in Figure 15 .

58. A comparison of the two sandstone tests is shown in Figure 16. The slow test specimen reached a peak stress in a little less than 1.9 in. of rotation or 13.4 percent circumferential strain $\varepsilon$. The rotating specimen had already rotated $10 \mathrm{in}$. or a strain of 72.7 percent at the initial value of 0.6 . The specimen had rotated approximately twice $(\varepsilon=200$ percent $)$ at the peak of 0.75 , and it had rotated four times $(\varepsilon=400$ percent) in reaching the low value of 0.2 .

\section{Oneota Dolomite}

59. Four tests were conducted on dolomite specimens with dry surfaces. Three normal tests were conducted at rates of $0.13,4,948$, and 13,700 in./min; one R-type test was conducted at a rate of 5,650 in./min. The results of test DD 11.3.0.N.300 are shown in Figure 17. The rotating specimen had a density of 150.3 pcf and the translating specimen had a density of $151.5 \mathrm{pcf}$. The test was at a normal stress of $430 \mathrm{psi}$. Posttest notes indicate the samples were scoured in two places. One sample was cracked. There was a clear initial value of friction of 0.41 followed by a decrease to 0.32 and then an increase 

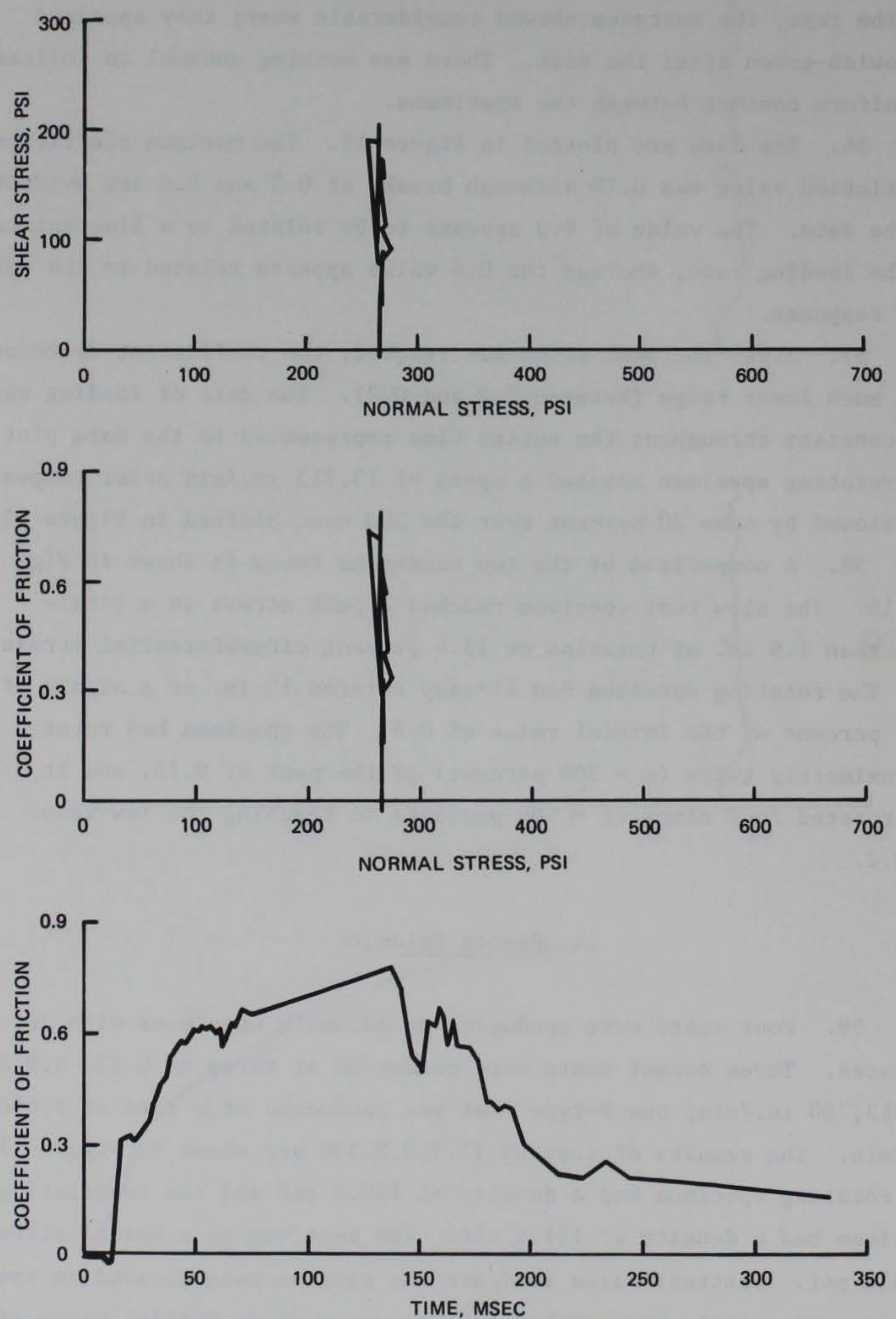

Figure 15. Results of kinetic test SS 12.5.1000.N.300W on sandstone 

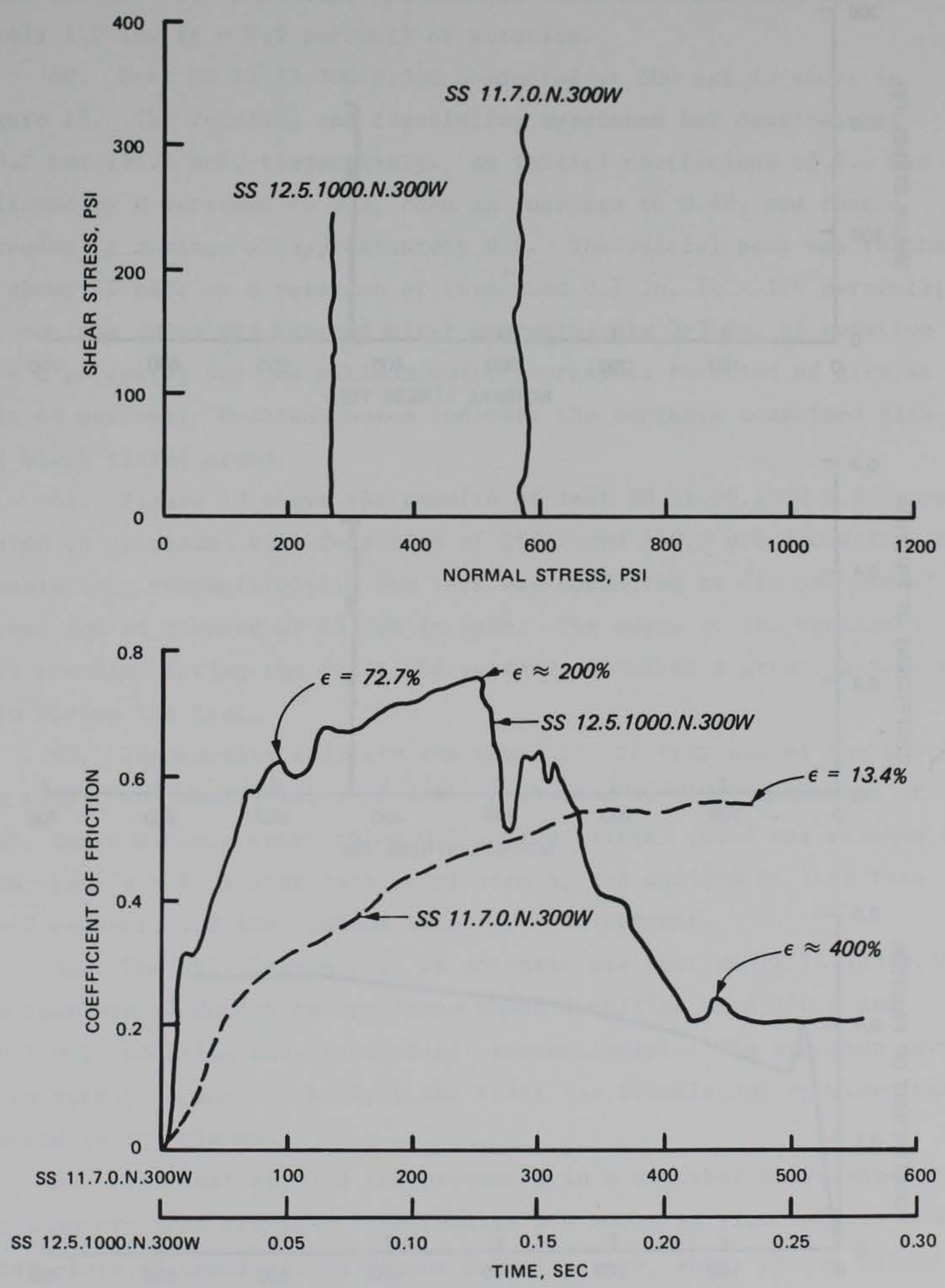

Figure 16. Comparison of tests SS 12.5.1000.N.300W and SS $11 \cdot 7 \cdot 0 . \mathrm{N} .300 \mathrm{~W}$ on sandstone 

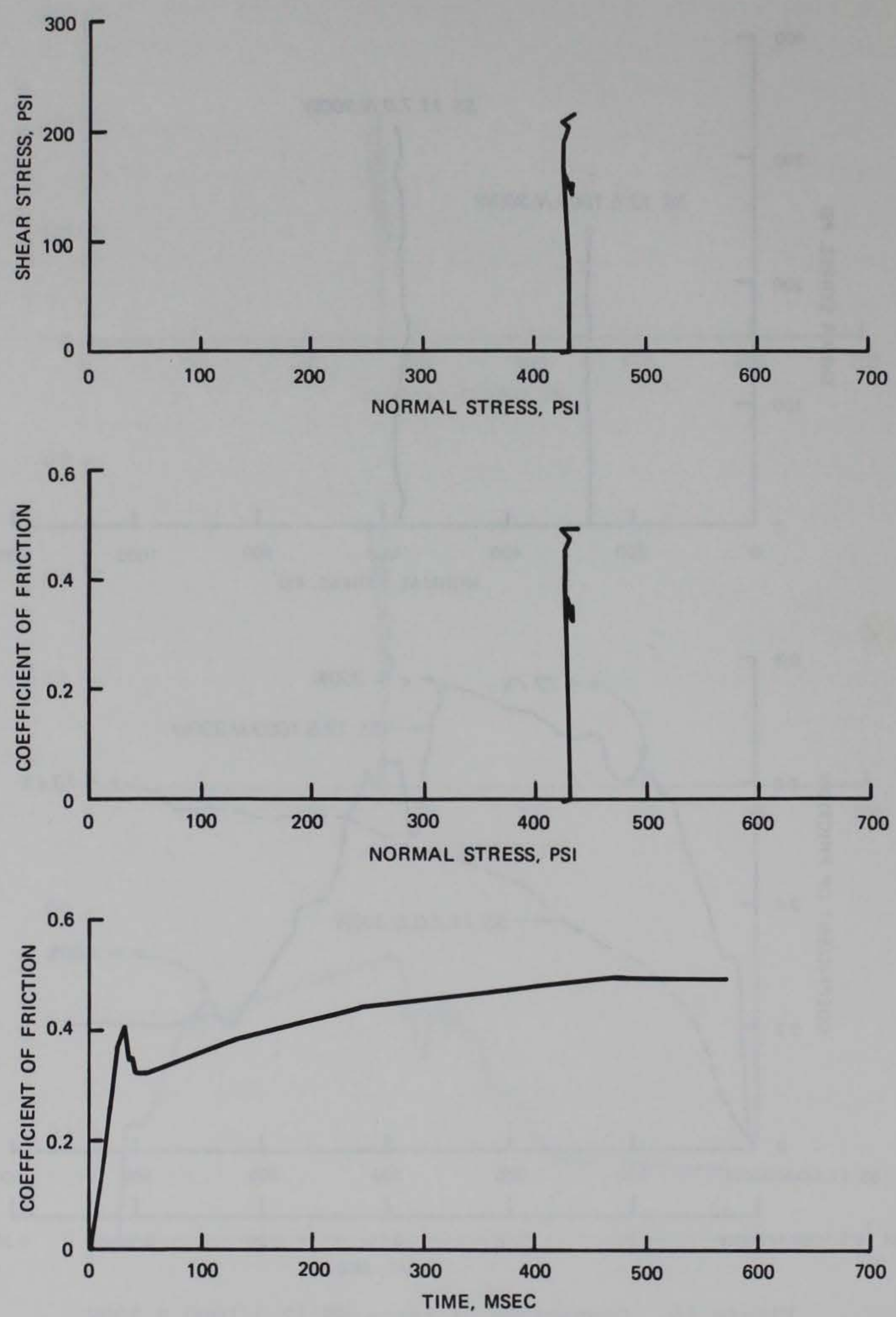

Figure 17. Results of static test DD 11.3.0.N.300 on dolomite 
to a maximum of 0.5 . The initial value was reached after a rotation of 0.065 in. ( $\varepsilon=0.5$ percent); the maximum value occurred with approximately 1.0 in. ( $\varepsilon=6.9$ percent $)$ of rotation.

60. Test DD 11.13.300.N.300 conducted at 500 psi is shown in Figure 18. The rotating and translating specimens had densities of 150.7 and 151.1 pcf, respectively. An initial coefficient of 0.4 was followed by a decrease to 0.3 , then an increase to 0.48 , and then a decrease to a range of approximately 0.3. The initial peak was reached in about $10 \mathrm{msec}$ or a rotation of less than $0.1 \mathrm{in.}(\varepsilon<1.0$ percent); the maximum value was reached after approximately 0.3 in. of rotation ( $\varepsilon=2$ percent); and the minimum value represents rotation of greater than 40 percent. Posttest notes indicate the surfaces contained pink and black pitted areas.

61. Figure 19 shows the results of test DD 11.29.1000.N.300 conducted on specimens with densities of 149.7 and 150.8 pcf (rotating and translating, respectively). The test was conducted at 470-psi normal stress and at a speed of 13,700 in./min. The edges of the specimens were crumbled during the test; the surfaces acquired a greenish-yellow film during the test.

62. The results indicate the same type of response as the previous test: an initial value of 0.45 , a minimum of 0.32 , a maximum of 0.38 , and a minimum approaching 0.25 . The initial value was reached in less than $\varepsilon=1$ percent rotational strain, the maximum in less than $\varepsilon=2$ percent, and the minimum after $\varepsilon=30$ percent.

63. The only R-type test on dolomite was test DD 11.14.300.R.300. The test was conducted on specimens whose densities were 150.0 and 150.7 pcf (rotating and translating, respectively). The specimen surfaces were pink and black after the test; the translating specimen was cracked in two places.

64. The test results are presented in a somewhat different format than previous results. The results are shown in Figure 20 as computer plots of shear stress versus normal stress, shear stress versus rotational displacement, coefficient of friction versus time, and coefficient of friction versus shear strain, respectively. The variation 

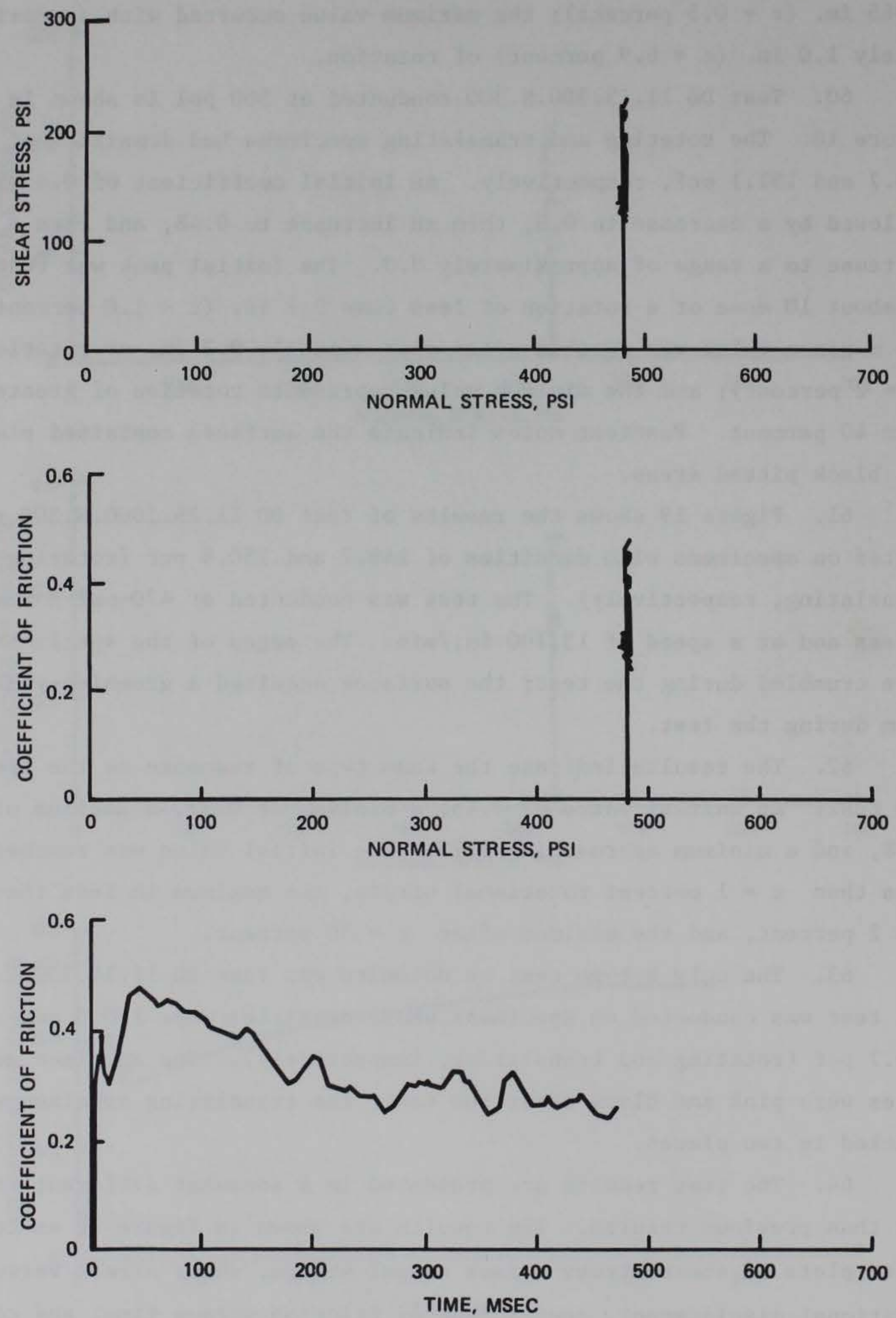

Figure 18. Results of kinetic test DD 11.13.300.N.300 on dolomite 

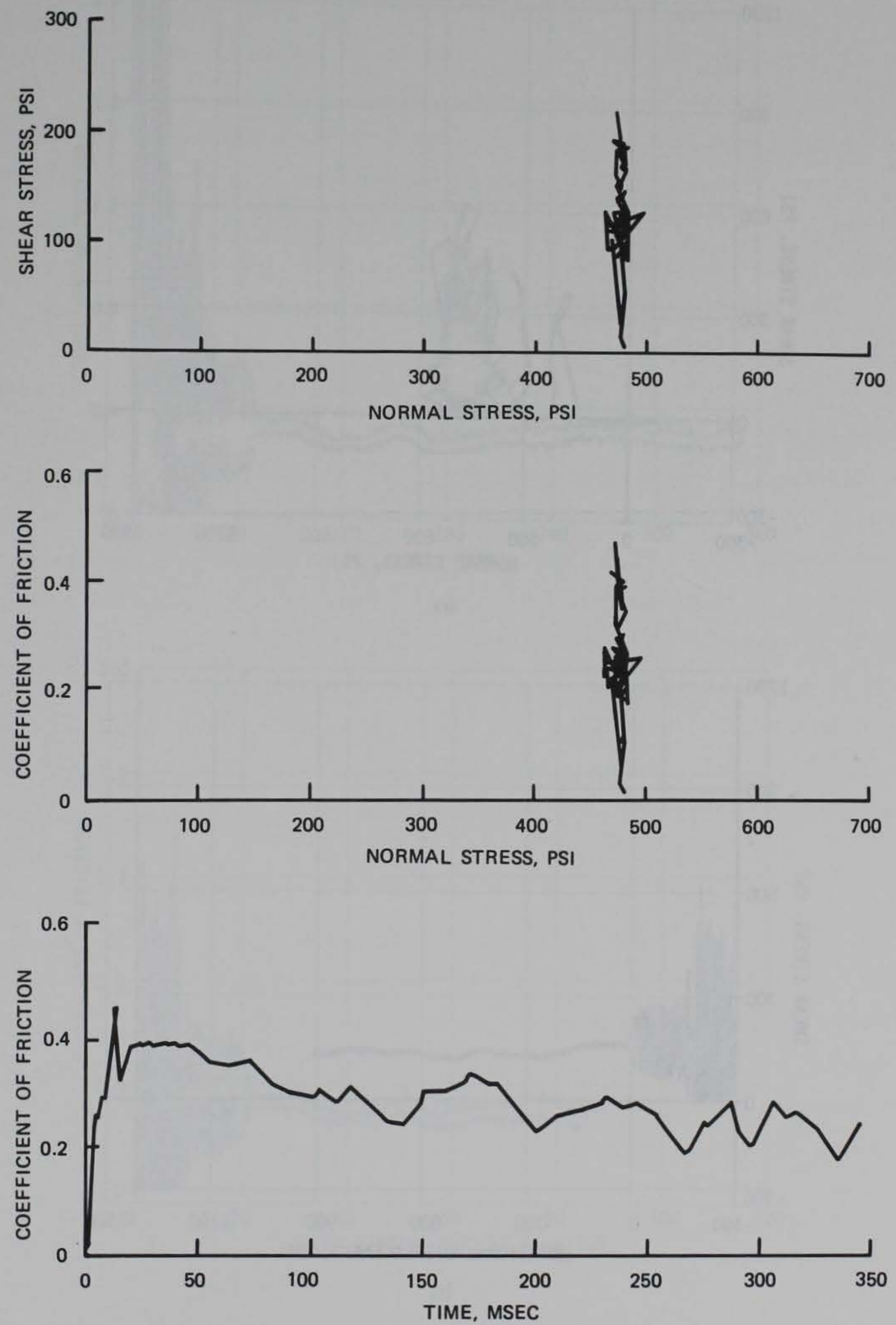

Figure 19. Results of kinetic test DD 11.29.1000.N.300 on dolomite 


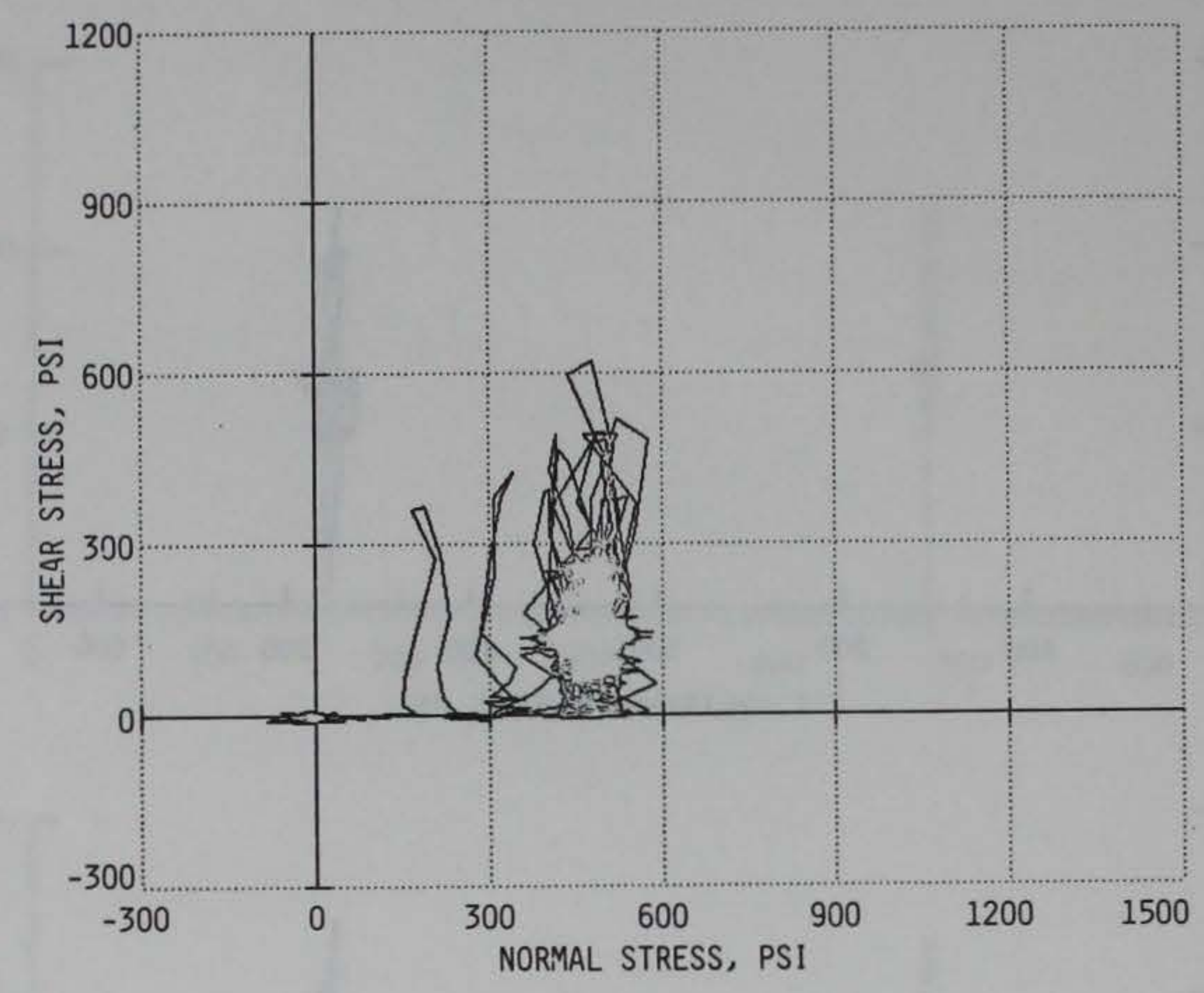

a.

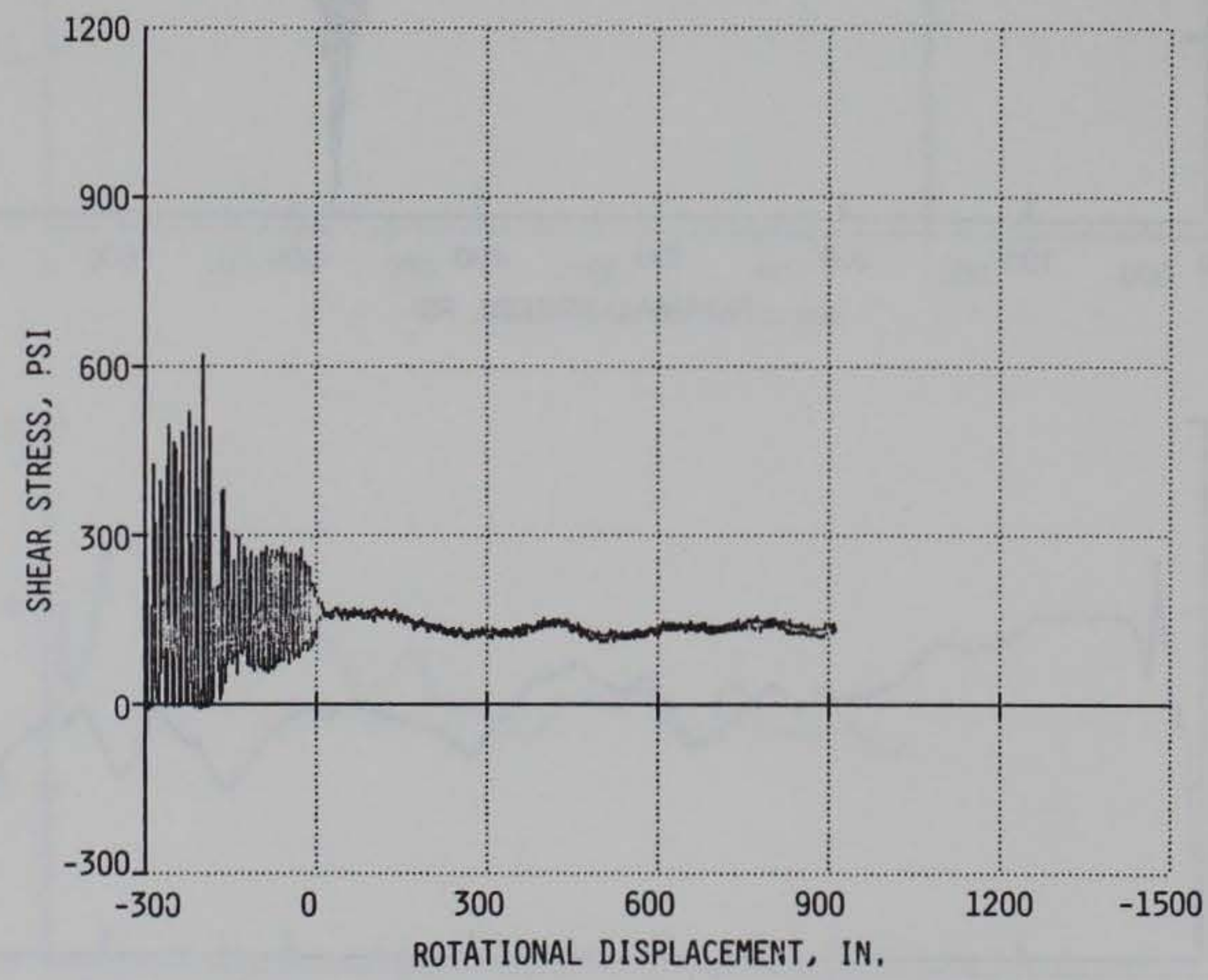

b.

Figure 20. Results of kinetic test DD 11.14.300.R.300 on dolomite (Continued) 

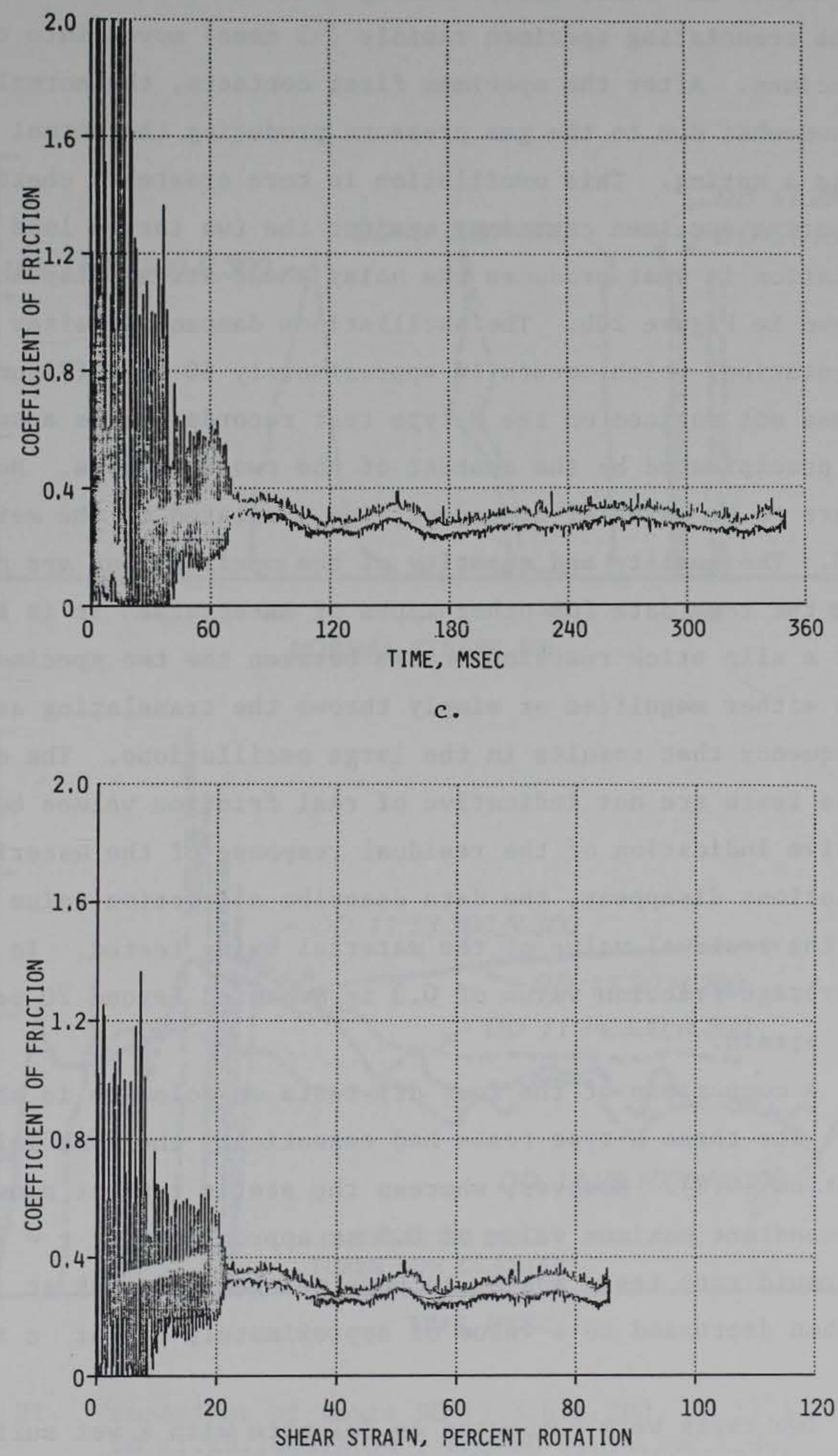

d.

Figure 20. (Concluded) 
in normal stress and shear stress during the test can be noted in R-type tests. The translating specimen rapidly $(<3 \mathrm{msec})$ moves into the rotating specimen. After the specimen first contacts, the normal load oscillates somewhat due to the gas pressure producing the normal force acting like a spring. This oscillation in turn creates a chattering of the translating specimen container against the two torque load cells. The oscillation is what produces the noisy shear stress-displacement record shown in Figure 20b. The oscillations dampen out after about $3 \mathrm{in}$. of rotation, which occurs in approximately $60 \mathrm{msec}$ (Figure 20c). Since it was not noticed on the N-type test records, it is assumed the action is precipitated by the contact of the two specimens. However, it also appears to be material-dependent; i.e., related to the material being tested. The quality and quantity of the oscillations are not always present in the test data for other types of materials. It is hypothesized that a slip stick reaction occurs between the two specimens that in turn is either magnified or simply throws the translating assembly into a frequency that results in the large oscillations. The data for such R-type tests are not indicative of real friction values but do give a qualitative indication of the residual response of the material. As the oscillations disappear, the data describe a friction value associated with the residual value of the material being tested. In Figure $20 \mathrm{~d}$, the average friction value of 0.3 is measured beyond 20 percent rotational strain.

65. A comparison of the four dry tests on dolomite is shown in Figure 21. The three $\mathrm{N}$-type tests had essentially the same initial value of friction (0.4). However, whereas the static test at slow speed reached a constant maximum value of 0.5 at approximately $\varepsilon=7$ percent, the three rapid rate tests appear to have reached the peak at $\varepsilon<2$ percent and then decreased to a value of approximately 0.3 at $\varepsilon>20$ or 30 percent.

66. Two tests were conducted on dolomite with a wet surface: a slow test, DD 11.6.0.N.300W; and a fast test, DD 11.30.1000.N.300W. Specimen preparation and test setup were the same as for the wet sandstone tests. 

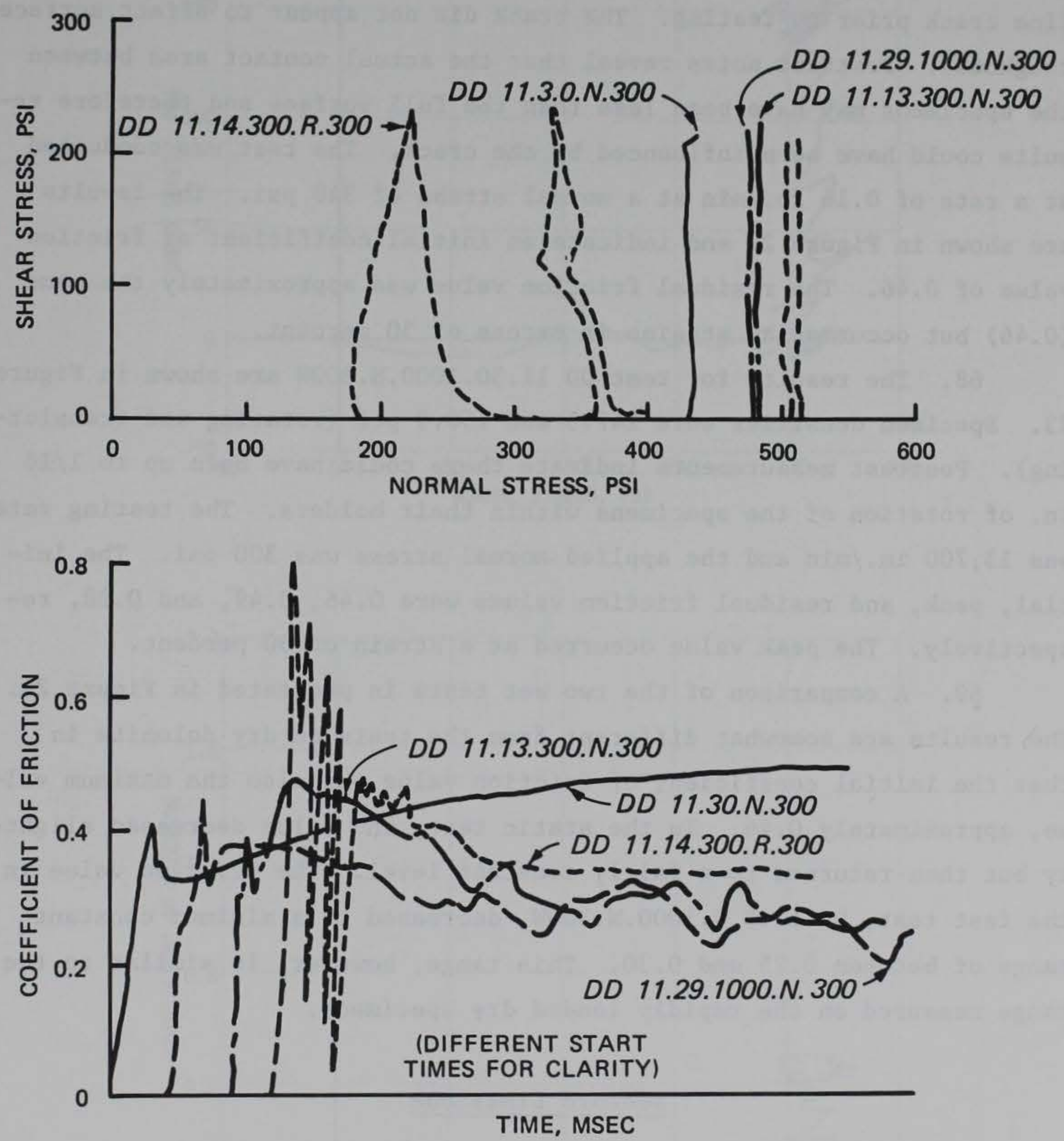

Figure 21. Comparison of tests DD 11.3.0.N.300, DD 11.13.300.N.300, DD 11.29.1000.N.300, and DD 11.14.300.4.300 
67. Test DD 11.6.0.N.300W was conducted on specimens with densities of 151.8 and 149.1 pcf (rotating and translating, respectively). The test notes indicate the translating specimen contained a small hairline crack prior to testing. The crack did not appear to affect surface roughness. Posttest notes reveal that the actual contact area between the specimens may have been less than the full surface and therefore results could have been influenced by the crack. The test was conducted at a rate of $0.16 \mathrm{in./min}$ at a normal stress of $340 \mathrm{psi}$. The results are shown in Figure 22 and indicate an initial coefficient of friction value of 0.46 . The residual friction value was approximately the same $(0.46)$ but occurred at strains in excess of 50 percent.

68. The results for test DD $11.30 .1000 . \mathrm{N} .300 \mathrm{~W}$ are shown in Figure 23. Specimen densities were 147.5 and 150.9 pcf (rotating and translating). Posttest measurements indicate there could have been up to $1 / 16$ in. of rotation of the specimens within their holders. The testing rate was 13,700 in./min and the applied normal stress was $300 \mathrm{psi}$. The initial, peak, and residual friction values were $0.46,0.49$, and 0.28 , respectively. The peak value occurred at a strain of 50 percent.

69. A comparison of the two wet tests is presented in Figure 24. The results are somewhat different from the tests on dry dolomite in that the initial coefficient of friction value was also the maximum value, approximately 0.46 . In the static test, the value decreased slightly but then returned to a fairly constant level. The friction value in the fast test, DD 11.3.0.1000.N.300W, decreased to a minimum constant range of between 0.25 and 0.30 . This range, however, is similar to the range measured on the rapidly loaded dry specimens.

\section{Bedford Limestone}

70. Seventeen tests were conducted on specimens of Bedford limestone. Twelve were conducted on specimens with dry surfaces. Five were conducted on specimens with wet surfaces. Table 5 presents a summary of all the tests, listing the type test, rotational speed, normal stress, and density. Values of average density are listed for several of the tests. 


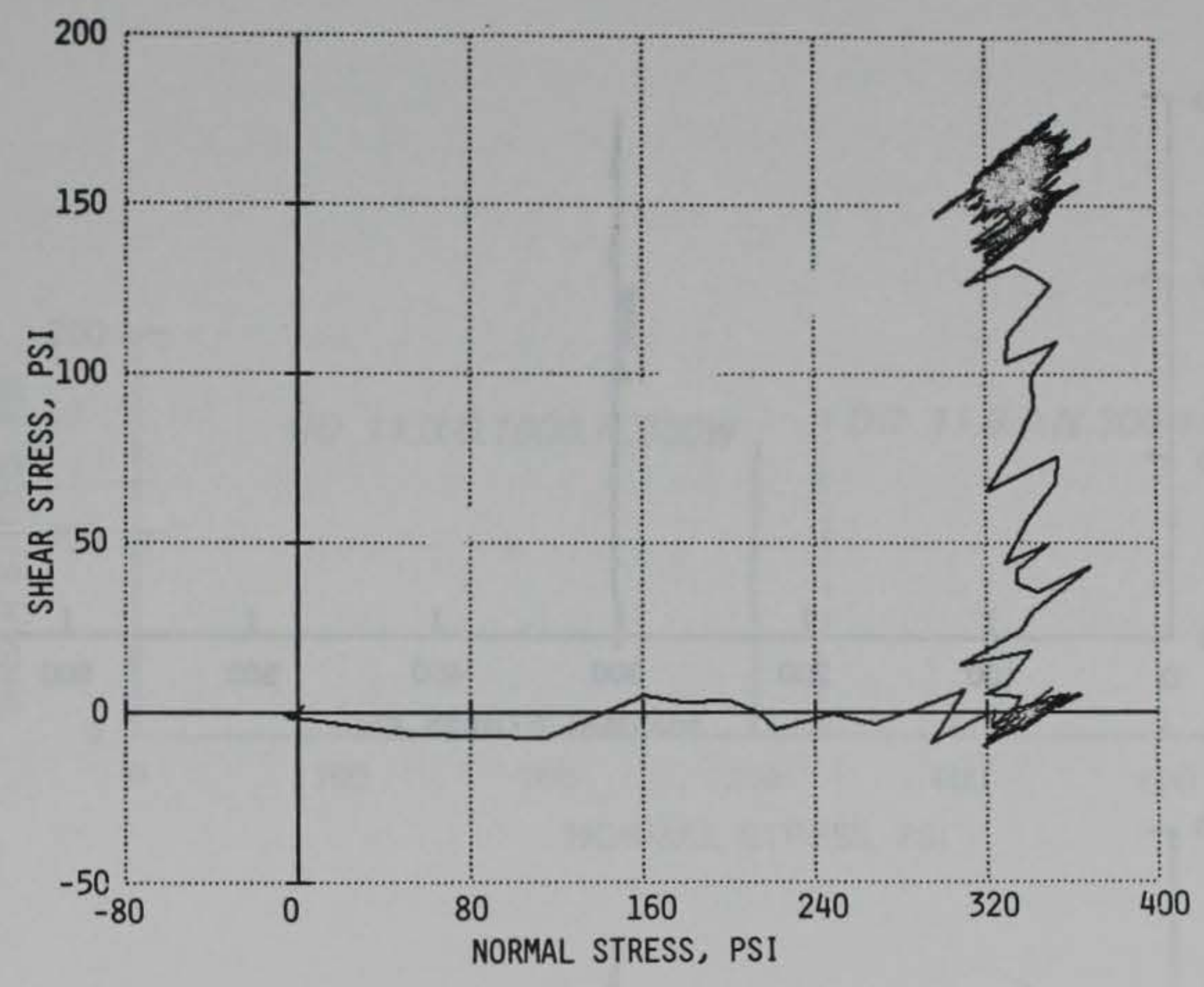

a.

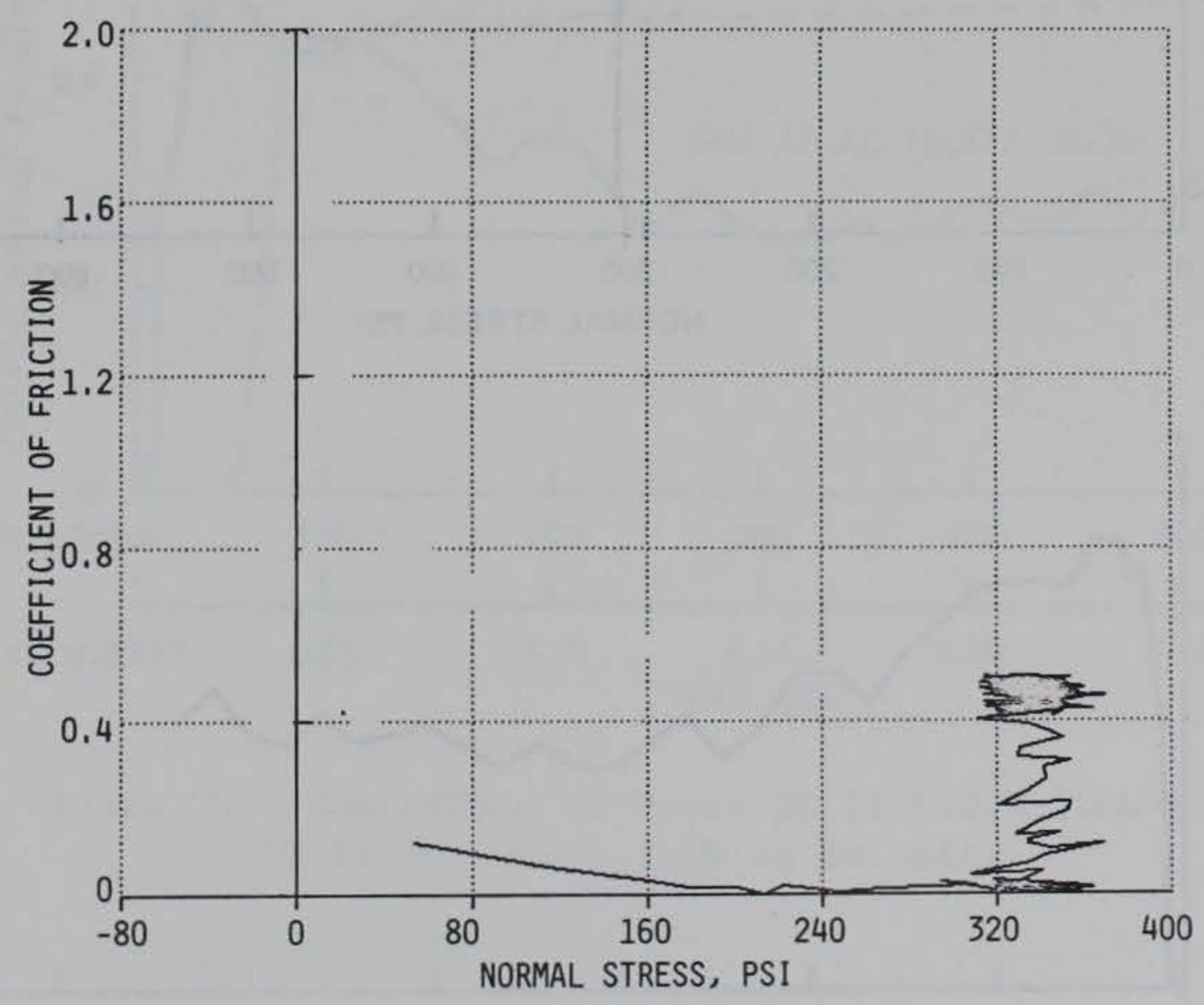

b.

Figure 22. Results of static test DD 11.6.0.N.300W on dolomite 

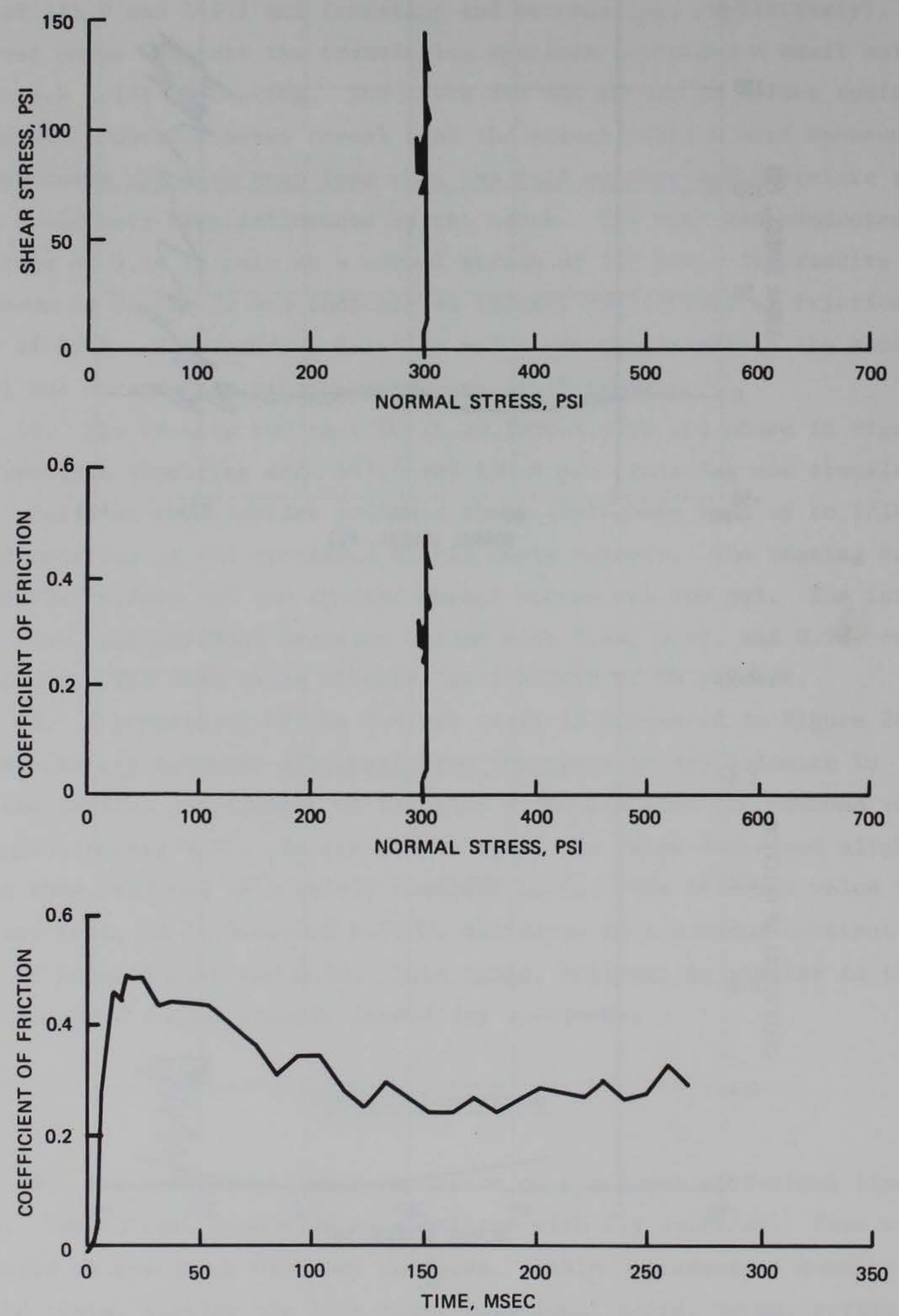

Figure 23. Results of kinetic test DD 11.30.1000.N.300W on dolomite 

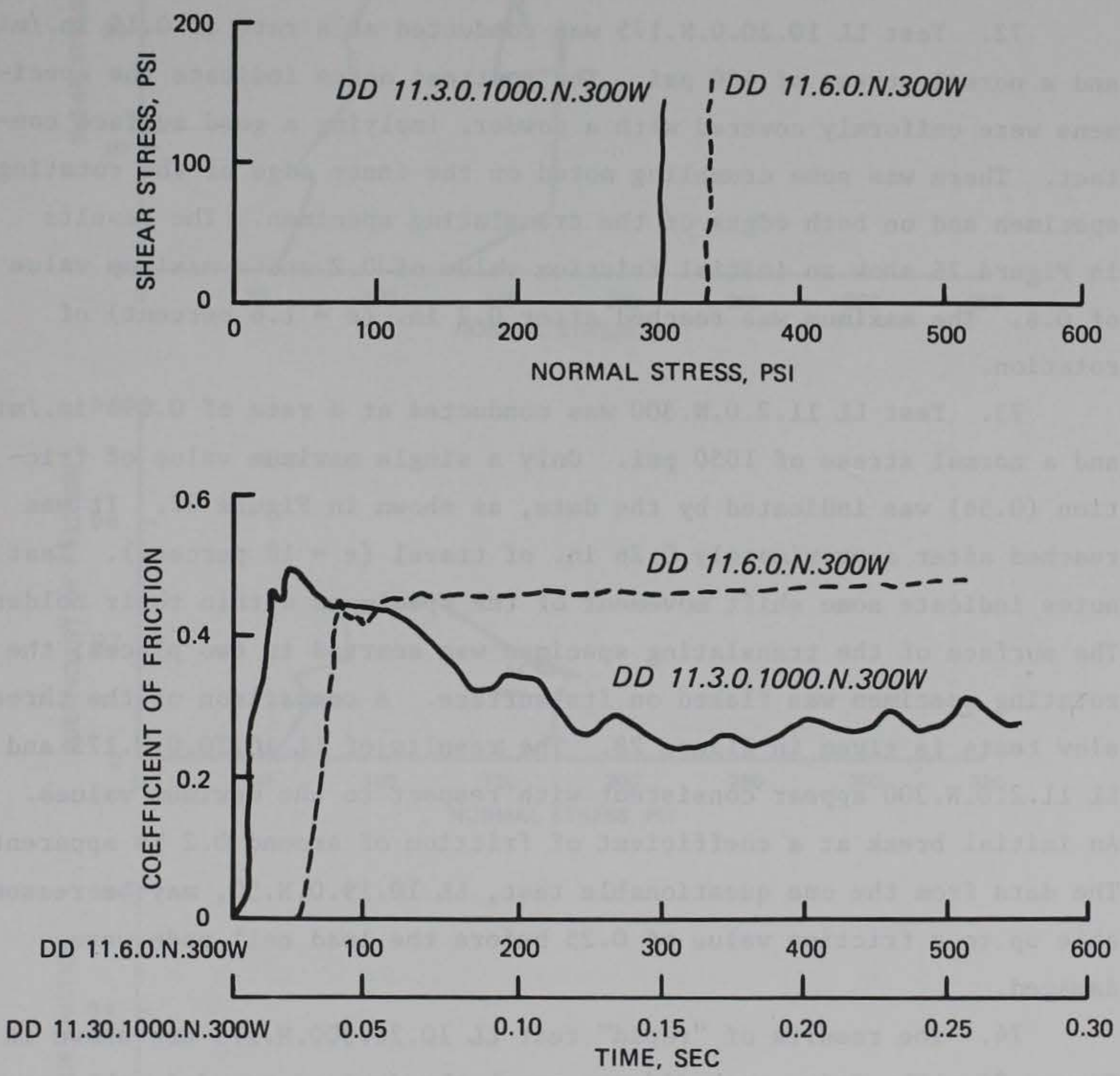

Figure 24. Comparison of tests DD 11.6.0.N.300W and DD 11.30 .1000$. N.300W on dolomite 
71. The results of test LL 10.19.0.N.50 are shown in Figure 25 . The test specimen was loaded at a rate of $0.21 \mathrm{in.} / \mathrm{min}$. The normal load varied from 60 to $150 \mathrm{psi}$. Test notes indicate that one or both of the torque load cell friction pads were damaged during the test; the data are considered questionable.

72. Test LL $10.20 \cdot 0 . \mathrm{N} .175$ was conducted at a rate of $0.15 \mathrm{in./min}$ and a normal stress of 480 psi. The posttest notes indicate the specimens were uniformly covered with a powder, implying a good surface contact. There was some crumbling noted on the inner edge of the rotating specimen and on both edges of the translating specimen. The results in Figure 26 show an initial friction value of 0.2 and a maximum value of 0.6 . The maximum was reached after $0.2 \mathrm{in}$. ( $\varepsilon=1.6$ percent $)$ of rotation.

73. Test LL 11.2.0.N. 300 was conducted at a rate of $0.094 \mathrm{in./min}$ and a normal stress of 1050 psi. Only a single maximum value of friction (0.56) was indicated by the data, as shown in Figure 27 . It was reached after approximately $0.26 \mathrm{in}$. of travel ( $\varepsilon=18$ percent). Test notes indicate some shift movement of the specimens within their holders. The surface of the translating specimen was scarred in two places; the rotating specimen was flaked on its surface. A comparison of the three slow tests is given in Figure 28. The results of LL 10.20.0.N.175 and LL 11.2.0.N.300 appear consistent with respect to the maximum values. An initial break at a coefficient of friction of around 0.2 is apparent. The data from the one questionable test, LL 10.19.0.N.50, may be reasonable up to a friction value of 0.25 before the load cell pads were damaged.

74. The results of "rapid" test LL 10.26.300.N.175 are shown in Figure 29. The drive rack did not reach the desired speed in this test, and hence it was conducted at a velocity of only $41 \mathrm{in./min}$. The initial friction value of 0.4 was followed by a decrease to 0.3 and then an increase to 0.44 . During the remainder of the test, the data oscillated about an average of 0.32 ; however, the test speed was sharply decreasing. The late time data are therefore not comparable with results of other rapid tests which were at fairly constant speeds. 

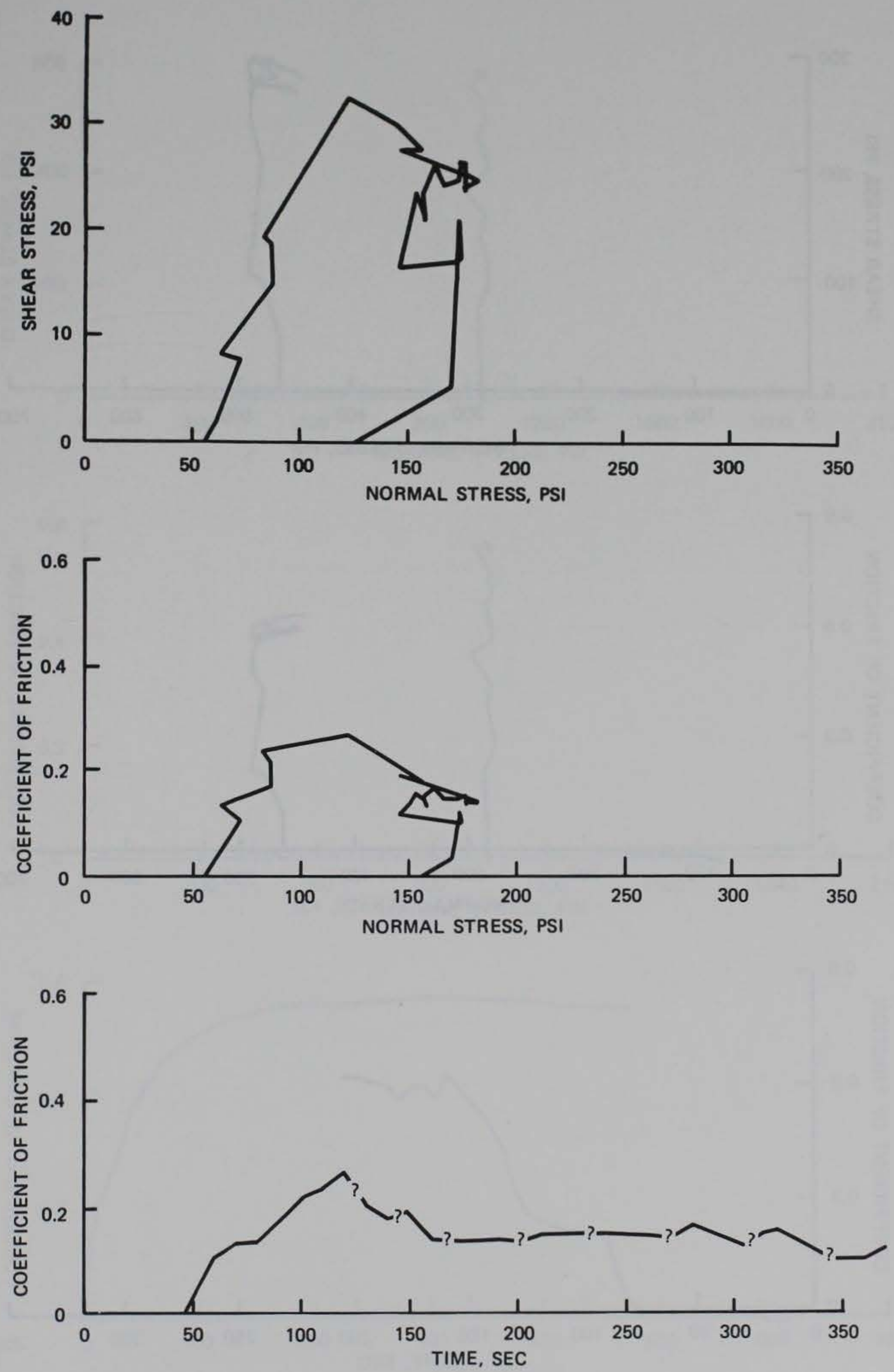

Figure 25. Results of static test LL 10.19.0.N.50 on limestone 

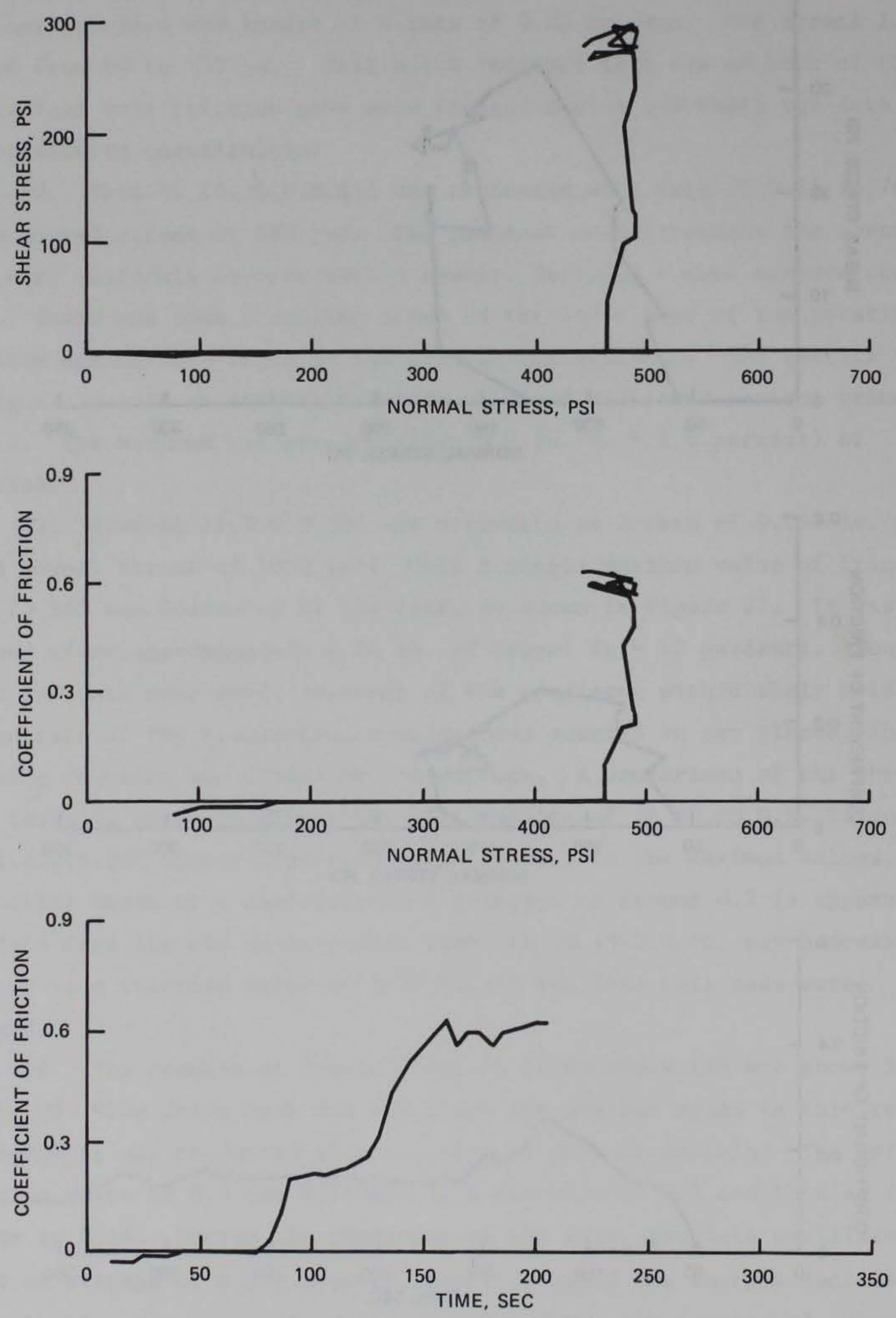

Figure 26. Results of static test LL 10.20.0.N.175 on 1imestone 

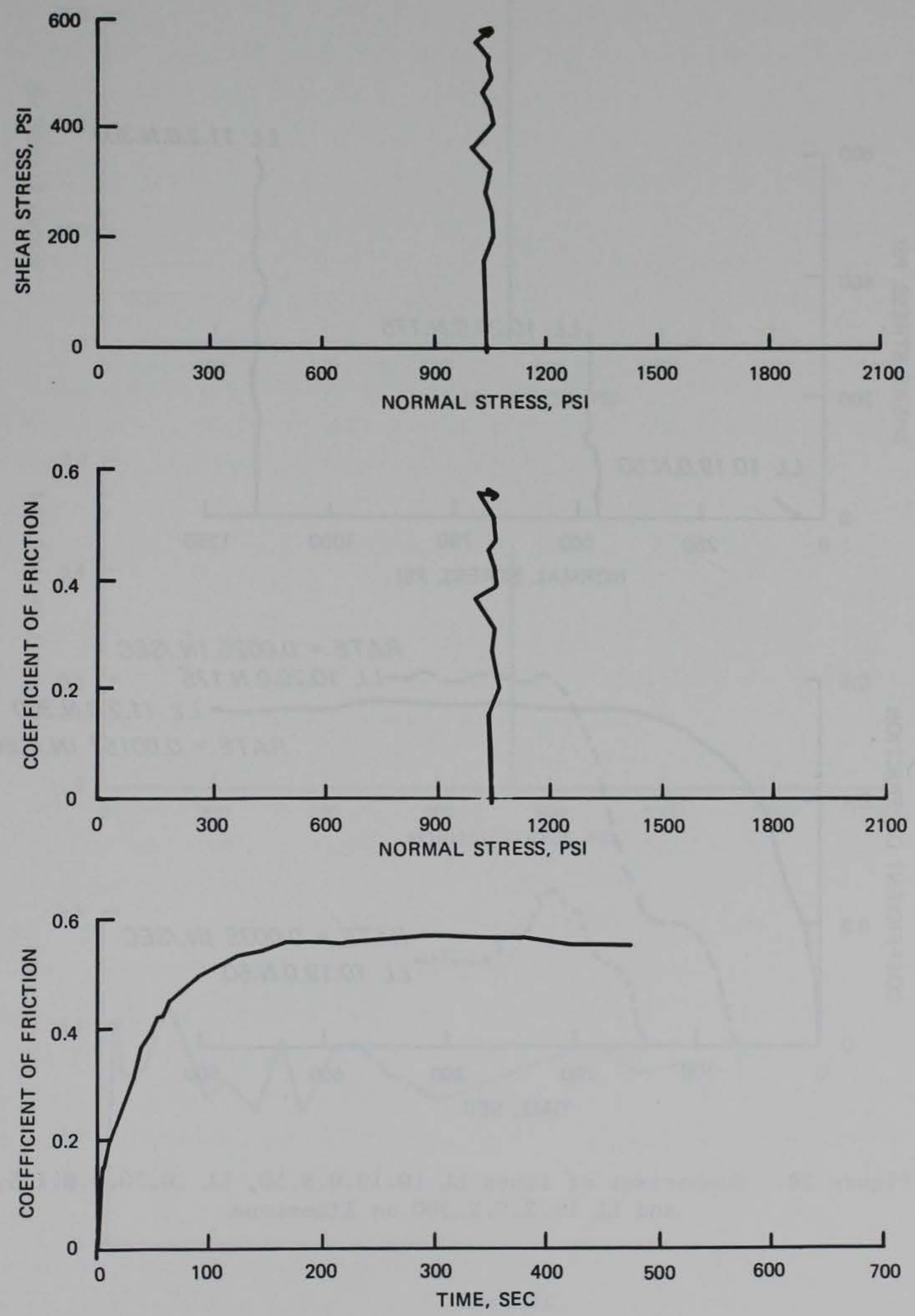

Figure 27. Results of static test LL 11.2.0.N.300 on 1imestone 

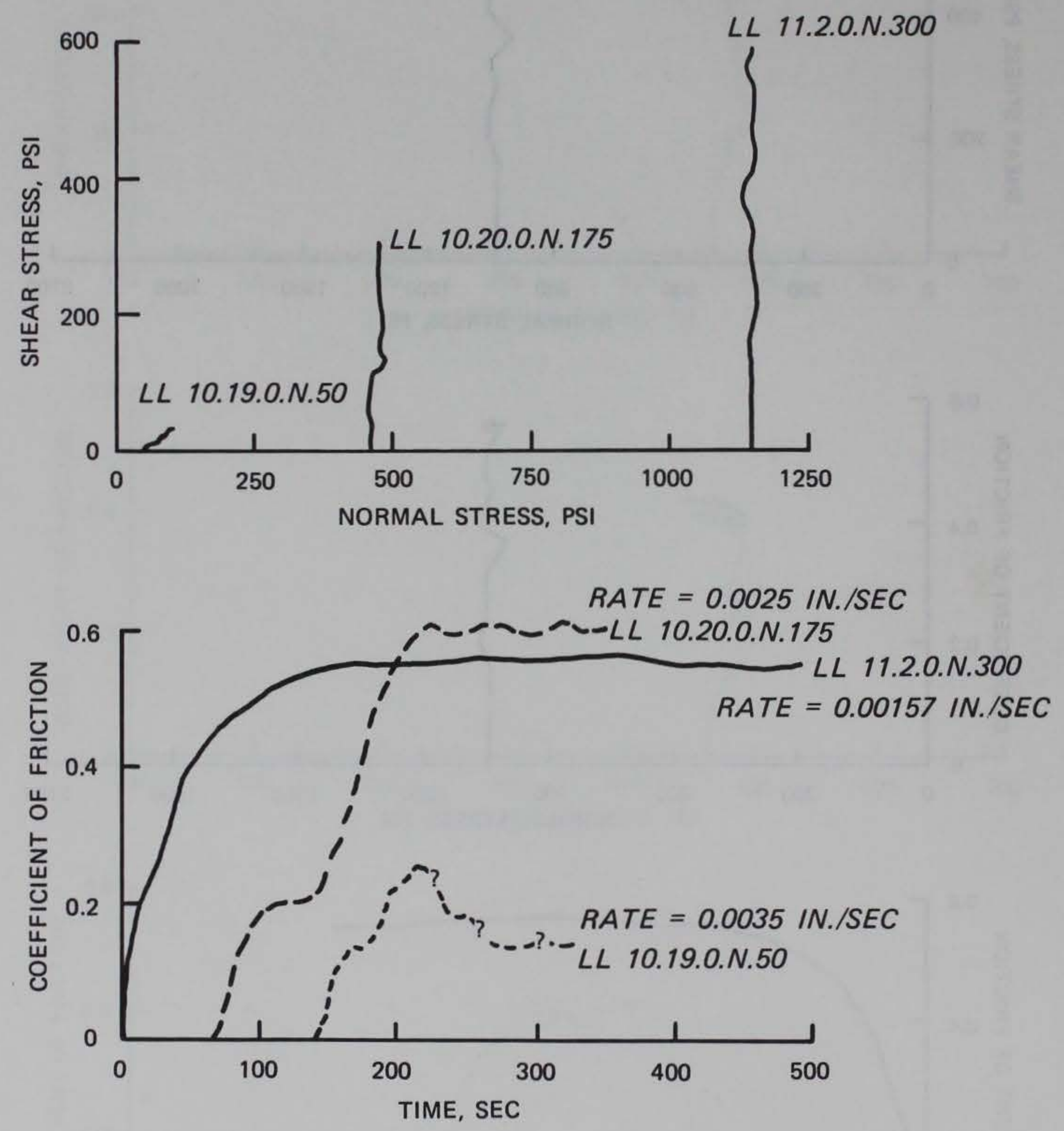

Figure 28. Comparison of tests LL 10.19.0.N.50, LL 10.20.0.N.175, and LL 11.2.0.N.300 on limestone 

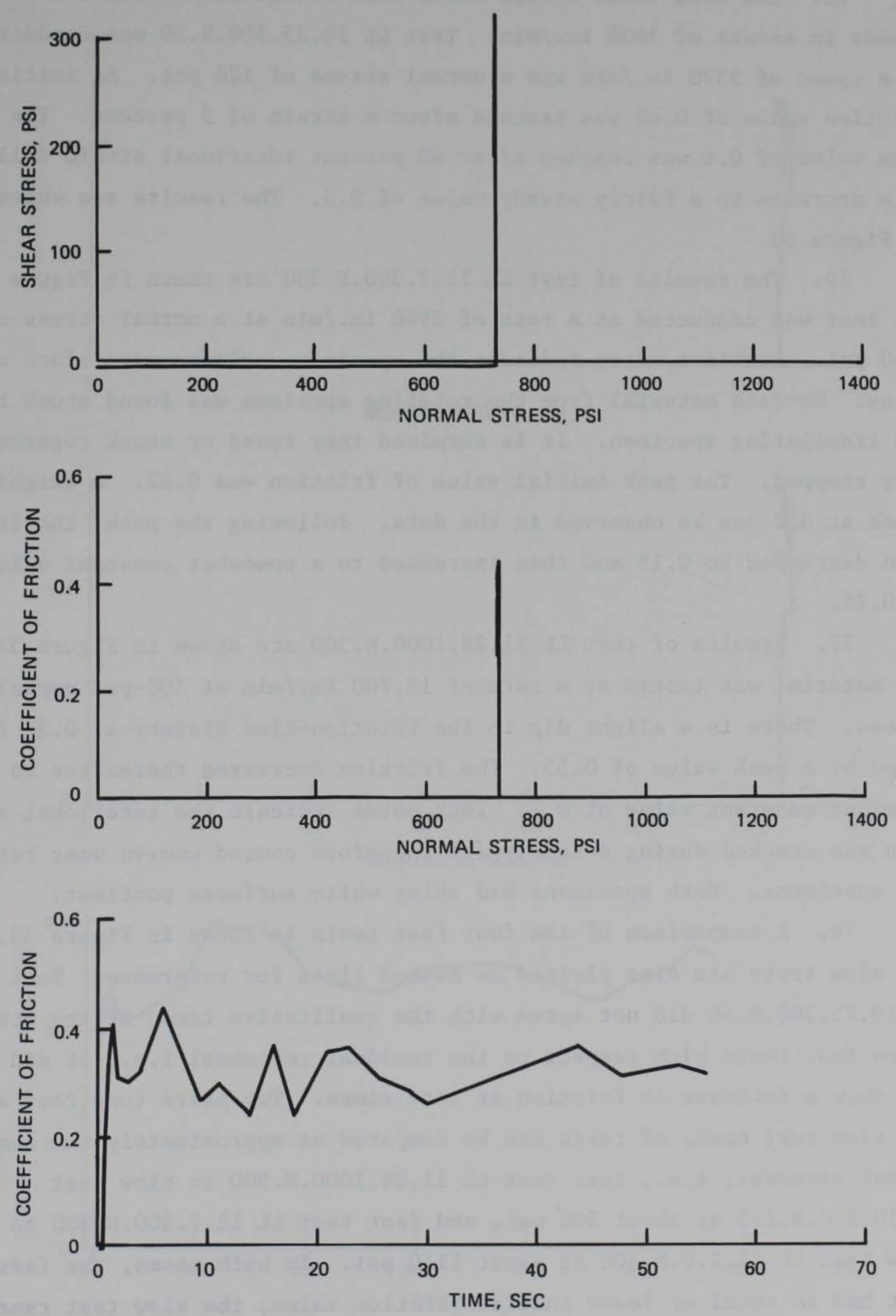

Figure 29. Results of static test LL 10.26.300.N.175 on limestone 
75. The next three $\mathrm{N}$-type tests were conducted at rotational speeds in excess of $3900 \mathrm{in./min.} \mathrm{Test} \mathrm{LL} \mathrm{10.25.300.N.50} \mathrm{was} \mathrm{conducted}$ at a speed of $5370 \mathrm{in./min}$ and a normal stress of $128 \mathrm{psi}$. An initial friction value of 0.48 was reached after a strain of 5 percent. The maximum value of 0.6 was reached after 40 percent rotational strain followed by a decrease to a fairly steady value of 0.5 . The results are shown in Figure 30.

76. The results of test LL 11.7.300.N.300 are shown in Figure 31 . The test was conducted at a rate of $3960 \mathrm{in./min}$ at a normal stress of 1160 psi. Posttest notes indicate the specimen surfaces were black and shiny. Surface material from the rotating specimen was found stuck to the translating specimen. It is surmised they fused or stuck together as they stopped. The peak initial value of friction was 0.32. A slight break at 0.2 can be observed in the data. Following the peak, the friction decreased to 0.15 and then increased to a somewhat constant value of 0.28 .

77. Results of test LL 11.28.1000.N.300 are shown in Figure 32 . The material was tested at a rate of $13,700 \mathrm{in.} / \mathrm{min}$ at $500-$ psi normal stress. There is a slight dip in the friction-time history at 0.32 followed by a peak value of 0.53 . The friction decreased thereafter to a somewhat constant value of 0.2 . Test notes indicate the rotational specimen was cracked during assembly and therefore caused uneven wear between the specimens. Both specimens had shiny white surfaces posttest.

78. A comparison of the four fast tests is shown in Figure 33. Two slow tests are also plotted as dashed lines for reference. Test LL 10.25.300.N.50 did not agree with the qualitative trend of the other three fast tests with respect to the residual response; i.e., it did not show a decrease in friction at late times. Two pairs (one fast and one slow test each) of tests can be compared at approximately the same normal stresses; i.e., fast test LL 11.28.1000.N.300 to slow test LL 10.2.0.N.175 at about 500 psi, and fast test LL 11.7.300.N.300 to slow test LL $11 \cdot 2 \cdot 0 . N .300$ at about 1150 psi. In both cases, the fast test had an equal or lower initial friction value; the slow test remained constant, whereas the fast test markedly decreased to a value around 

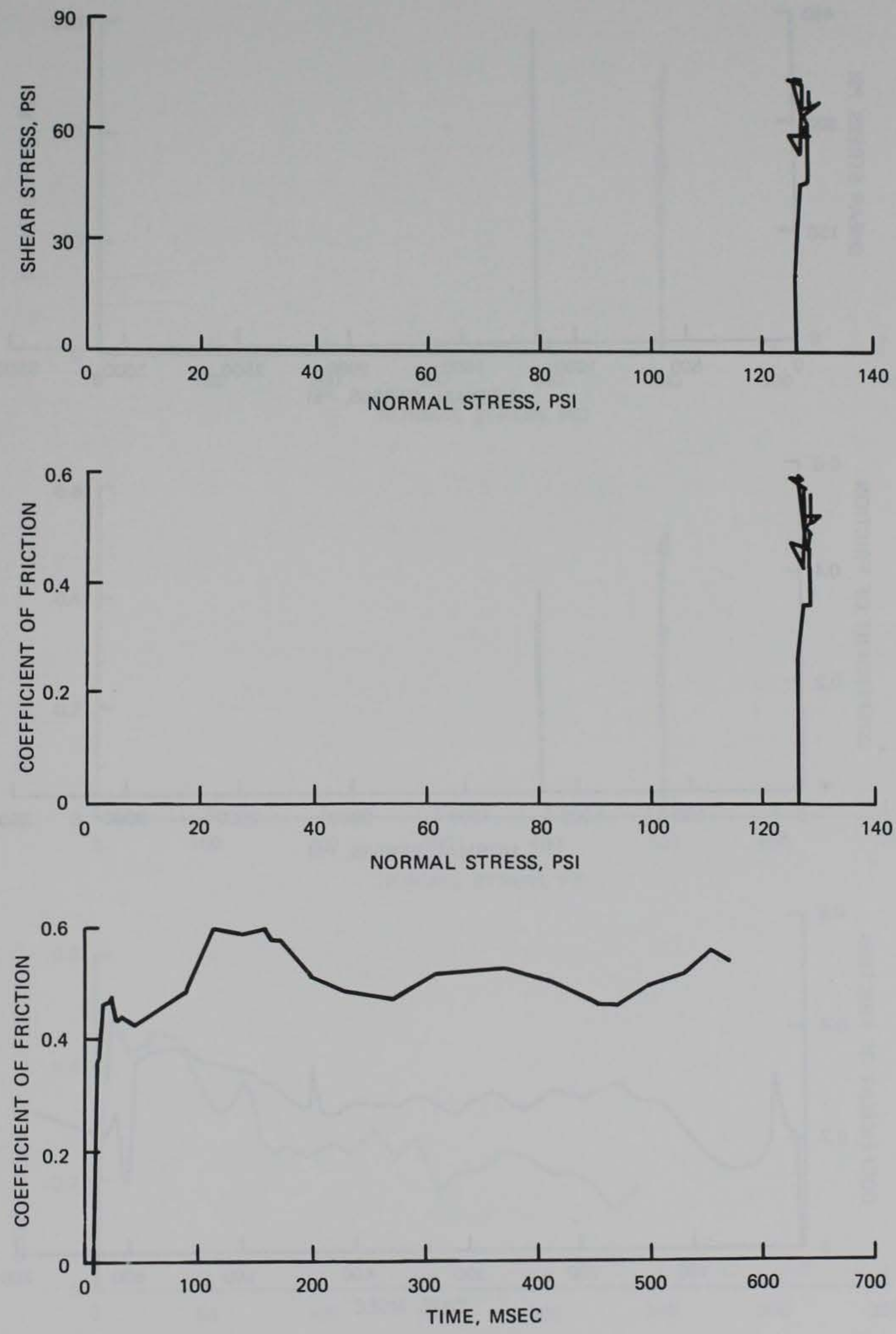

Figure 30. Results of kinetic test LL 10.25.300.N.50 on limestone 

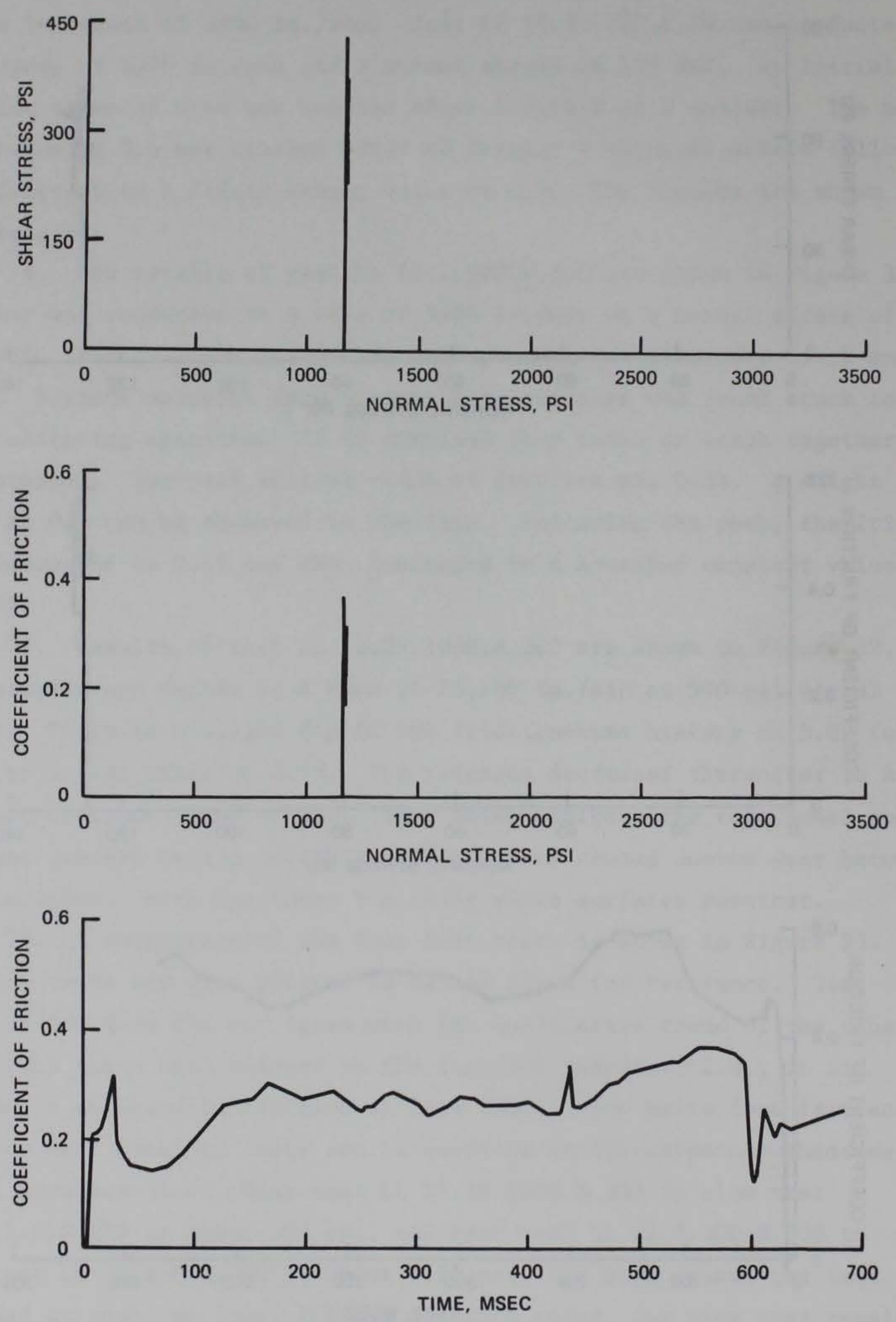

Figure 31. Results of kinetic test LL 11.7.300.N.300 on 1imestone 

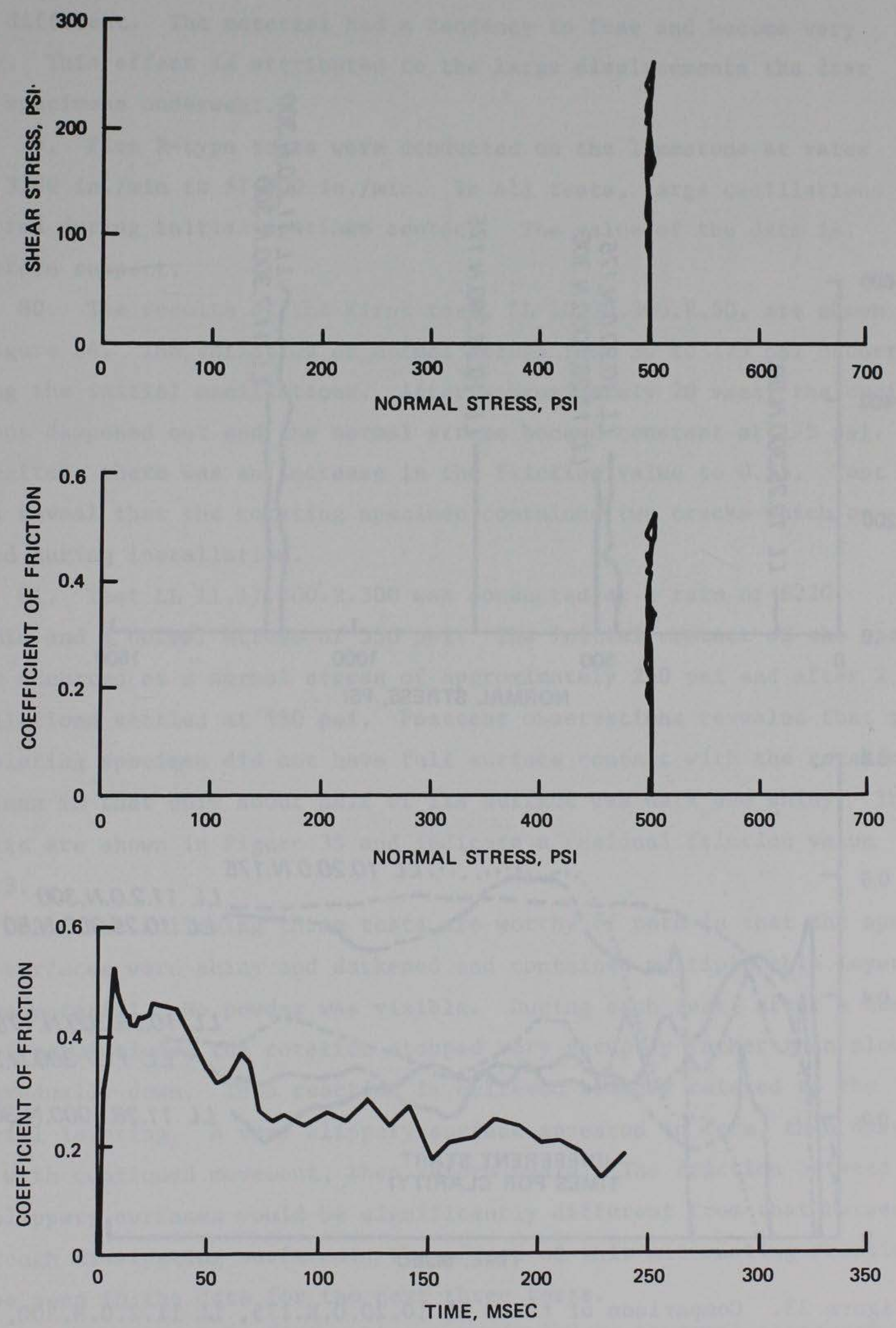

Figure 32. Results of kinetic test LL 11.28.1000.N.300 on limestone 

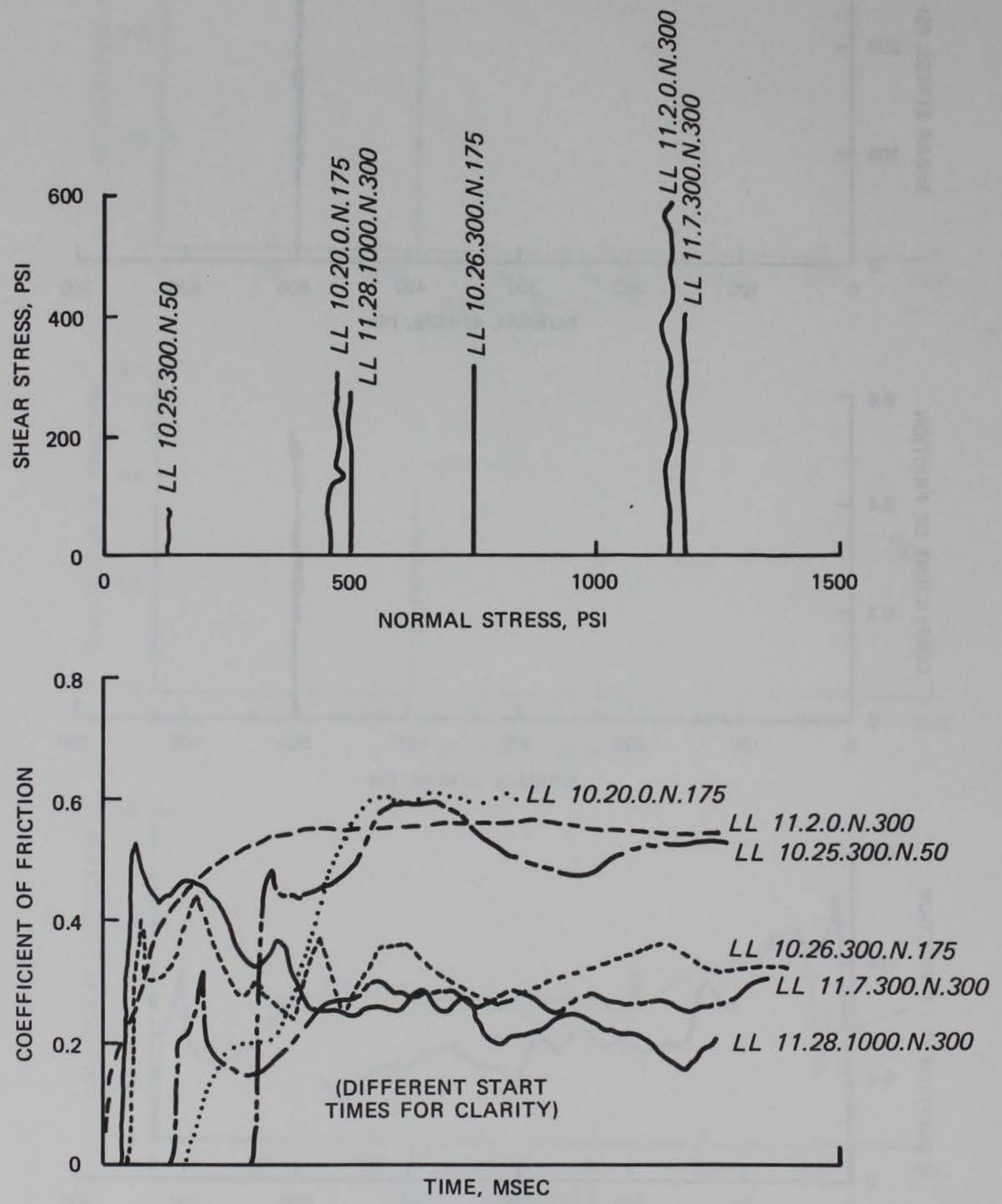

Figure 33. Comparison of tests LL 10.20.0.N.175, LL 11.2.0.N.300, LL 10.25.300.N.50, LL 10.26.300.N.175, LL 11.7.300.N.300, and LL $11.28 \cdot 1000$. N. 300 on limestone 
0.25 to 0.30 . Surface wear on the specimens in the fast tests was markedly different. The material had a tendency to fuse and become very shiny. This effect is attributed to the large displacements the fast test specimens underwent.

79. Five R-type tests were conducted on the limestone at rates from $3700 \mathrm{in./min} \mathrm{to} \mathrm{57,900} \mathrm{in./min.} \mathrm{In} \mathrm{all} \mathrm{tests,} \mathrm{large} \mathrm{oscillations}$ occurred during initial specimen contact. The value of the data is therefore suspect.

80. The results of the first test, LL 10.30.300.R.50, are shown in Figure 34. The variation of normal stress from 30 to 175 psi occurred during the initial oscillations. After approximately $20 \mathrm{msec}$, the oscillations dampened out and the normal stress became constant at 175 psi. Thereafter, there was an increase in the friction value to 0.55 . Test notes reveal that the rotating specimen contained two cracks which occurred during installation.

81. Test LL 11.17.300.R. 300 was conducted at a rate of 6220 in./min and a normal stress of $550 \mathrm{psi}$. The initial contact of the specimens occurred at a normal stress of approximately 250 psi and after 2 oscillations settled at 550 psi. Posttest observations revealed that the translating specimen did not have full surface contact with the rotating specimen in that only about half of its surface was dark and shiny. The results are shown in Figure 35 and indicate a residual friction value of 0.3 .

82. The following three tests are worthy of note in that the specimen surfaces were shiny and darkened and contained multiple thin layers of the material. No powder was visible. During each test, after a number of revolutions, the rotation stopped very abruptly rather than slowing gradually down. This reaction is believed somehow related to the material layering. A very slippery surface appeared to form, then dissipate with continued movement, then reform again. The friction between the slippery surfaces would be significantly different from that between the rough dissipating surfaces. The effect of this alternating reaction can be seen in the data for the next three tests.

83. Test LL 9.20.3000.R.50 was conducted at a normal stress of 

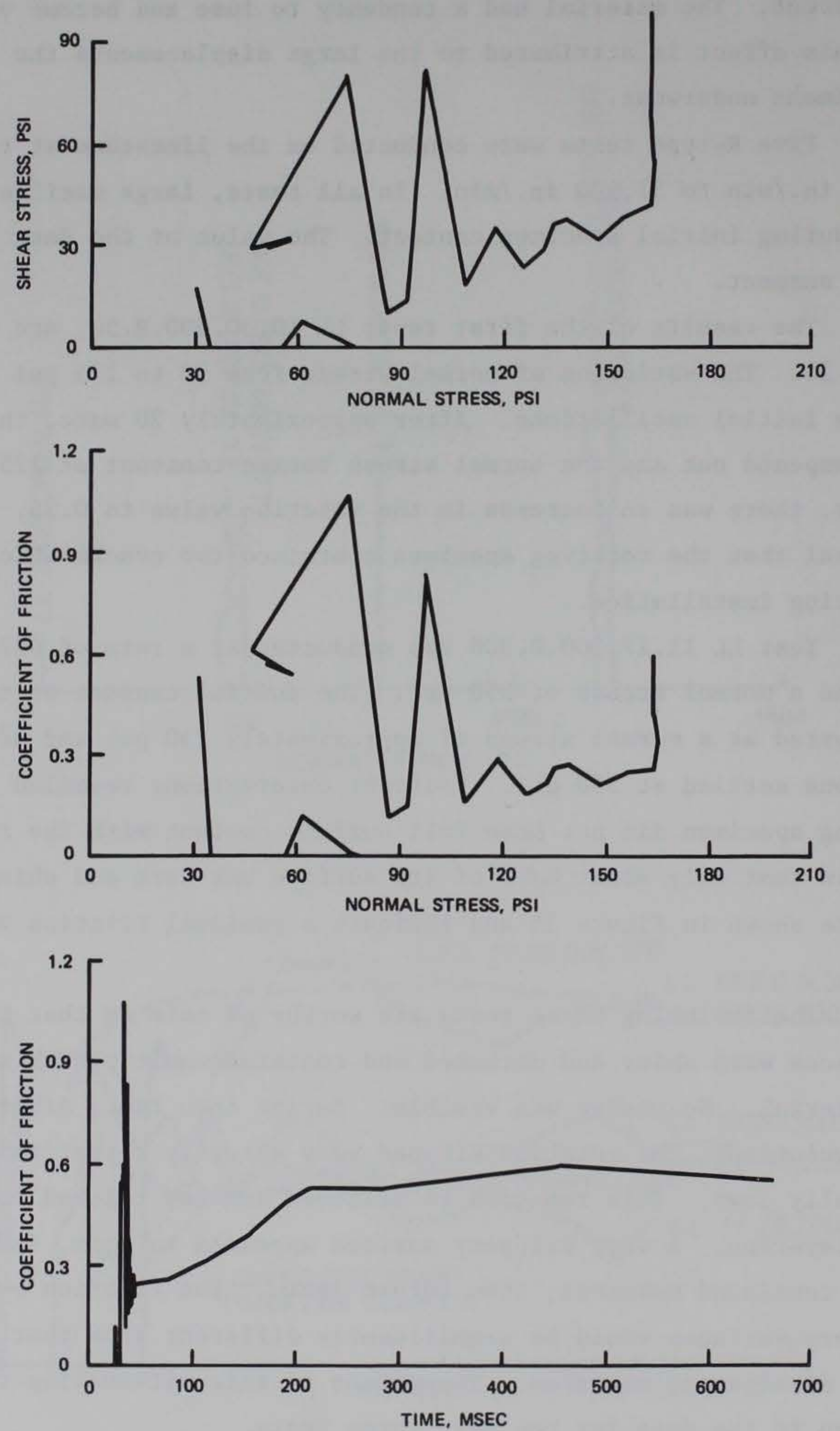

Figure 34. Results of kinetic test LL 10.30.300.R.50 on limestone 

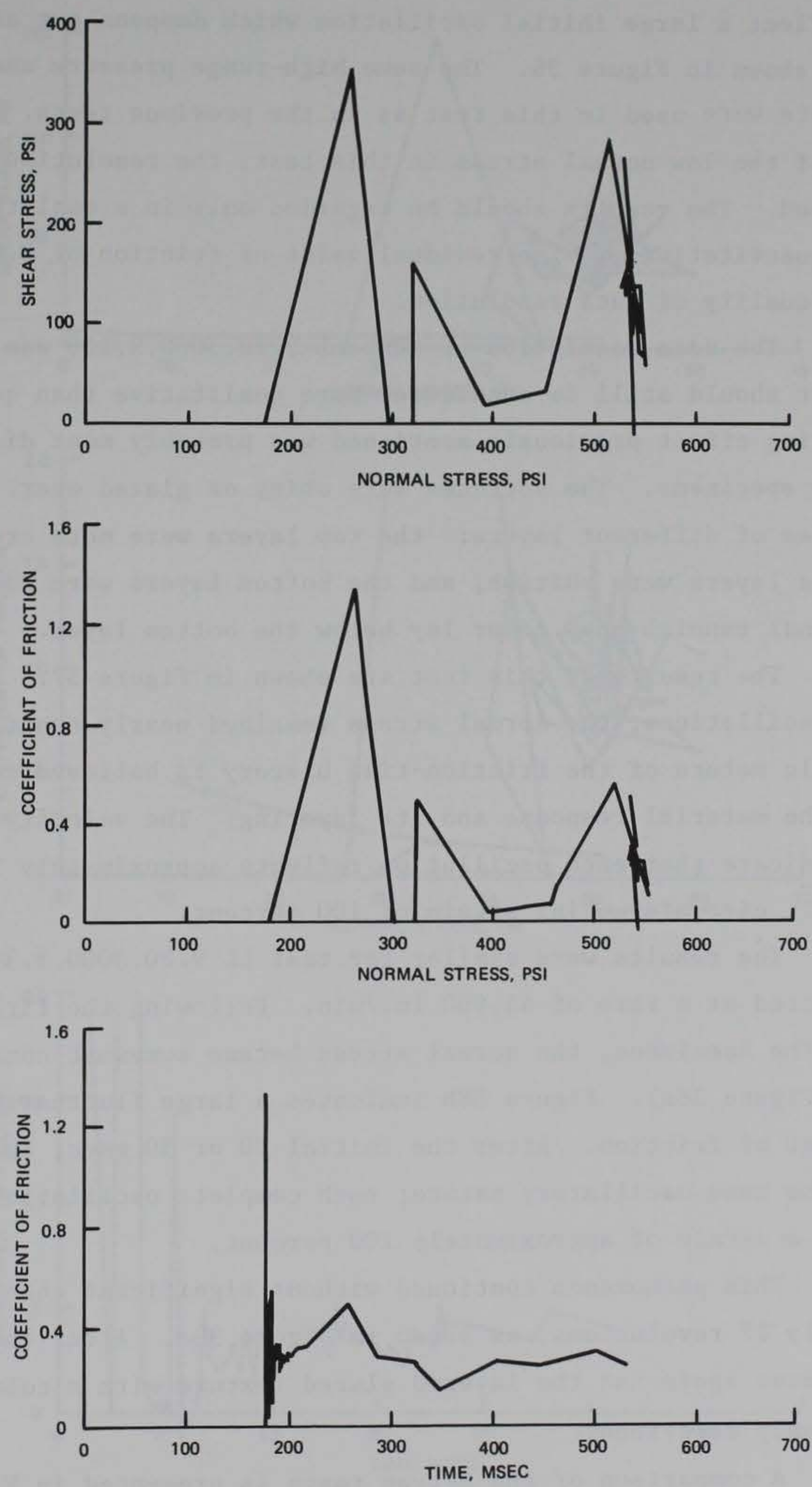

Figure 35. Results of kinetic test LL 11.17.300.R.300 on limestone 
approximately $50 \mathrm{psi}$ and at a rotation rate of $43,400 \mathrm{in} / \mathrm{sec}$. The results reflect a large initial oscillation which dampens out after 20 msec, as shown in Figure 36. The same high-range pressure and load transducers were used in this test as in the previous tests. Therefore, because of the low normal stress in this test, the resolution of the data is not good. The results should be regarded only in a qualitative nature and not quantitatively. The residual value of friction of 0.8 reflects the poor quality of data resolution.

84. The data resolution of test LL 9.20.3000.R.150 was somewhat better but should still be considered more qualitative than quantitative. The layering effect previously mentioned was probably most distinctive on these two specimens. The surfaces were shiny or glazed over. There were three types of different layers: the top layers were more cream colored, the middle layers were whitish, and the bottom layers were dark gray. The original tannish-gray color lay below the bottom layer.

85. The results of this test are shown in Figure 37. After the initial oscillations, the normal stress remained nearly constant. The very cyclic nature of the friction-time history is believed to be a result of the material response and its layering. The velocity-time histories indicate that each oscillation reflects approximately 1 revolution; i.e., circumferential strain of 100 percent.

86. The results were similar for test LL 9.20.3000.R. 300 which was conducted at a rate of $43,900 \mathrm{in.} / \mathrm{min}$. Following the first few contacts of the specimens, the normal stress became somewhat constant at 150 psi (Figure 38a). Figure 38b indicates a large fluctuation in the coefficient of friction. After the initial 20 or $30 \mathrm{msec}$, the data reflected the same oscillatory nature; each complete oscillation corresponds to a strain of approximately 100 percent.

87. This phenomenon continued without significant change for approximately 17 revolutions, as shown in Figure 38c. After the test, the specimens again had the layered glazed texture with a color the same as previously described.

88. A comparison of the R-type tests is presented in Figure 39. Although the initial stages of the data appear chaotic, there is no 

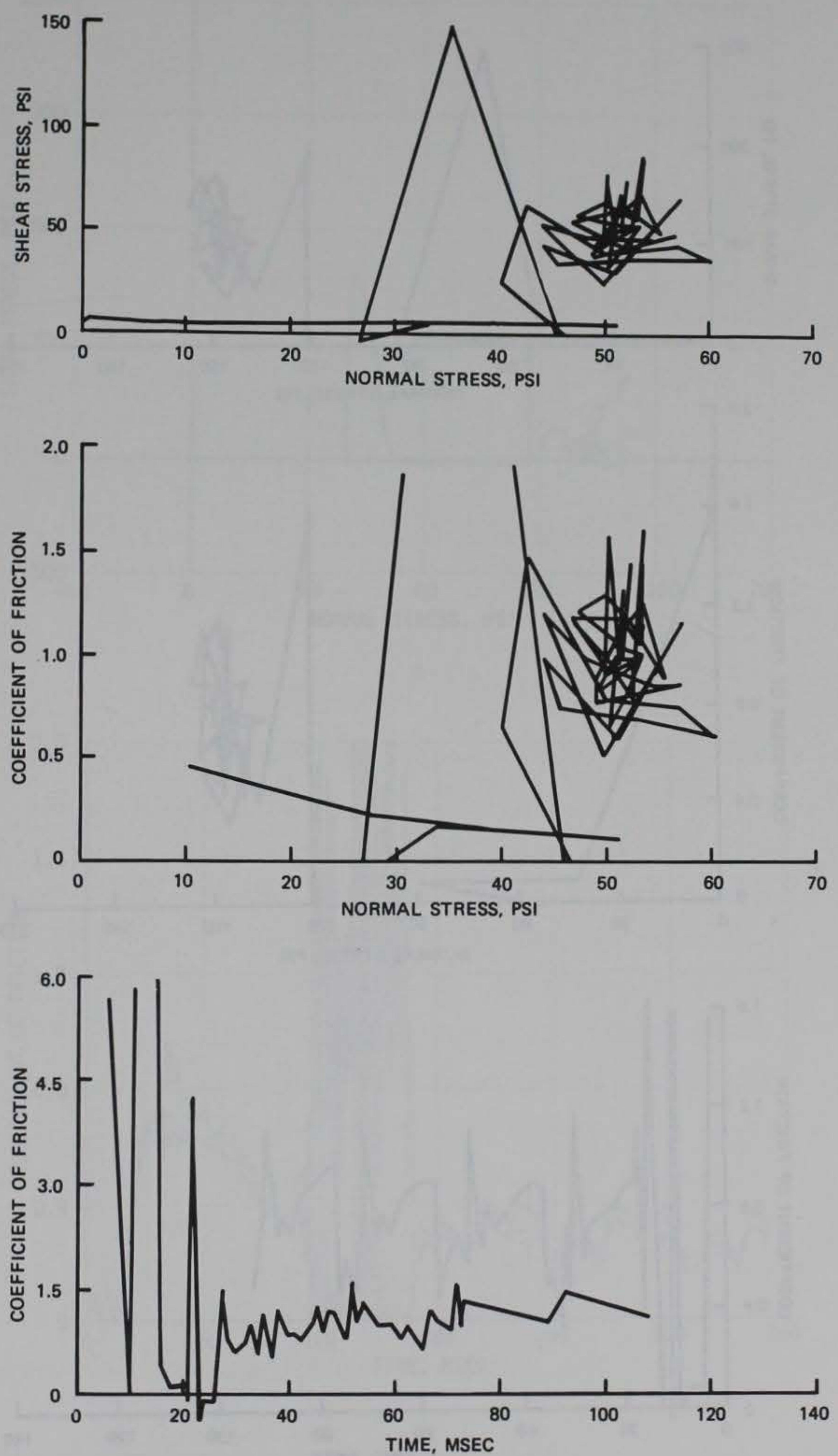

Figure 36. Results of kinetic test LL 9.20.3000.R.50 on limestone 

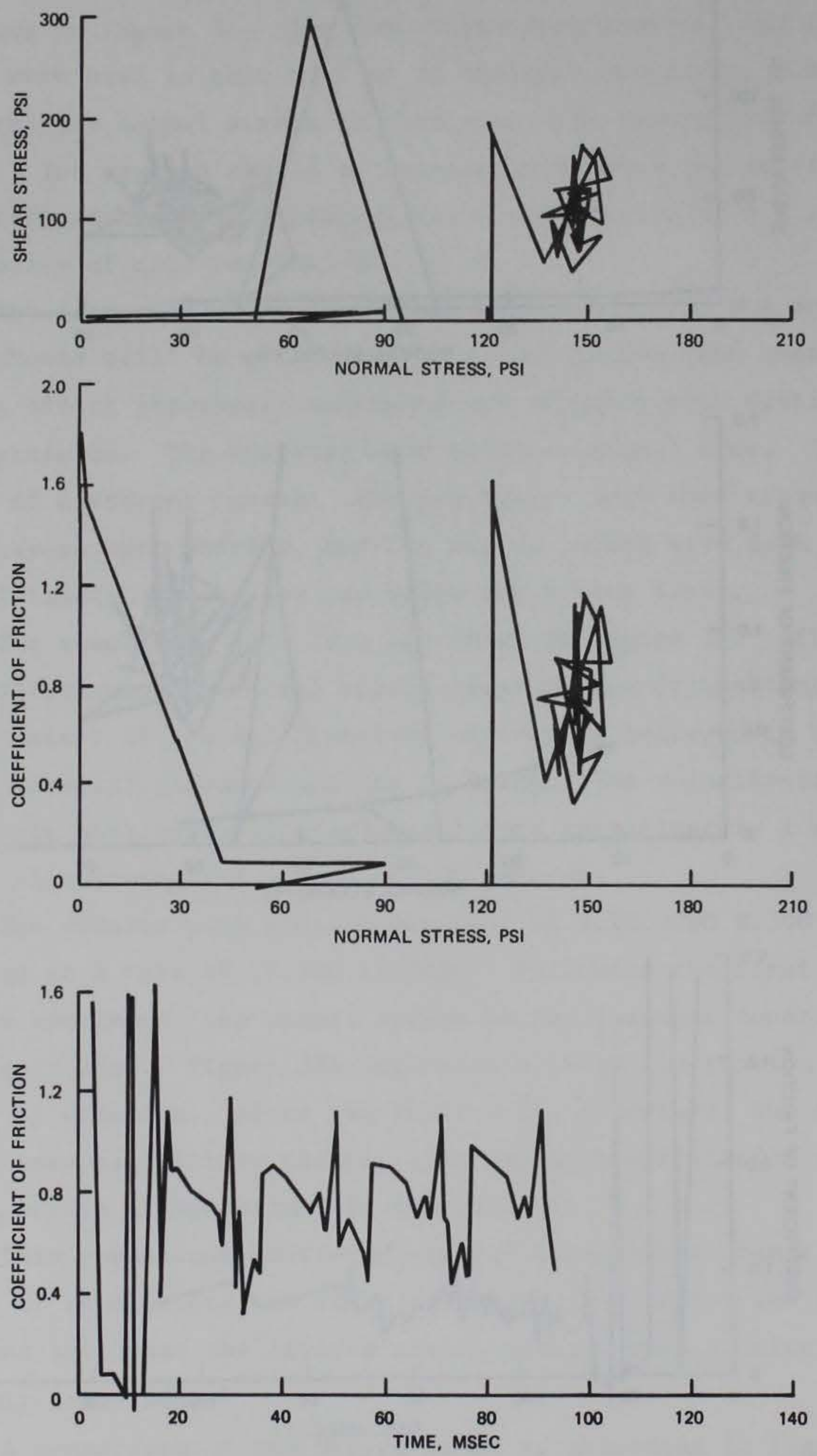

Figure 37. Results of kinetic test LL 9.20.3000.R.150 on limestone

64 


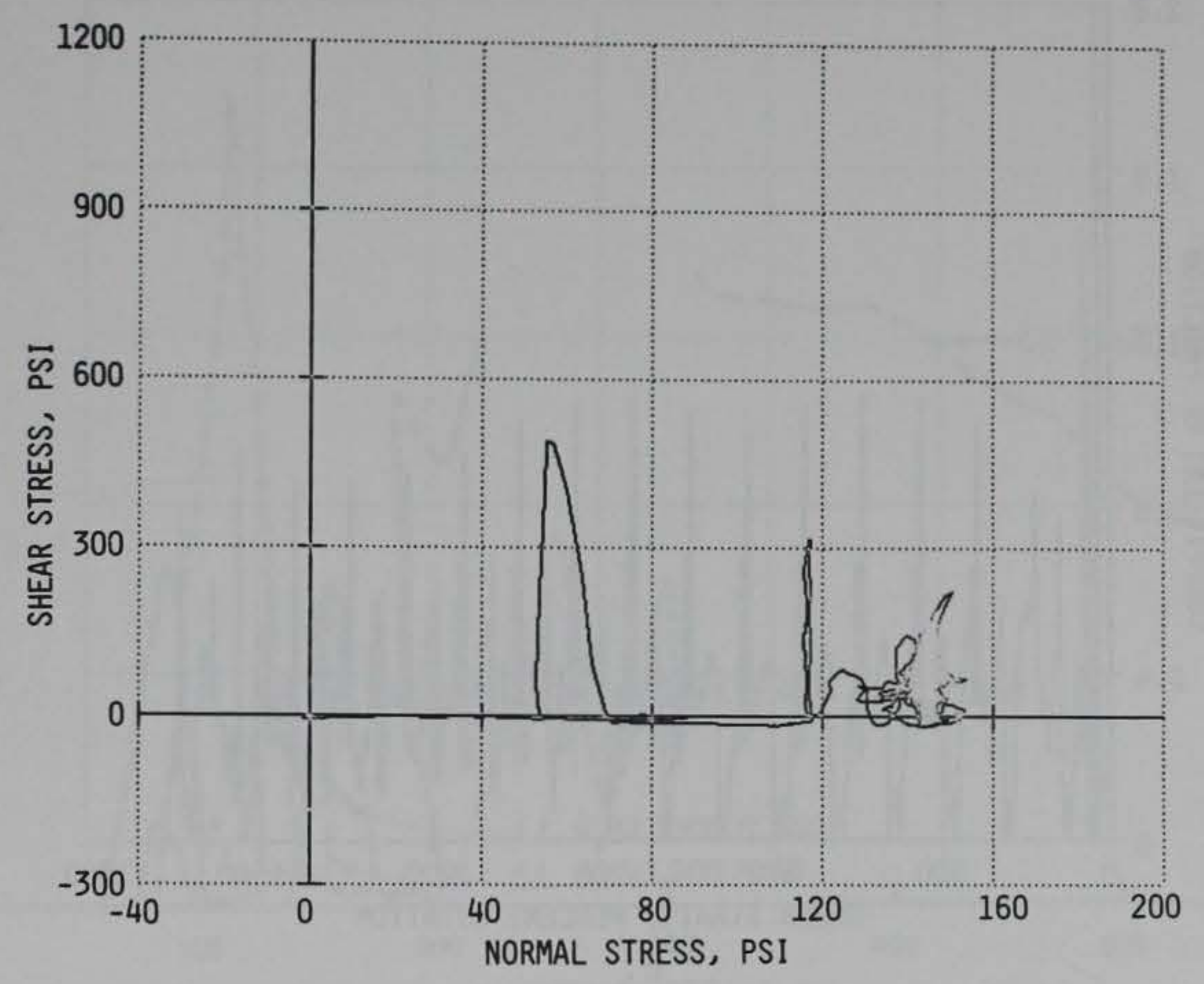

a.

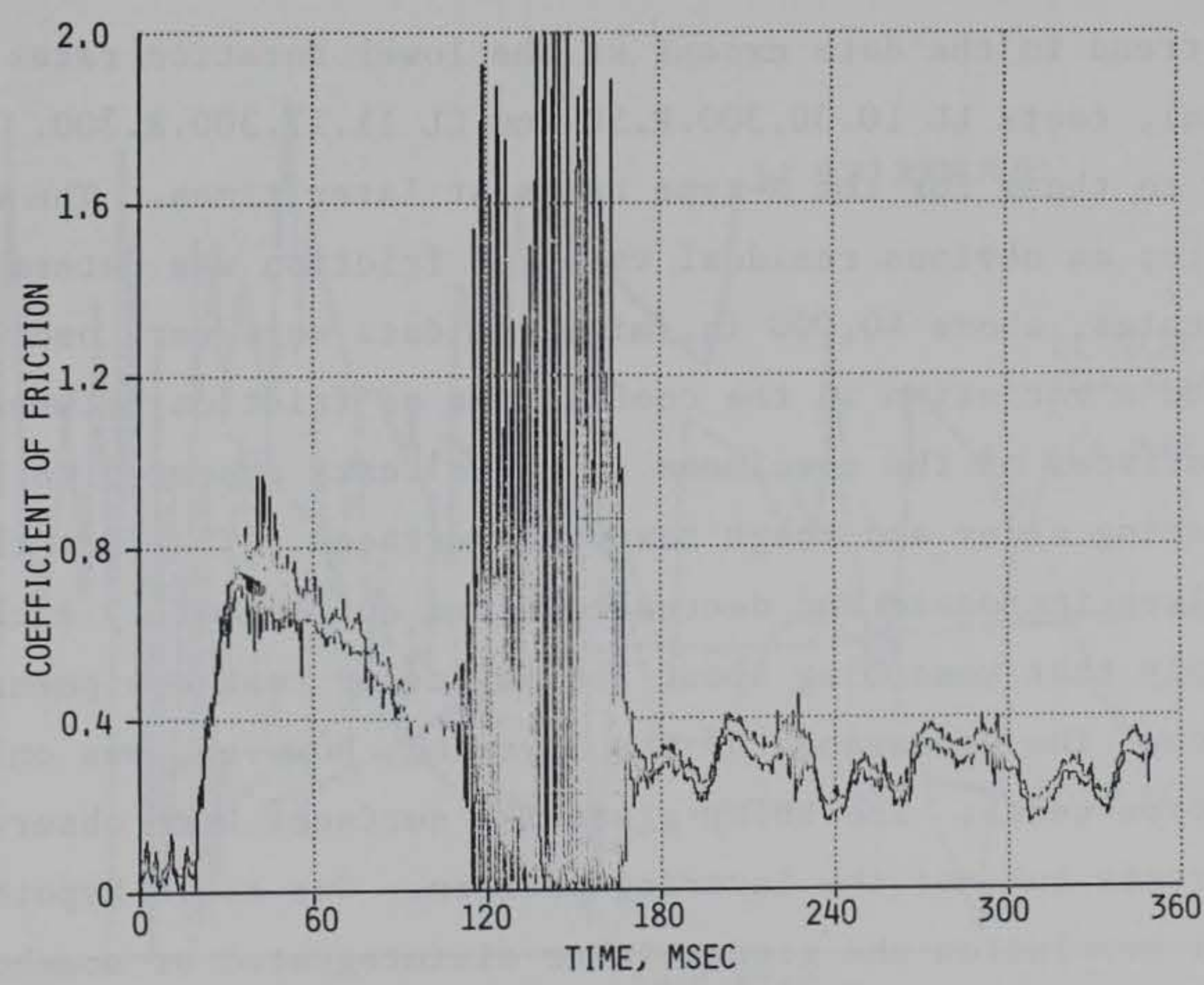

b.

Figure 38. Results of kinetic test LL 9.20.3000.R. 300 on limestone (Continued) 


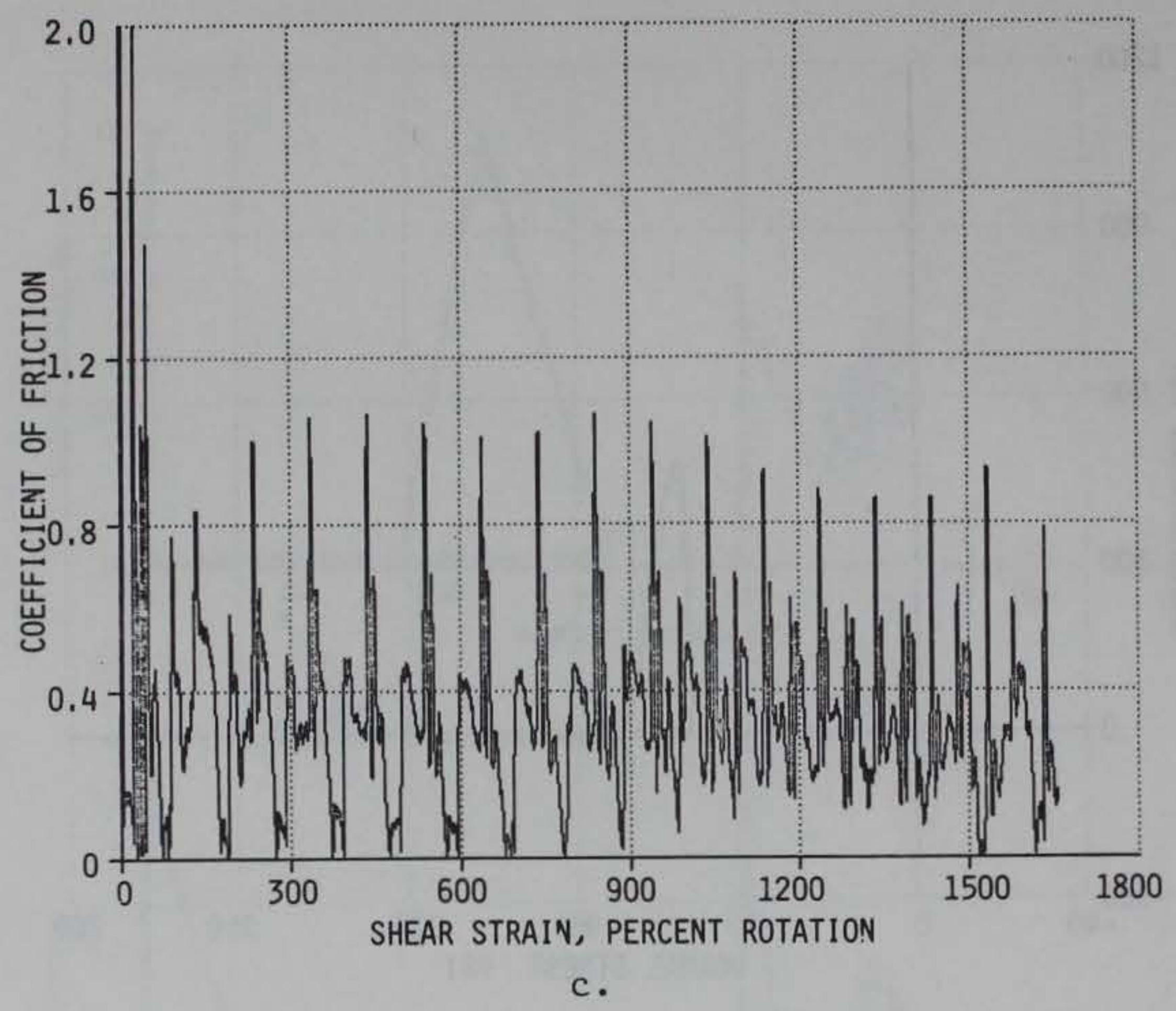

Figure 38. (Concluded)

consistent trend in the data except at the lower rotation rates (3000 to 4000 in./min), tests LL 10.30.300.R. 50 and LL 11.17.300.R.300. The data are similar to those for the N-type tests at later times. The data did not oscillate; an obvious residual value of friction was determined. At the faster rates, above $40,000 \mathrm{in.} / \mathrm{min}$, the data were very oscillatory, which created a variation in the coefficient of friction between 0.4 and 0.6. The surfaces of the specimens in these tests appeared to be layered with alternating shiny and rough textured surfaces. The fact that the friction values increased and decreased after approximately each revolution may imply that something about the device or test equipment created the condition. The appearance of the layering, however, was only noted on these R-type tests. The shiny glazelike surfaces were observed in the N-type tests but not the layering pattern. One could hypothesize that after 1 revolution the glaze either disintegrated or somehow disappeared and the friction abruptly increased.

89. Five tests were conducted using specimens with wet surfaces: three were $\mathrm{N}$-type tests, two were R-type tests. The results of test 

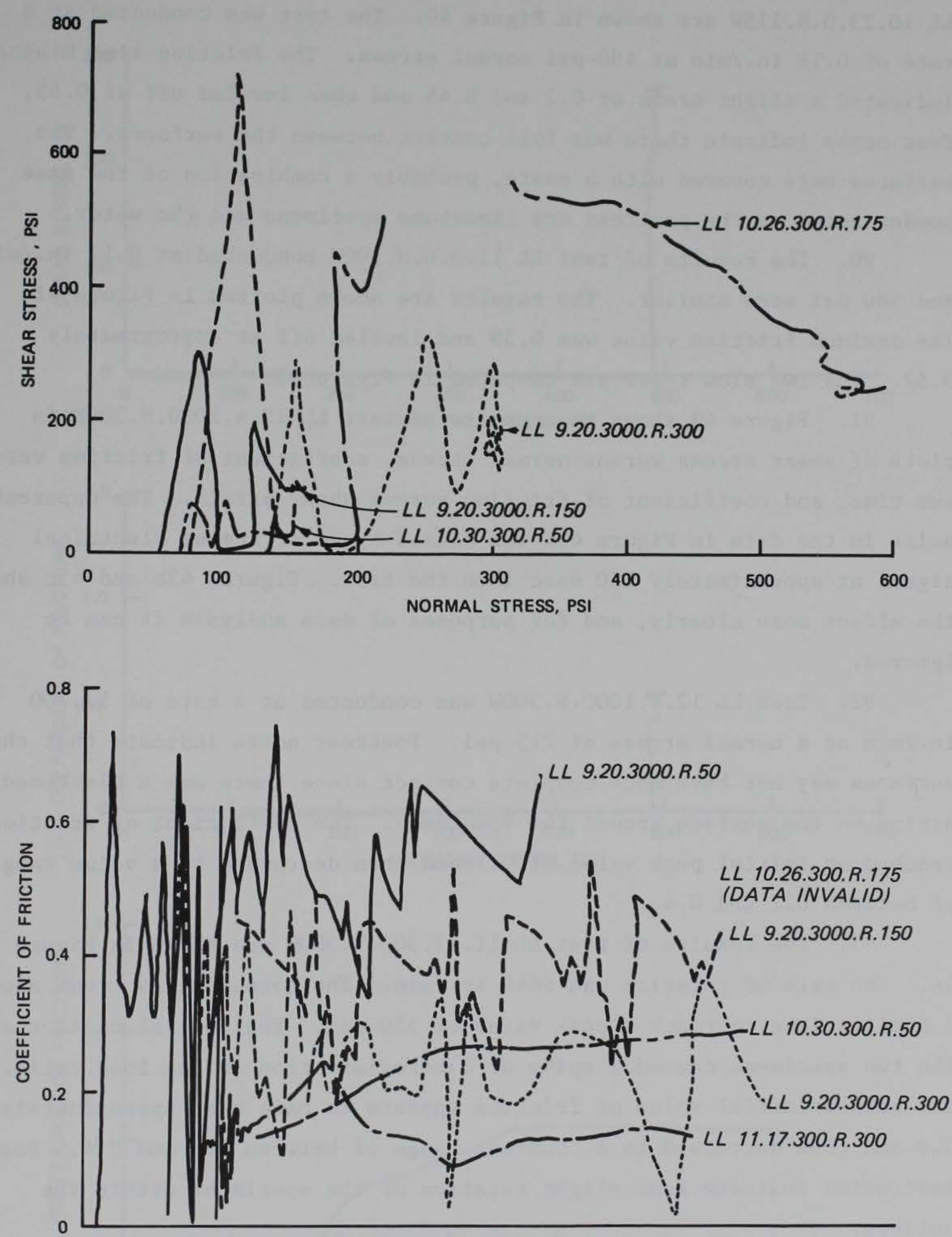

TIME, MSEC

Figure 39. Comparison of tests LL 9.20.3000.R.50, LL 10.26.300.R.175, LL 9.20.3000.R.150, LL 10.30.300.R.50, LL 9.20.3000.R.300, and LL 11.17 .300$. R. 300 on limestone 
LL 10.23.0.N.175W are shown in Figure 40. The test was conducted at a rate of $0.18 \mathrm{in./min}$ at 490-psi normal stress. The friction-time history indicated a slight break at 0.3 and 0.45 and then leveled off at 0.55 . Test notes indicate there was full contact between the surfaces. The surfaces were covered with a paste, probably a combination of the same powder noted on the posttest dry limestone specimens and the water.

90. The results of test LL $11 \cdot 3 \cdot 0 . \mathrm{N} .300 \mathrm{~W}$ conducted at $0.17 \mathrm{in} . / \mathrm{min}$ and 580 psi were similar. The results are shown plotted in Figure 41. The maximum friction value was 0.59 and leveled off at approximately 0.57. The two slow tests are compared in Figure 42.

91. Figure 43 shows the results of test LL 12.4.1000.N.300W in plots of shear stress versus normal stress, coefficient of friction versus time, and coefficient of friction versus shear strain. The apparent noise in the data in Figure $43 \mathrm{a}$ was caused by an erroneous electrical signal at approximately $120 \mathrm{msec}$ into the test. Figures $43 \mathrm{~b}$ and $43 \mathrm{c}$ show the effect more clearly, and for purposes of data analysis it can be ignored.

92. Test LL $12 \cdot 4 \cdot 1000$.N. $300 \mathrm{~W}$ was conducted at a rate of 12,700 in./min at a normal stress of 215 psi. Posttest notes indicate that the surfaces may not have made complete contact since there was a blackened stripe on the surface around the specimens. The coefficient of friction reached an initial peak value of 0.7 and then decreased to a value range of between 0.2 and 0.4 .

93. The results of test LL 11.17.300.R.300W are shown in Figure 44. The rate of rotation was $6640 \mathrm{in./min}$. The normal stress took about 2 oscillations to reach a peak value of $550 \mathrm{psi}$. The initial contact of the two specimens caused a spike or overregistration on the load cells. The actual initial value of friction appears to have been approximately 0.6 and then decreased to a constant range of between 0.3 and 0.4 . Posttest notes indicate some slight rotation of the specimens within the holders.

94. Test LL 9.21.3000.R. $300 \mathrm{~W}$ was conducted at a rate of 42,400 in./min and at a maximum normal stress of $300 \mathrm{psi}$. The initial contact between specimens severely interfered with the measurements. Therefore, 

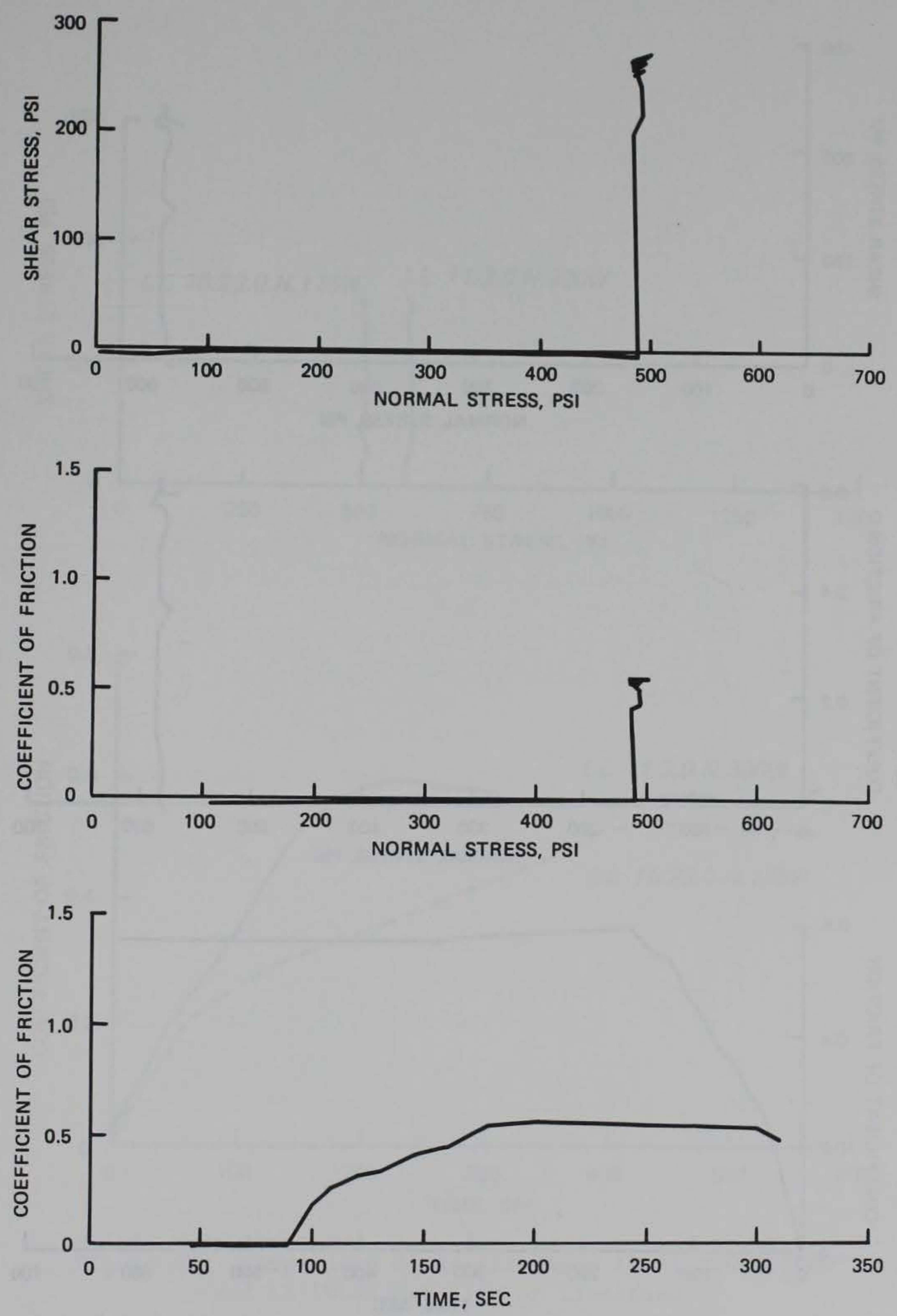

Figure 40. Results of static test LL 10.23.0.N.175W on 1imestone 

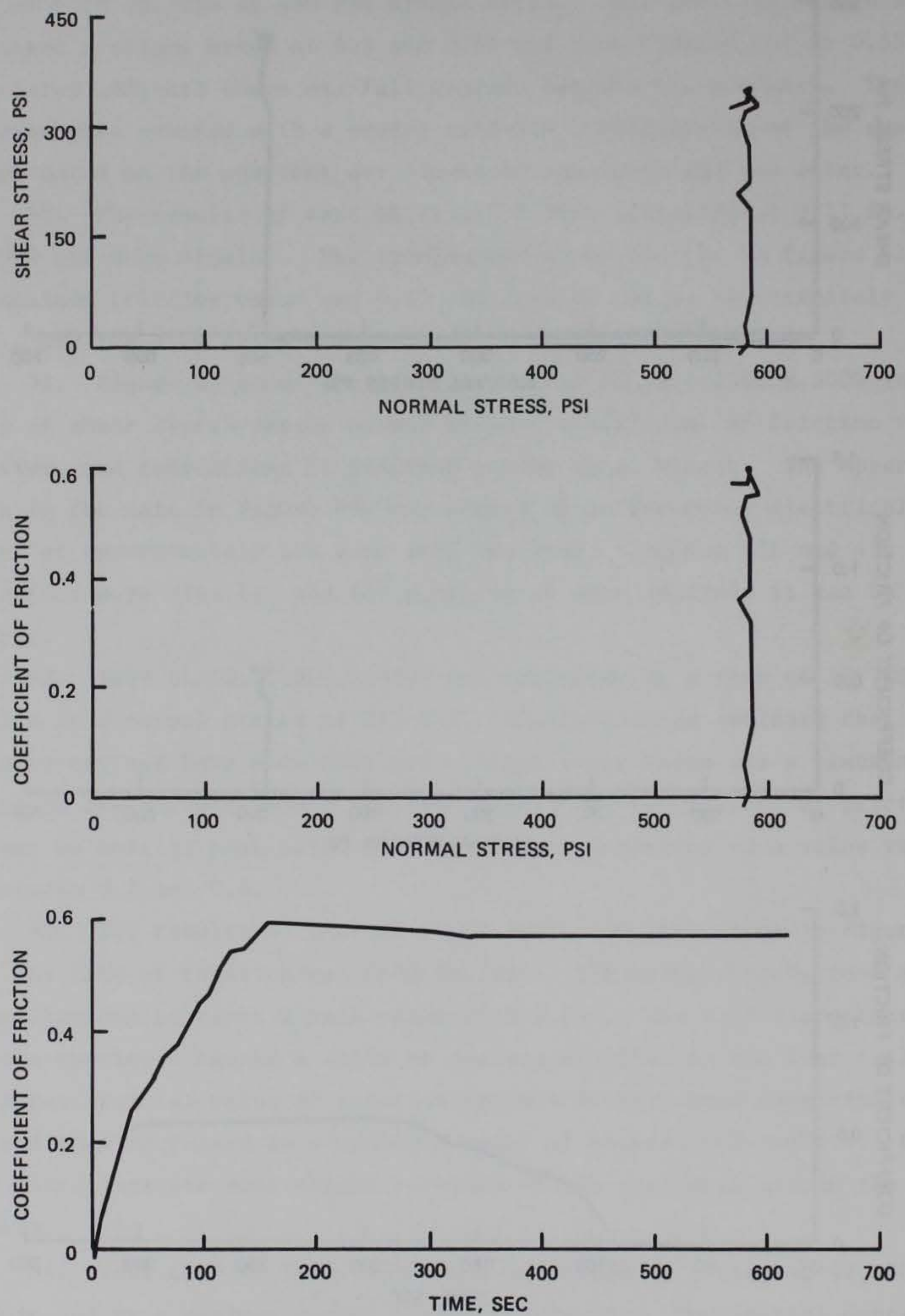

Figure 41. Results of static test LL 11.3.0.N.300W on limestone 

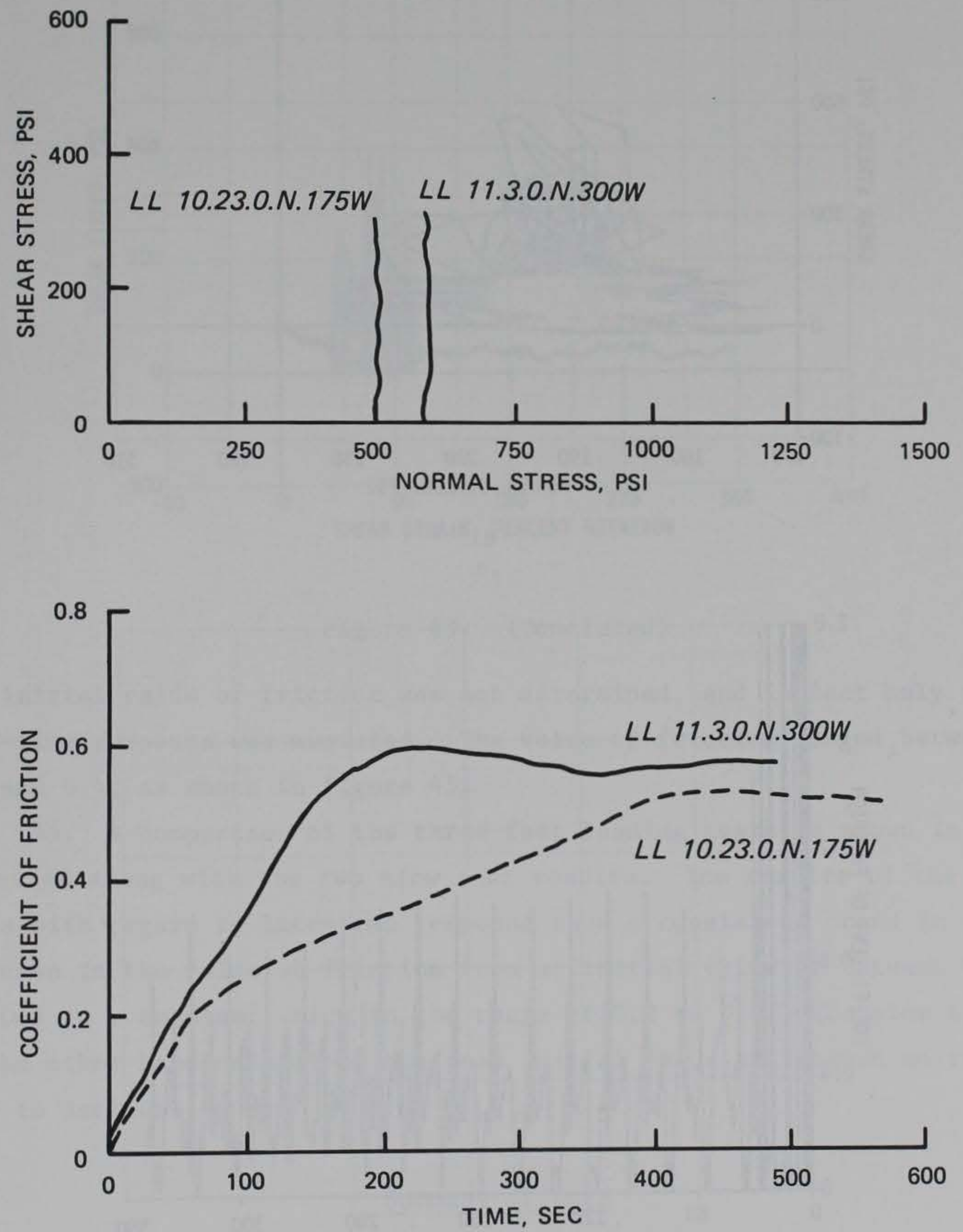

Figure 42. Comparison of static tests LL 11.3.0.N.300W and LL $10.23 .0 . \mathrm{N} .175 \mathrm{~W}$ on limestone 


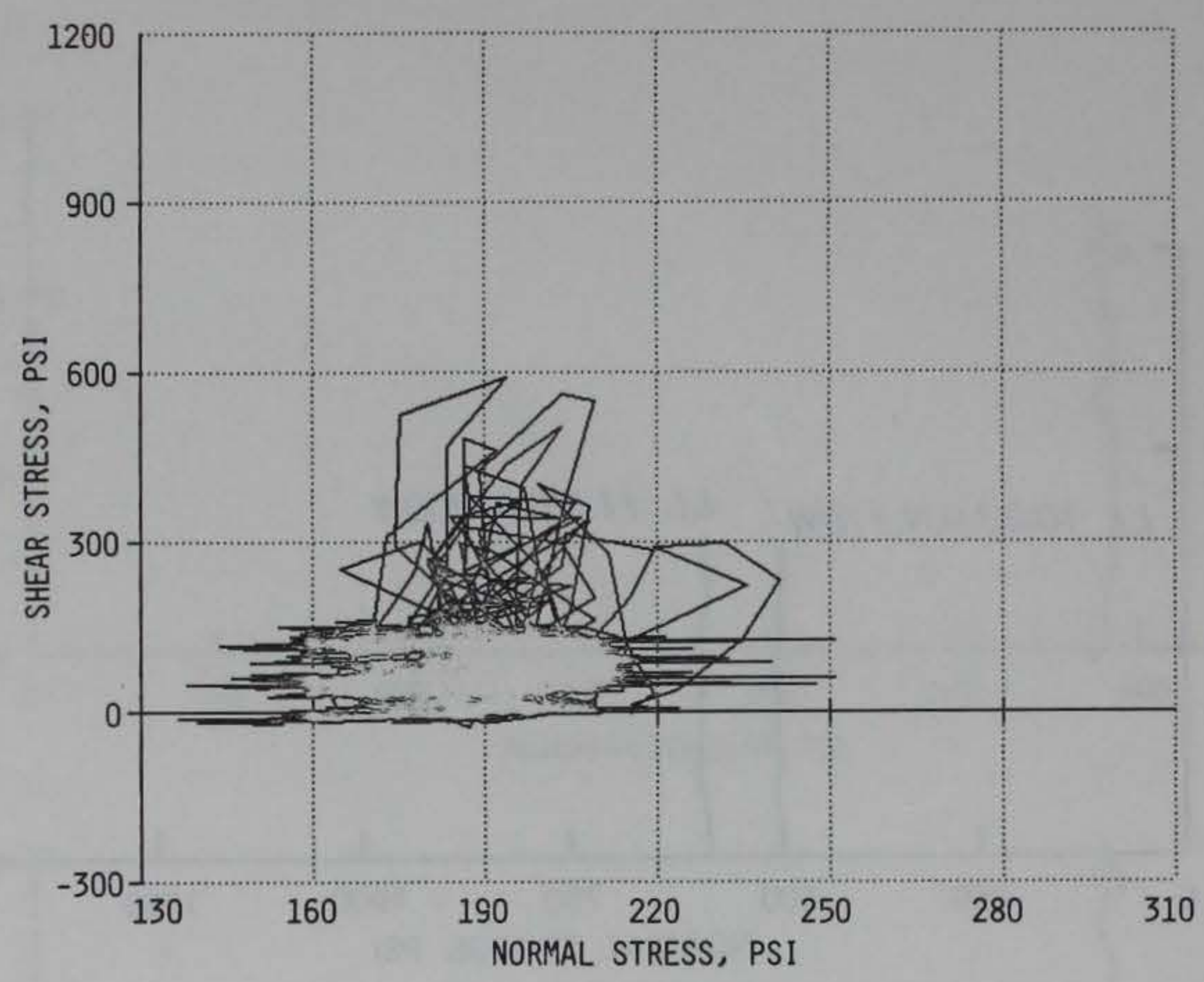

a.

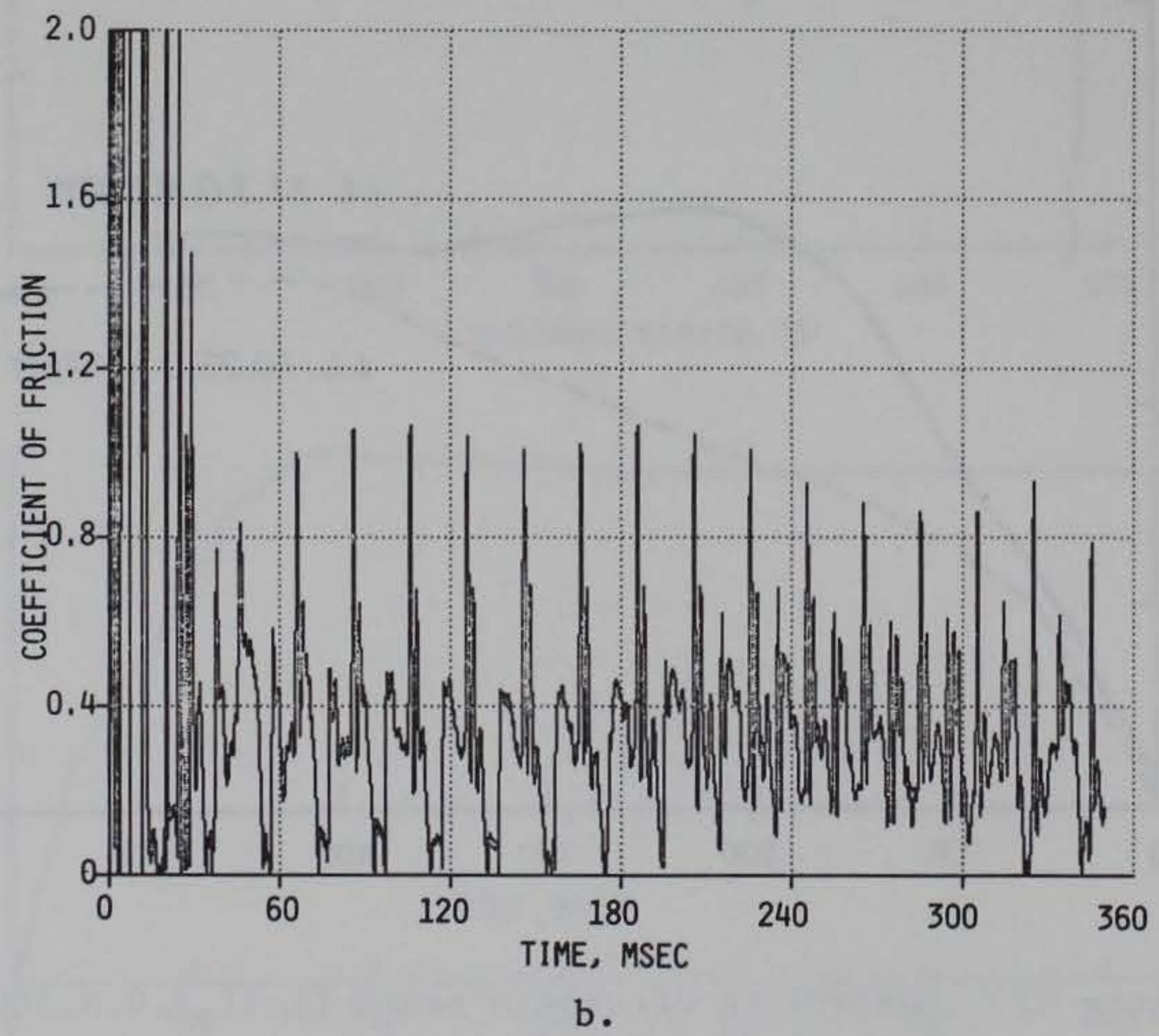

Figure 43. Results of kinetic test LL 12.4.1000.N.300W on limestone (Continued) 


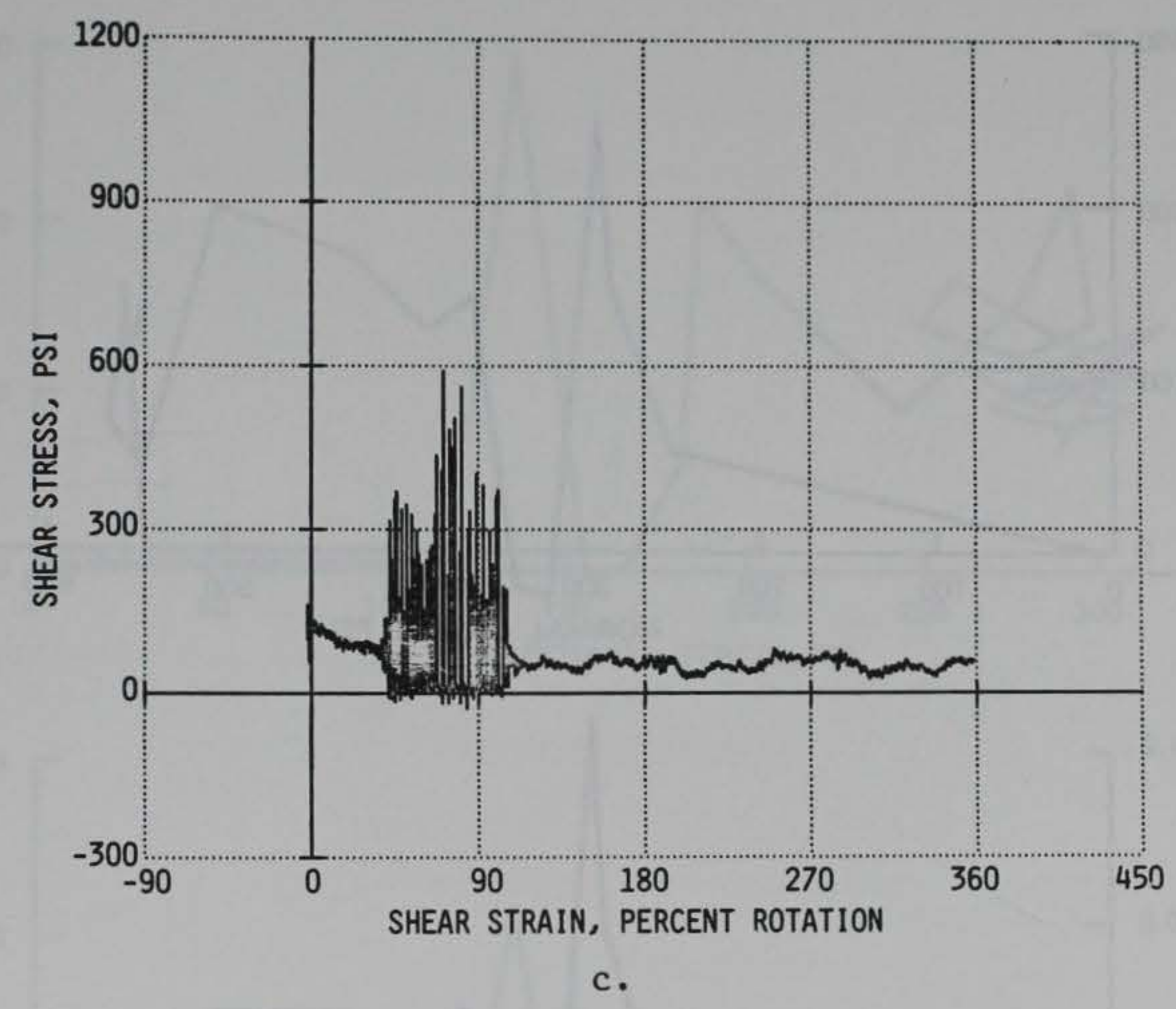

Figure 43. (Concluded)

the initial value of friction was not determined, and in fact only the late-time response was measured. The value of friction ranged between 0.3 and 0.4 , as shown in Figure 45.

95. A comparison of the three fast loading tests is shown in Figure 46 along with the two slow test results. The results of the fast tests with regard to late-time response show a consistent trend in a decrease in the value of friction from an initial value of between 0.6 and 0.8 to a constant value in the range of 0.3 to 0.4 . The slow tests on the other hand maintained the peak initial value and showed no tendency to decrease.

\section{Summary of Data}

96. The test results on the three different rock types can be presented a number of ways. One common plot is of shear stress versus normal stress in which the initial, peak, or residual stress values from 

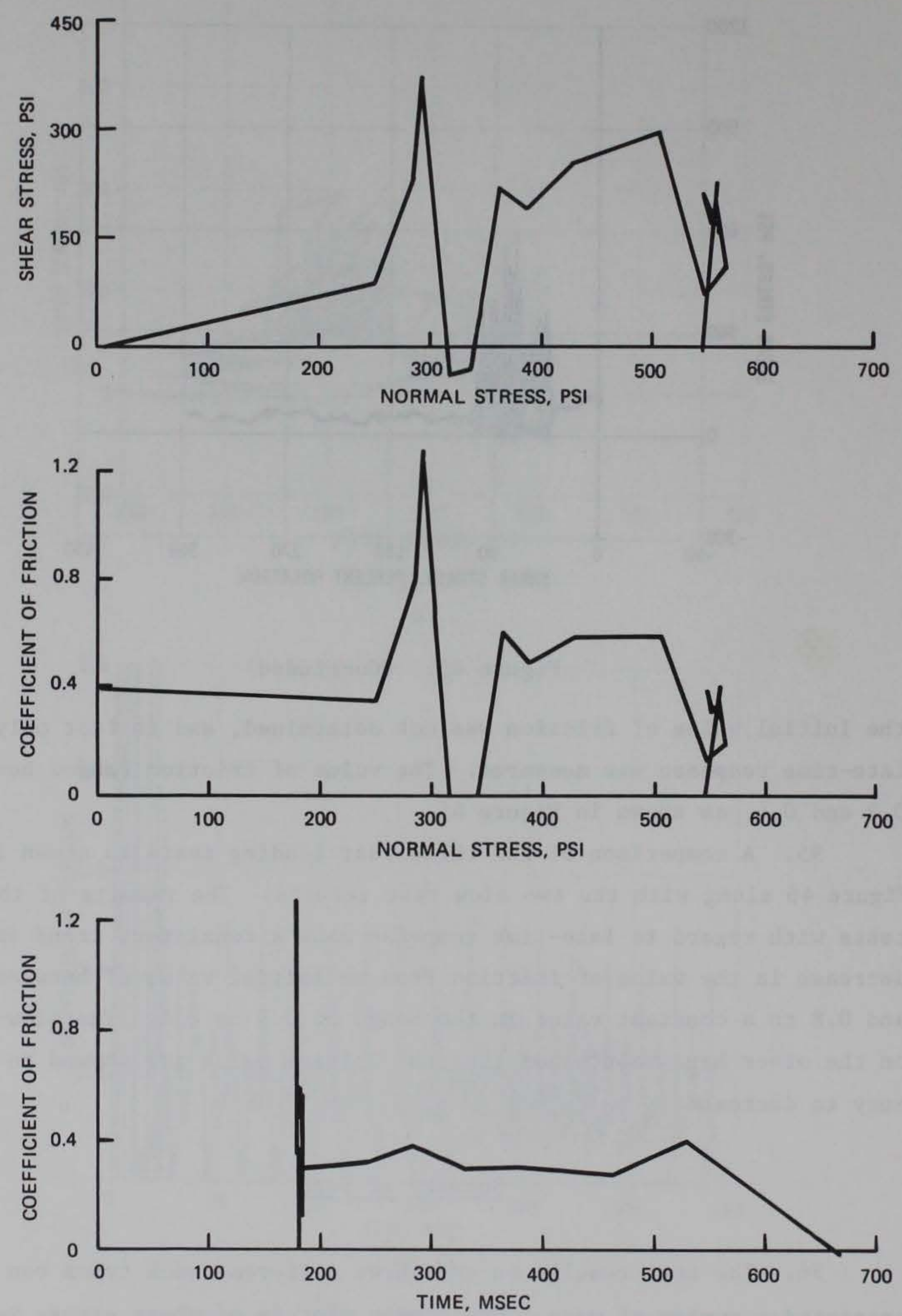

Figure 44. Results of kinetic test LL 11.17.300.R.300W on limestone 

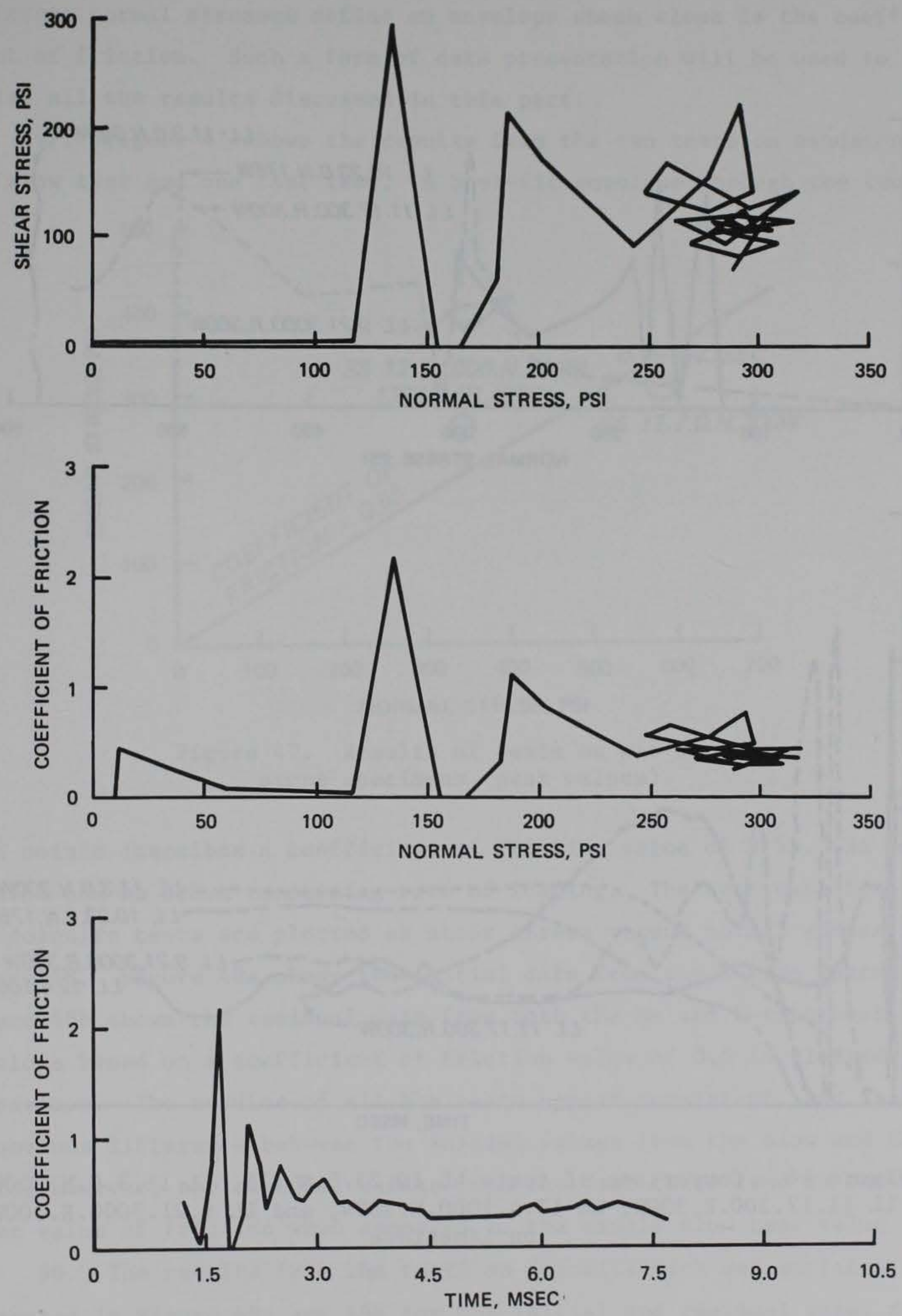

Figure 45. Results of kinetic test LL 9.21.3000.R.300W on limestone 

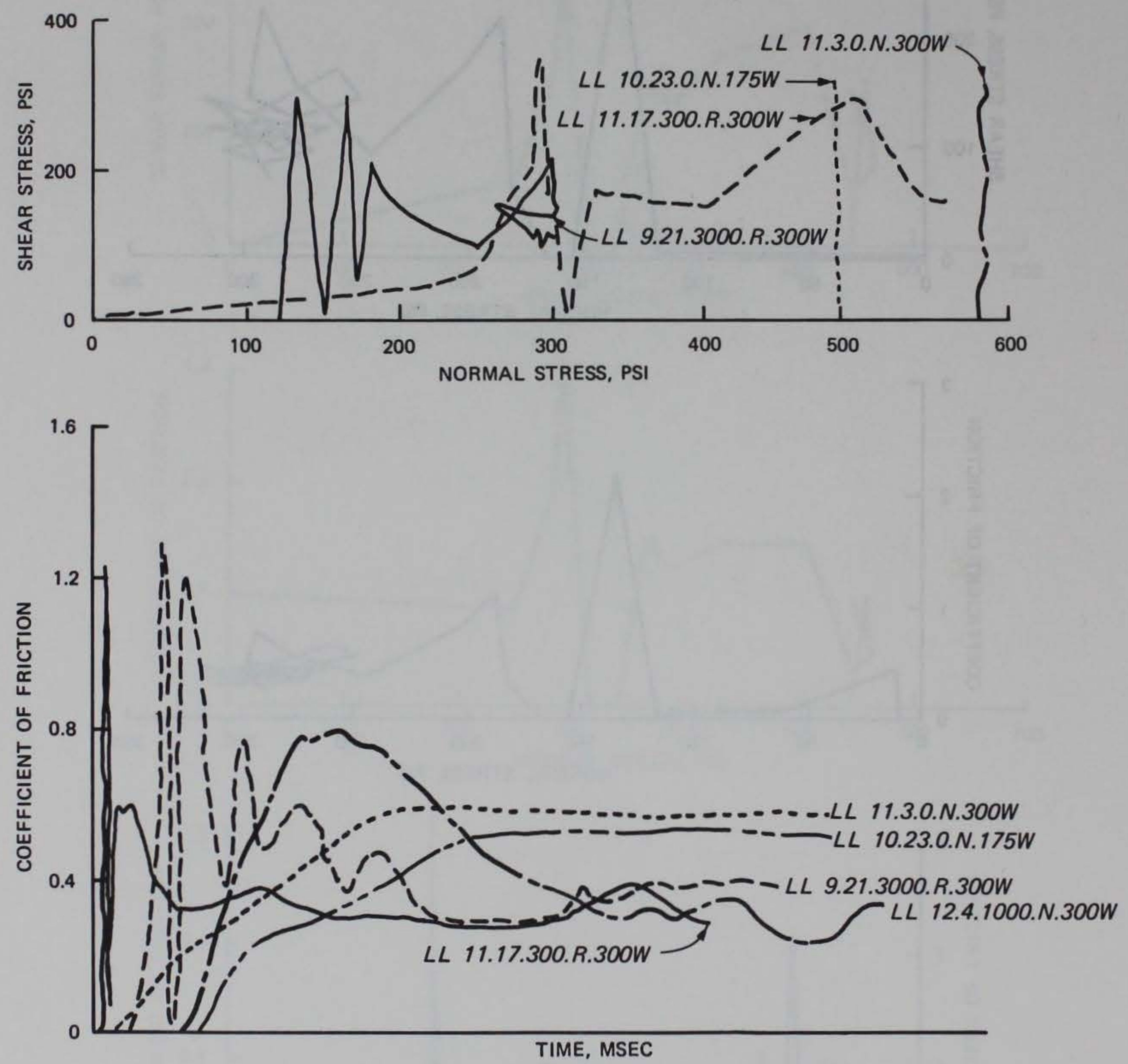

Figure 46. Comparison of tests LL 10.23.0.N.175, LL 11.3.0.N.300W, LL 11.17.300.R.300W, LL 12.4.1000.N.300W, and LL 9.21.3000.R.300W on limestone 
each test are plotted. The data points from several tests conducted at different normal stresses define an envelope whose slope is the coefficient of friction. Such a form of data presentation will be used to summarize all the results discussed in this part.

97. Figure 47 shows the results from the two tests on sandstone: one slow test and one fast test. A best-fit envelope through the two

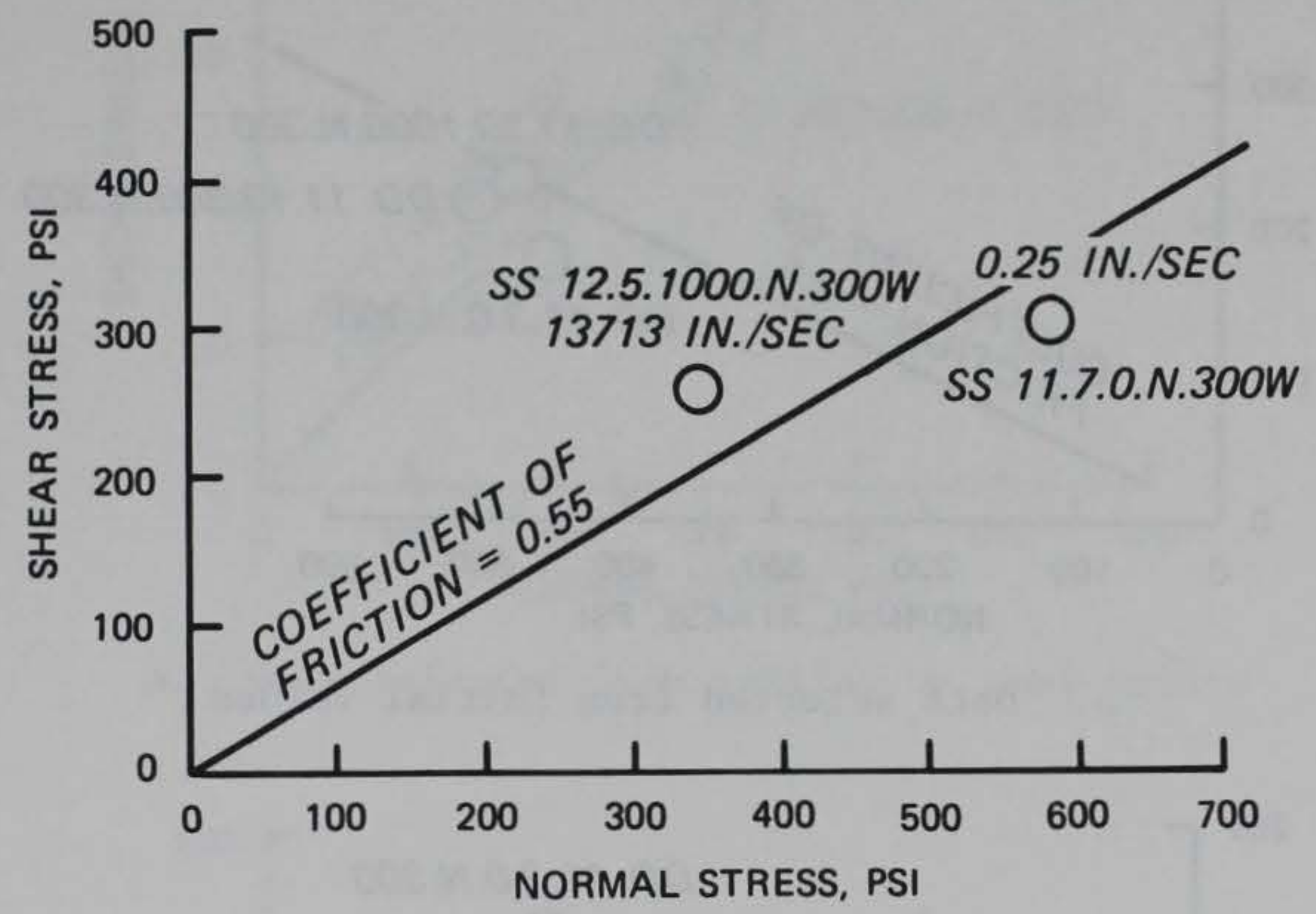

Figure 47. Results of tests on wet sandstone specimens (peak values)

data points describes a coefficient of friction value of 0.55 . No conclusion can be drawn concerning rate of loading. The test data for the dry dolomite tests are plotted as shear stress versus normal stress in Figure 48. Figure $48 \mathrm{a}$ shows the initial data from the N-type tests, and Figure $48 \mathrm{~b}$ shows the residual data from both the $\mathrm{N}$ - and R-type tests. An envelope based on a coefficient of friction value of 0.5 is plotted for comparison. The results of all the tests appear consistent, and there is no obvious difference between the initial values from the slow and fast tests; however, the residual values from the fast tests tend to define a lower value of friction when compared to the single slow test value.

98. The results from the tests on dolomite with wet surfaces are presented in Figure $49 \mathrm{a}$ and $49 \mathrm{~b}$ for the initial and residual data, respectively. Both tests appear to yield reasonable initial values but 


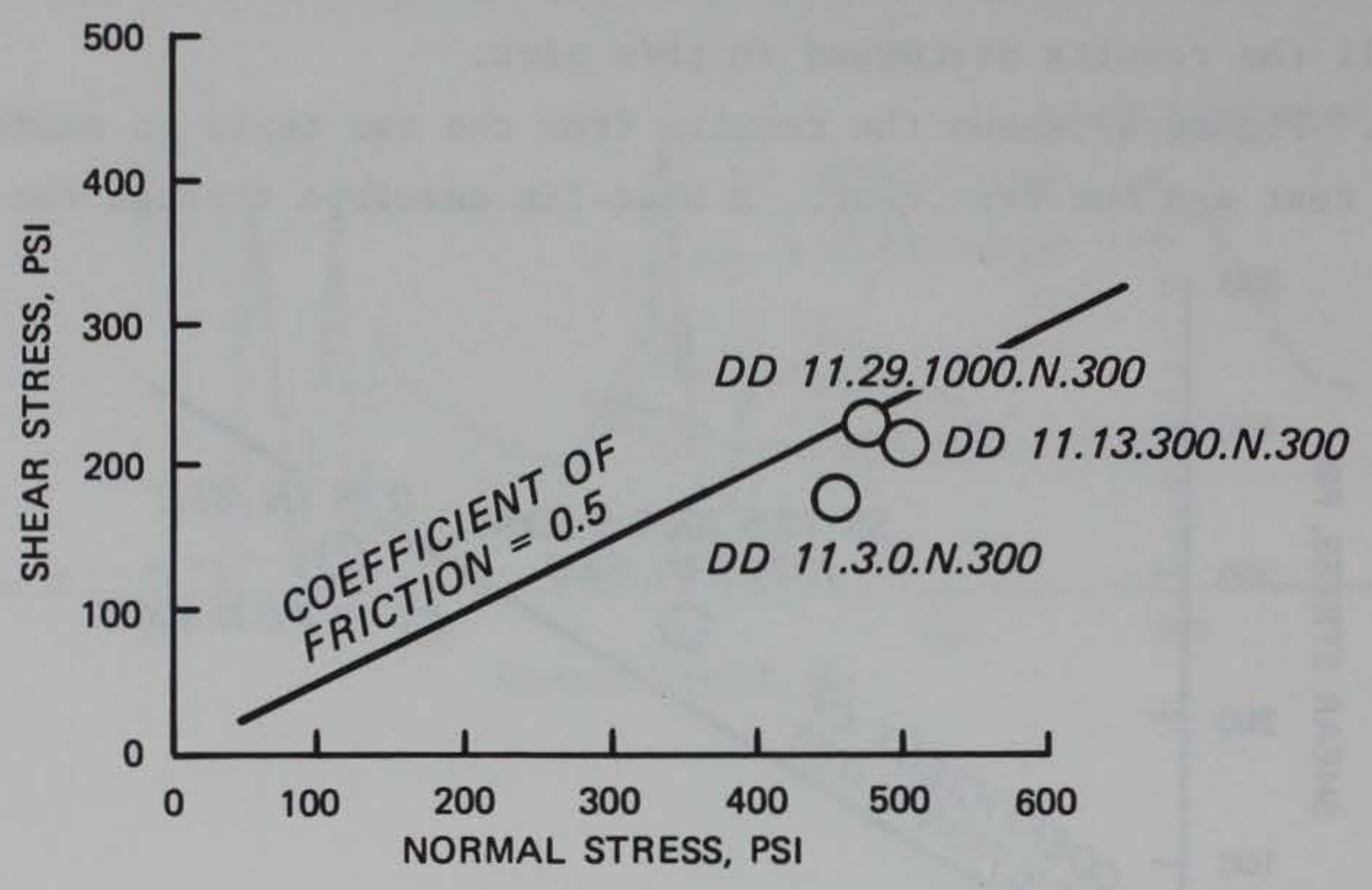

a. Data selected from initial values

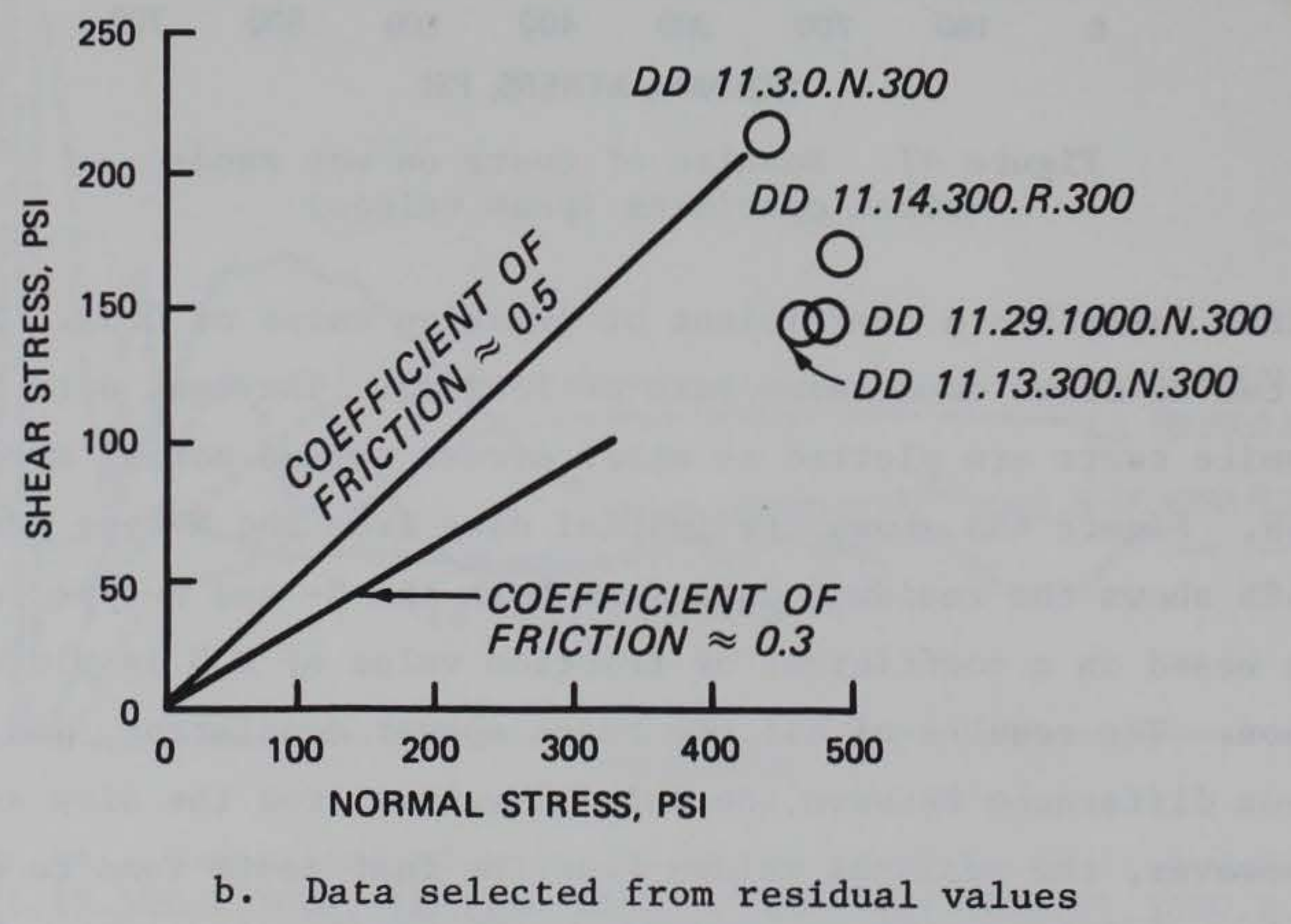

Figure 48. Results of tests on dry dolomite specimens 


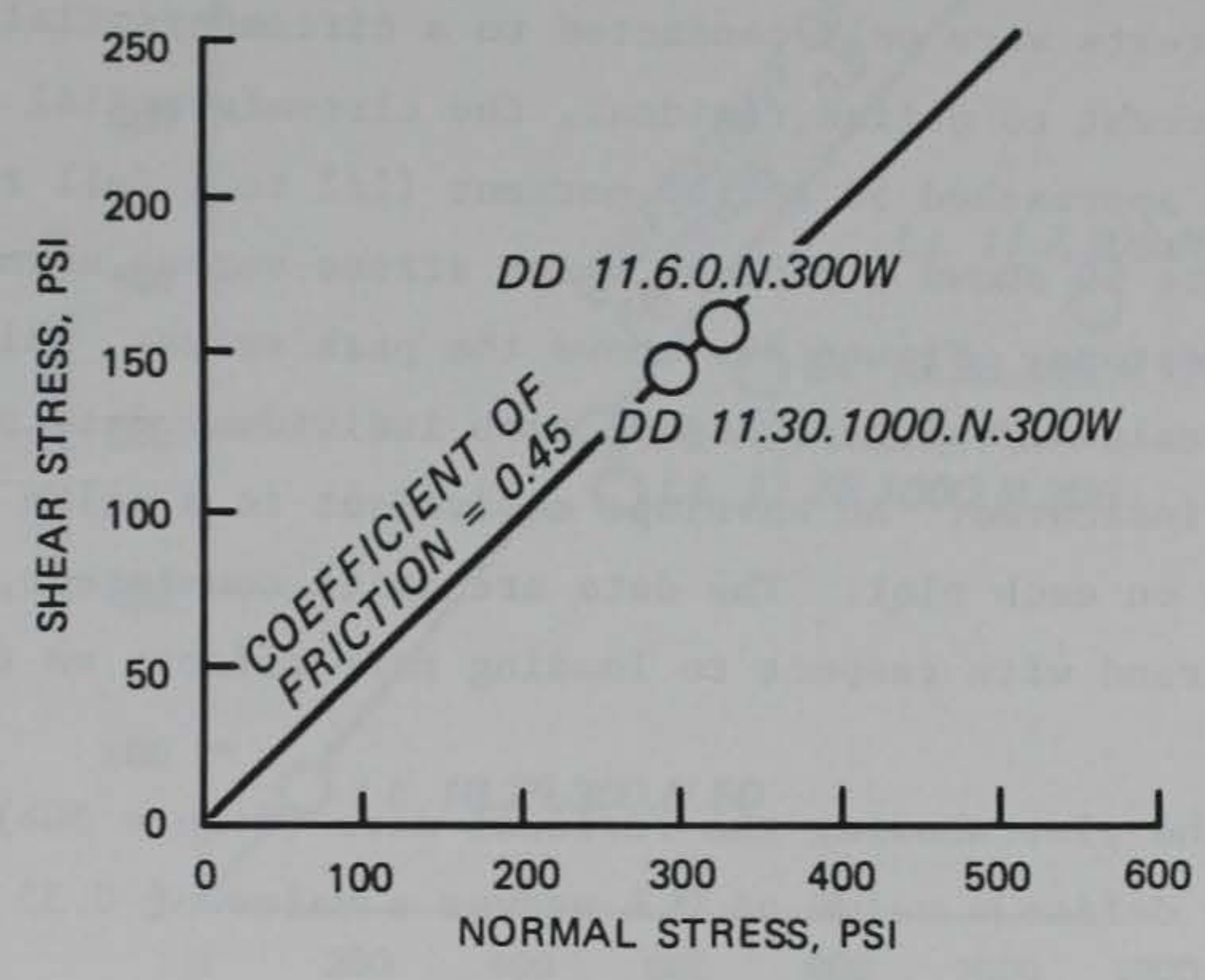

a. Data selected from initial or peak values

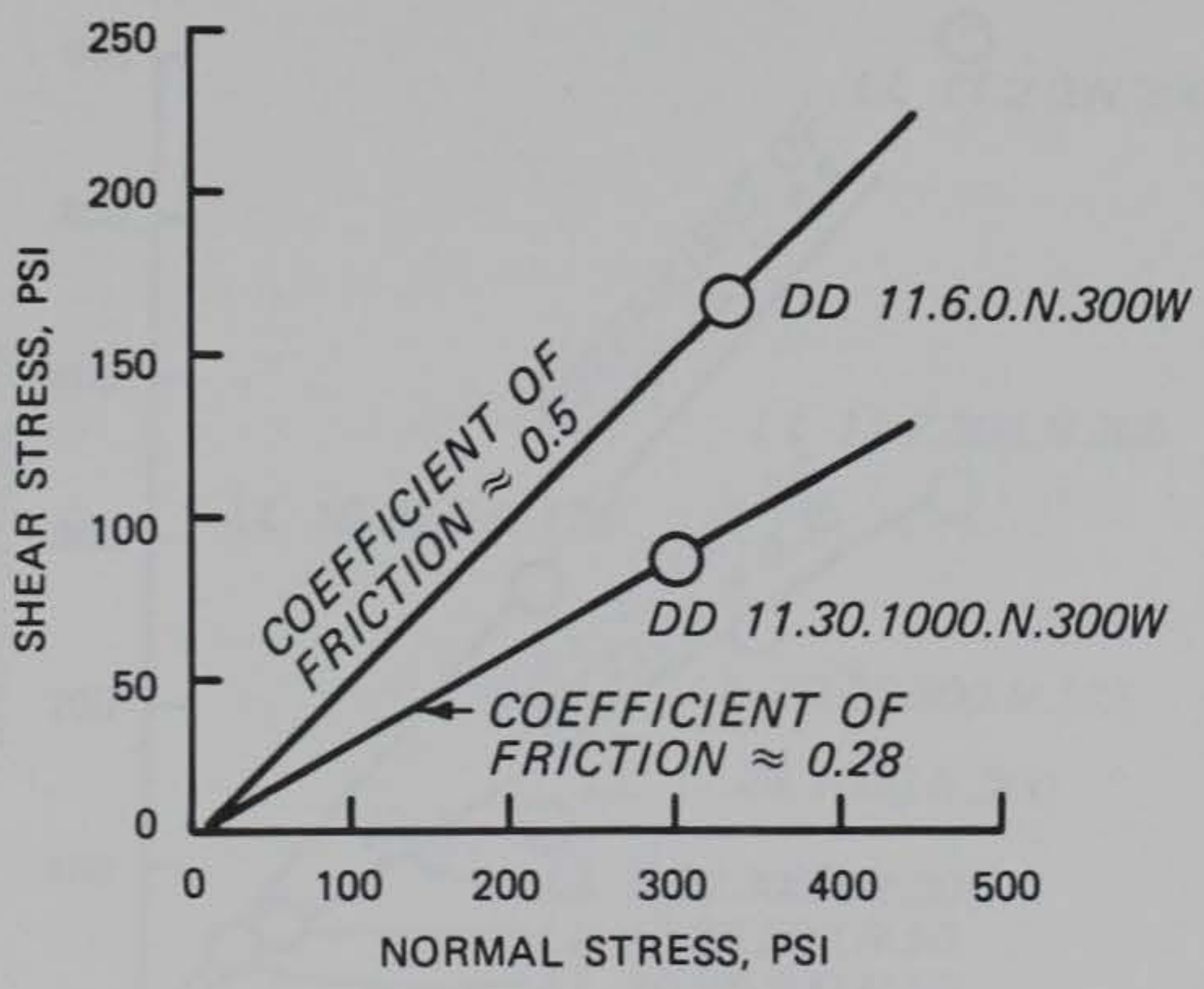

b. Data selected from residual values

Figure 49. Results of tests on wet dolomite specimens 
differ in their residual values with a trend similar to that observed for the tests on dolomite with dry surfaces. It should be noted that, where the slow tests were only conducted to a circumferential strain of less than 10 percent to define residual, the circumferential strains of the rapid tests approached 50 to 100 percent ( $1 / 2$ to 1 full revolution). 99. Figure 50 shows a plot of shear stress versus normal stress for the dry limestone. Figure 50a shows the peak values, while Figure $50 \mathrm{~b}$ shows the residual values. Beside each individual data point, the test number is indicated. An envelope equivalent to a value of friction of 0.6 is shown on each plot. The data are quite consistent, and there is no obvious trend with respect to loading rate effects on the peak values.

100. In the plot showing the residual data (Figure 50b), the slow tests generally define a value of 0.6 versus a value of 0.35 defined by the fast tests.

101. Figure 51 shows the same type of trend for the tests on limestone with wet surfaces. 


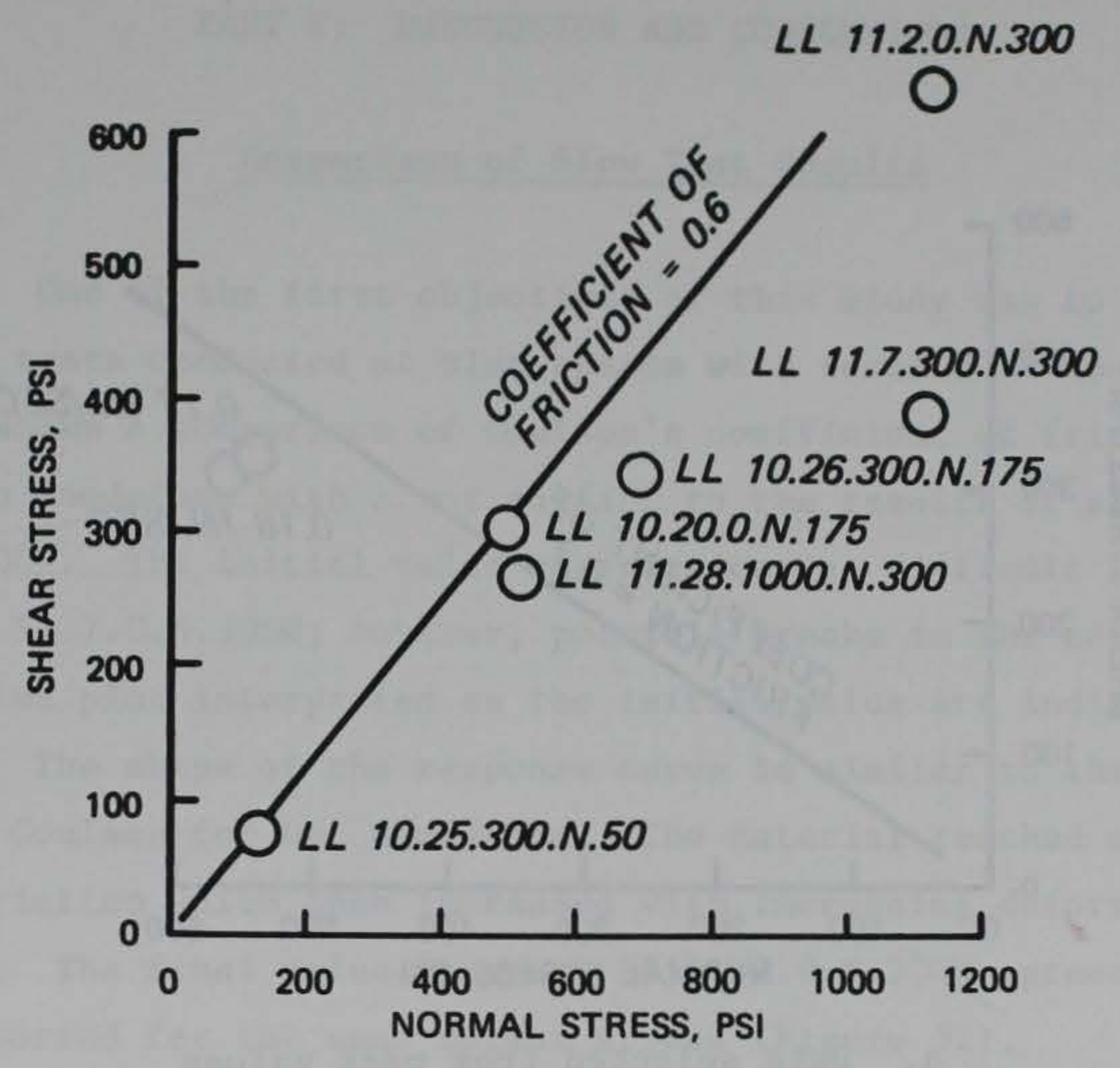

a. Data selected from initial values

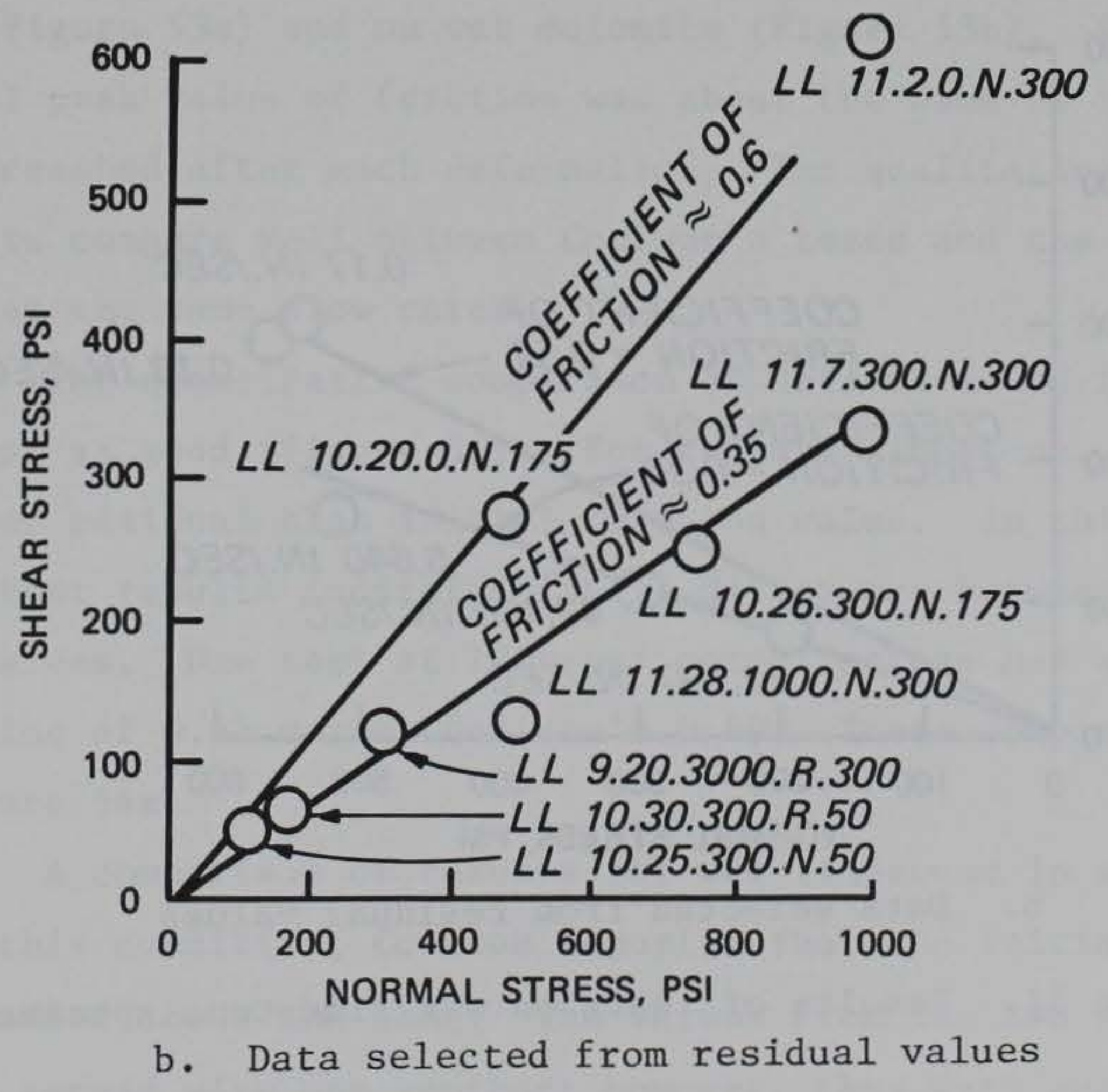

Figure 50. Results of tests on dry limestone specimens 


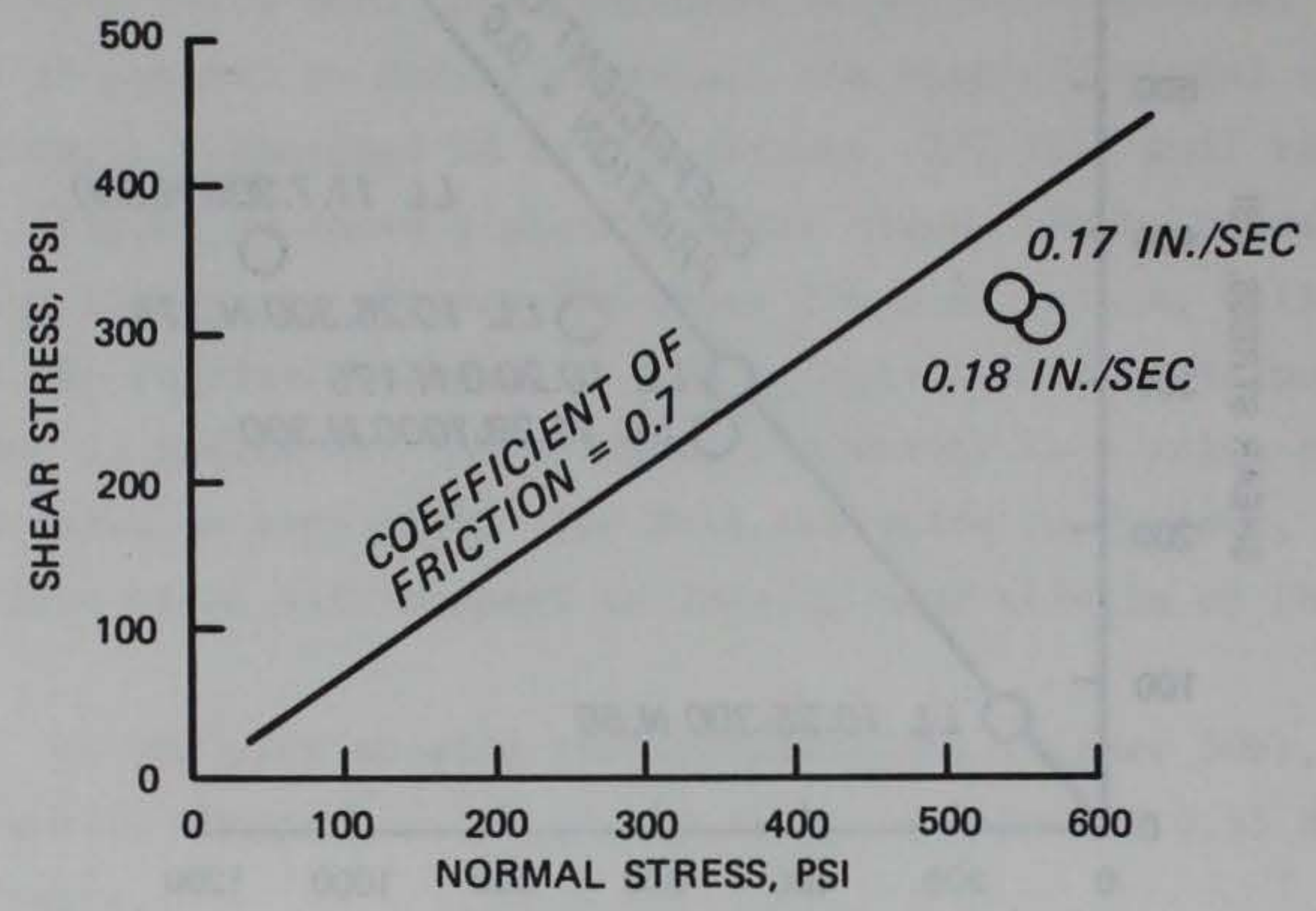

a. Data selected from peak values

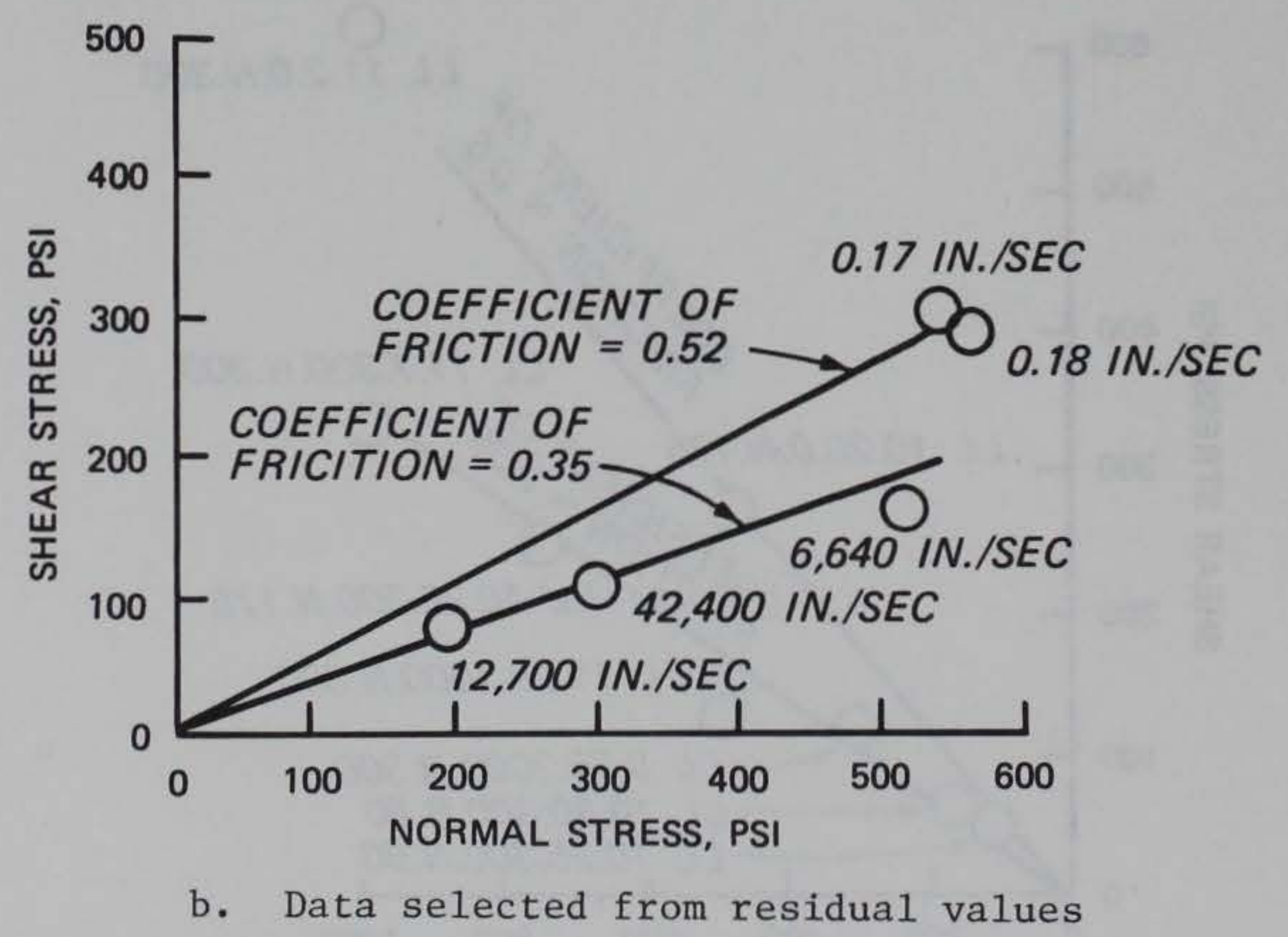

Figure 51. Results of tests on wet limestone specimens 


\section{PART V: DISCUSSION AND CONCLUSIONS}

\section{Comparison of Slow Test Results}

102. One of the first objectives of this study was to compare the results of tests conducted at slow speeds with results of Coulson (1970). Figure 52 shows a comparison of Coulson's coefficient of friction values obtained on sandstone with a wet surface to the results of slow test SS 11.7.0.N.300W. The initial value of friction was difficult to recognize in test SS 11.7.0.N.300W; however, possible breaks in the coefficient of friction-time plot interpreted as the initial value are indicated in Figure 52. The shape of the response curve is similar to the one described by Coulson for wet sandstone. The material reached an initial value of friction which then increased with increasing deformation to a peak value. The final value for test SS 11.7.0.N.300W agrees with what Coulson reported for the same normal stress (Figure 52).

103. Figure 53 shows comparisons with results of Coulson on dry dolomite (Figure 53a) and on wet dolomite (Figure 53b). For this rock, the initial peak value of friction was about the same as the final value which was reached after much deformation. The qualitative and quantitative results compare well between Coulson's tests and the two WES tests conducted at the same slow rates.

104. The quantitative comparison of data obtained for the limestone is not as good (Figure 54). For the dry limestone, Coulson reported a greater residual than initial friction value. In this study, however, the test results indicated little difference between the peak and residual values. One test at 1000-psi normal stress had a much lower initial value of 0.55 versus Coulson's 0.69 . These comparisons are plotted in Figure 54 a.

105. A comparison of results for wet limestone is shown in Figure 54b. For this condition, Coulson reported that the initial and residual values remained about the same. The values from the two slow tests of this study agreed with one another; however, they were quantitatively about 20 percent lower than Coulson's. As with the case of the dry 

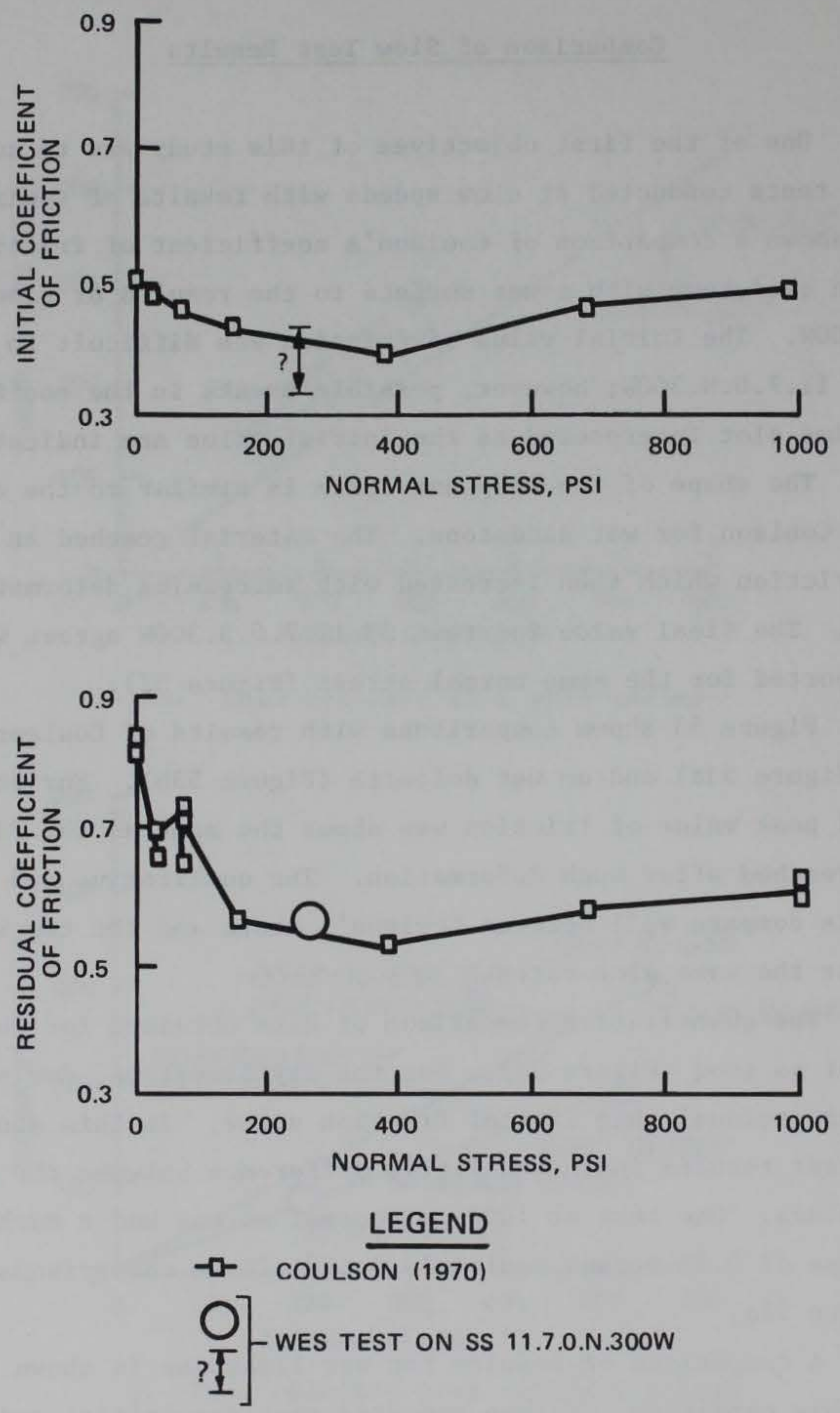

NOTE: INITIAL VALUE OF COEFFICIENT OF FRICTION NOT RECOGNIZED ON TEST SS 11.7.0.N.300W.

Figure 52. Comparison of WES results on wet sandsone with those of Coulson (1970) 

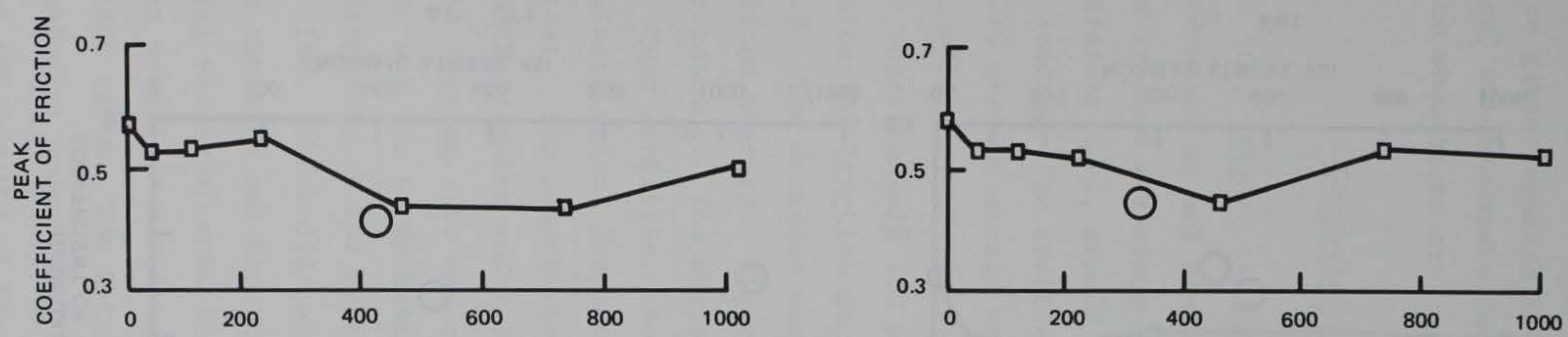

$\stackrel{\infty}{\circlearrowleft}$
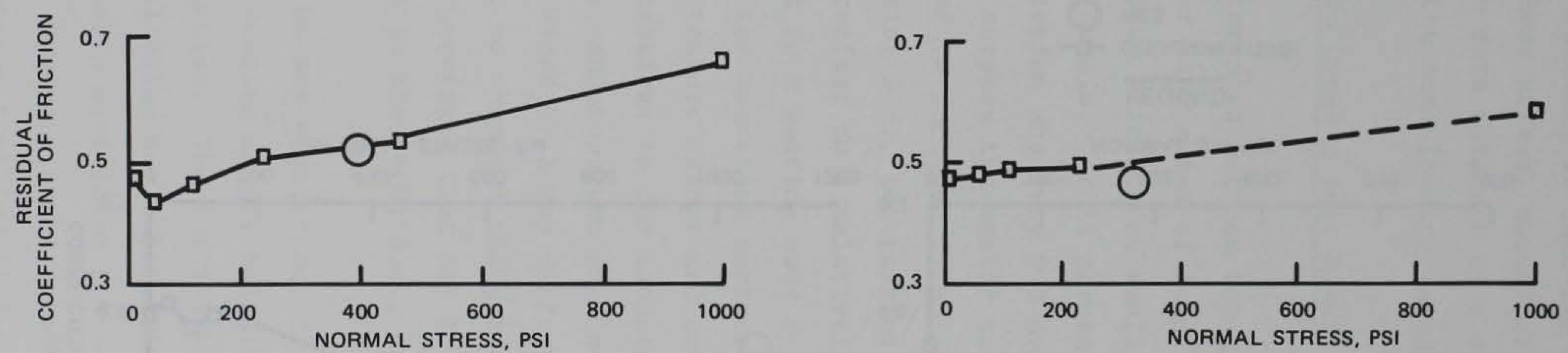

a. Dry

b. Wet

Figure 53. Comparison of WES results on dolomite with dry and wet surfaces with those of Coulson (1970) 

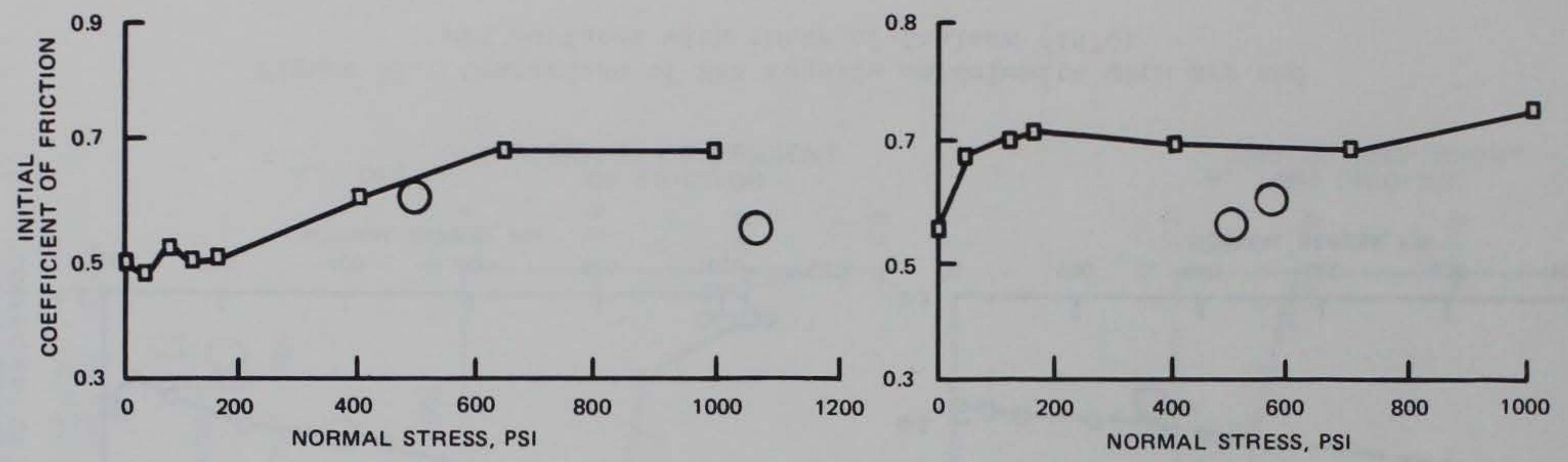

$\stackrel{\infty}{2}$

\section{LEGEND}

$\rightarrow-$ COULSON (1970)
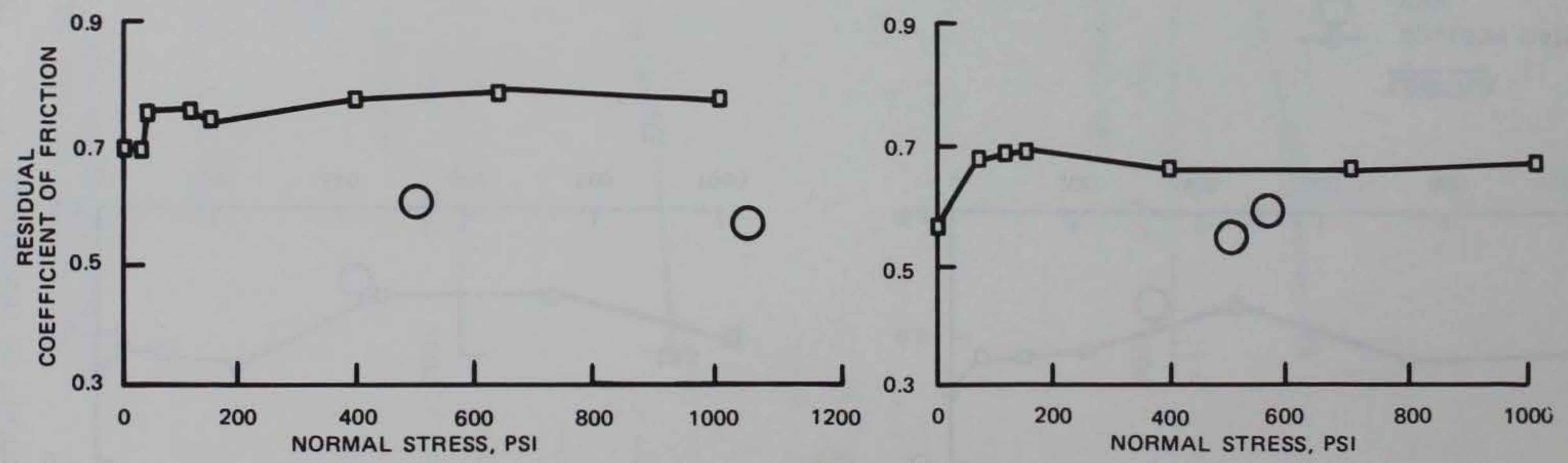

a. Dry

b. Wet

Figure 54. Comparison of WES results on limestone with dry and wet surfaces with those of Coulson (1970) 
limestone, the reason for the difference is not clear.

106. The overall conclusion, however, is that the dynamic friction device gives response data (i.e., shear stress, normal stress, and deformation) which compare favorably with data obtained by a direct shear type device when tests are conducted at the same loading rates.

\section{Comparison of Static to Dynamic Test Results}

107. Figure 55 indicates differences between the static and dynamic responses of wet sandstone. Under slow rates of loading, the sandstone reached a maximum value $(0.55)$ of friction at small deformations or strains; i.e., around 10 percent strain. At 10 percent strain for the fast loading, the coefficient of friction was only 0.3 and required more than 70 percent strain to reach and surpass the static maximum value. The coefficient of friction continued to increase with increasing strain up to approximately 200 percent strain; i.e., two revolutions. The coefficient of friction decreased thereafter to a relatively constant value of 0.2 . The decrease was attributed to a wearing away of the surface to a uniform texture. Figure 56 shows the sandstone surface before and after testing. The photos show the texture change and smoothness of the after-test condition. No other alterations to the sandstone were noted. The mineralogical composition of the sandstone was examined pretest and posttest. The composition was determined by X-ray diffraction. Table 6 lists the results and indicates that no chemical changes were observed due to testing. It was concluded, therefore, that the frictional response was due to mechanical changes in the rock; i.e., wearing or breaking away of the asperities.

108. There did not appear to be any significant differences between the slow and fast N-type test results on dry dolomite relative to initial values of coefficient of friction. The initial strain or deformation needed to mobilize the initial value was substantially greater for the fast tests. The R-type test results oscillated too severely to allow a meaningful comparison. Figure 57, however, shows a tabulated comparison of the results of Coulson, the static test (DD 11.3.0.N.300), and the 

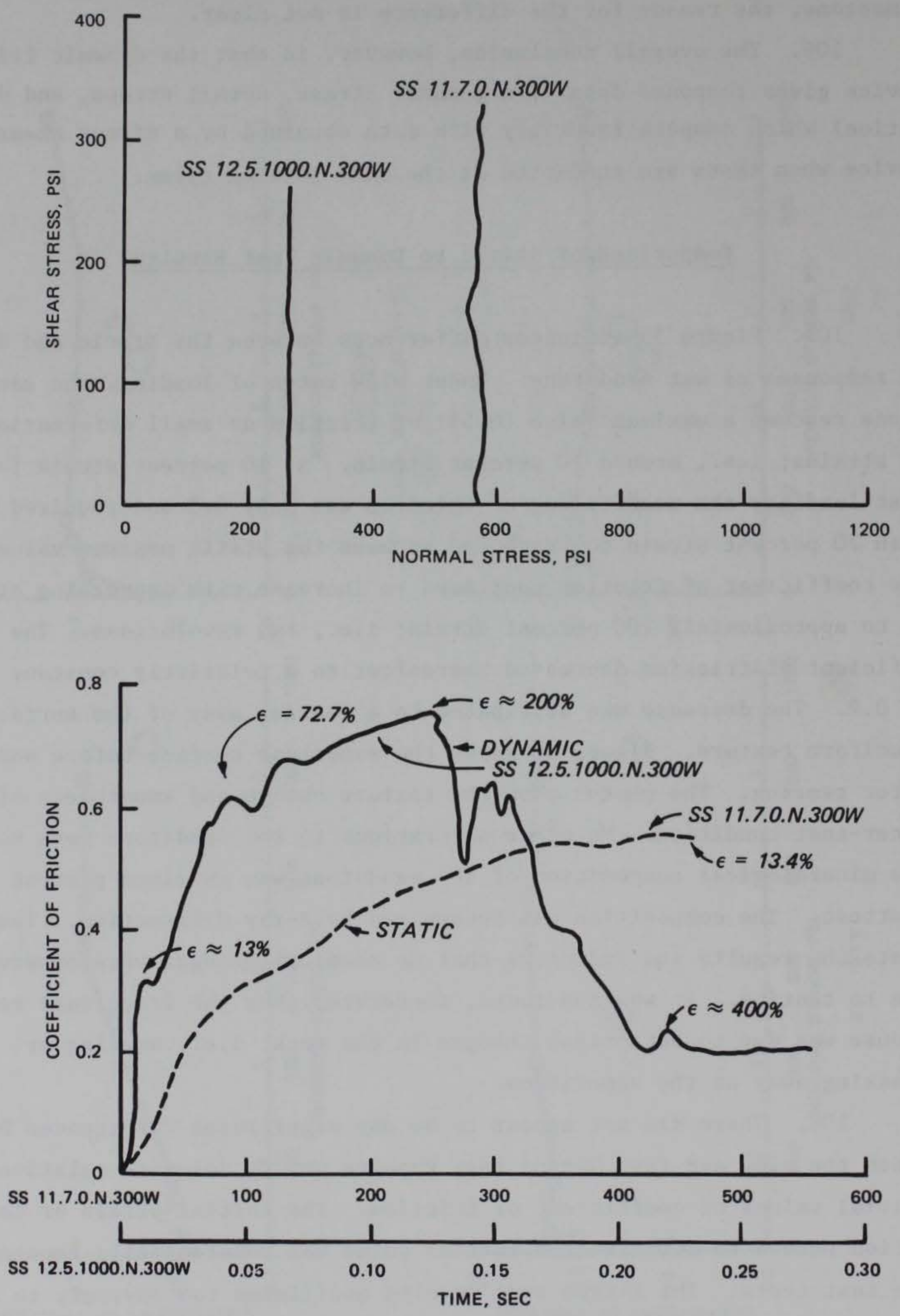

Figure 55. Comparison of results of static and dynamic tests on wet sandstone 


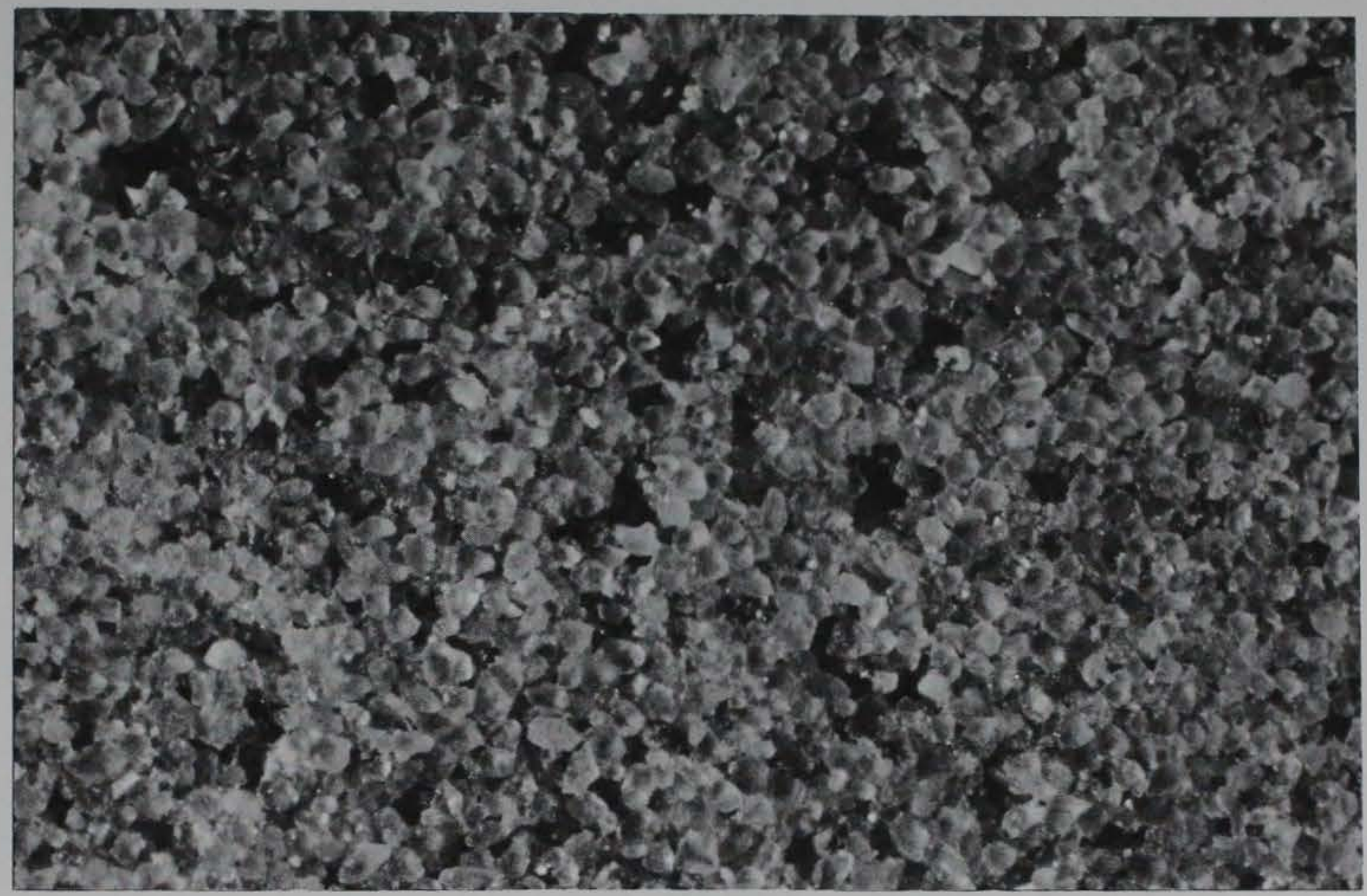

\section{a. Before testing}

F.

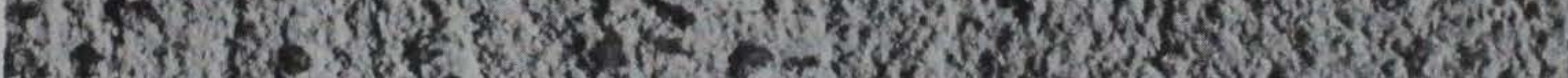

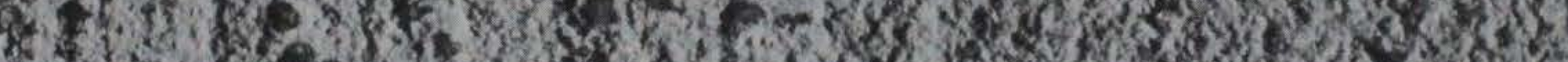

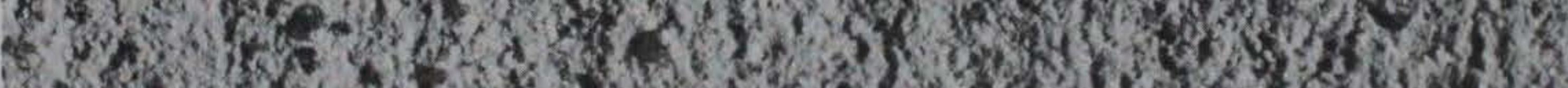

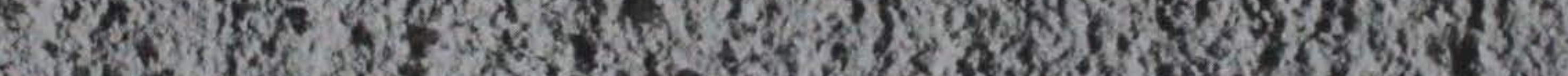

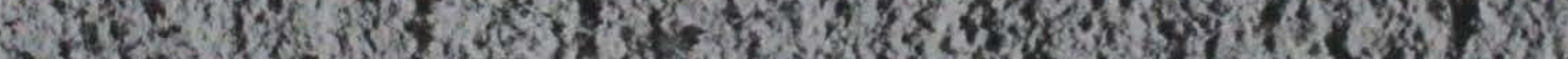

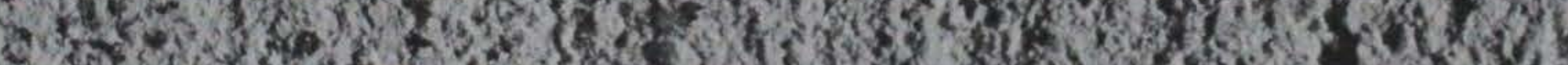

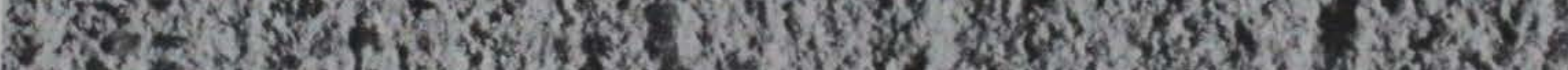
Q

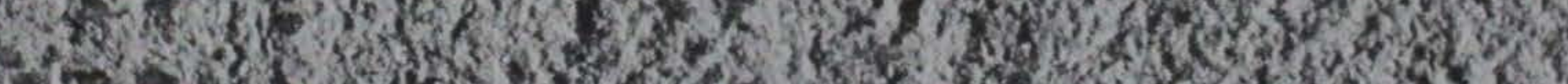

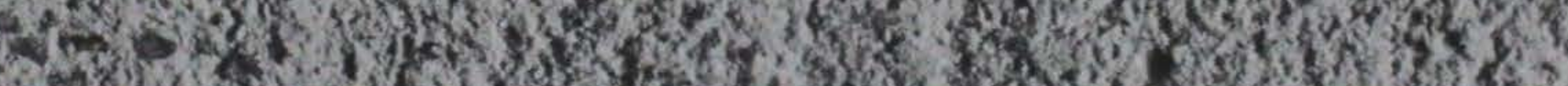

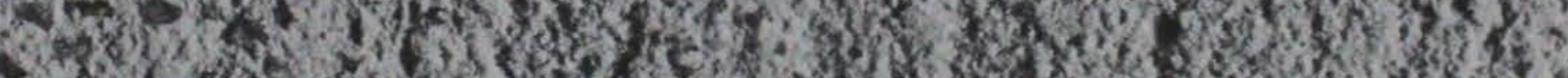

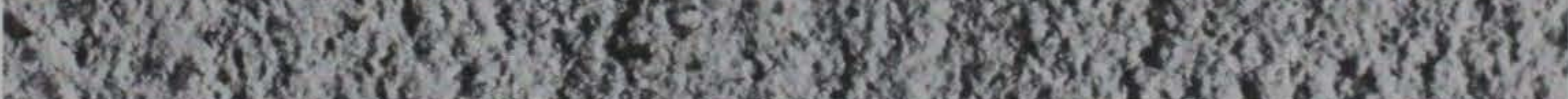

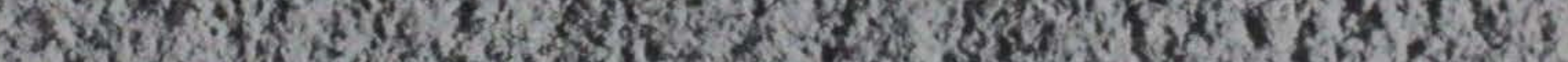

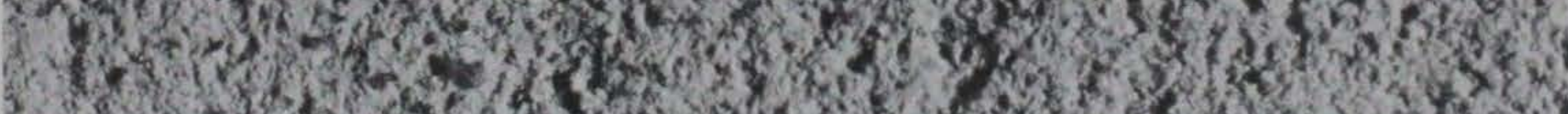

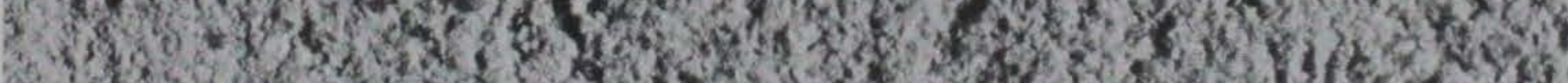

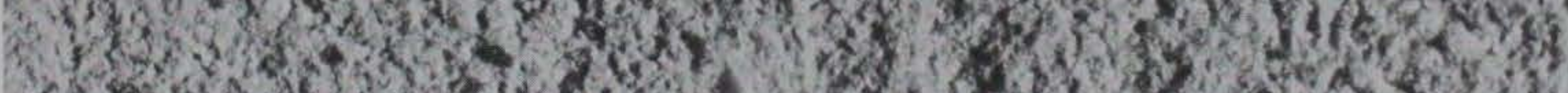

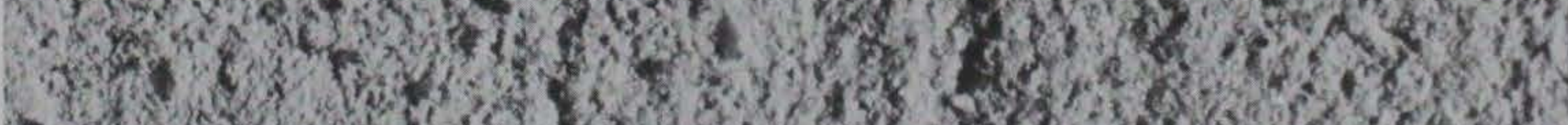
20 in F.

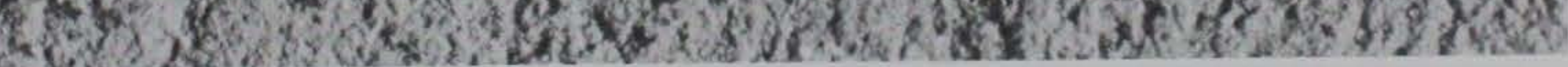

b. After wet testing (SS 12.5.1000.N.300)

Figure 56. Sandstone surface before and after testing 
Table 6

Composition* of Sandstone

Untested (SS 12.5.1000.N.300W)

Nonclays

Quartz

Potassium feldspar

Plagioclase feldspar

Siderite

Calcite

$\underline{\text { Clay minerals }}$

Kaolinite

Clay mica
Abundant

Minor

Minor

Minor

Rare

Minor

Rare
Abundant

Minor

Minor

Minor

Rare

Minor

n.d.**

* Estimated amounts are: abundant, $>50$ percent; minor, 5 to 10 percent; rare, $<5$ percent.

** Not detected. 


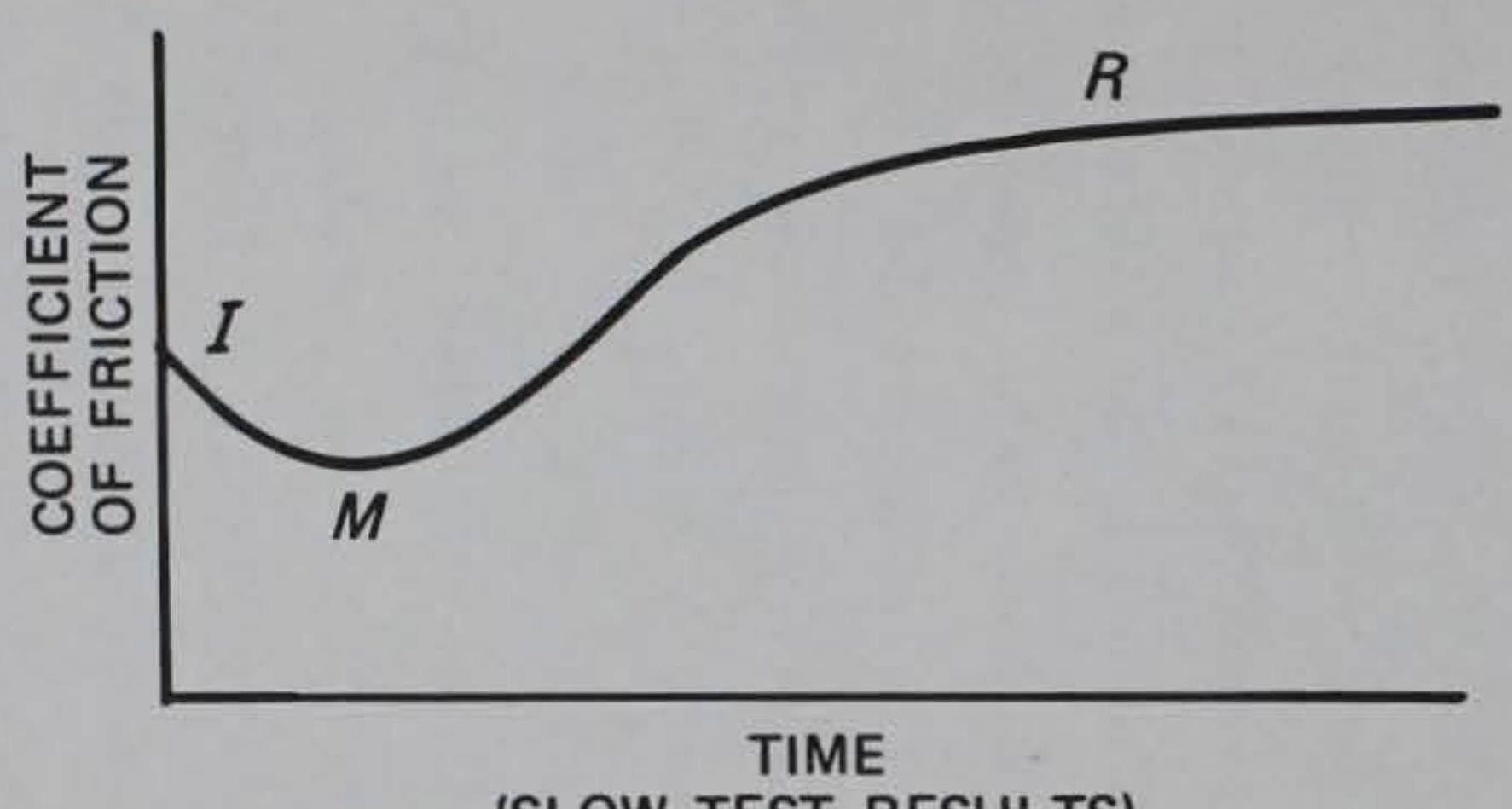

(SLOW TEST RESULTS)

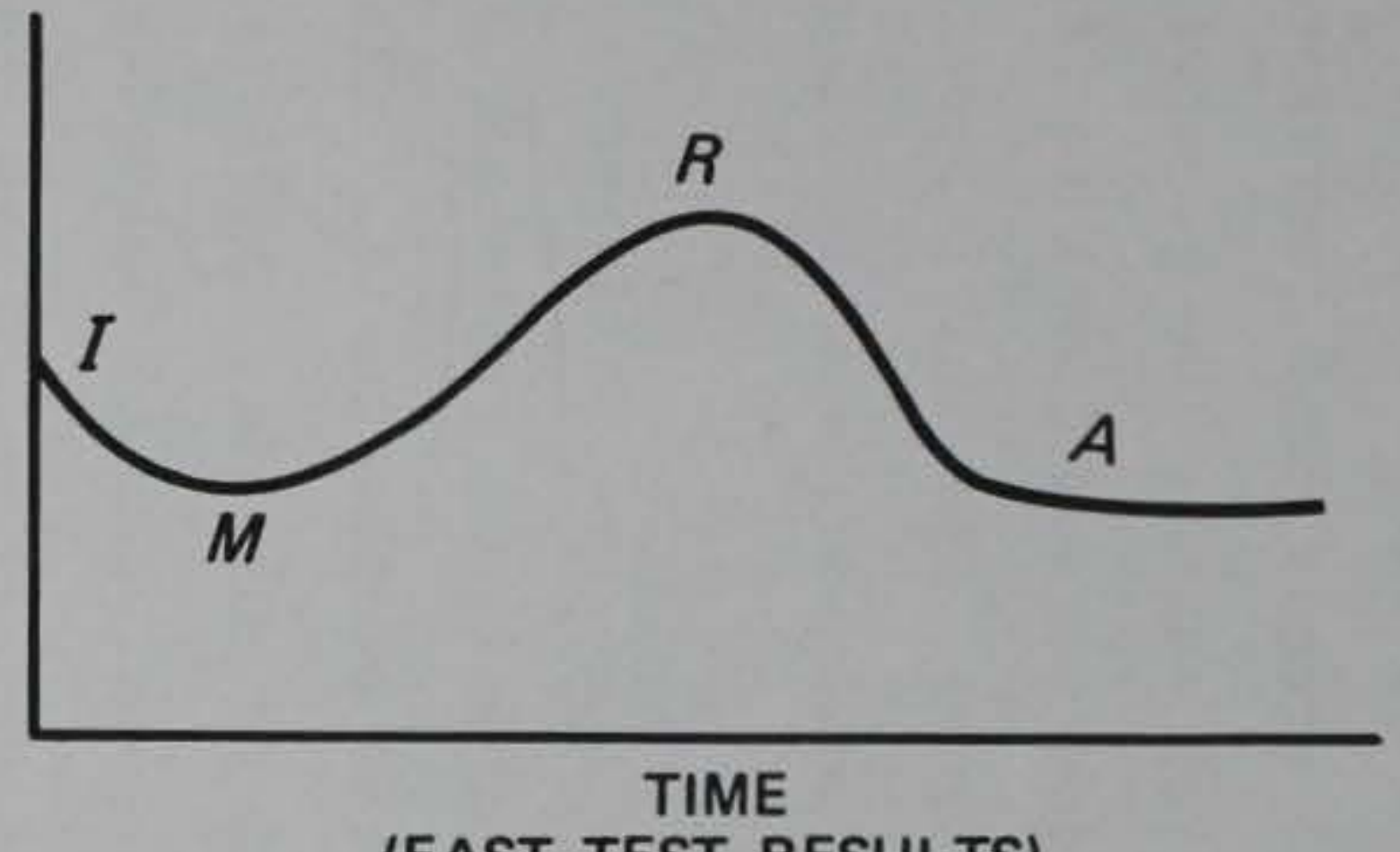

(FAST TEST RESULTS)

\begin{tabular}{|c|c|c|c|c|c|c|c|c|c|}
\hline & \multirow[b]{2}{*}{$\begin{array}{l}\text { NORMAL } \\
\text { STRESS } \\
\end{array}$} & \multicolumn{2}{|l|}{ INITIAL } & \multicolumn{2}{|c|}{ MINIMUM } & \multicolumn{2}{|c|}{ RESIDUAL } & \multicolumn{2}{|l|}{ AVERAGE } \\
\hline & & $\begin{array}{l}\text { COEFFICIENT } \\
\text { OF FRICTION } \\
\end{array}$ & $\begin{array}{l}\text { TIME } \\
\text { SEC } \\
\end{array}$ & $\begin{array}{l}\text { COEFFICIENT } \\
\text { OF FRICTION } \\
\end{array}$ & $\begin{array}{l}\text { TIME } \\
\text { SEC } \\
\end{array}$ & $\begin{array}{l}\text { COEFFICIENT } \\
\text { OF FRICTION } \\
\end{array}$ & $\begin{array}{l}\text { TIME } \\
\text { SEC } \\
\end{array}$ & $\begin{array}{l}\text { COEFFICIENT } \\
\text { OF FRICTION } \\
\end{array}$ & $\begin{array}{r}\text { TIME } \\
\text { SEC } \\
\end{array}$ \\
\hline COULSON (1970)* & 466 & 0.442 & NA & 0.400 & 60.000 & 0.545 & 557.000 & - & - \\
\hline DD 11.3.0.N.300* & 410 & 0.401 & 32.000 & 0.320 & 52.000 & 0.496 & 570.000 & - & - \\
\hline DD 11.13 .300$. N. $300^{* *}$ & 491 & 0.390 & 0.011 & 0.303 & 0.017 & 0.477 & 0.046 & 0.300 & 0.171 \\
\hline DD 11.29 .1000$. N.300** & 485 & 0.440 & 0.012 & 0.31 & 0.017 & 0.389 & 0.026 & 0.276 & 0.093 \\
\hline
\end{tabular}


two fast N-type tests (DD 11.13.300.N.300 and DD 11.29.1000.N.300). A11 four tests had approximately the same normal stress, and therefore any differences should have been caused by loading rate. The general shape of the response curve (coefficient of friction versus time) for the slow tests (Coulson and DD 11.3.0.N.300) is the same. The initial value was reached, followed by a decrease, and then a maximum residual value was reached.

109. Similarly the two fast tests had the same qualitative and quantitative responses except that a second and final residual value was obtained that was much lower than that for the static tests. Again, much larger strains or deformations were required to mobilize the friction values. Photographs of the before and after surfaces of dolomite indicate that the asperities seen before testing are absent after testing (Figure 58). The smoother surface would cause a lower value of friction.

110. The same types of observations were made relative to the tests on wet dolomite. Figure 59 shows the comparison of results for the slow and fast tests. As with the dry surfaces, the final residual value for the fast tests was substantially lower than that for the slow tests. Figure 60 shows the surface of the wet dolomite posttest. The values of initial friction for the wet dolomite were consistently higher or greater than the values measured on dry surfaces. There was no difference between wet and dry specimens for the final residual value measured in the fast tests. Coulson pointed out that the wet surface could yield greater values if it is considered that the water actually increased rather than decreased the friction. The presence of water, however, did not appear to affect the fast test results.

111. The mineralogical composition of the dolomite was examined to determine if chemical changes had occurred during fast testing. One untested and two tested specimens were examined by X-ray diffraction. The results are shown in Table 7 and suggest that some reaction may have occurred because of the presence of more calcite in the tested specimens. The cost of determining the exact cause and the actual processes involved in the reaction were considered prohibitive for the value of return. The results indicate however that, in the case of the dolomite, the altered 


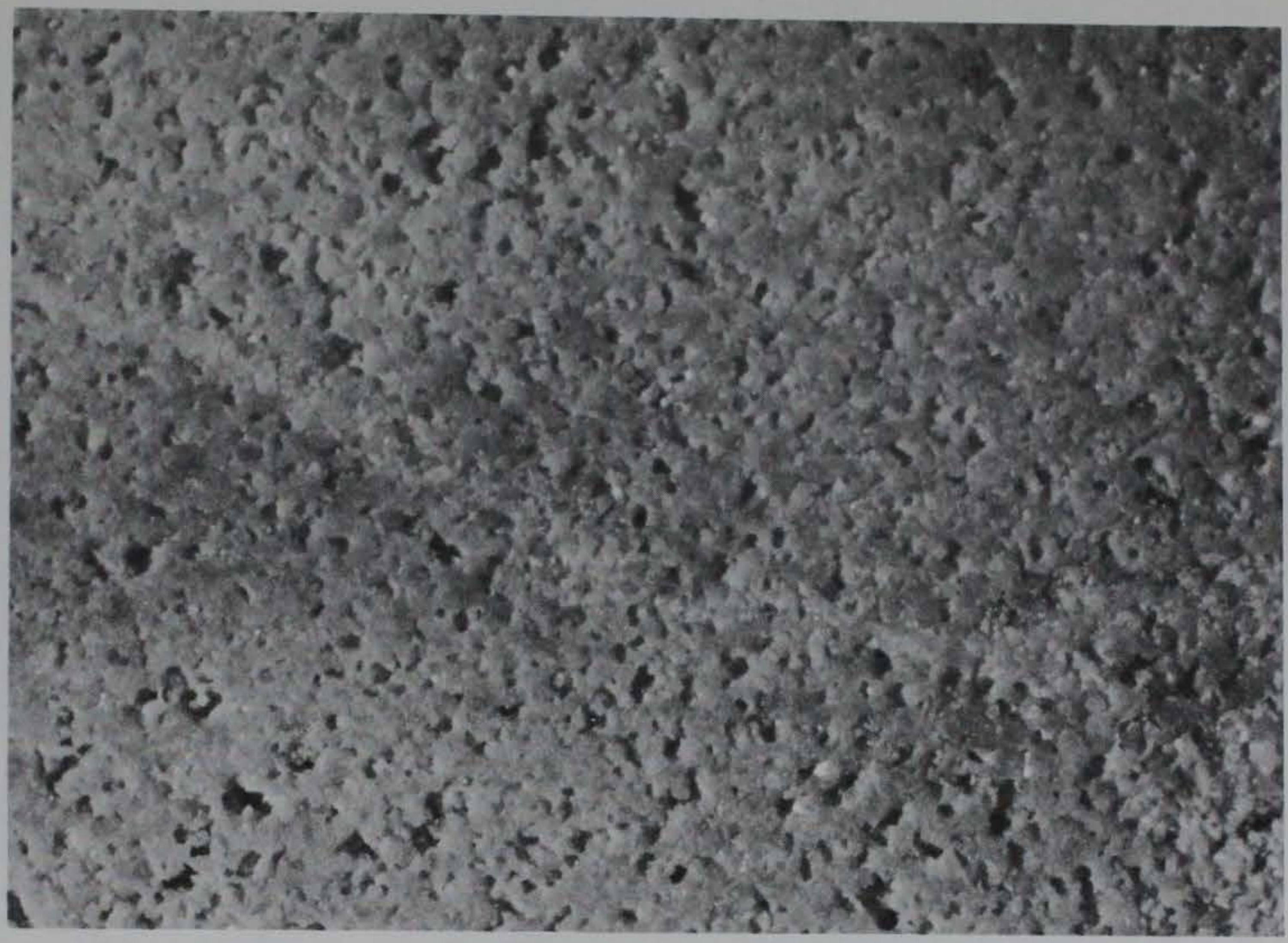

\section{a. Before testing}

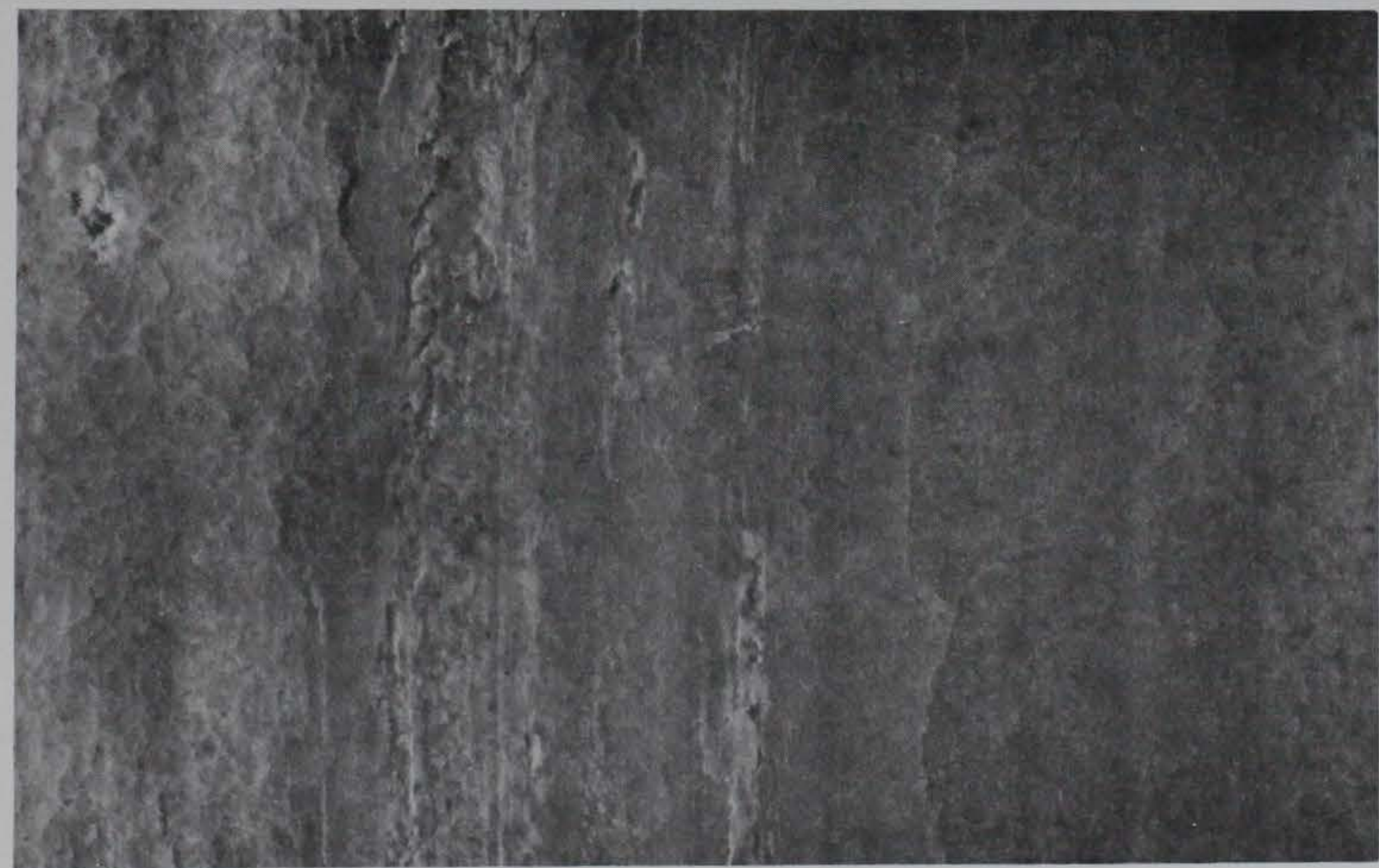

b. After dry testing (DD 11.29.1000.N.300)

Figure 58. Dolomite surface before and after testing 

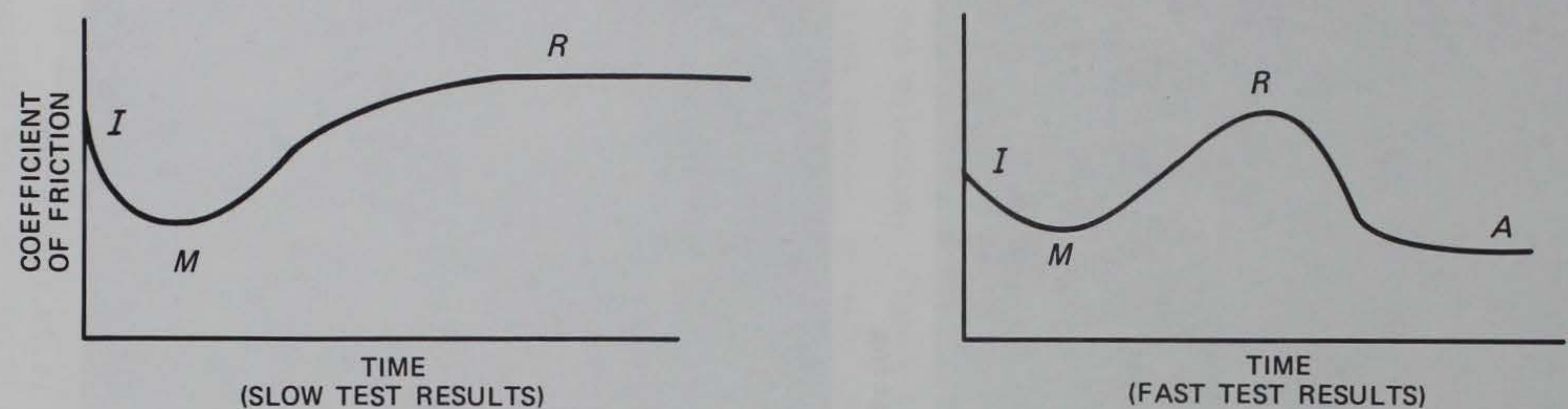

\begin{tabular}{|c|c|c|c|c|c|c|c|c|c|}
\hline & \multirow[b]{2}{*}{$\begin{array}{l}\text { NORMAL } \\
\text { STRESS } \\
\end{array}$} & \multicolumn{2}{|l|}{ INITIAL } & \multicolumn{2}{|c|}{ MINIMUM } & \multicolumn{2}{|c|}{ RESIDUAL } & \multicolumn{2}{|l|}{ AVERAGE } \\
\hline & & $\begin{array}{l}\text { COEFFICIENT } \\
\text { OF FRICTION } \\
\end{array}$ & $\begin{array}{l}\text { TIME } \\
\text { SEC } \\
\end{array}$ & $\begin{array}{l}\text { COEFFICIENT } \\
\text { OF FRICTION } \\
\end{array}$ & $\begin{array}{l}\text { TIME } \\
\text { SEC } \\
\end{array}$ & $\begin{array}{l}\text { COEFFICIENT } \\
\text { OF FRICTION } \\
\end{array}$ & $\left\{\begin{array}{l}\text { TIME } \\
\text { SEC }\end{array}\right.$ & $\begin{array}{l}\text { COEFFICIENT } \\
\text { OF FRICTION } \\
\end{array}$ & $\begin{array}{r}\text { TIME } \\
\text { SEC } \\
\end{array}$ \\
\hline COULSON $(1970)^{*}$ & 233 & 0.523 & NA & 0.467 & 197.000 & 0.508 & 1714 & -- & - \\
\hline DD 11.6.0.N.300W* & 340 & 0.471 & 35.000 & 0.426 & NA & 0.470 & NA & -- & -- \\
\hline DD 11.30 .1000$. N.300W** & * 293 & 0.476 & 0.014 & 0.449 & 0.015 & 0.500 & 0.019 & 0.290 & 0.115 \\
\hline COULSON $(1970)^{*}$ & 467 & 0.450 & NA & 0.354 & 103.000 & 0.371 & 1209.000 & -- & -- \\
\hline
\end{tabular}

\section{* SLOW TEST \\ ** FAST TEST}

Figure 59. Summary of two WES tests and two tests by Coulson on dolomite with wet surfaces 


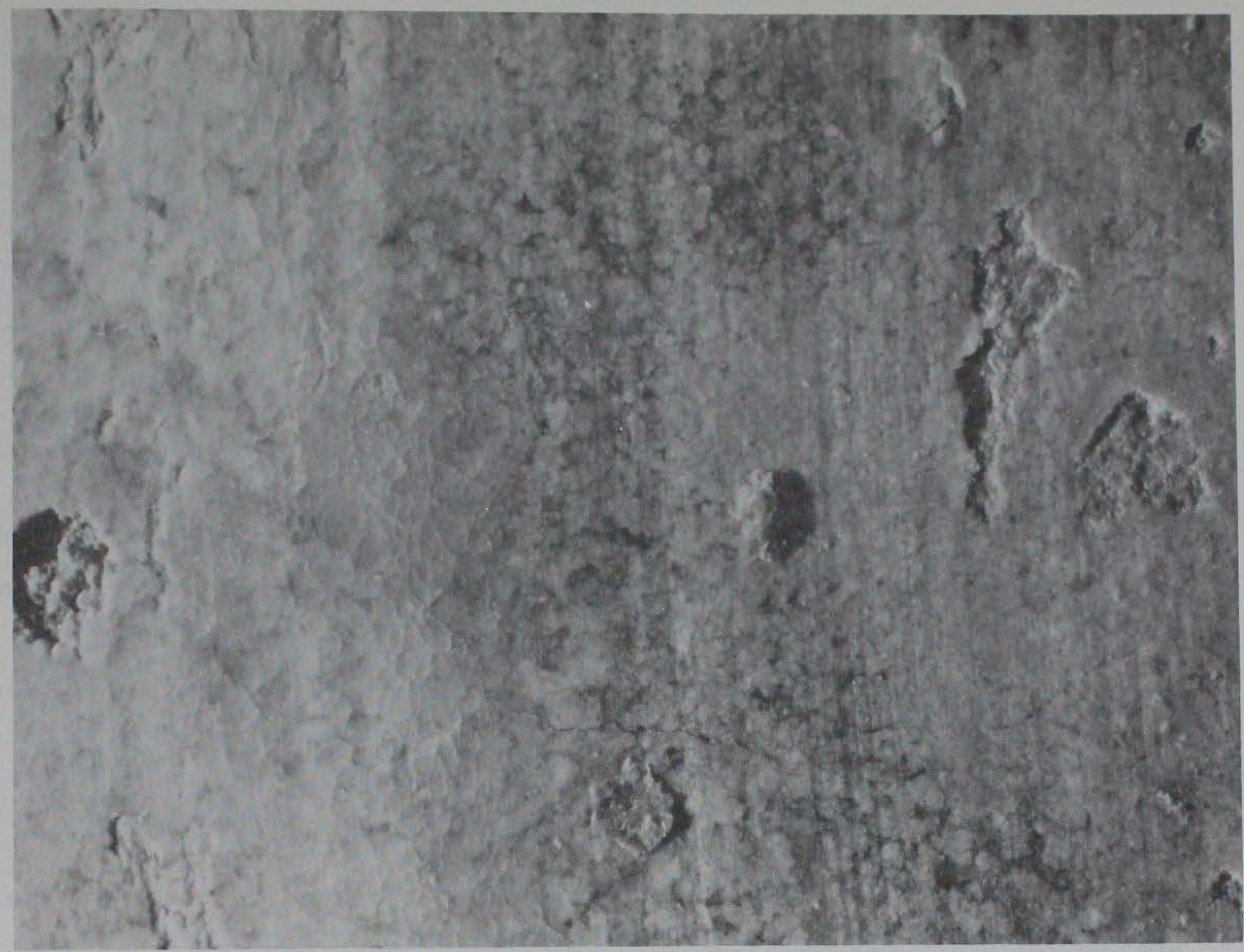

Figure 60. Photograph of dolomite with wet surface after testing (DD 11.30.1000.N.300)

Table 7

Composition* of Dolomite

\begin{tabular}{|c|c|c|c|c|c|}
\hline & & & Afte & Test & \\
\hline & Untested & (DD & $\begin{array}{c}\text { Dry } \\
11.29 \cdot 1000 \cdot \text { N.300) }\end{array}$ & (DD & $\begin{array}{c}\text { Wet } \\
11.30 .1000 \cdot N \cdot 300 \mathrm{~W})\end{array}$ \\
\hline Dolomite & Abundant & & Abundant & & Abundant \\
\hline Quartz & Common & & Common & & Common \\
\hline Feldspar & Minor & & Minor & & Minor \\
\hline Calcite & Rare & & Common & & Minor \\
\hline
\end{tabular}

* Estimated amounts are: abundant, $>50$ percent; common, 10 to 25 percent; minor, 5 to 10 percent; rate, $<5$ percent. 
surface is predominately caused by mechanical and a possible slight chemical change in the rock.

112. The static friction tests on limestone were consistent, indicating an initial value of around 0.2 and then increasing to a maximum and residual of approximately 0.55 to 0.60 . The fast N-type tests, however, indicated a somewhat different response in that the initial value was reached followed by a slight decrease and then increase. Initial values varied from approximately 0.32 to 0.52 , with the average around 0.4. There was not a discernible effect of normal stress and friction or speed and friction. The residual values for all but one fast test ranged between 0.2 and 0.3 . These results were previously presented in Figure 33. Again, the deformation needed to mobilize comparable friction values from fast tests was significantly greater than that for slow tests.

113. The R-type test results were subject to severe oscillations caused by the nontranslating specimen holder chattering against the torque load cells. The chattering could only be related to the response of the specimens, possibly very rapidly sticking and then releasing across the interface. However, a much more detailed study that is warranted would be required to understand the mechanism. The general response following the initial oscillations appeared to be a function of the condition of the specimen surfaces following impact. Some test results were more erratic, making any sort of analysis impossible.

114. Photographs of the pretest and posttest surfaces of the limestone are shown in Figure 61. The general character of the posttest surface is quite different than the pretest. The direction of apparent grooving of the surface of the posttest specimen is parallel with the spin direction (as expected). Somewhat surprising is the relative roughness of the surface which may help to explain the more erratic behavior of the test results at even faster spin rates; i.e., in the R-type tests.

115. The response of the wet specimens is summarized in Figure 46. Except for the initial oscillations in the R-type test results, the two slow tests are consistent as are the three fast tests. The final residual value for the fast tests was lower than that for the slow tests; i.e., 0.3 to 0.4 versus 0.45 to 0.5 , respectively. A photograph of a wet 


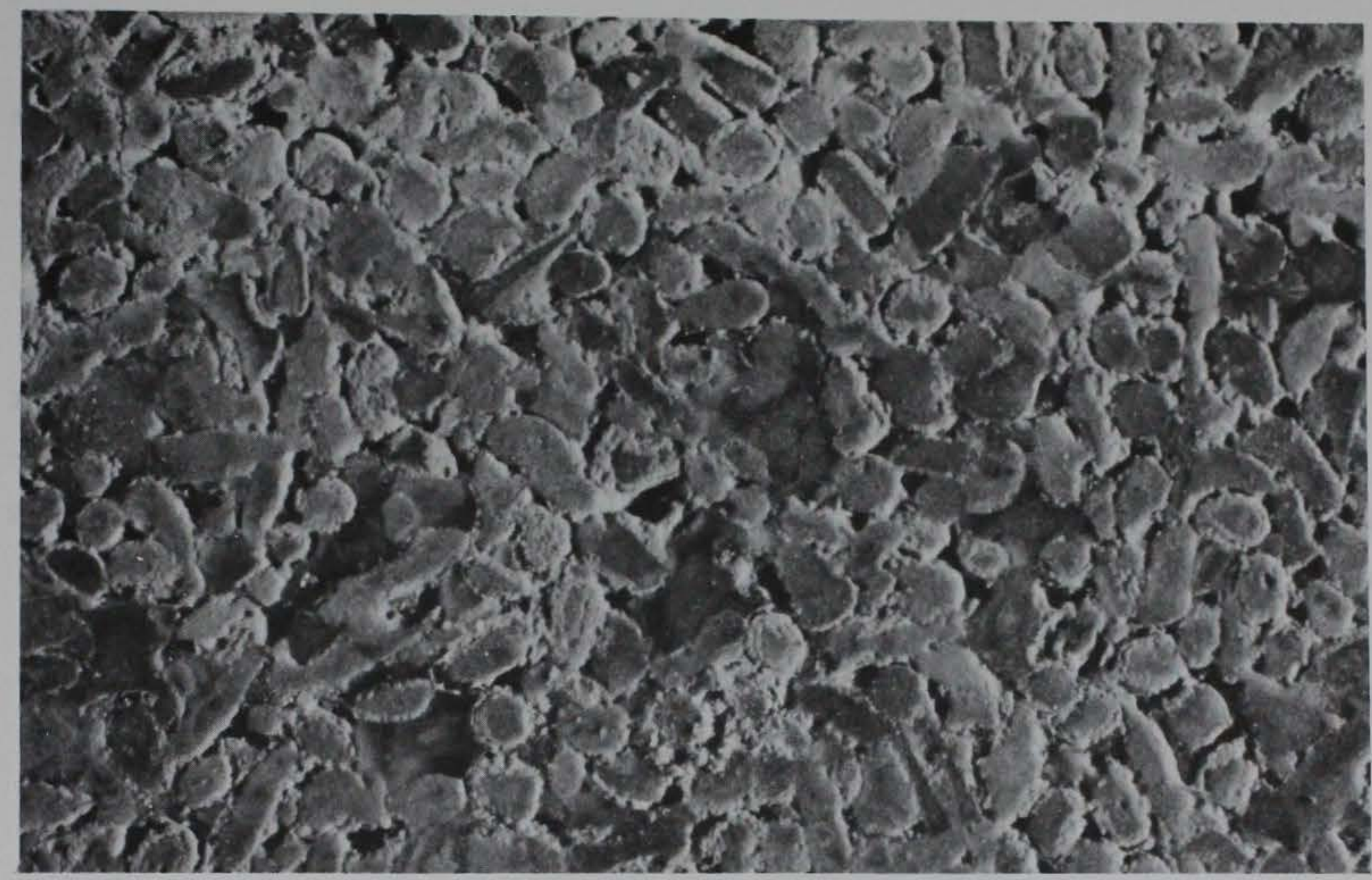

\section{a. Before testing}

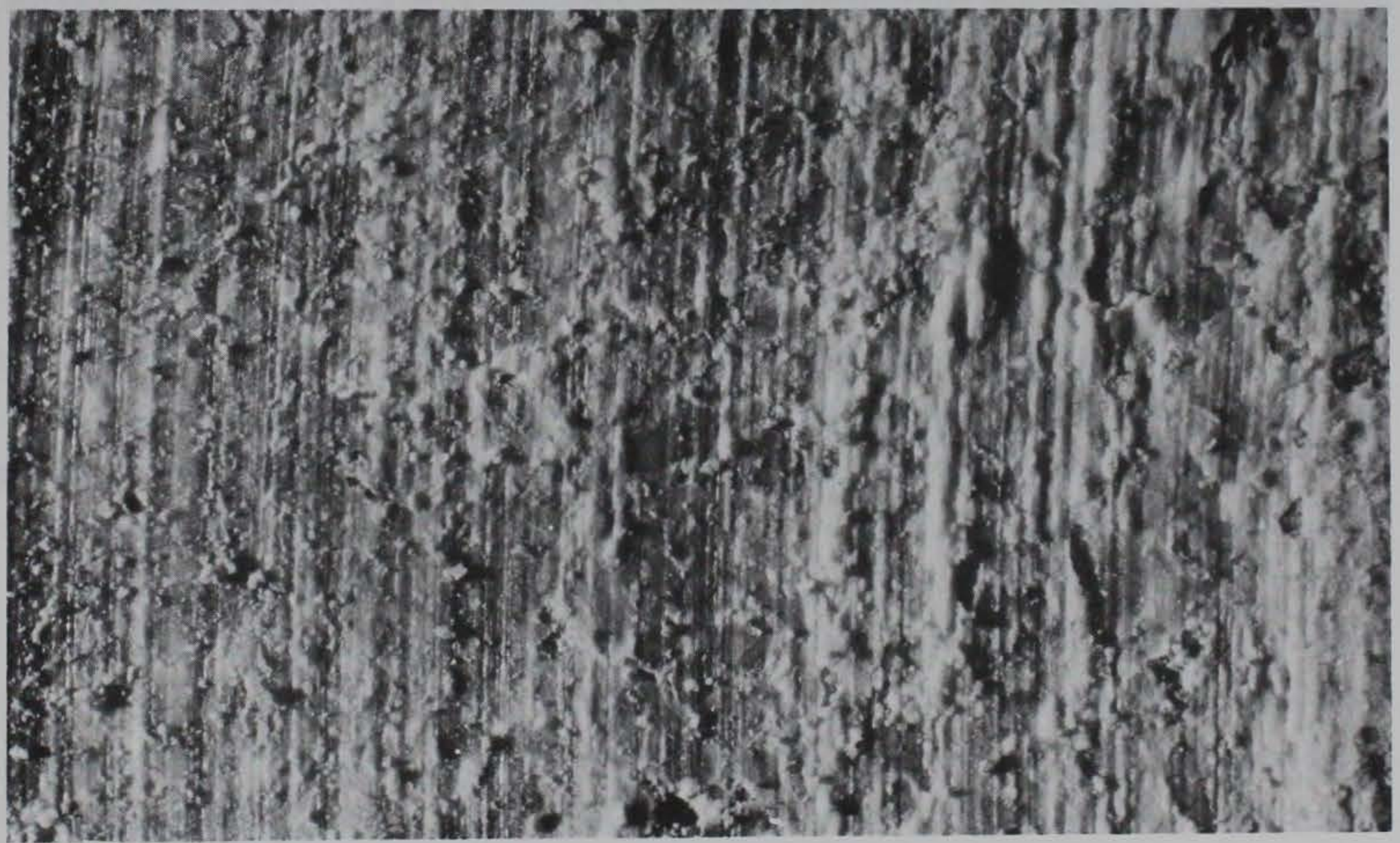

b. After dry testing (LL 11.28.1000.N.300)

Figure 61. Limestone surface before and after testing 
tested specimen surface is shown in Figure 62. The appearance of this surface is very similar to that of the pretested specimen shown in Figure 61. The surface was obviously smoothed, and some blending together of the individual grains had occurred. The large gouge marks, parallel to the direction of spin, were probably caused by pieces being ripped loose and dragged along the surface.

116. Because of the very plated and unusual nature of the posttest limestone surface, the mineral composition of the limestone was of interest. The results, which are listed in Table 8 , indicate that measureable chemical changes did take place as a result of testing. It was hypothesized that, if the limestone were altered by the combination of heat and/or pressure in the test, then some of the calcite would be altered to free calcium oxide $(\mathrm{CaO})$. This in turn would eventually hydrate to calcium hydroxide $\left(\mathrm{Ca}(\mathrm{OH})_{2}\right)$ and then might carbonate to calcium carbonate (calcite $-\mathrm{CaCO}_{3}$ ). Since free calcium oxide and calcium hydroxide were found in the wet specimen posttest, calcium hydroxide found in the dry specimen posttest indicates the reactions occurred. The conclusion is, therefore, that friction response is influenced by both mechanical and chemical changes.

\section{Conclusions}

117. The purpose of this study was to determine typical laboratory values of kinetic friction, the relationship between static and kinetic friction, and those factors governing kinetic friction during shear along clean discontinuities in rock. The device used in this study permitted the frictional testing of two hollow cylindrically shaped specimens at a variety of rates under two loading conditions. In the N-type test, the specimens are brought into contact and then spun. In the R-type test, the specimens are first carried to a constant spin rate and then brought into contact. An infinite amount of deflection or revolution strain between the two specimen surfaces is possible because of the ring-shaped specimens used in the experiment. Once the specimens are in contact, the same surfaces rub against one another; i.e., no new surface is brought 


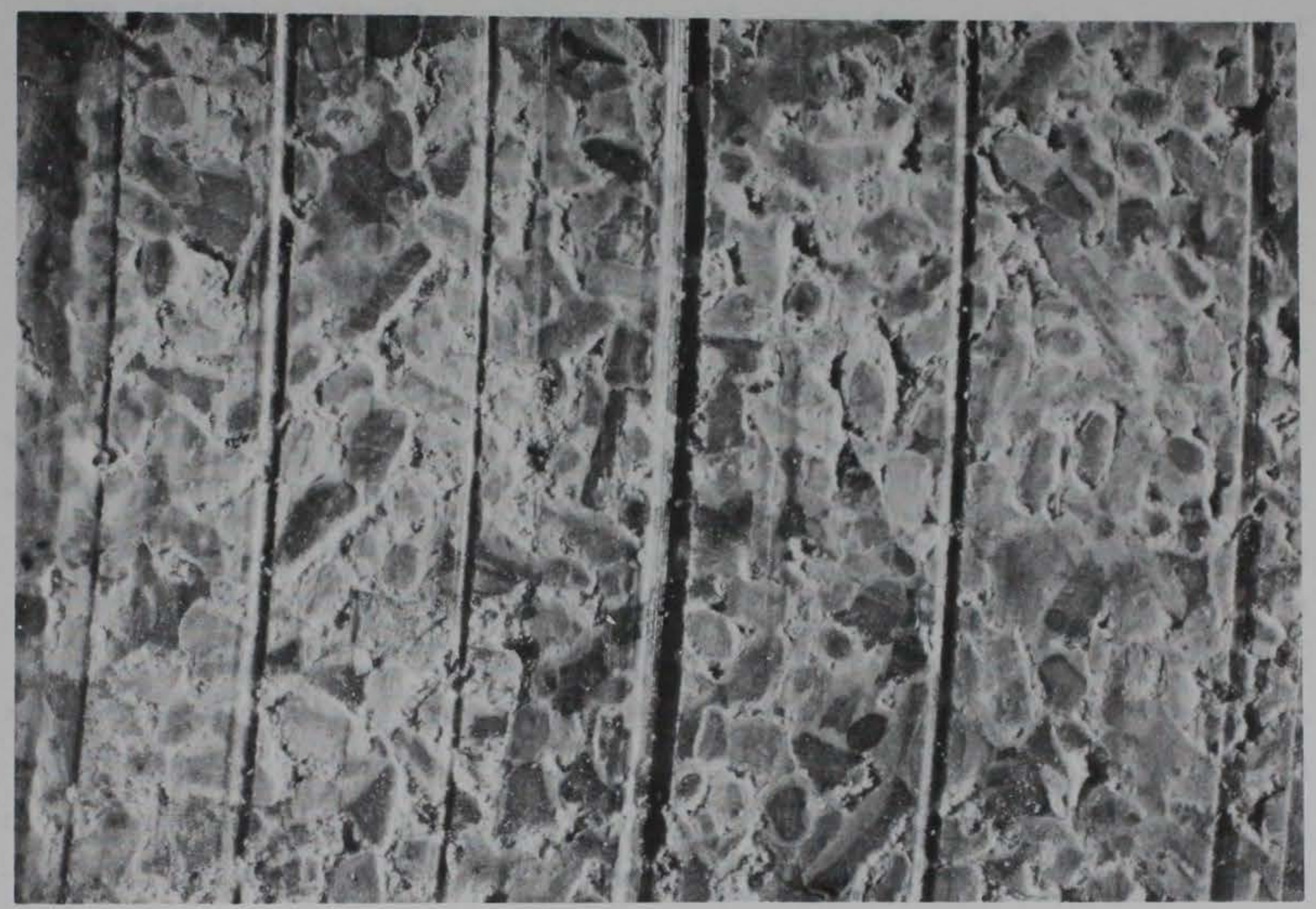

Figure 62. Limestone with wet surface after testing (LL 12.4.1000.N.300)

Table 8

Composition* of Limestone

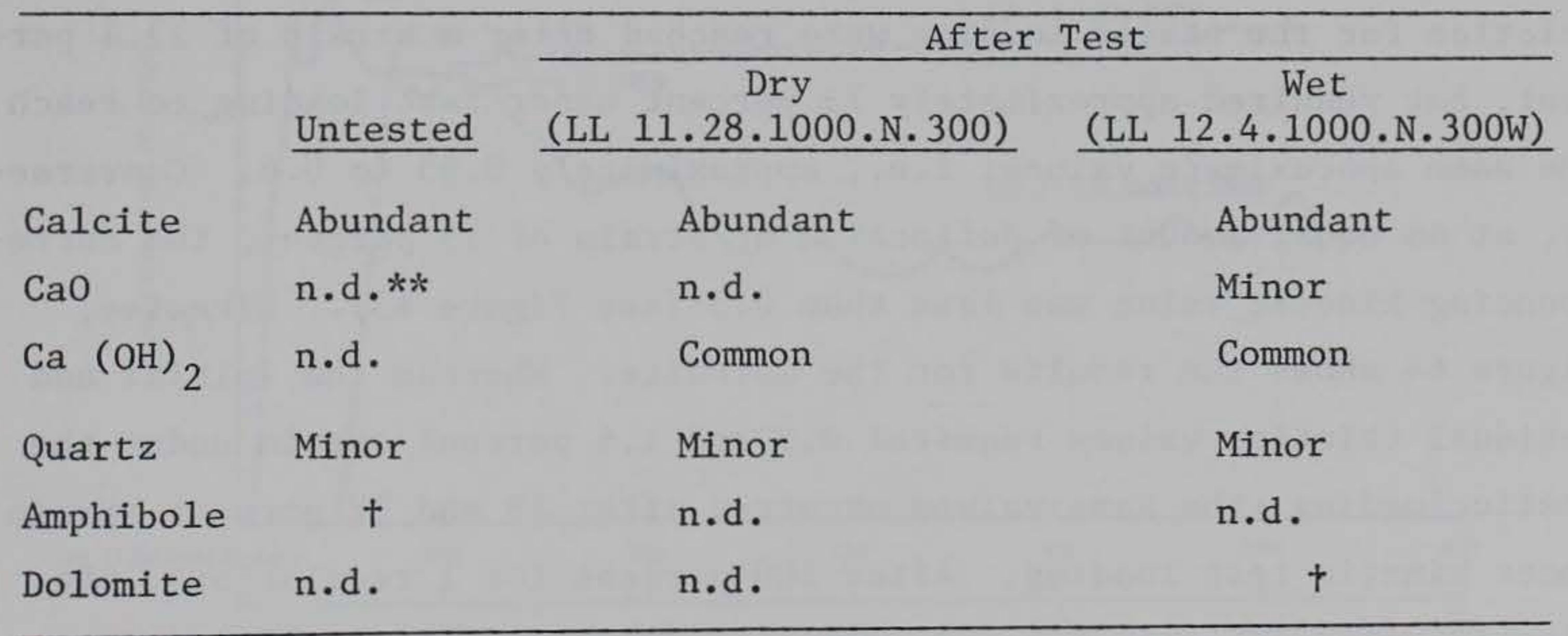

* Estimated amounts are: abundant, $>50$ percent; common, 10 to 25 percent; minor, 5 to 10 percent; and rare, $<5$ percent.

** Not detected.

+ May be present. 
into contact. Three rock types (Berea sandstone, Oneota dolomite, and Bedford limestone) were tested in this study. They were prepared to the same surface conditions (using a No. $600 \mathrm{grit}$ ) as reported by Coulson (1970) and then tested at slow rates. The results of tests at slow rates compared favorably to the results of Coulson with the exception of the limestone results. The values of friction reported by Coulson for limestone were somewhat higher than those obtained in this study, although the general shape of the friction coefficient-time history was similar.

118. The fast $\mathrm{N}$-type test results were similar in form to the slow test results with the exception of a decrease in friction measured at extremely large deflections; i.e., at approximately 2 revolutions. R-type test results were highly oscillatory on initial loading but shared the same general wave form as the N-type tests. In general, there were not statistically meaningful differences between the peak static and the peak kinetic values of friction. Although there was not a difference between the static friction values and kinetic friction values, there appeared to be a definite difference in the response of the three rock types to loading rate. The significant difference noted was that the kinetic values of friction occurred at different strains or deflections than the static values. The specimens tested under fast loading required greater deflections to reach values of friction similar to those reached under static loadings. For example, the wet sandstone peak and residual values of friction for the static loading were reached after a strain of 13.4 percent, but required approximately 73 percent under fast loading to reach the same approximate values; i.e., approximately 0.55 to 0.6 . Converse$1 y$, at an equal amount of deflection or strain of 13 percent, the corresponding kinetic value was less than 0.3 (see Figure 63). Likewise, Figure 64 shows the results for the dolomite. Whereas the initial and residual friction values required 0.5 and 1.6 percent strain under the static loading, the same values occurred after 19 and 32 percent strain under kinetic test loading. After 100 percent (or 1 revolution), the kinetic value actually began decreasing. Similar comparisons could be made for the limestone. The factors which influenced the kinetic response of the sandstone were mechanical in nature. No chemical reaction 


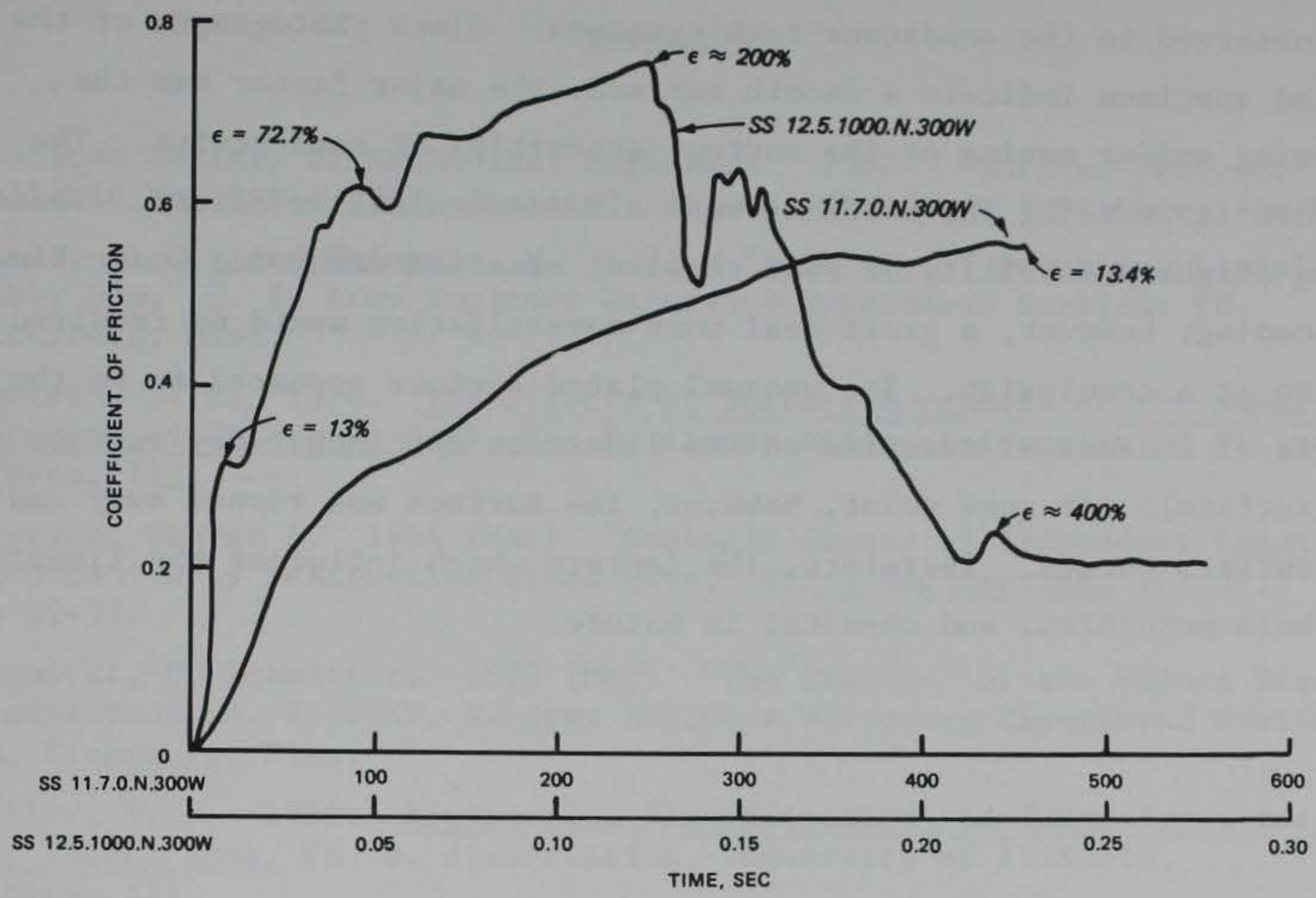

Figure 63. Comparison of tests SS 12.5.1000.N.300W and SS 11.7.0.N.300W on sandstone

\begin{tabular}{|c|c|c|c|}
\hline TEST & $\begin{array}{l}\text { SPEED } \\
\text { IN./MIN } \\
\end{array}$ & $\begin{array}{c}\text { STRAIN AT } \\
\text { PEAK } \\
\end{array}$ & $\begin{array}{l}\text { STRAIN AT } \\
\text { RESID } \\
\end{array}$ \\
\hline DD 11.6 .0 & 0.16 & $0.6 \%$ & $1.6 \%$ \\
\hline DD 11.3.0.1000.N.300W & $13,700.00$ & $19 \%$ & $32 \%$ \\
\hline
\end{tabular}

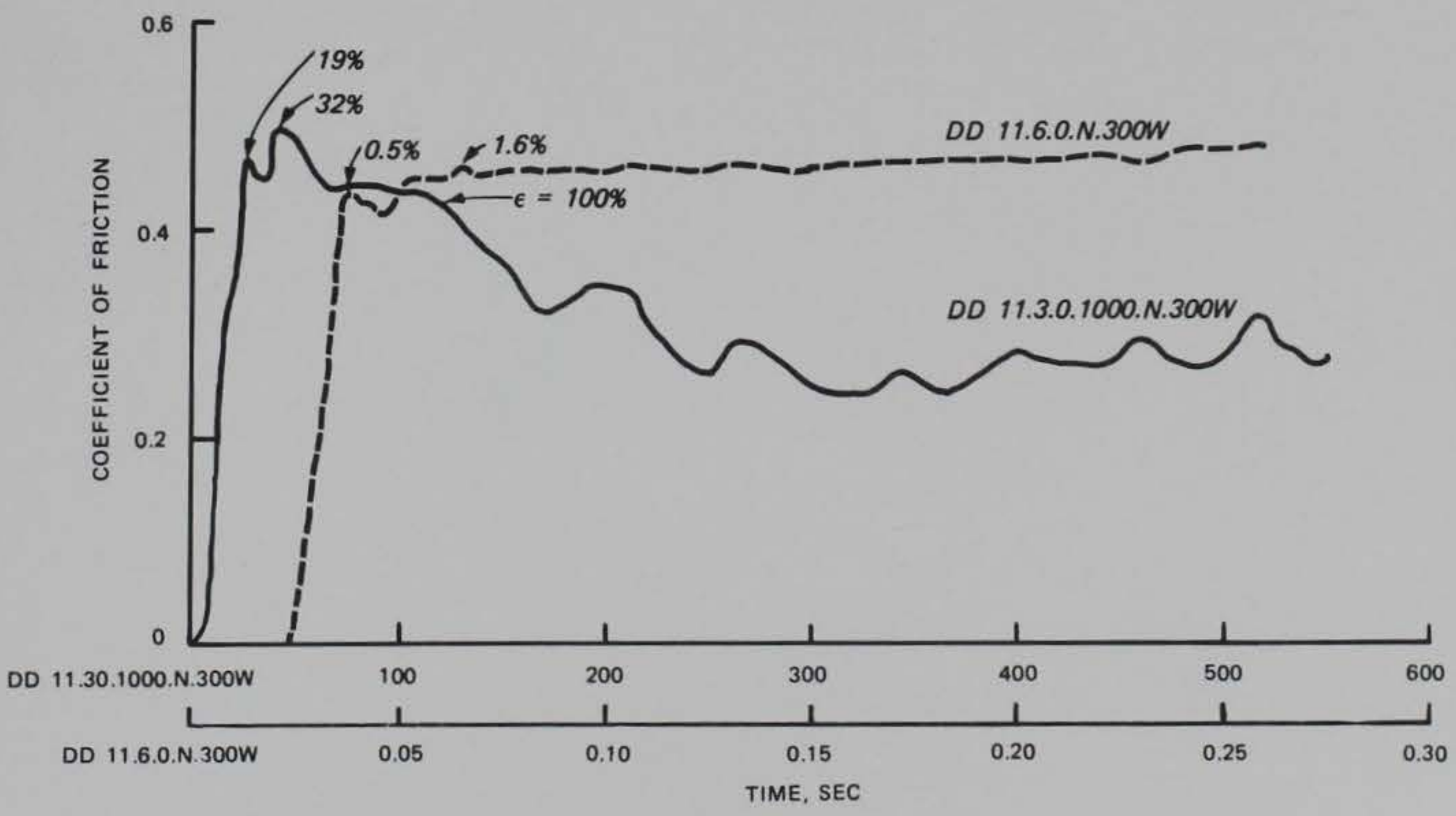

Figure 64. Comparison of tests DD 11.6.0.N.300W and DD 11.30.1000.N.300W on dolomite 
was observed in the sandstone test specimen. Since photographs of the tested specimen indicate a smooth surface, the major factor was the shearing and/or moving of the surface asperities or sand grains. The factors influencing the dolomite were also mechanical in nature. There was a slight possibility of some chemical reaction occurring under kinetic loading; however, a great deal more investigation would be required to arrive at a conclusion. The unusual plated surface appeared to be the result of a chemical reaction on the limestone specimens (dry surface and wet surface). At some point, however, the surface was ripped away and a new surface formed. Therefore, the factors which influence the limestone are both mechanical and chemical in nature. 


\section{REFERENCES}

American Society of Mechanical Engineers. 1962. "Surface Texture," Bulletin No. B46.1-1962, American National Standards Institute, New York. Banks, D. C., and DeAngelo, M. 1972. "Velocity of Potential Landslides, Libby Dam," U. S. Army Engineer Waterways Experiment Station, CE, Vicksburg, Miss.

Coulson, J. H. 1970. The Effects of Surface Roughness on the Shear Strength of Joints in Rock, Ph. D. dissertation, University of Illinois, Urbana, I11.

Kiersch, George A. 1964 (Mar) "Geologic Causes of Tremendous Landslide Accompanied by Destructive Flood Wave," Civil Engineering, Vol 34, pp 32-35.

Kusnacht, G. Schmitter. 1973 (May) "The Disaster of the Vaiont River," Translation No. 73-6, U. S. Army Engineer Waterways Experiment Station, CE, Vicksburg, Miss.

Miller, R. P. 1966. Engineering Classification and Index Properties for Intact Rock, Ph. D. dissertation, University of Illinois, Urbana, I11.

The Rock-Color Chart Committee, E. N. Goddard, Chairman. 1975. "RockColor Chart," Geological Society of America, Boulder, Colo. 


\section{APPENDIX A: COMMENTS CONCERNING SURFACE ROUGHNESS}

1. The roughness of any surface may be measured quantitatively and assigned a number called the arithmetic average deviation* or AA . For the representative surface profile shown in Figure Al, AA is defined by the following expression over a known interval $\&$ called the roughnesswidth cutoff:

$$
\mathrm{AA}=\frac{1}{\ell} \int_{0}^{\ell}|\mathrm{Y}| \mathrm{dx}
$$

$Y$ is measured from the center line or mean value of the ordinates over the interval $\ell$. AA is also called the roughness height of the surface.

2. Although $\mathrm{AA}$ is useful in characterizing a surface finish, it does have its shortcomings. It is the purpose of this appendix to illustrate, through examination of a simple surface roughness model, why AA is not a sufficient measure of surface roughness.

3. Let the portion of a surface profile within the roughness-width cutoff $\ell$ be represented by a number of right isosceles triangles resting on the center line, as shown in Figure A2. There may be $m$ such triangles of height $C_{i} A$ where $A$ is the height of the tallest triangle. Furthermore, let the base of each triangle be $a_{i}$. Then,

$$
\sum_{i=1}^{m} a_{i} \leq \ell
$$

If $\xi_{i}=a_{i} / \ell$, then

$$
\sum_{i=1}^{m} \xi_{i} \leq 1
$$

* American National Standards Bulletin B46.1-1962, "Surface Texture." 


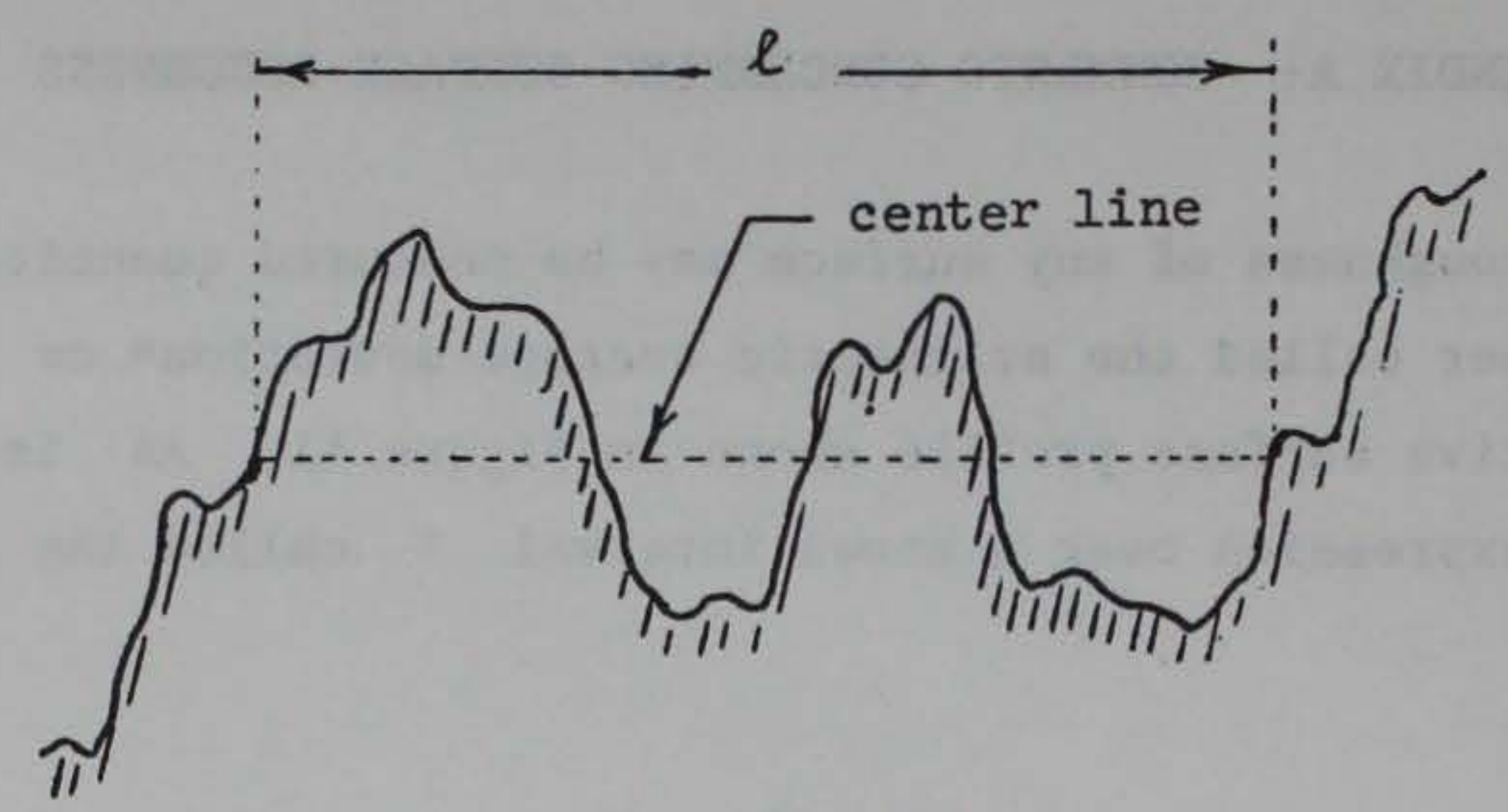

Figure Al. A representative surface profile

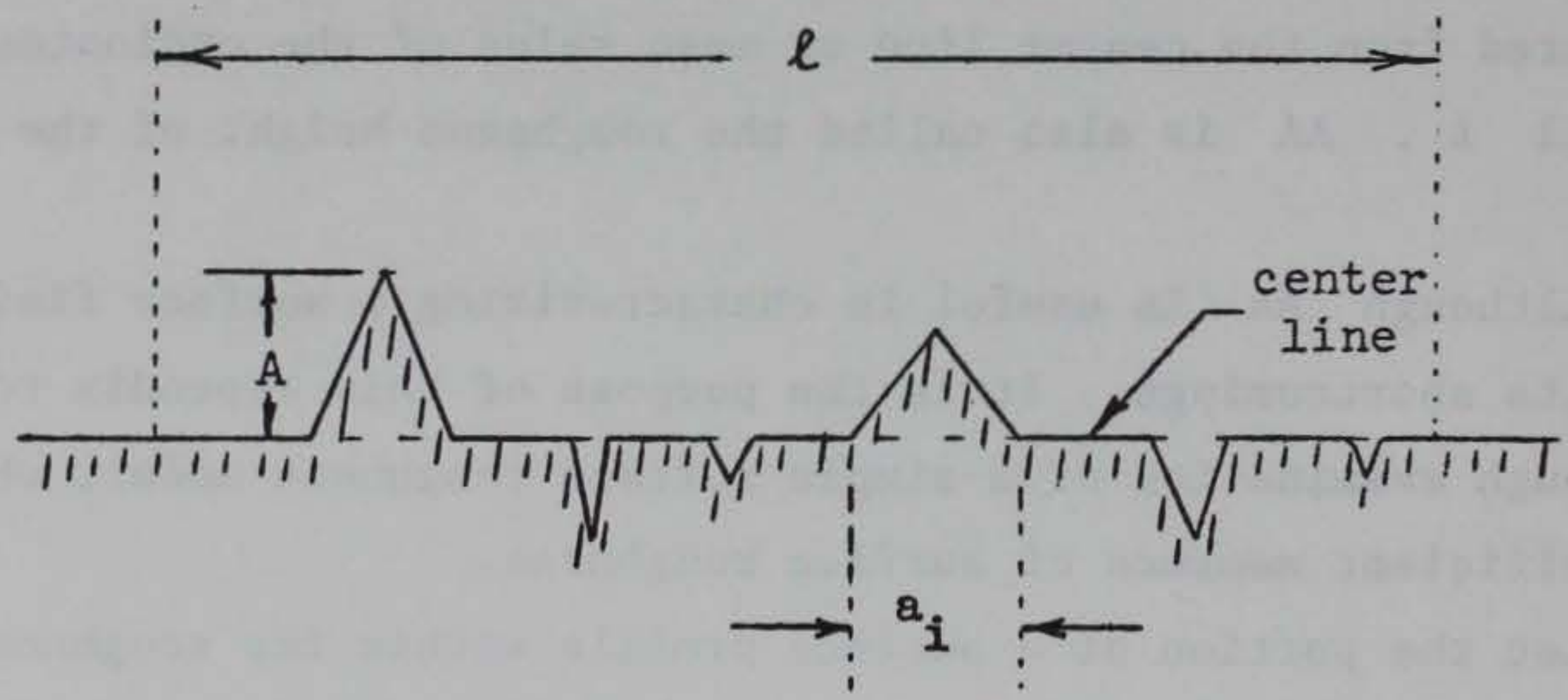

Figure A2. A surface roughness model

4. From the definition in Equation $\mathrm{Al}$, the arithmetic average deviation, or roughness height, for this simple model becomes

$$
\mathrm{AA}=\frac{1}{\ell} \int_{0}^{\ell}|\mathrm{Y}| \mathrm{dx}=\frac{1}{\ell} \sum_{i=1}^{\mathrm{m}} \frac{1}{2} \mathrm{a}_{i} \mathrm{C}_{i} \mathrm{~A}=\frac{1}{2 \ell} \sum_{i=1}^{\mathrm{m}} \xi_{1} \ell \mathrm{C}_{i} \mathrm{~A}
$$

or

$$
\mathrm{AA}=\frac{\mathrm{A}}{2} \sum_{i=1}^{\mathrm{m}} \xi_{1} \mathrm{C}_{i}
$$


5. It is obvious from Equation $\mathrm{A} 2$ that roughness height $\mathrm{AA}$ is a function of several factors, including the number of asperities on the surface and their shapes. For example, let all of the triangles be identical. Then, $c_{i}=1$, and

$$
\mathrm{AA}=\frac{\mathrm{A}}{2} \sum_{i=1}^{\mathrm{m}} \xi_{i}
$$

In this case, $\mathrm{AA}$ is a function of the number of asperities only or the frequency of their occurrence. Thus, one profile having more identical peaks than another profile within a given cutoff interval will show a larger value of roughness height, as shown in Figure A3. Furthermore,

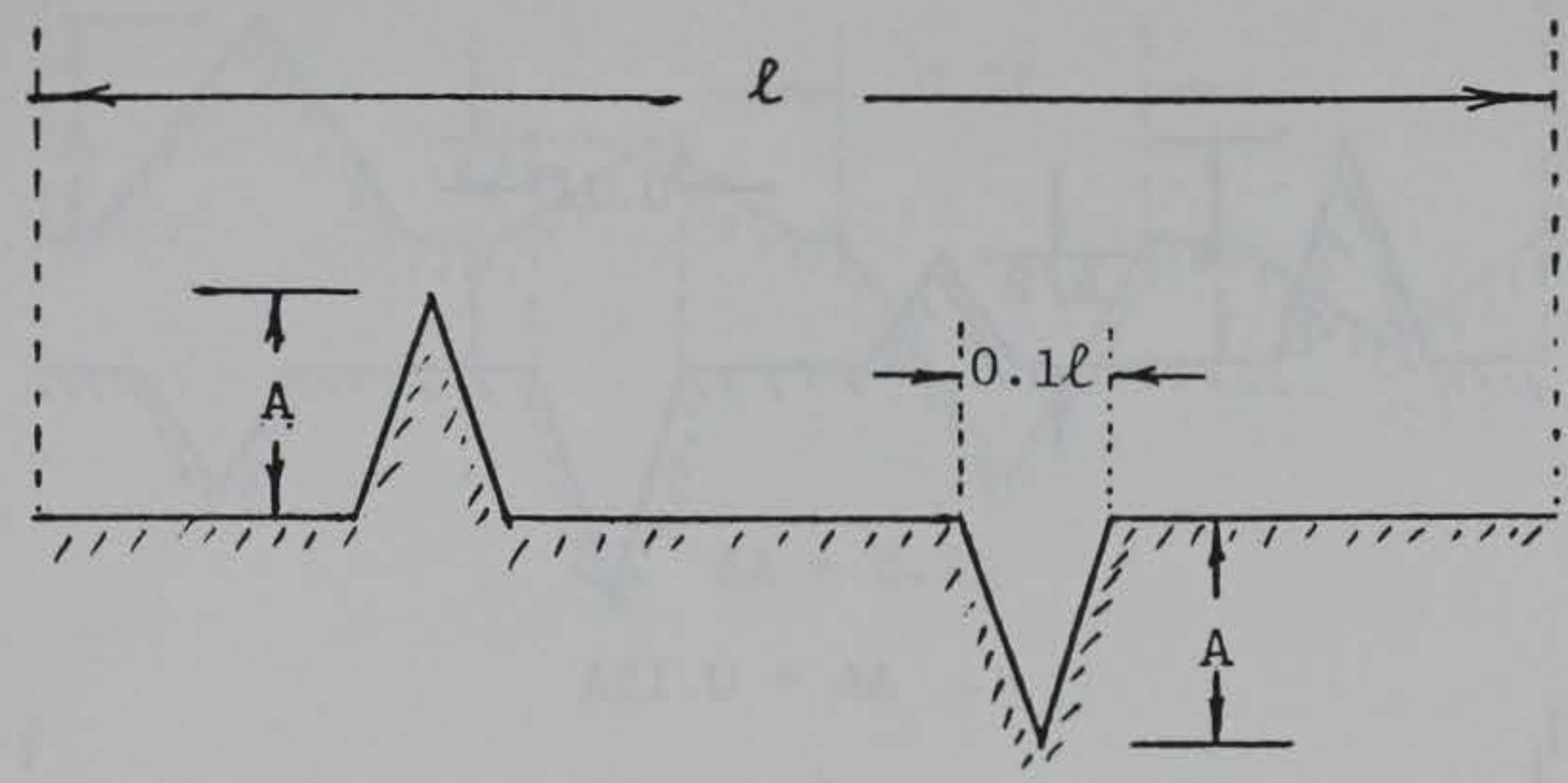

a. $\mathrm{AA}=0.1 \mathrm{~A}$

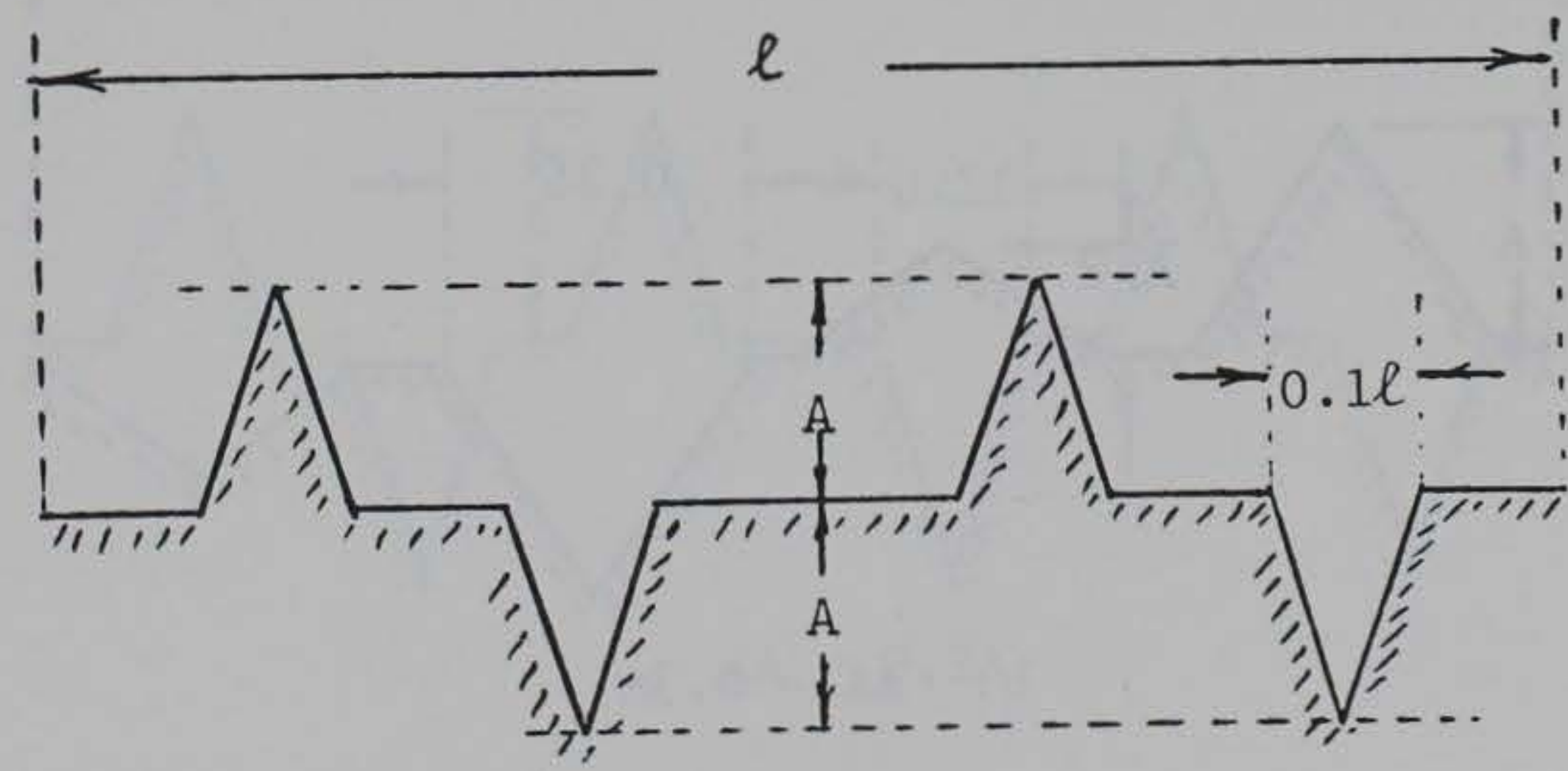

b. $\mathrm{AA}=0.2 \mathrm{~A}$

Figure A3. Two profiles with identically shaped asperities 
for these circumstances, the largest value of roughness height will be $\mathrm{A} / 2$.

6. Now, consider two profiles where each has the same number of peaks in the cutoff interval as well as the same distribution of heights (Figure A4). Then, from Equation $\mathrm{A} 2$, the only variable is $\xi_{i}$ or the base width of each triangle. In this case, it is apparent that two profiles having the same number of triangular asperities with the same distribution of heights will have different roughness heights depending upon the width of those asperities.

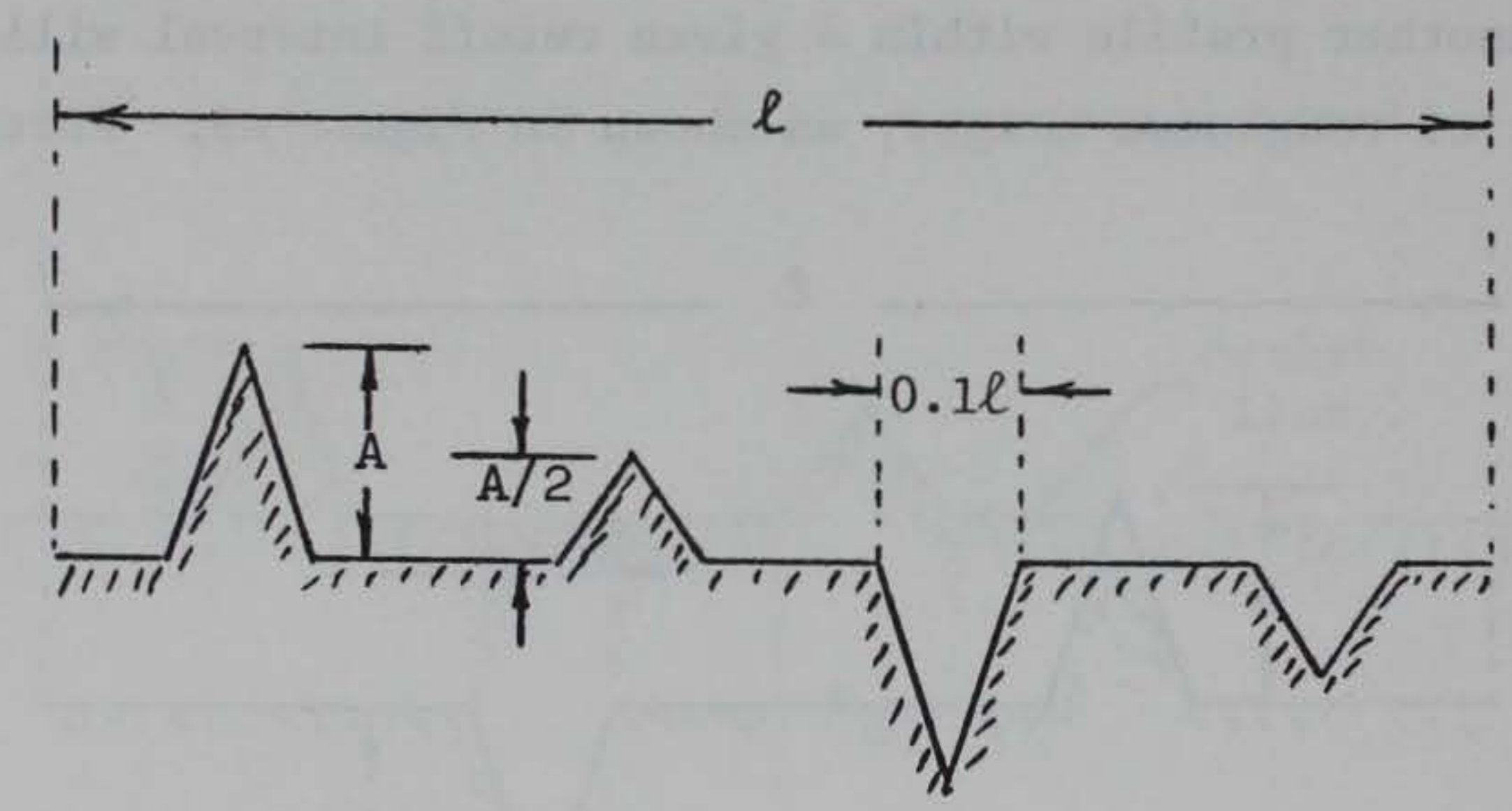

a. $\mathrm{AA}=0.15 \mathrm{~A}$

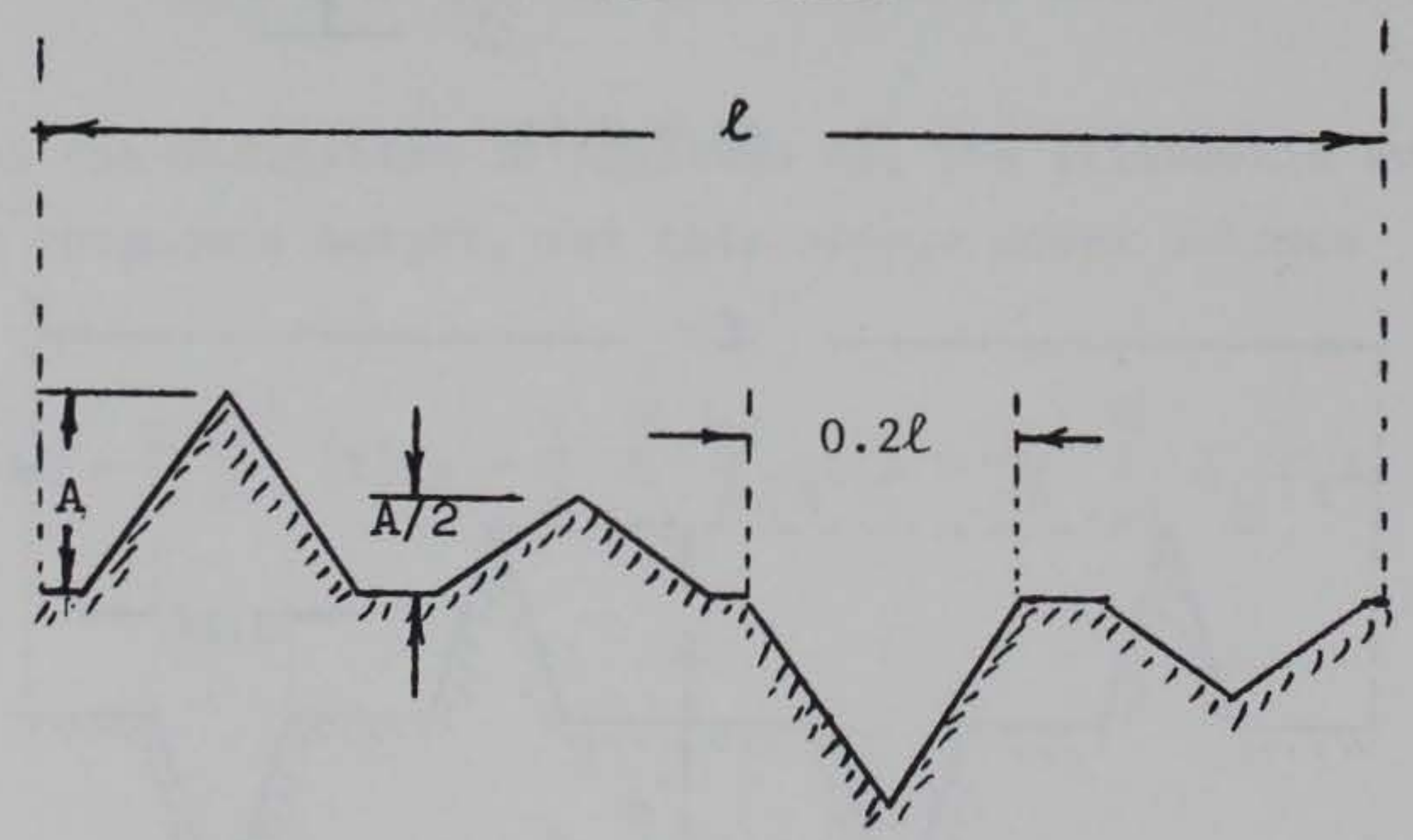

b. $\mathrm{AA}=0.3 \mathrm{~A}$

Figure A4. Two profiles with the same number of asperities and the same height distribution 
7. It should be clear from this presentation of a simple surface roughness model that the quantity called the arithmetic average deviation, or roughness height, is not a sufficient measure of surface roughness in that the frequency of surface asperities and their shape are two interrelated variables that both contribute to AA but that conversely may not be represented by the roughness height number. An obvious example of this is shown in Figure A5 where the two profiles have the same AA value but look very different.

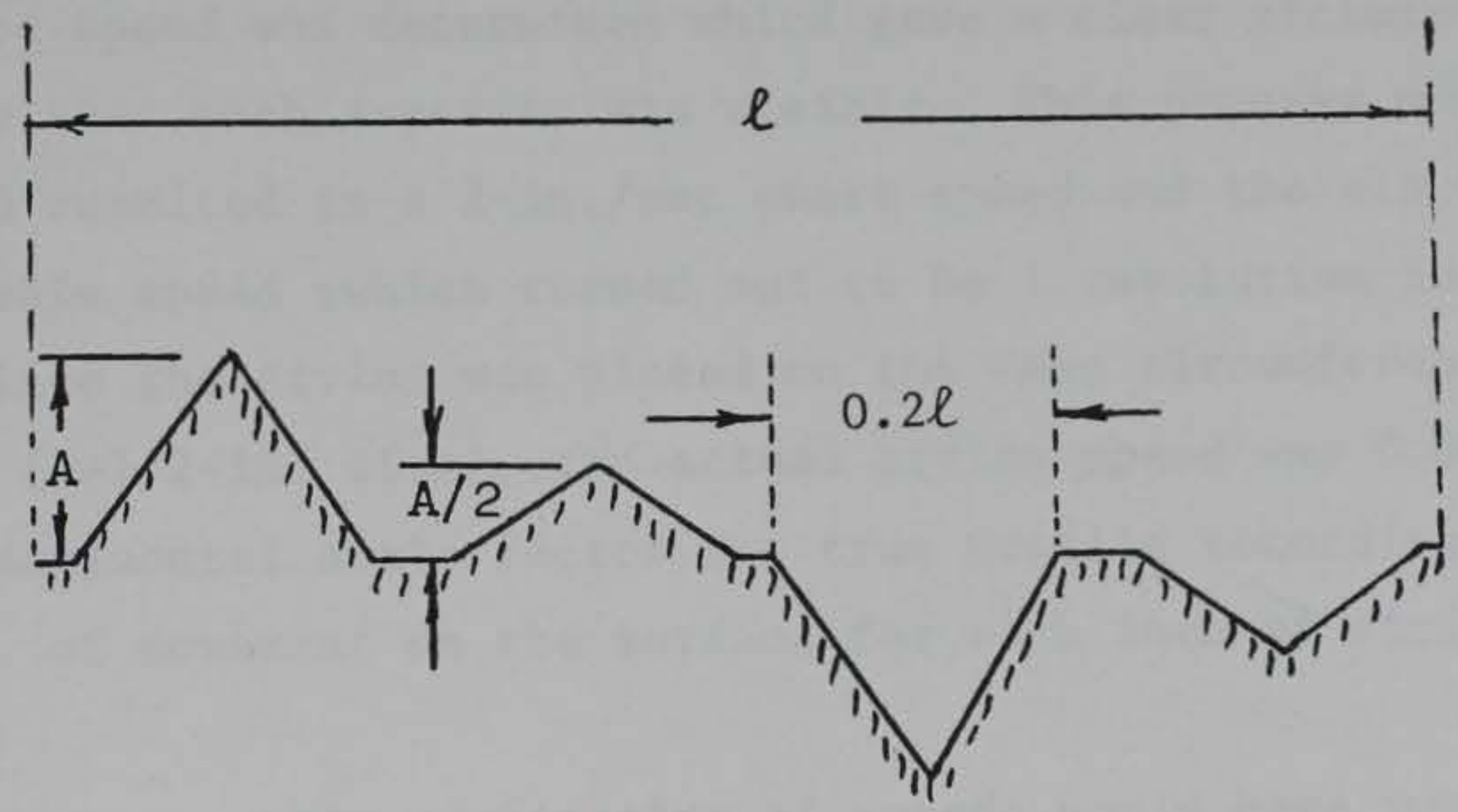

a. $\mathrm{AA}=0.3 \mathrm{~A}$

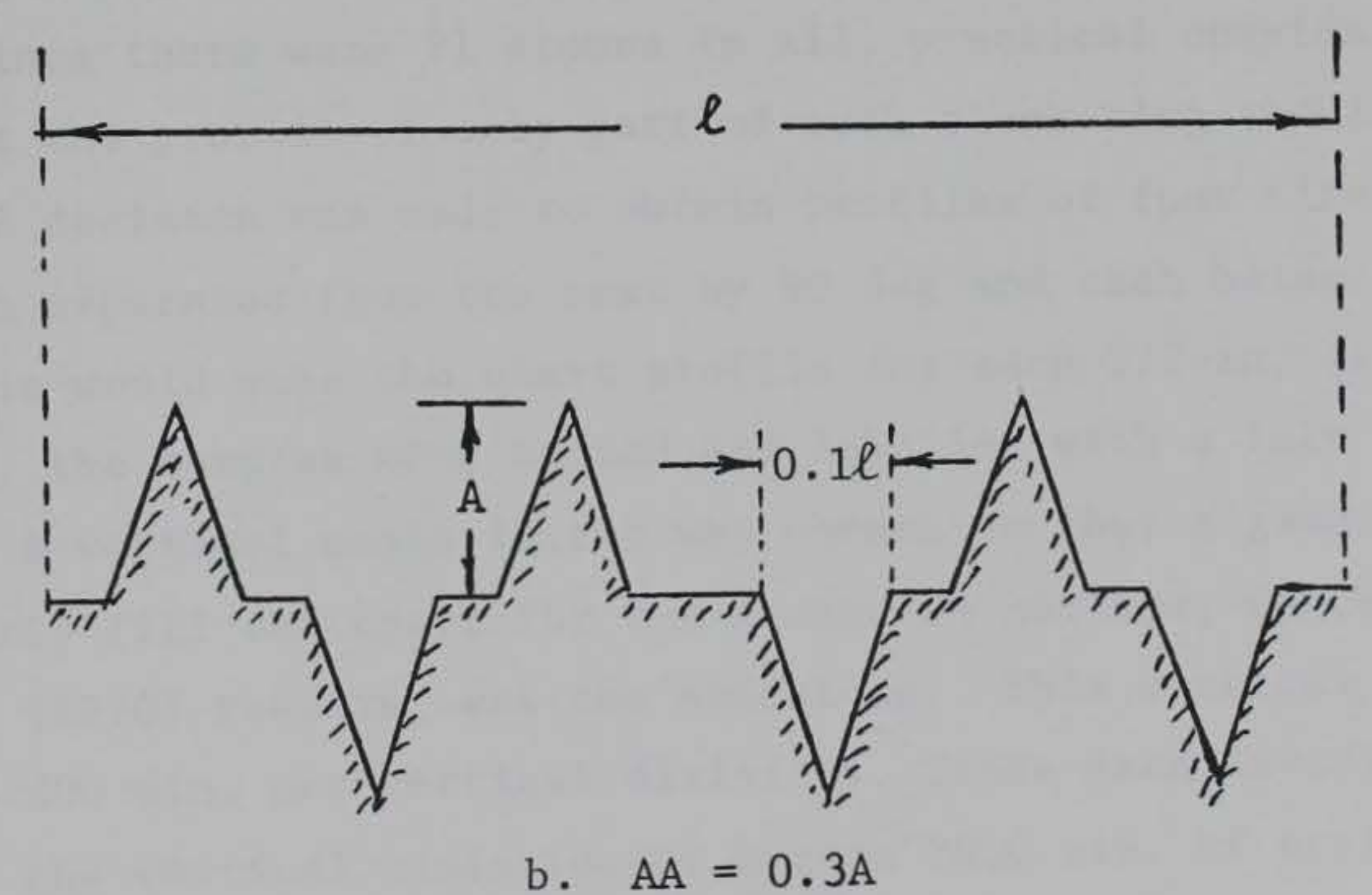

Figure A5. Two different profiles with identical roughness heights 


\section{APPENDIX B: SURFACE PROFILES}

1. True profiles of the stone surfaces were the first quantities recorded. These measurements were made on the Surfanalyzer 136. The overall test setup consisted of a stone sample resting on a rotating table. A strip chart recorder and system amplifier were used to record the measurements.

2. By trial and error, a combination of stylus speed and strip chart record speed was determined which gave a clear picture of surface profiles so that each asperity was visible. This process was purely subjective and resulted in a $2-i n . / s e c$ chart speed and the slowest possible rotating table speed (which turned out to be 1 revolution in $5 \mathrm{~min}$ and $5 \mathrm{sec})$. Since the stylus was placed on the mean circumference of each stone ring (4-1/2-in. diam), the actual stylus speed was $0.046 \mathrm{in} . / \mathrm{sec}$. Thus, the horizontal scale factor for true profile recordings was about $23,000 \mu \mathrm{in}$. of movement on the surface for each inch of strip chart paper.

3. However, this combination of speeds would have resulted in a 50-ft-long strip chart recording for a complete surface profile on each stone. Since there were 21 stones in all, practical considerations dictated that the profile of only part of each stone ring should be recorded. A decision was made to obtain profiles of four circumferential arcs, each separated from the next by $90 \mathrm{deg}$ and each being about 1/2 in. 1ong. This would make the chart profile for each $1 / 2-i n$. arc about 20 in. long. The samples were marked and labelled with a felt pen.

4. A vertical scale factor was chosen so that a generated profile would nearly fill the chart for the roughness surface, which, based upon Coulson's (1970) results, was the sandstone. This vertical scale turned out to be $200 \mu$ in. per vertical division. Since each division was 0.1 in. long, the vertical scale factor became $2000 \mu \mathrm{in}$. of stylus movement per inch of strip chart paper.

5. The adjustable rotating table on the 136 system was balanced for all of the true profile recordings, except for sandstone sample 
No. 1. Therefore, any incline on the strip chart profiles reflects a true tilt of that surface.

6. True profiles of the 21 stones are shown in Figures B1-B21, starting with the sandstone rings and followed by the 1 imestone and dolomite specimens. Each ring was numbered, and the four segments where profiles were being measured were assigned the letters "a" through "d."

7. Consider first the profiles for sandstone sample No. 1 found in Figure Bl. As was stated previously, a vertical scale factor was chosen so that the true profile of the roughest material (sandstone) would fill the strip chart, while a horizontal scale factor was chosen to clearly show the surface asperities without causing the records to be excessively long. These scale factors are shown on the record for section $\mathrm{A}$ in Figure $\mathrm{Bl}$ and were the same for the remaining true profiles. Also note from the section A record what is stone and what is air.

8. True profiles are representative "snapshots" of what surfaces actually look like and aid in making relative visual comparisons of surfaces from different materials. In this regard, only a few comments need to be made on the results shown in Figures B1-B21.

9. First of all, note that these so-called "true profiles" are compressed on the horizontal scale so that valleys on the surface appear much sharper than they actually are.

10. Furthermore, the actual shape of the stylus tip (a cone with a 90-deg included angle and a tangential 200- $\mu$ in.-radius spherical tip) prevents a true profile from being recorded. If one thinks of the profile as a series of plateaus connected by valleys, the stylus is capable of following the surface only when the valley walls have less than a 45deg slope. From the scale factors shown in Figure B1, any lines with a slope of about 1 horizontal unit to 10 vertical units probably reflect a false recording. In addition, any profile with sharp points at the bottom of valleys is probably not accurate. Figure B22 illustrates these shortcomings.

11. Since the scale factors of all the true profiles are identical, it can be observed that, in general, the sandstone samples appear to have a rougher surface than either the limestone or the dolomite 

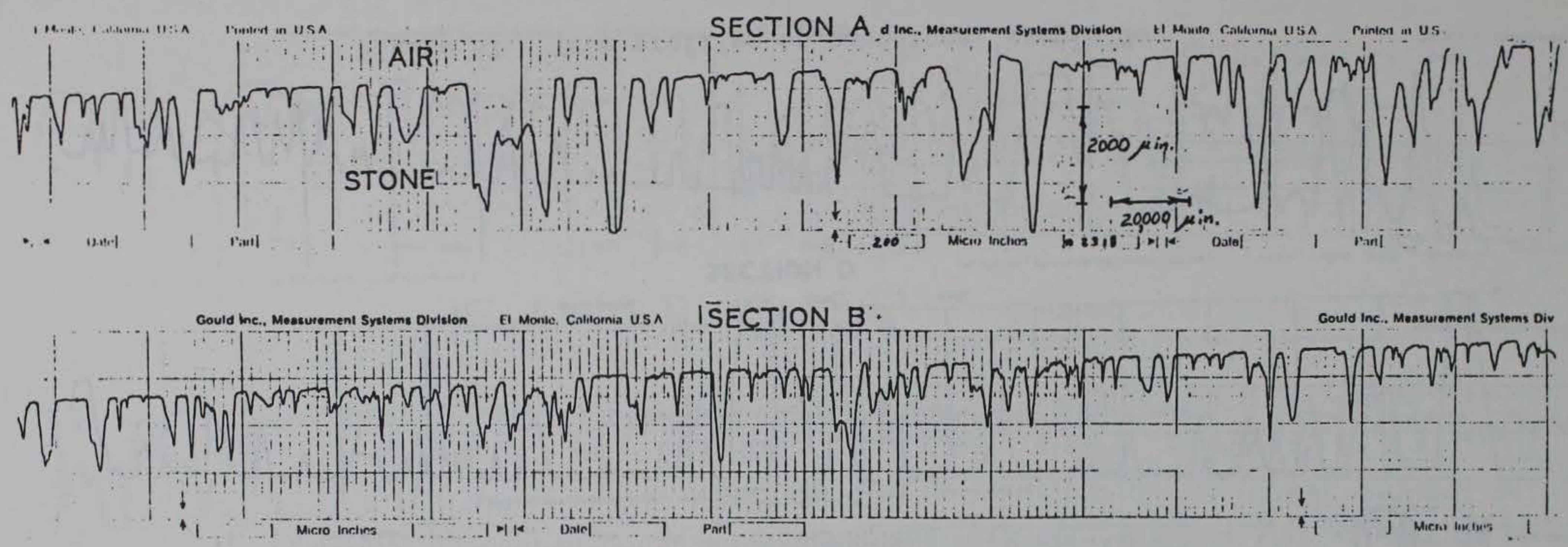

$\underset{\omega}{\varpi}$

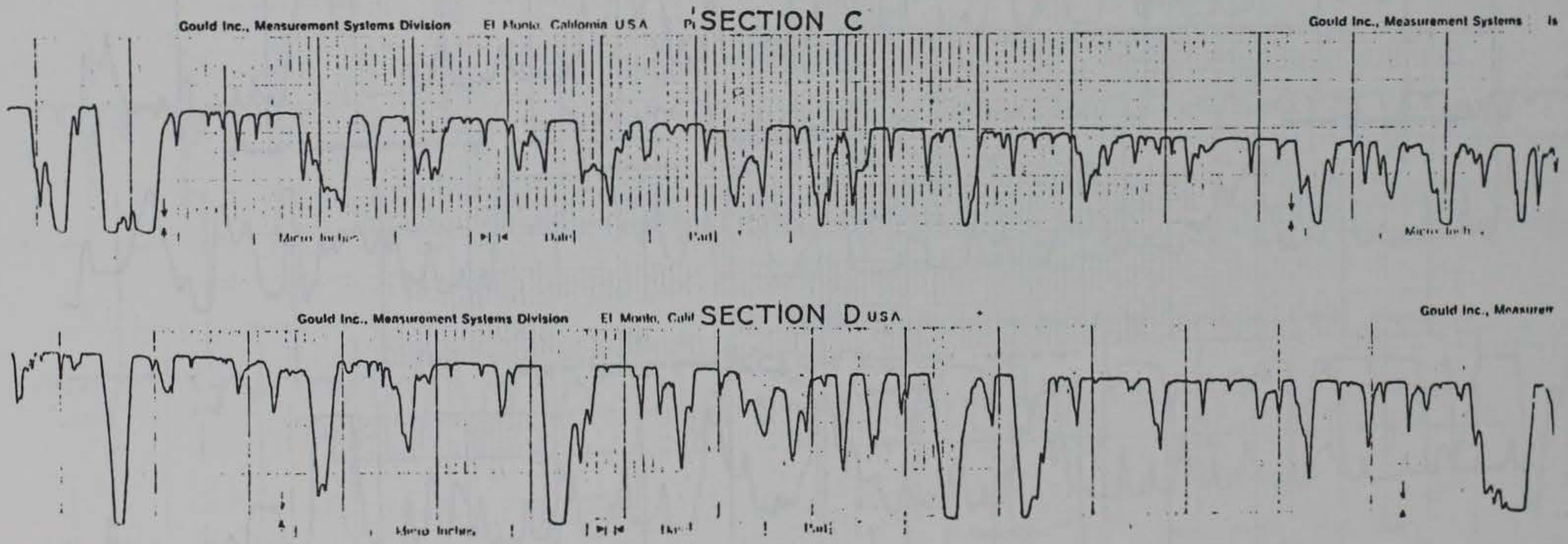

Figure B1. True profiles on sandstone, sample No. 1 


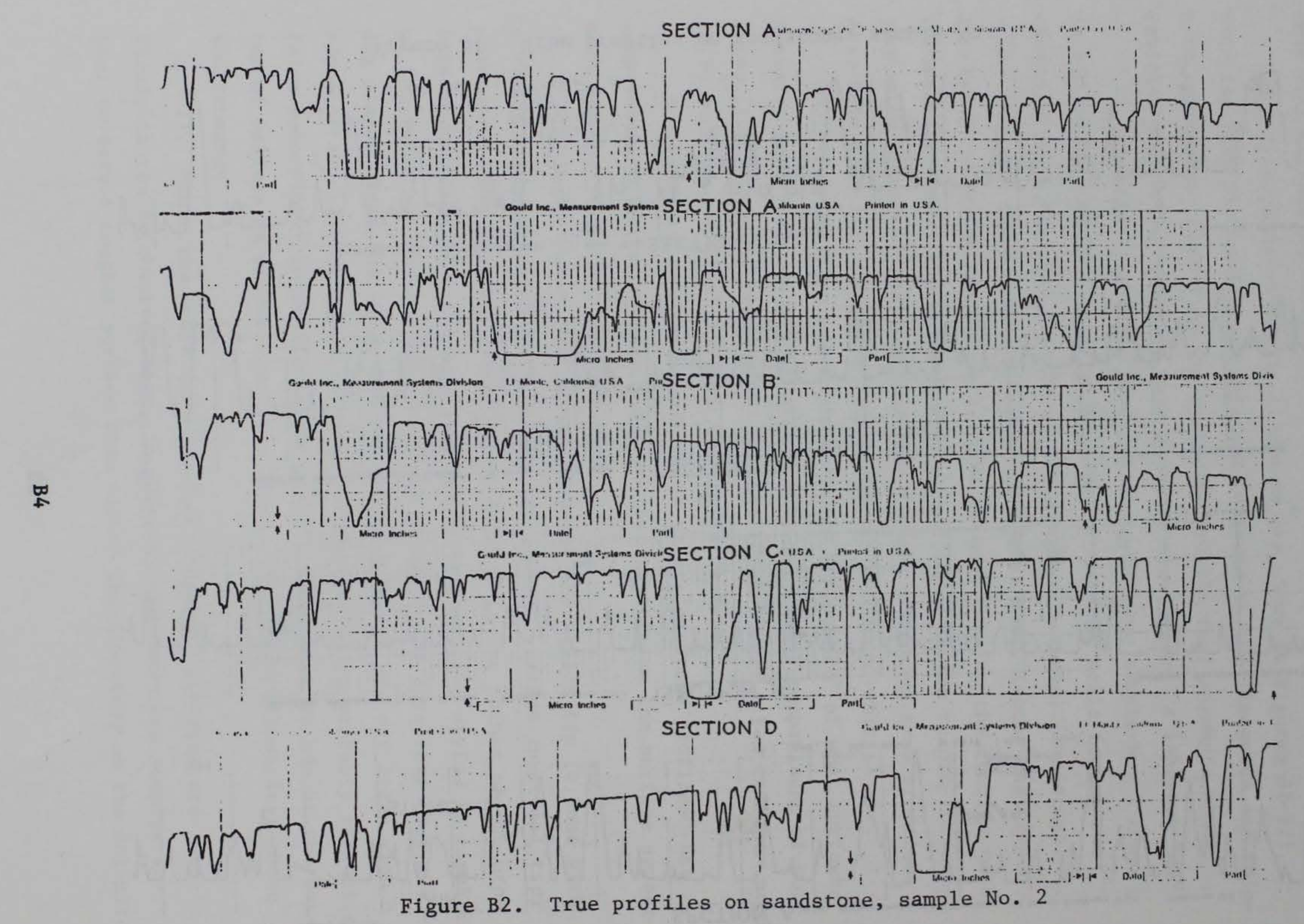



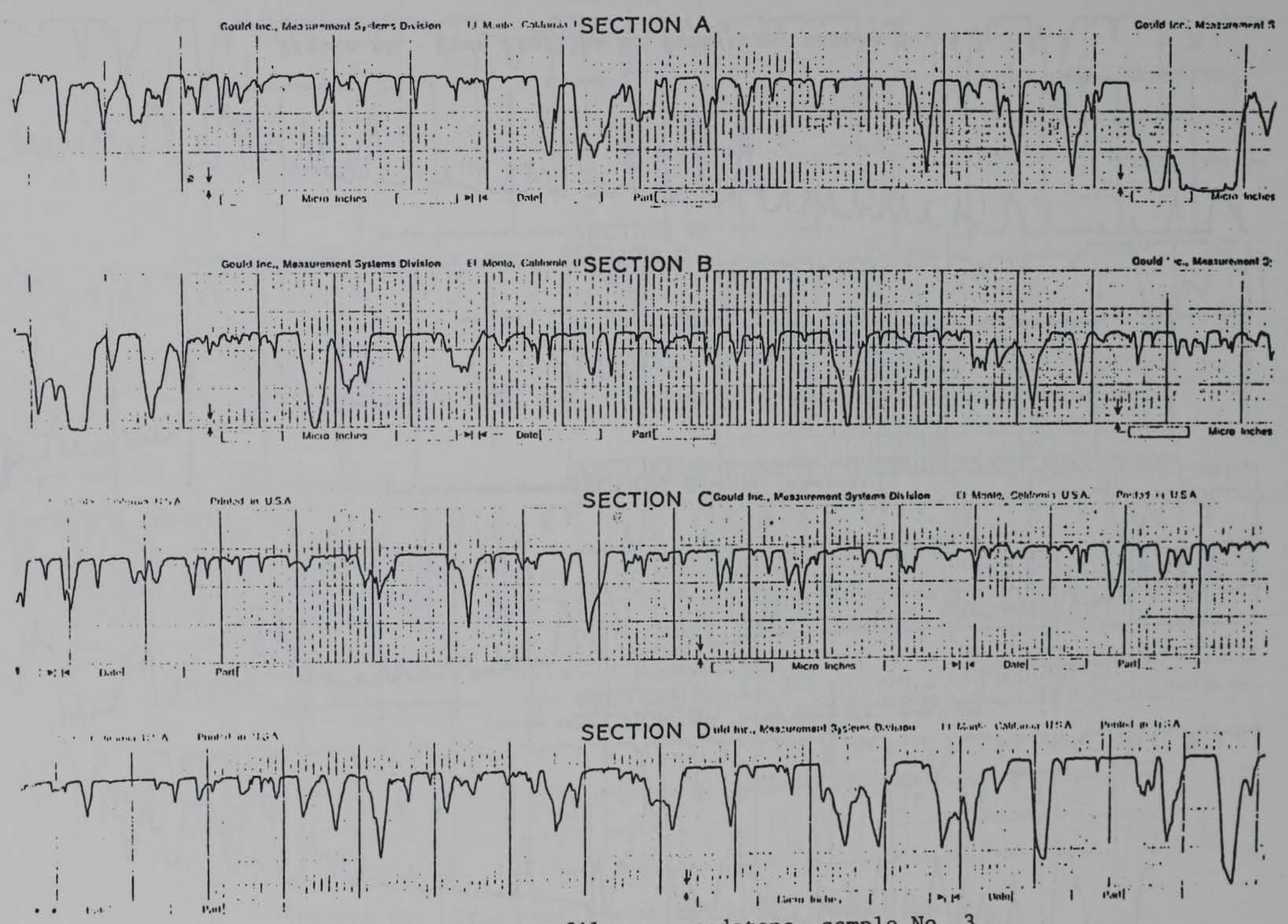

Figure B3. True profiles on sandstone, sample No. 3 

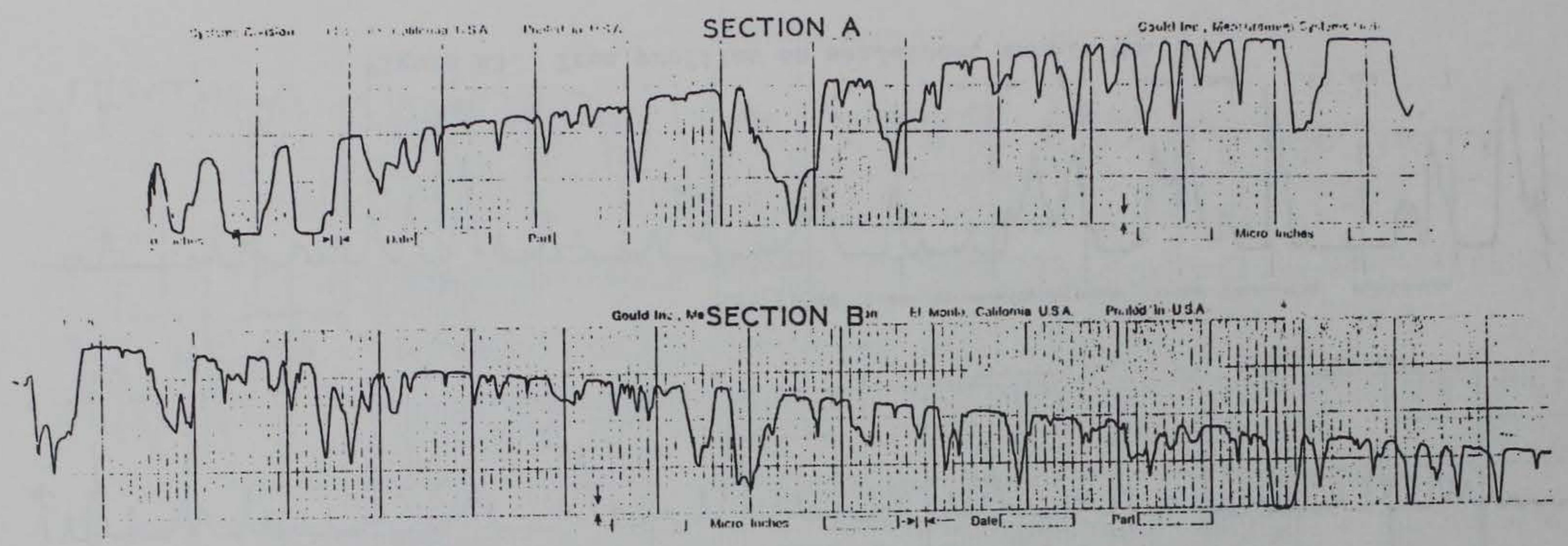

Eू

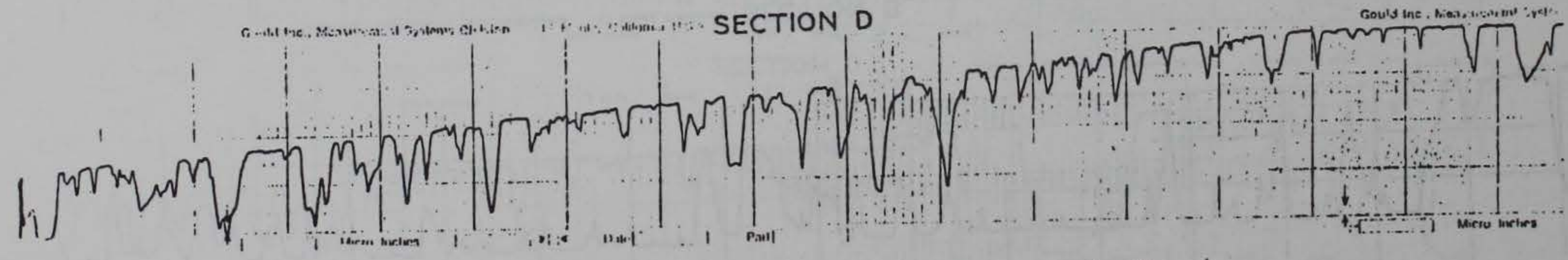

Figure B4. True profiles on sandstone, sample No. 4 

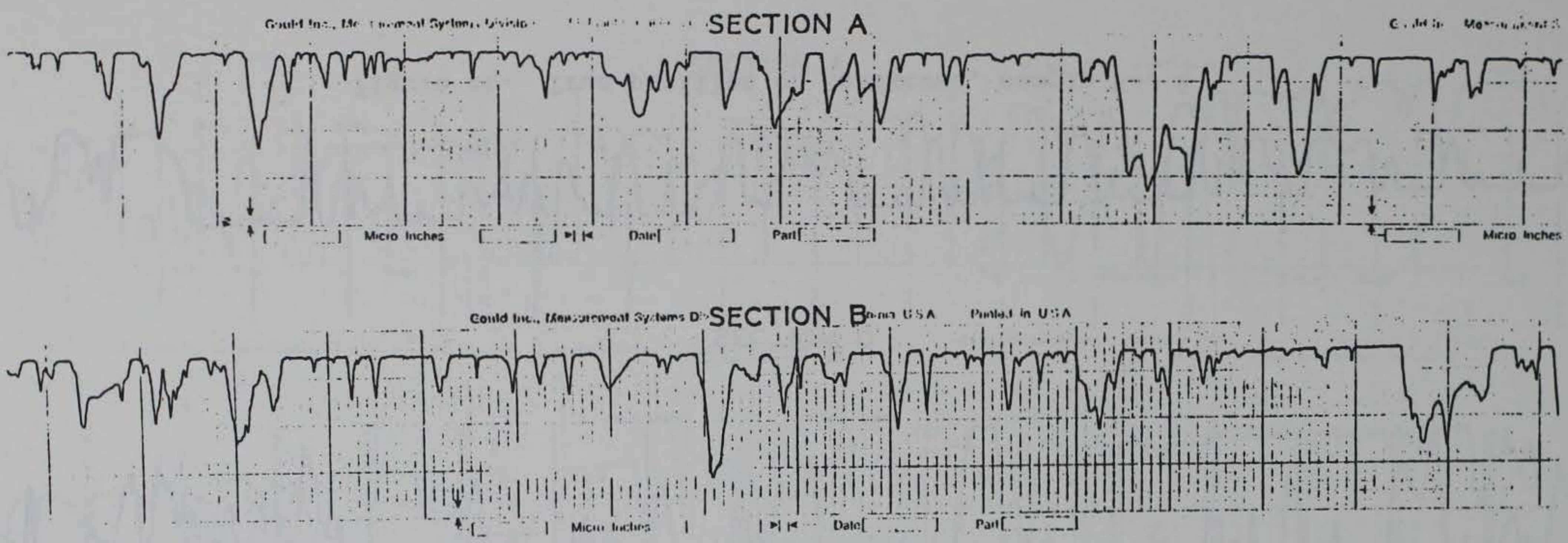

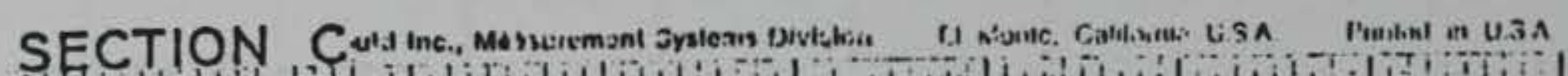

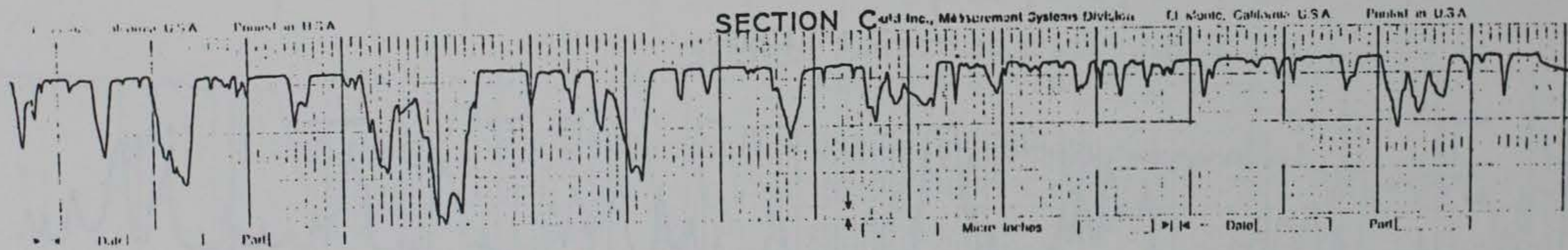

(1)

Figure B5. True profiles on sandstone, sample No. 5 

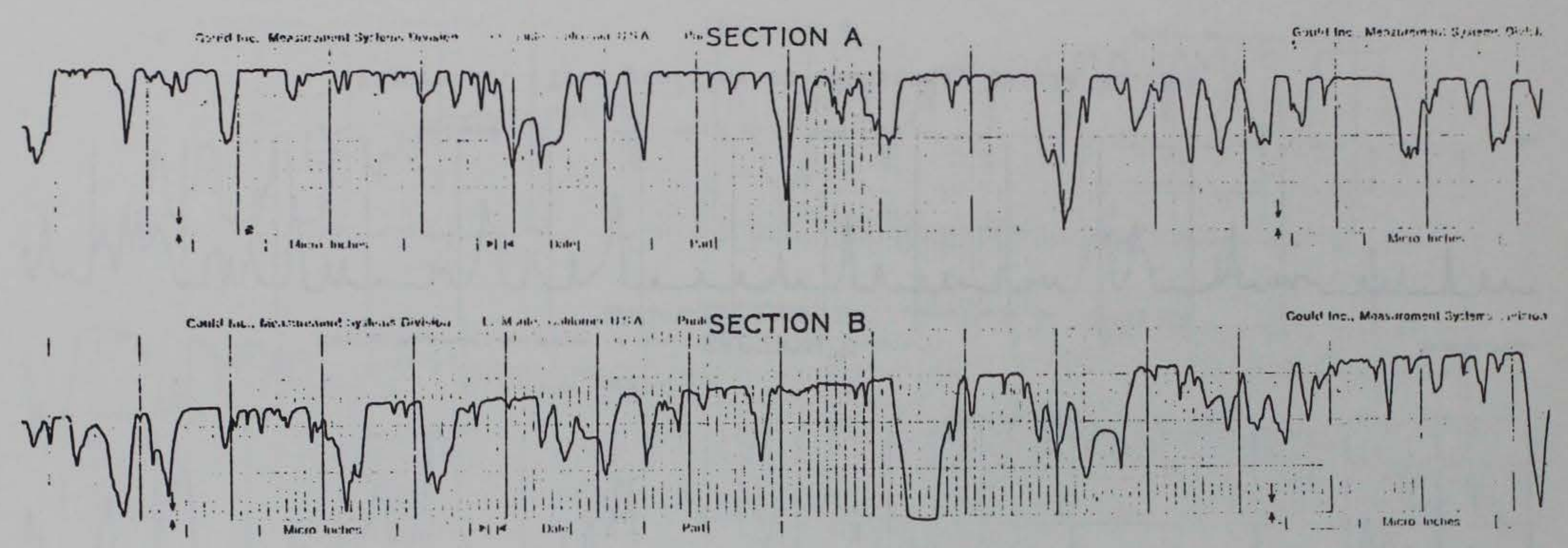

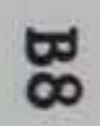
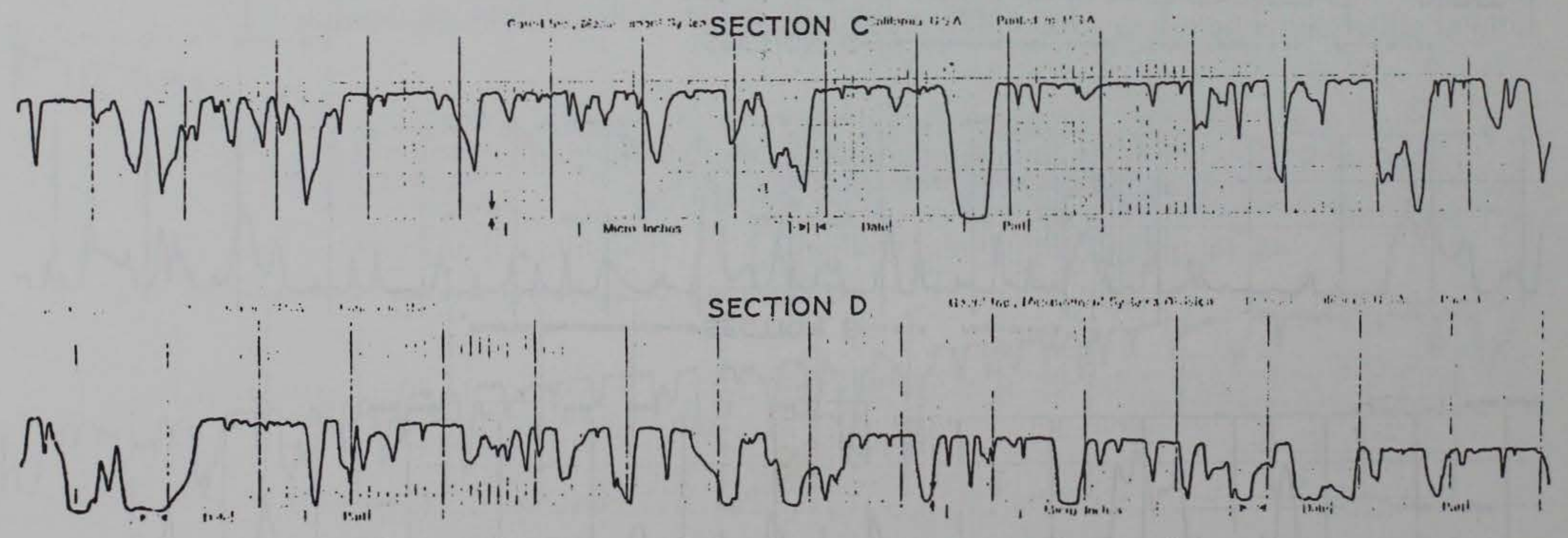

Figure B6. True profiles on sandstone, sample No. 6 

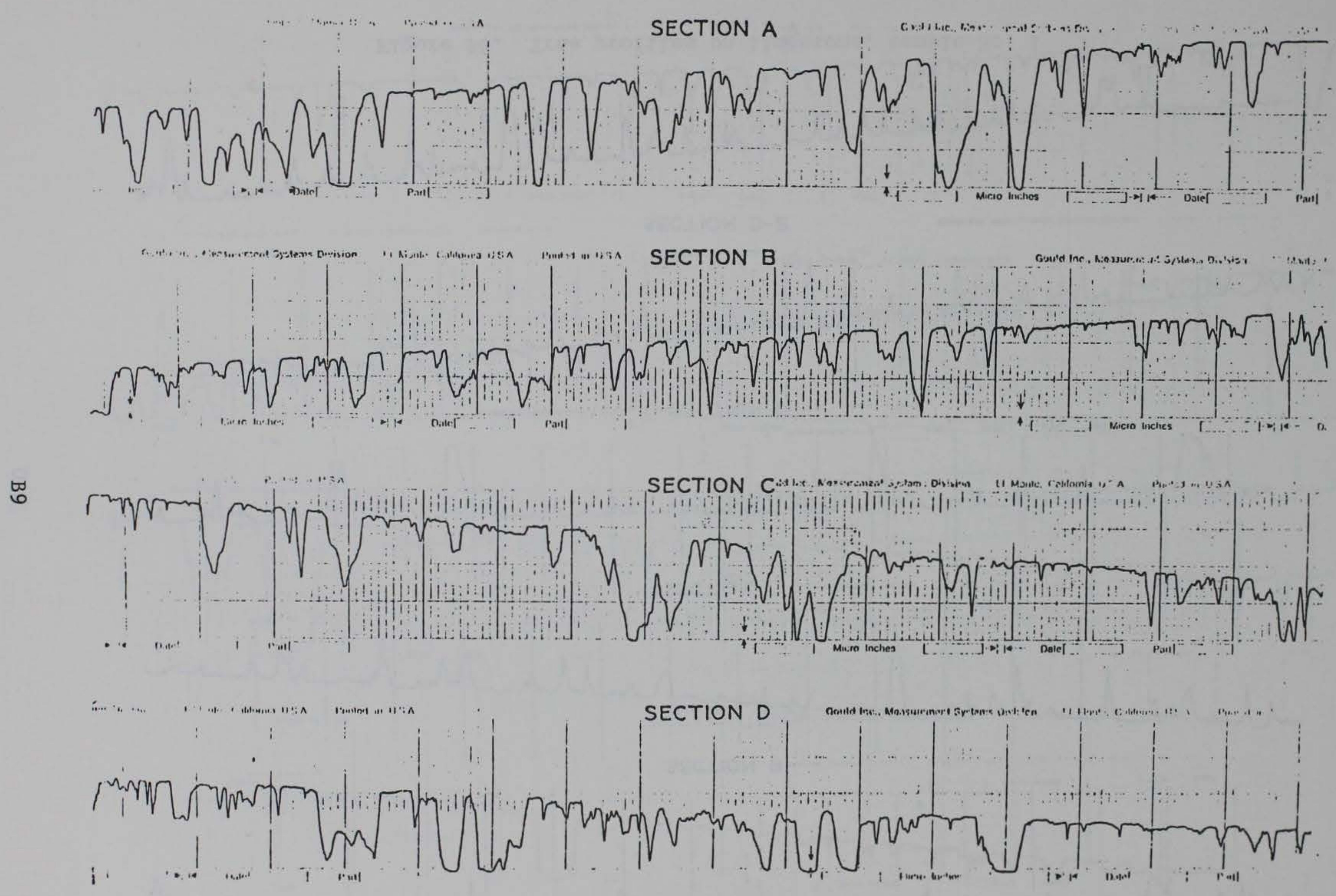

Figure B7. True profiles on sandstone, sample No. 7 

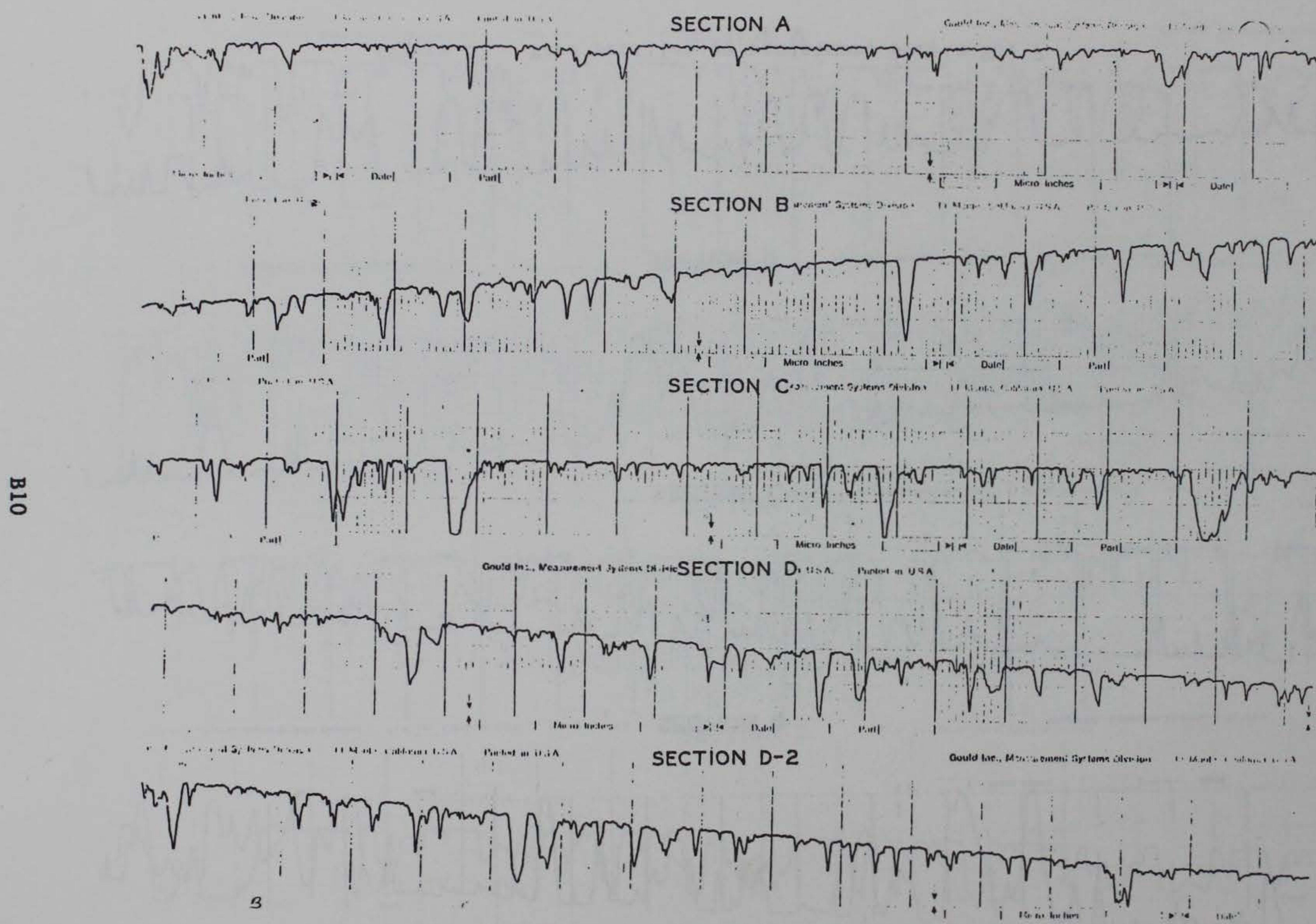

Figure B8. True profiles on limestone, sample No. 1 

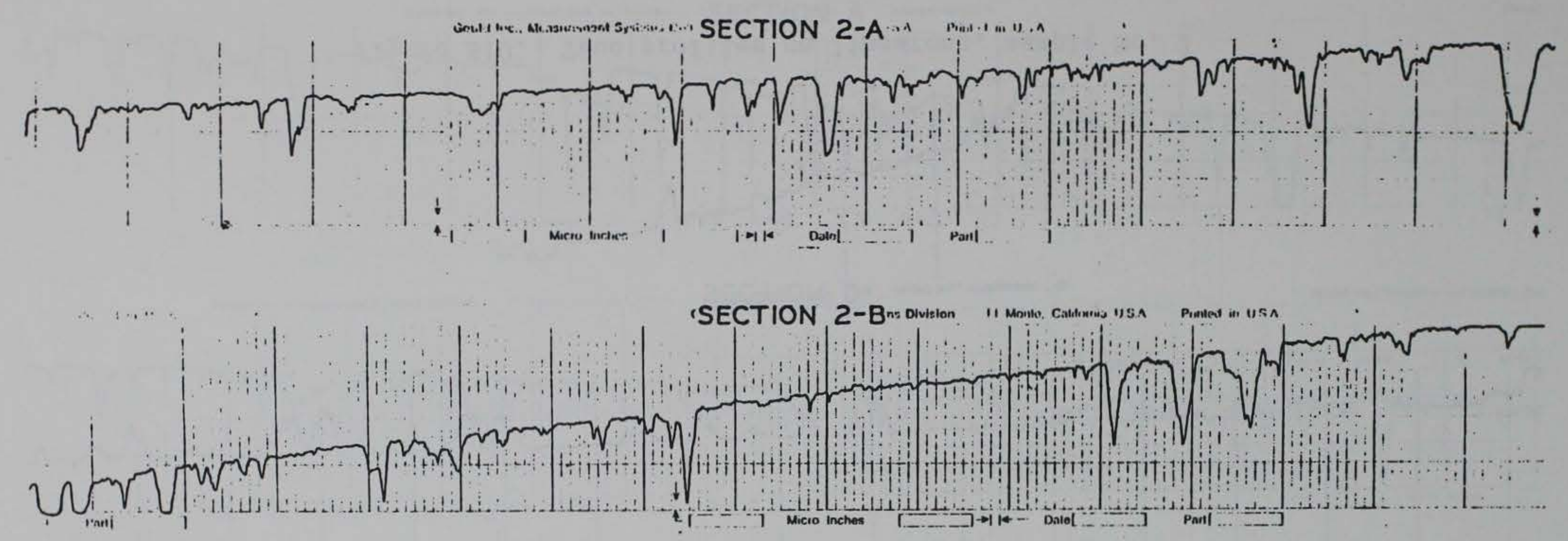

$\stackrel{\varpi 0}{=}$
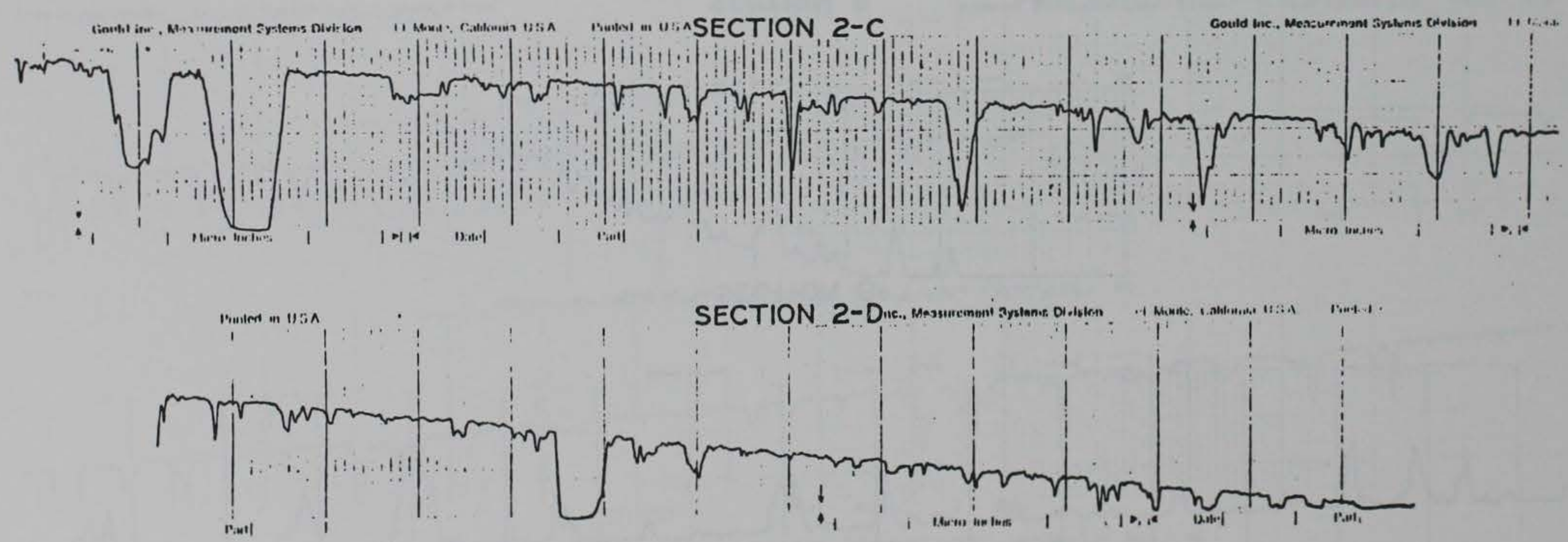

Figure B9. True profiles on limestone, sample No. 2 

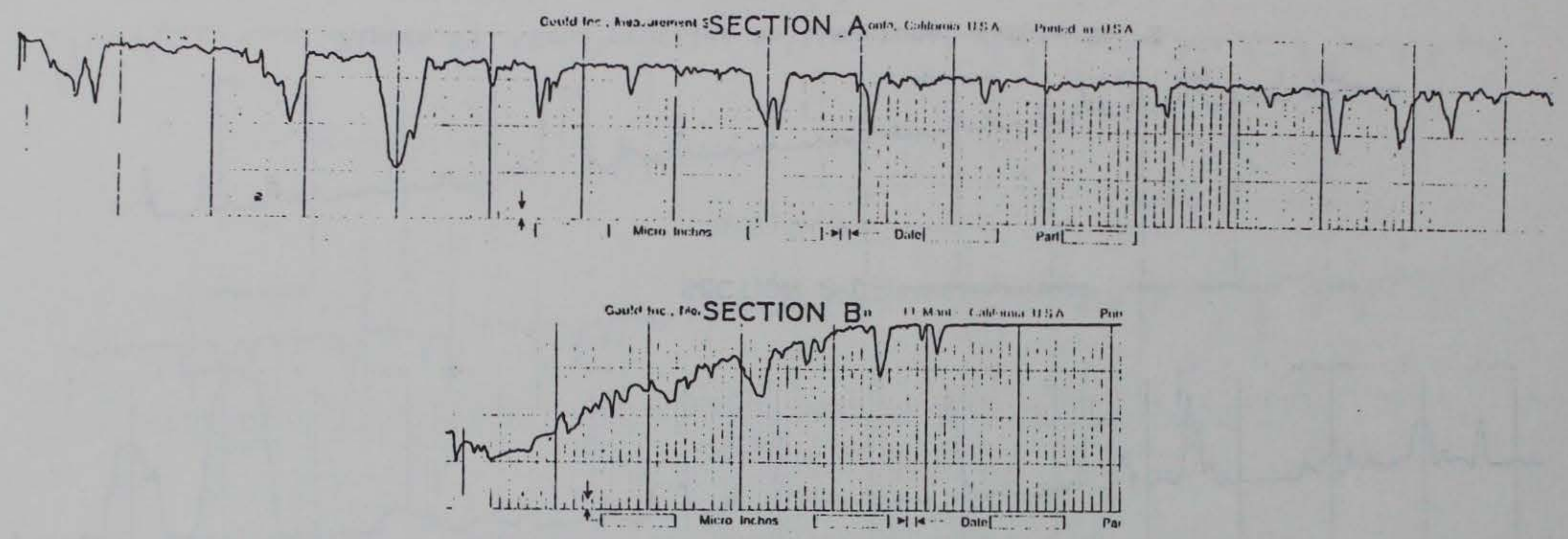

$\stackrel{\varpi}{\sim}$
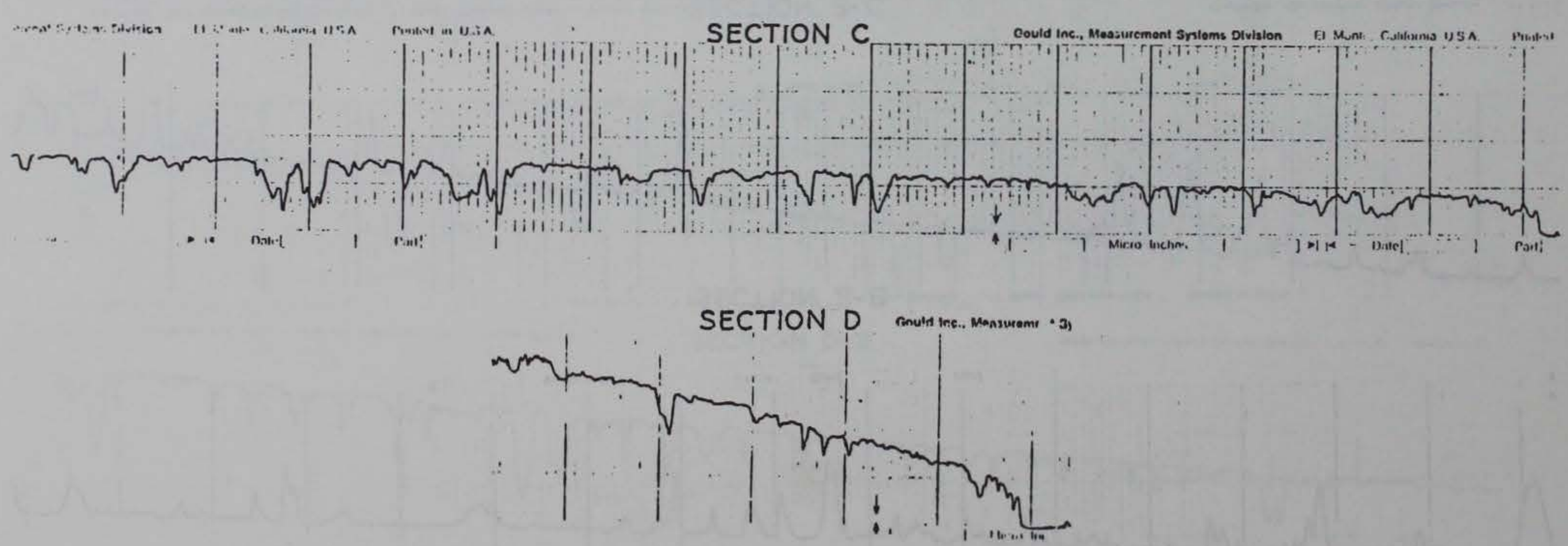

Figure B10. True profiles on limestone, sample No. 3 

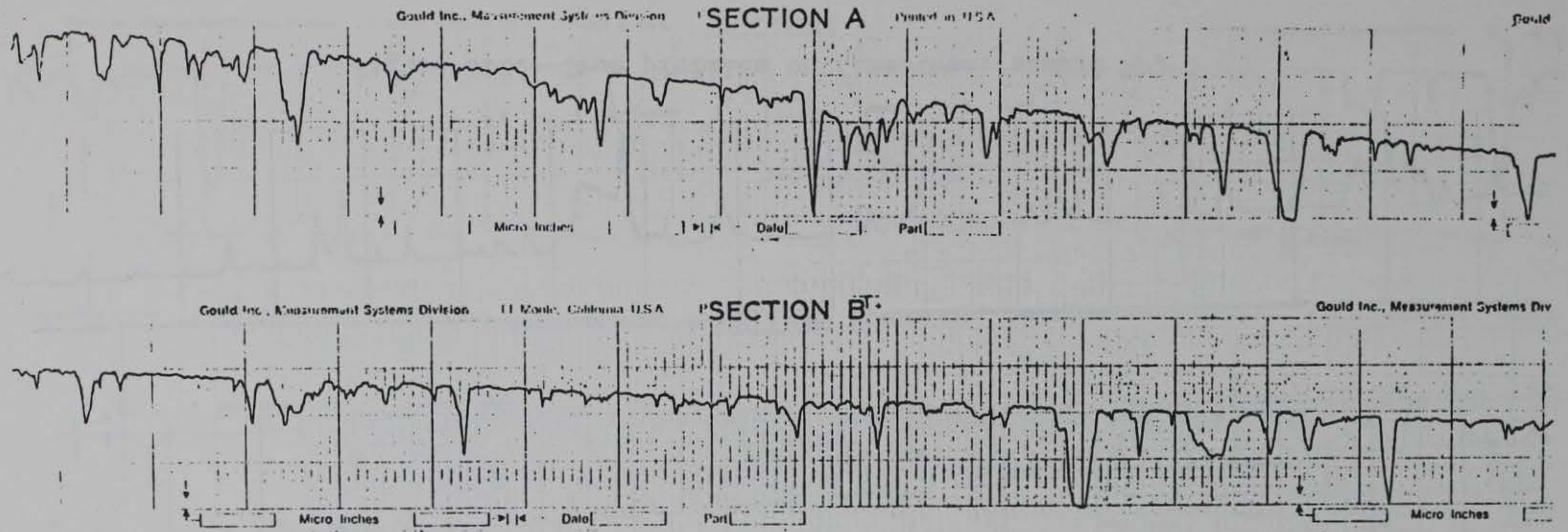

$\stackrel{\varpi}{\omega}$
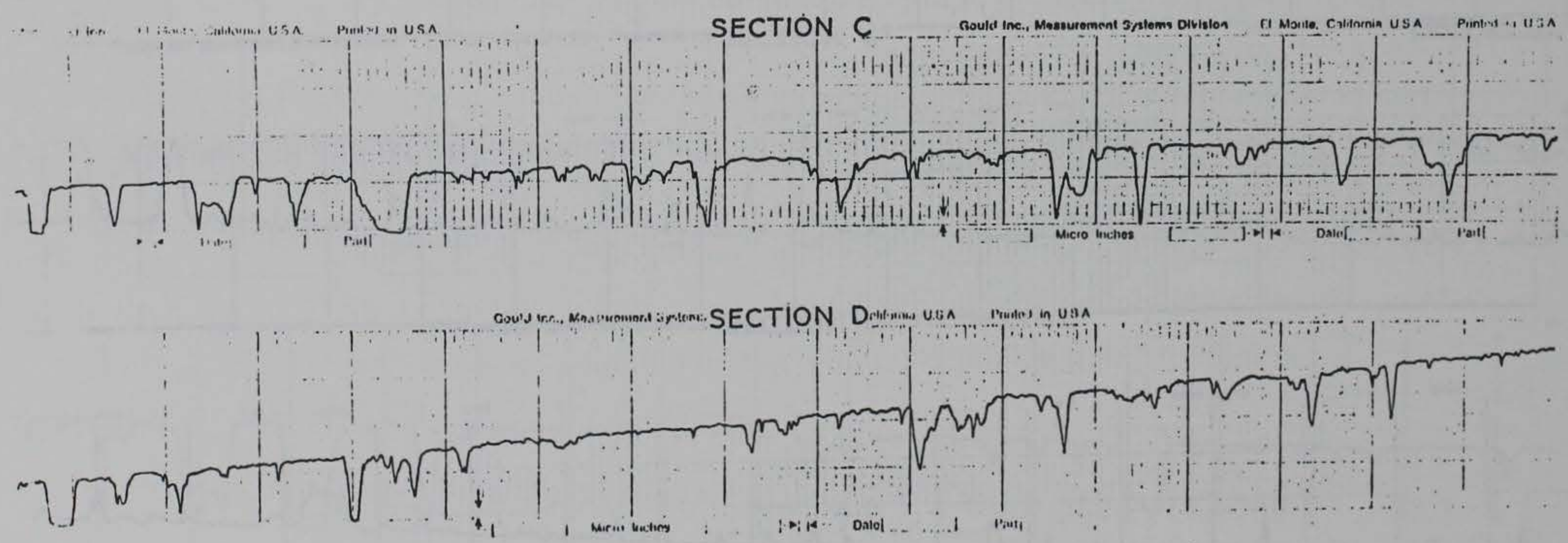

Figure B11. True profiles on limestone, sample No. 4 

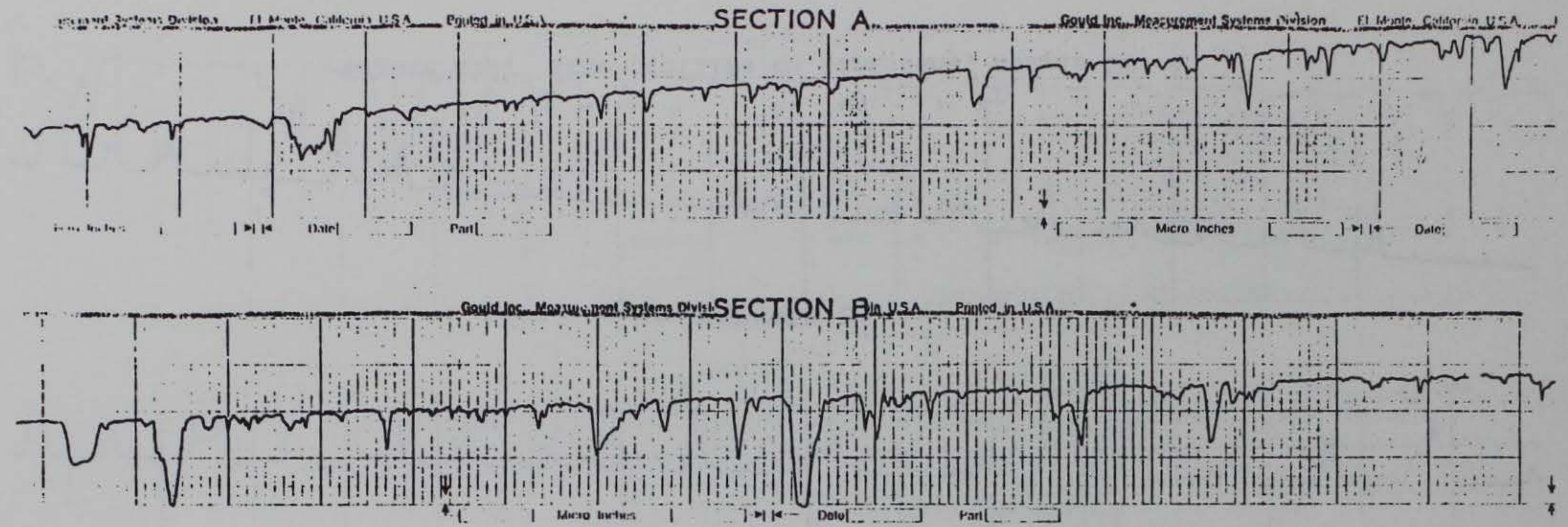

$\underset{\leftarrow}{\stackrel{6}{5}}$
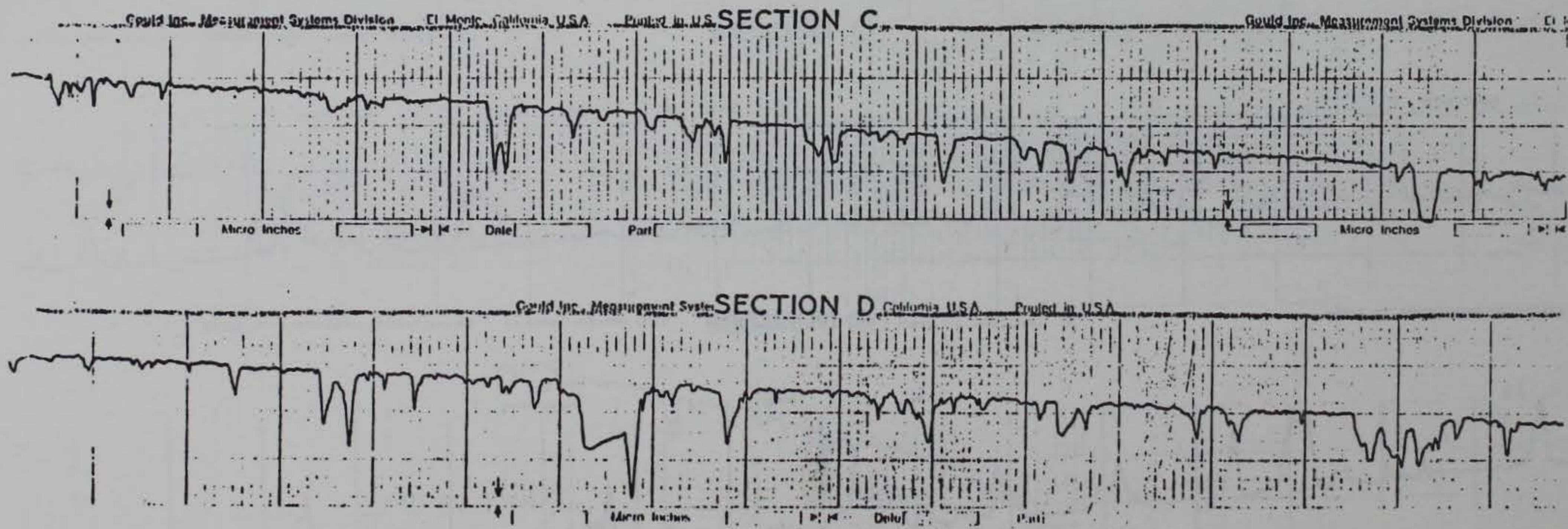

Figure B12. True profiles on limestone, sample No. 5 

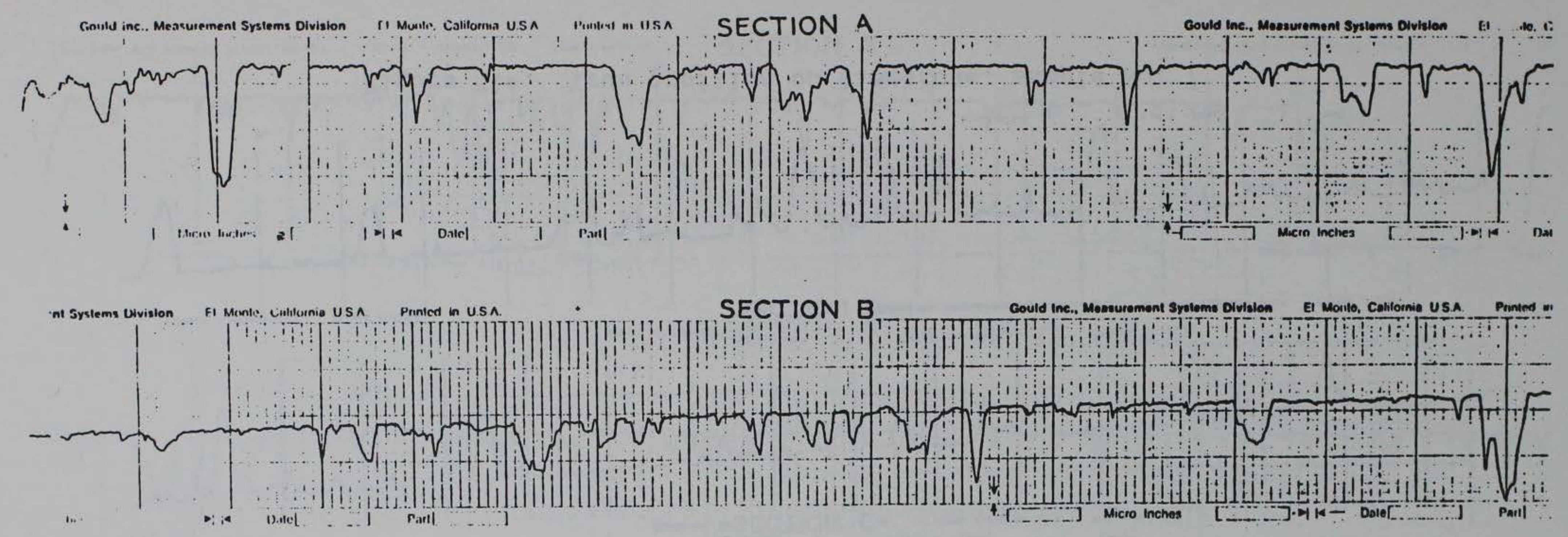

苞
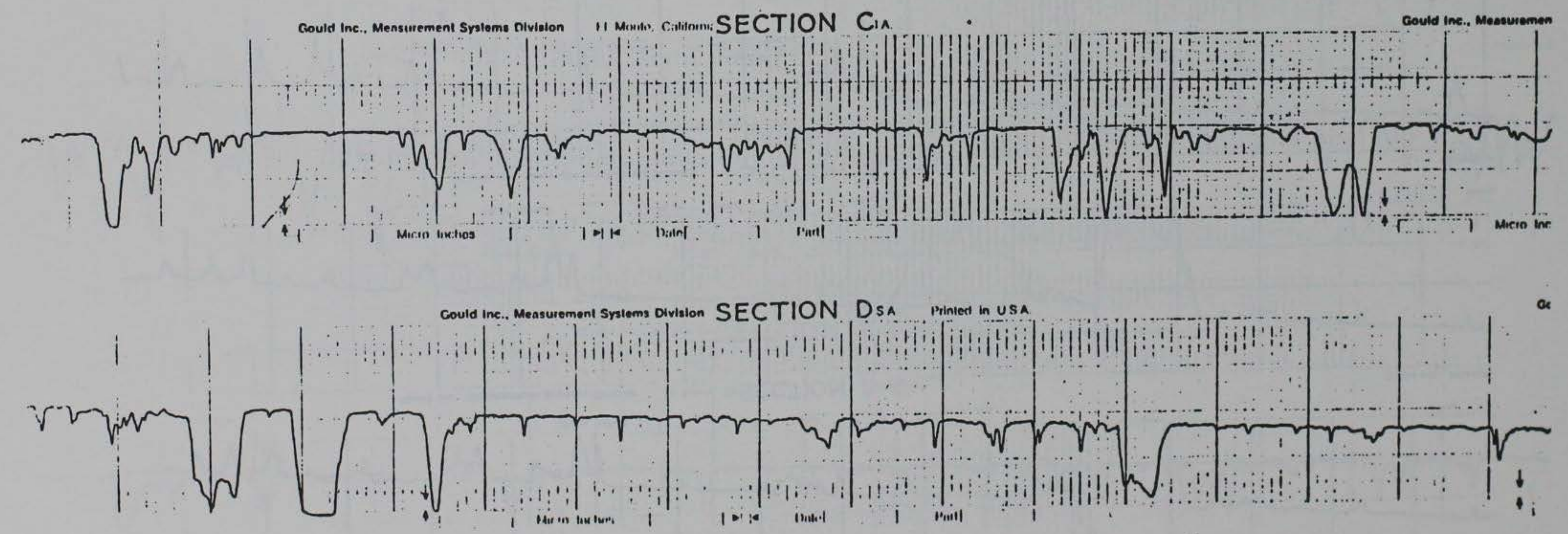

Figure B13. True profiles on limestone, sample No. 6 

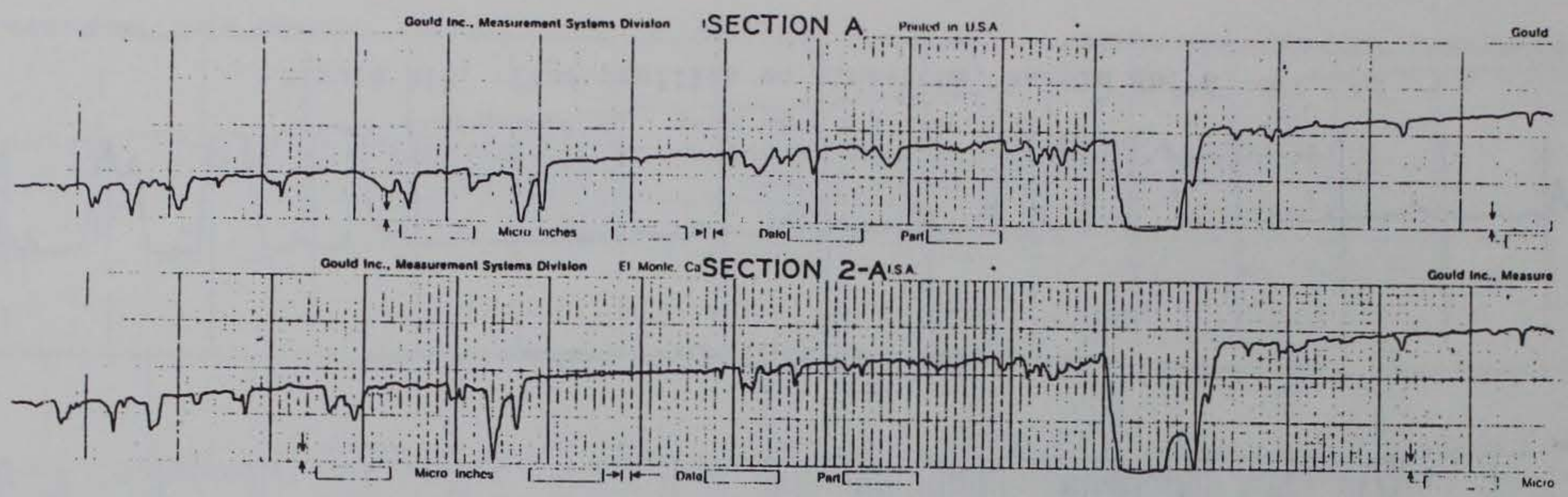

could inc., Mesong

ESECTION B Printed in USA
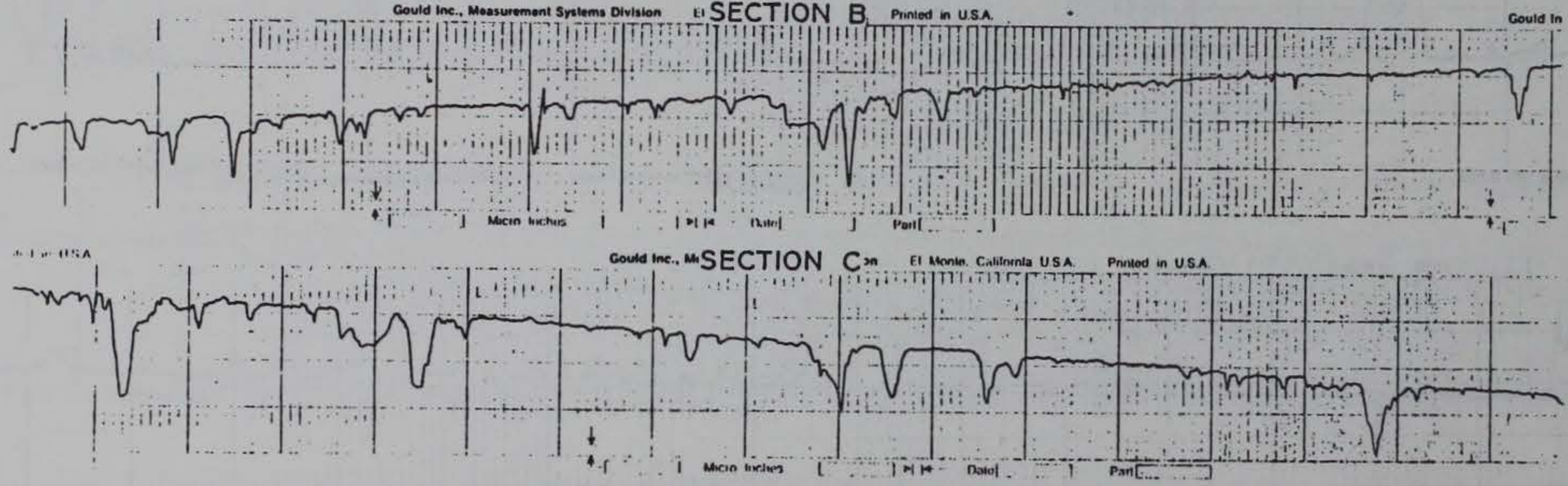

Govid inc., mSECTION Con El Monne. Canthonta USA Promod in USA

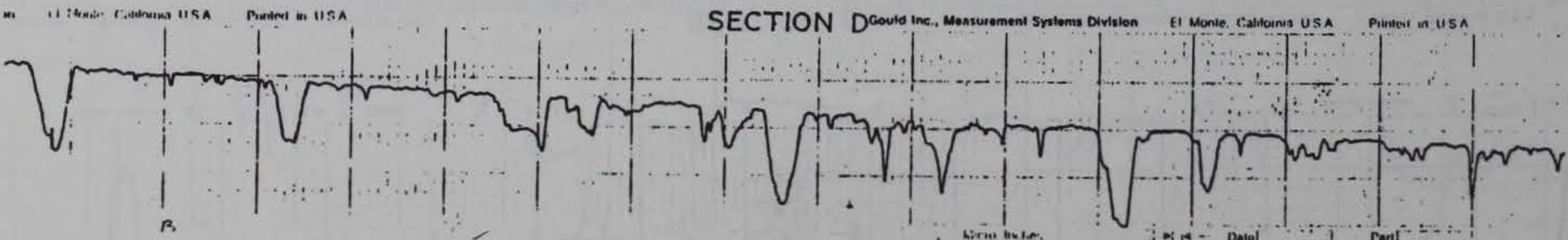

Figure B14. True profiles on limestone, sample No. 7 

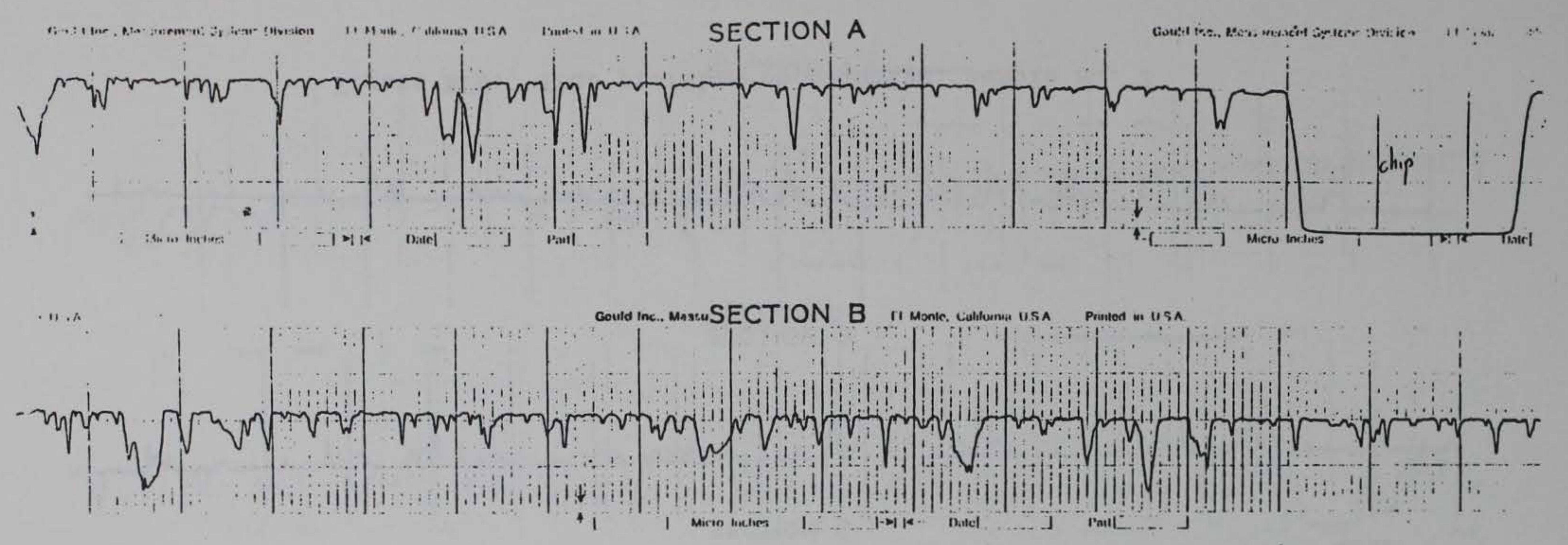

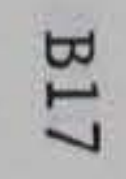
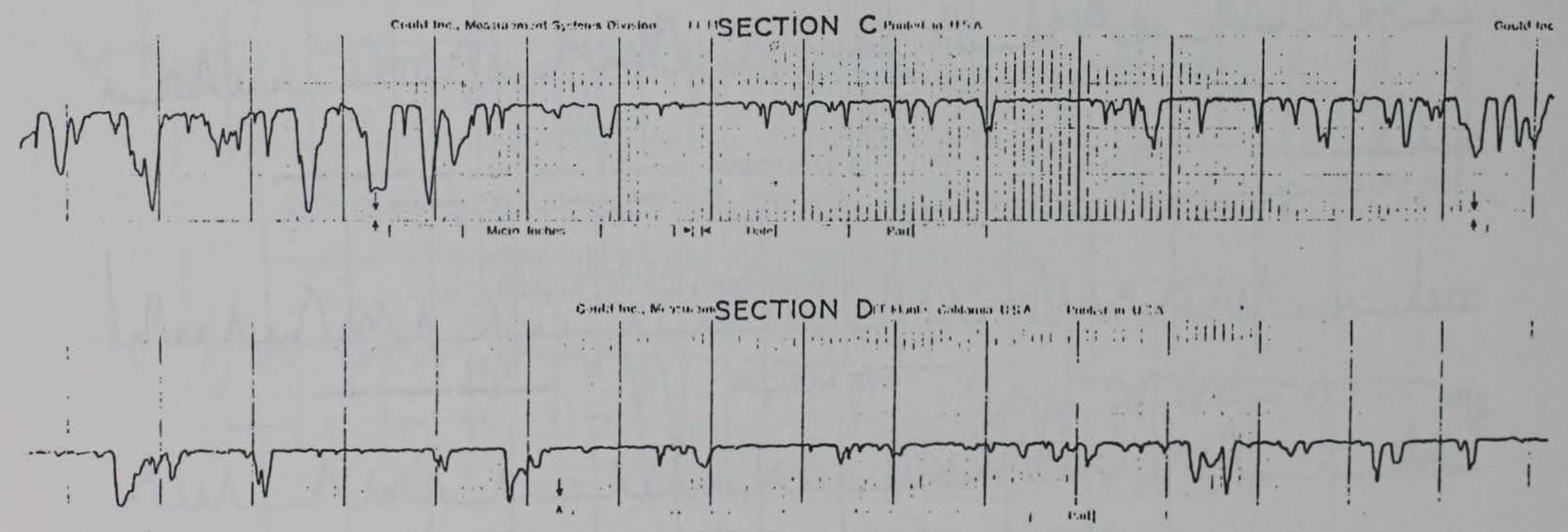

Figure B15. True profiles on dolomite, sample No. 1 


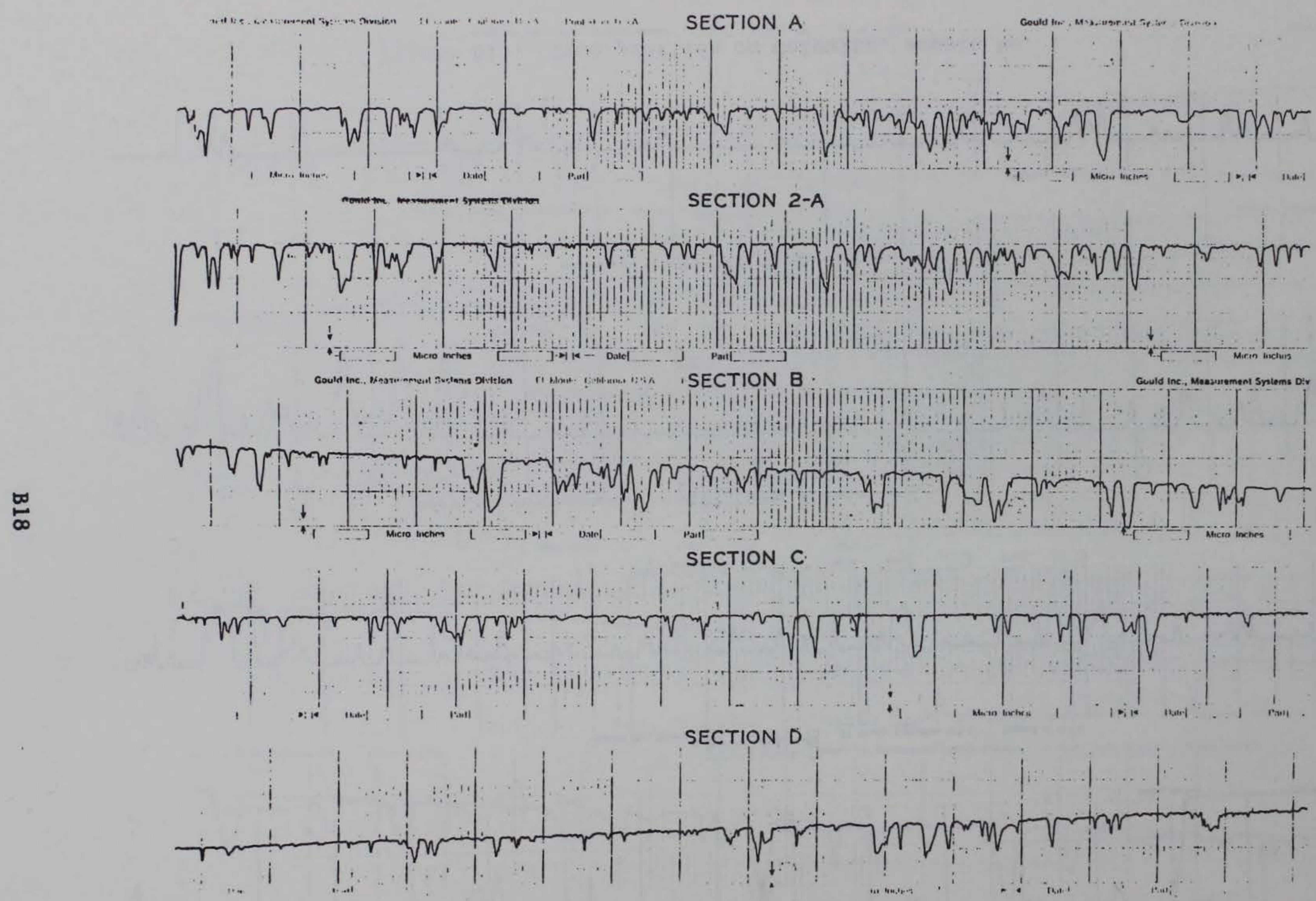

Figure B16. True profiles on dolomite, sample No. 2 

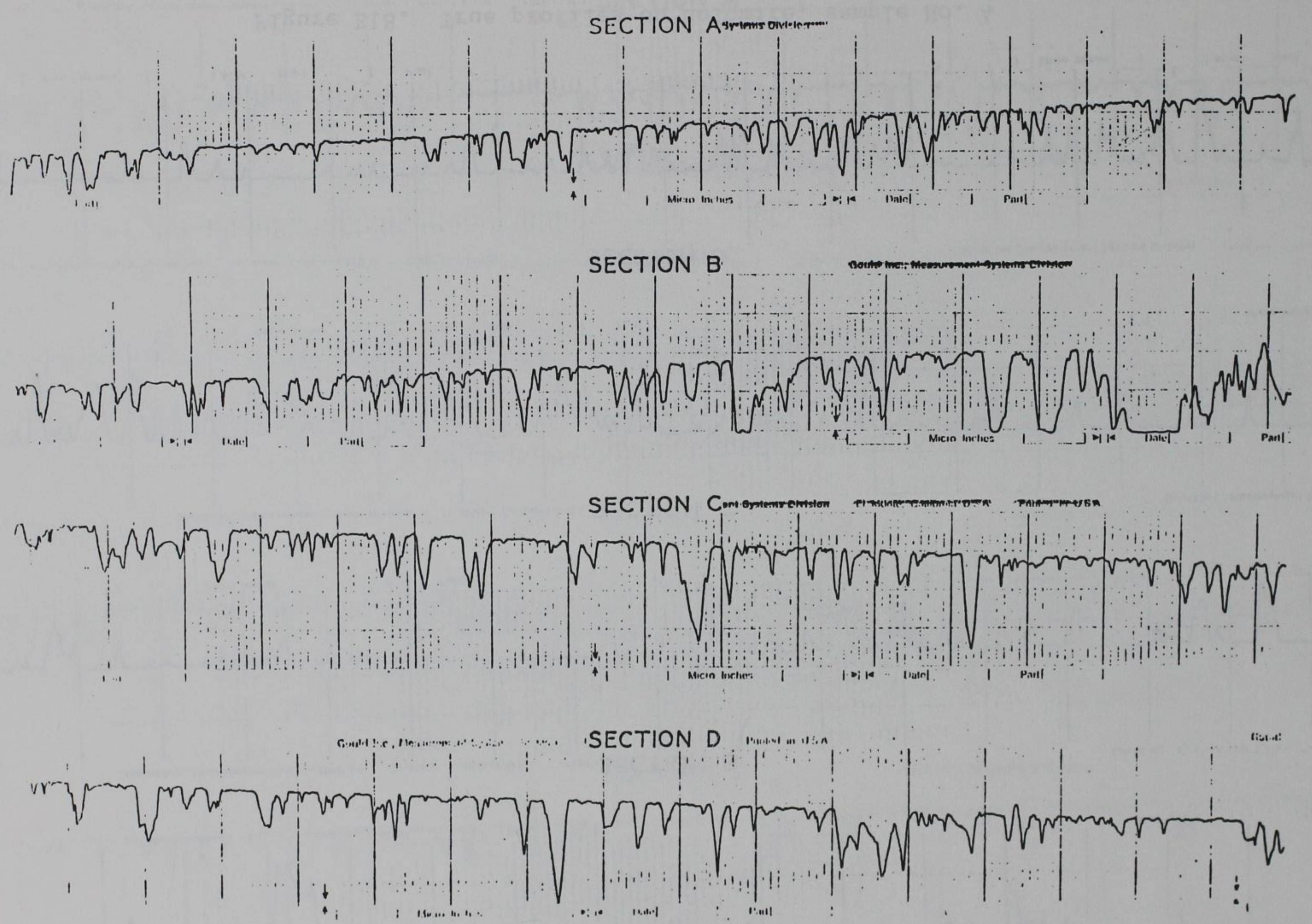

Figure B17. True profiles on dolomite, sample No. 3 

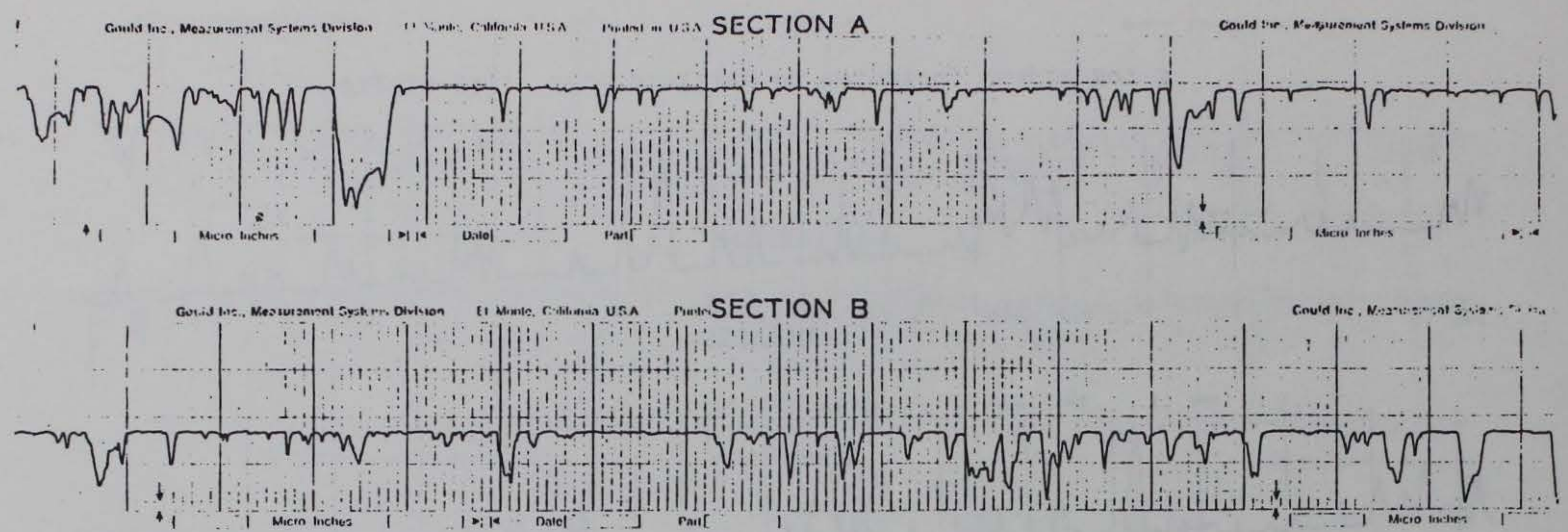

苑
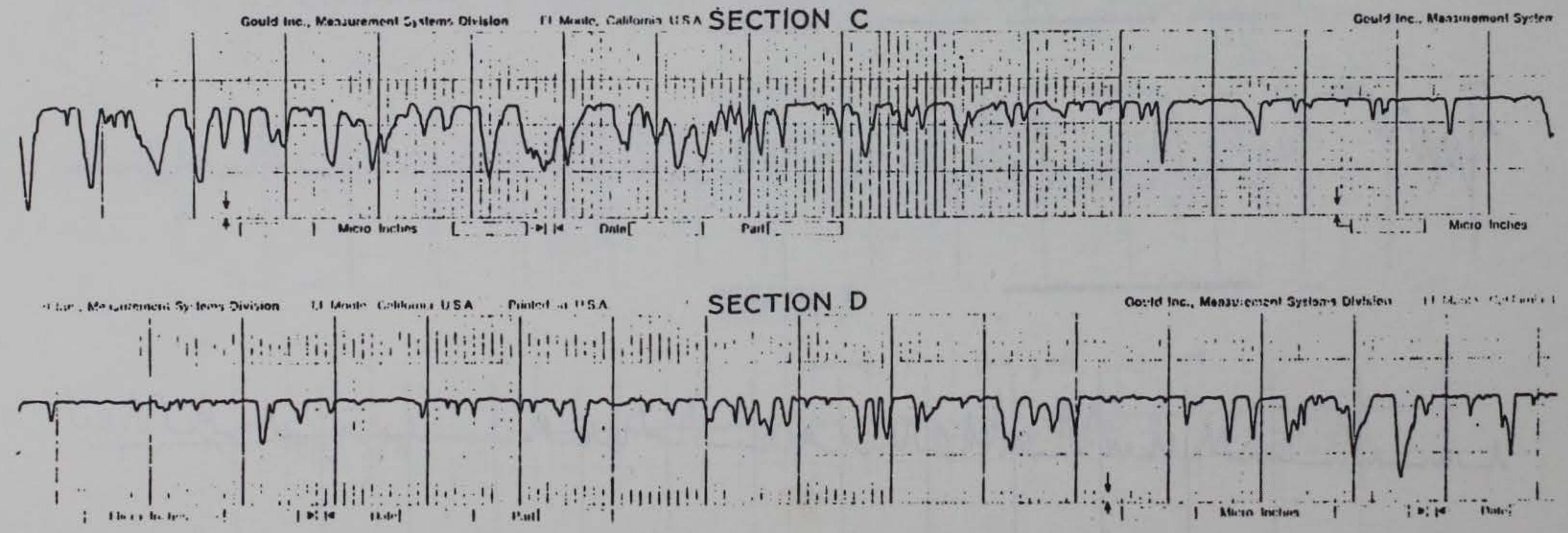

Figure B18. True profiles on dolomite, sample No. 4 

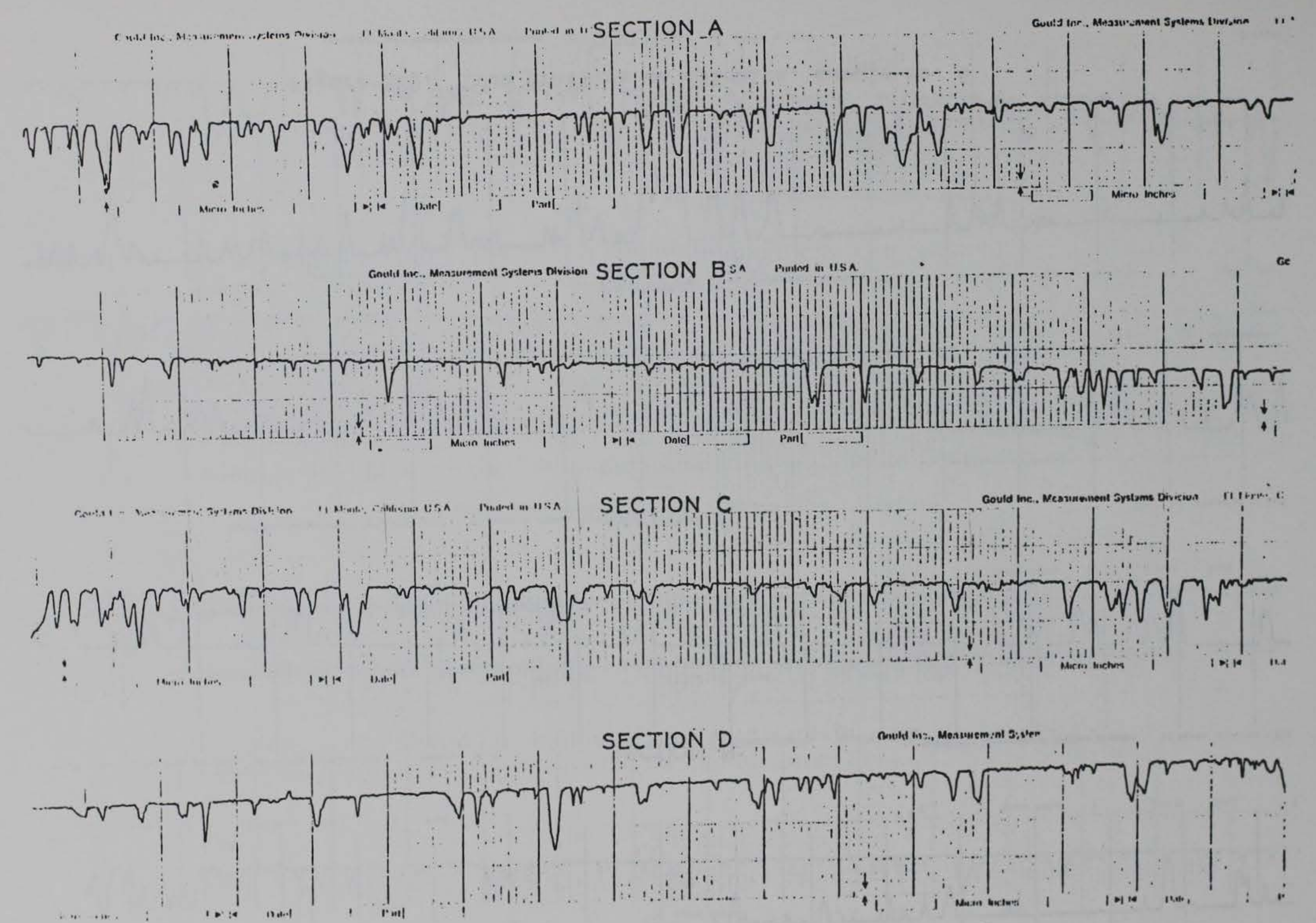

Figure B19. True profiles on dolomite, sample No. 5 

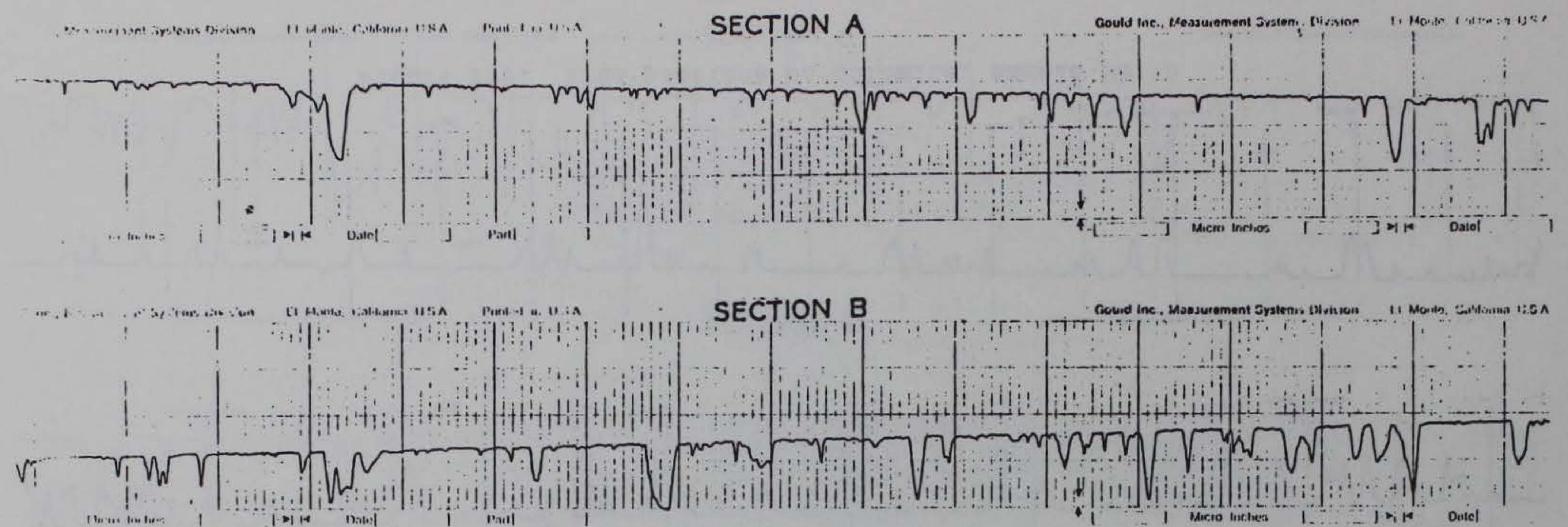

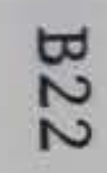
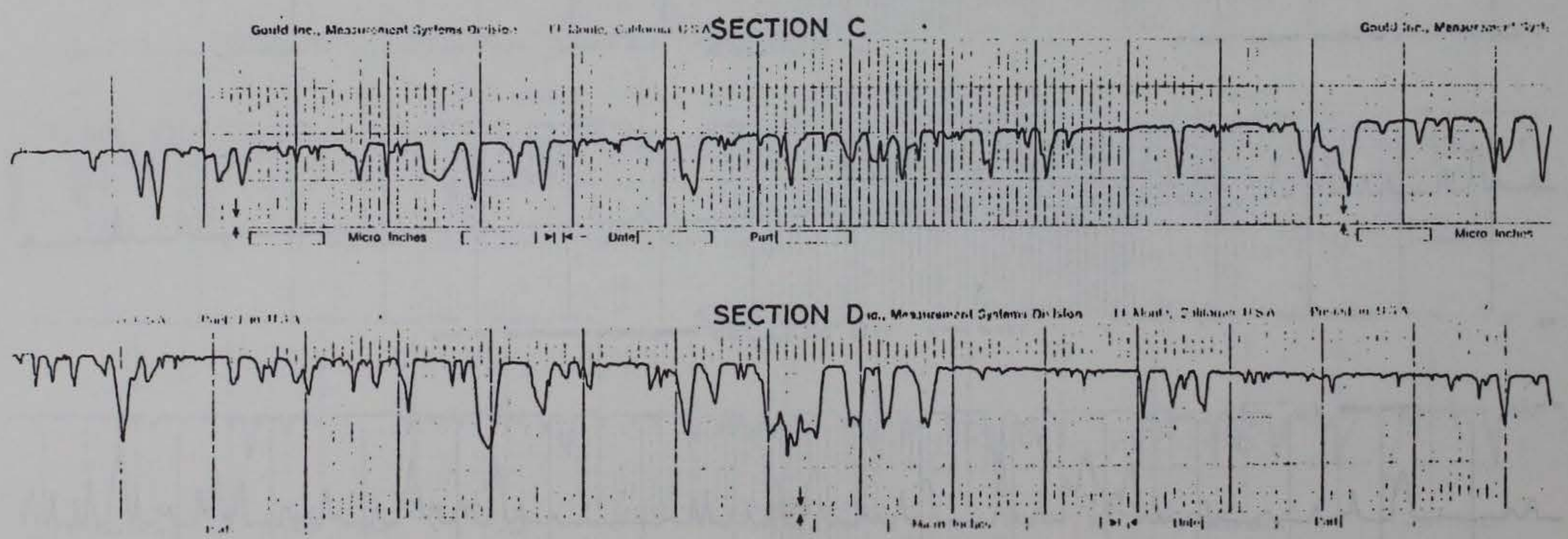

Figure B20. True profiles on dolomite, sample No. 6 

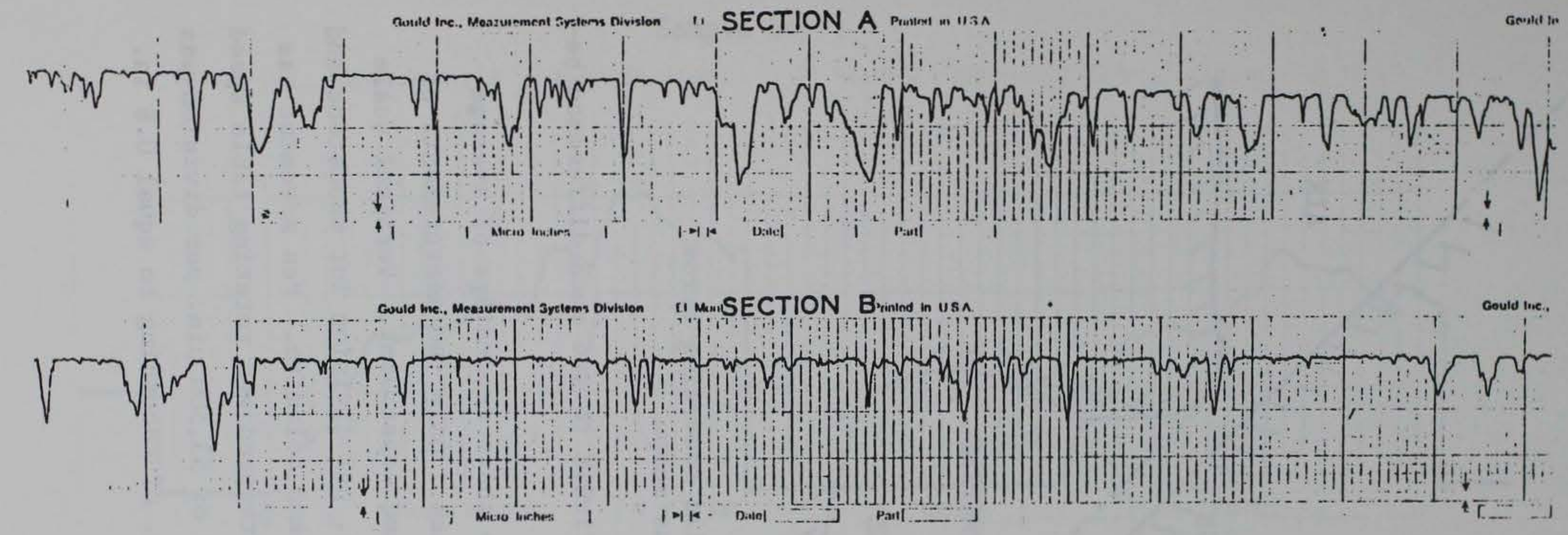

$\underset{\omega}{\mathscr{\omega}}$
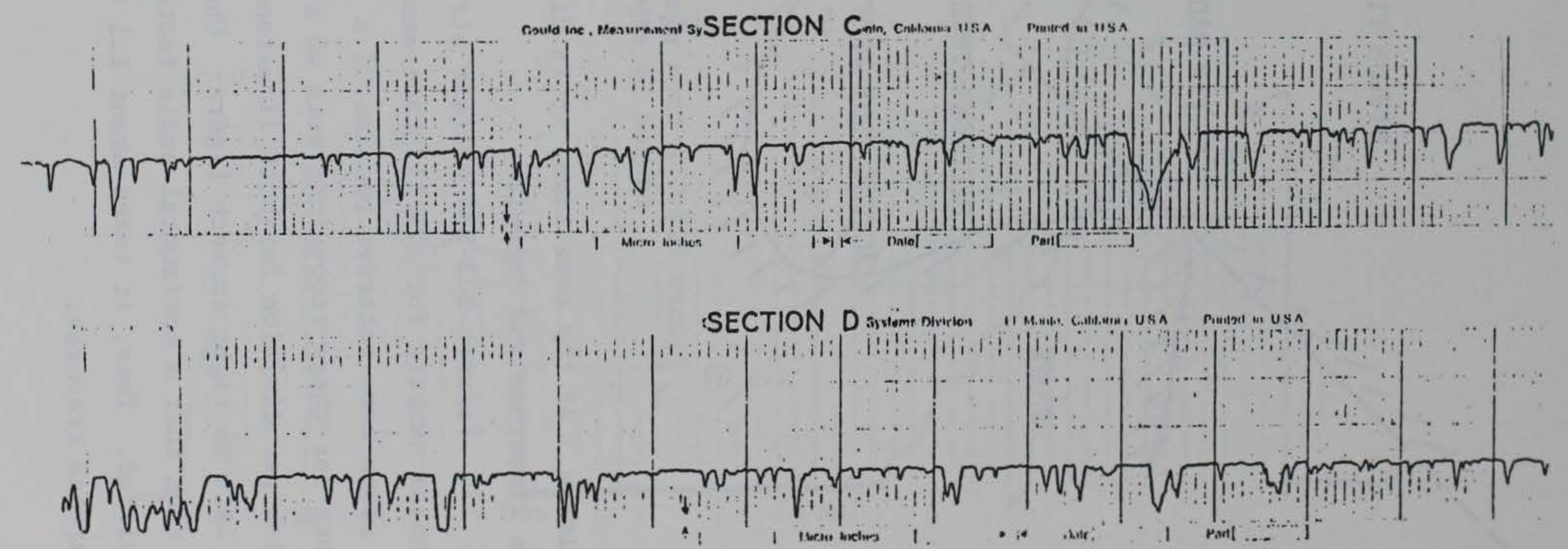

Figure B21. True profiles on dolomite, sample No. 7 


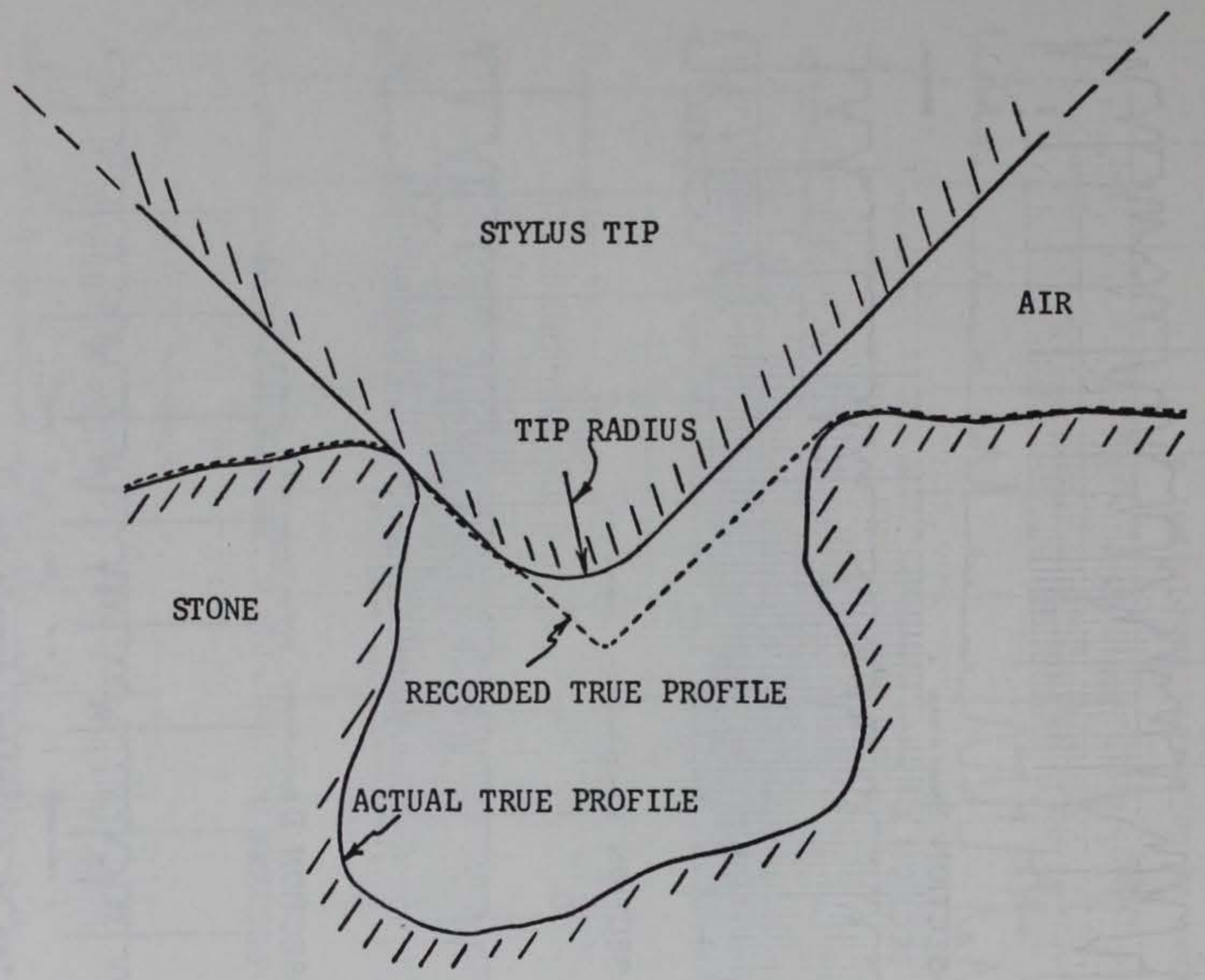

Figure B22. A true profile recording error caused by stylus shape

specimens. At the same time, it is difficult to see much difference between limestone and dolomite.

12. Figures B23-B35 contain strip chart recordings of average roughness numbers for all 21 stone samples. Only two measurements of each stone were recorded because of a time constraint. Vertical scale factors for these recordings were $40 \mu \mathrm{in}$. per division for sandstone and 20 min. per division for both limestone and dolomite. Pen movement was from left to right in each figure. Chart speed and rotating table speed were such that a horizontal scale factor of $53,500 \mu$ in. per division was calculated. Thus, it takes about $1.1 \mathrm{in}$. of recording to equal 0.6 in. of surface traverse. 
Sample No. 1

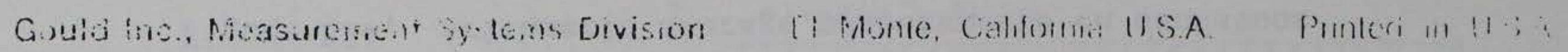

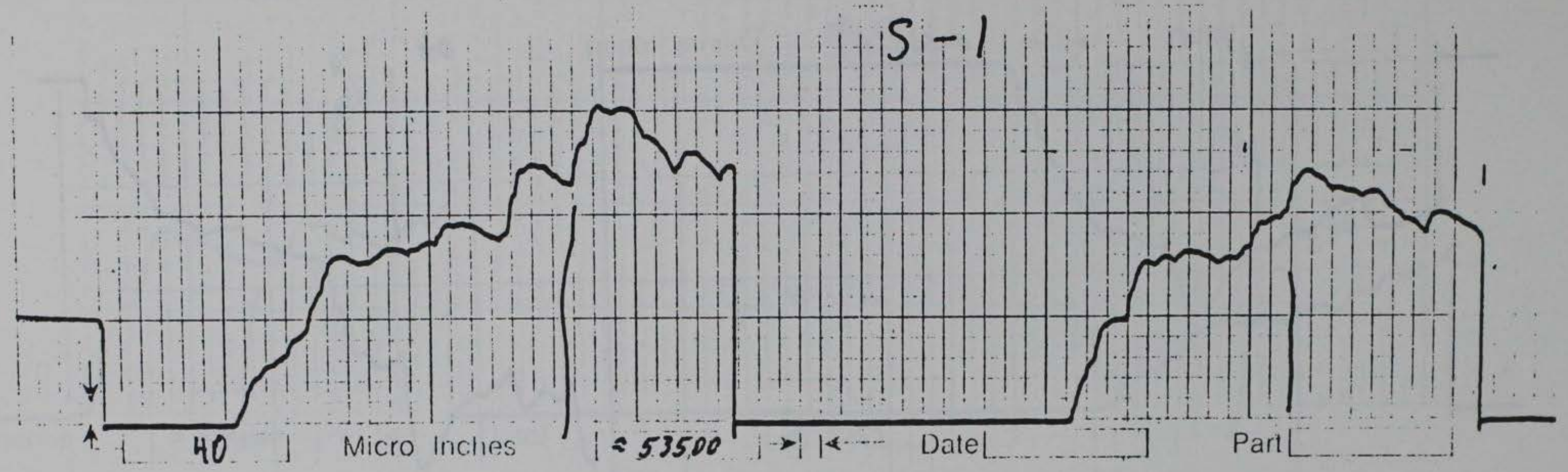

Sample No. 2

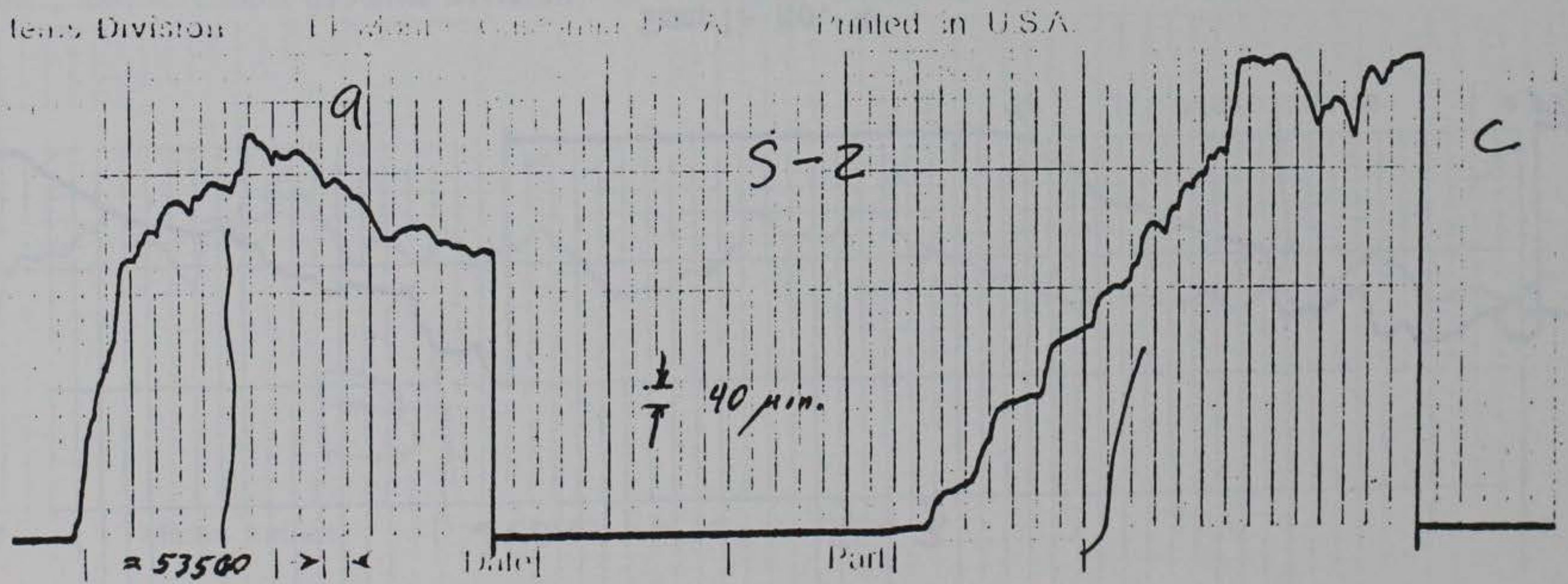

Figure B23. Arithmetic average measurements on sandstone 
Sample No. 3

Cotild ne.. Measurement Syst: 1,1 .

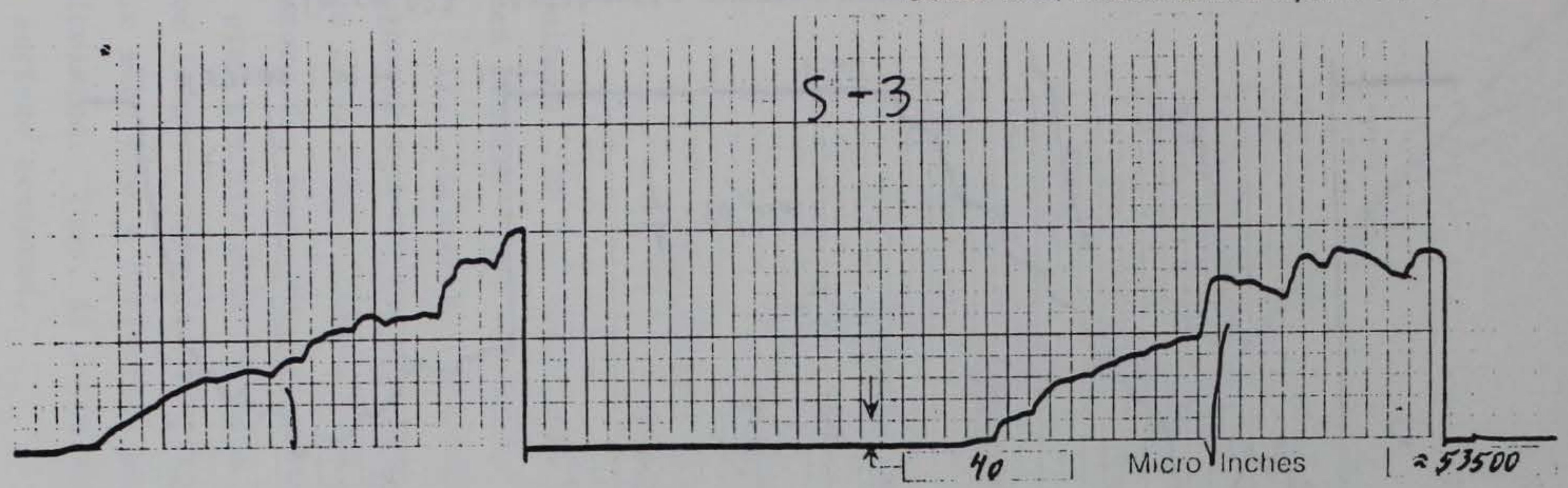

Sample No. 4

$\stackrel{\mathscr{N}}{\sim}$

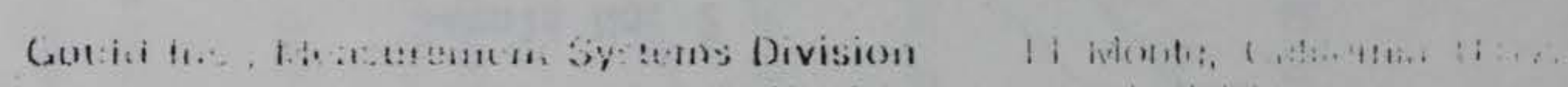

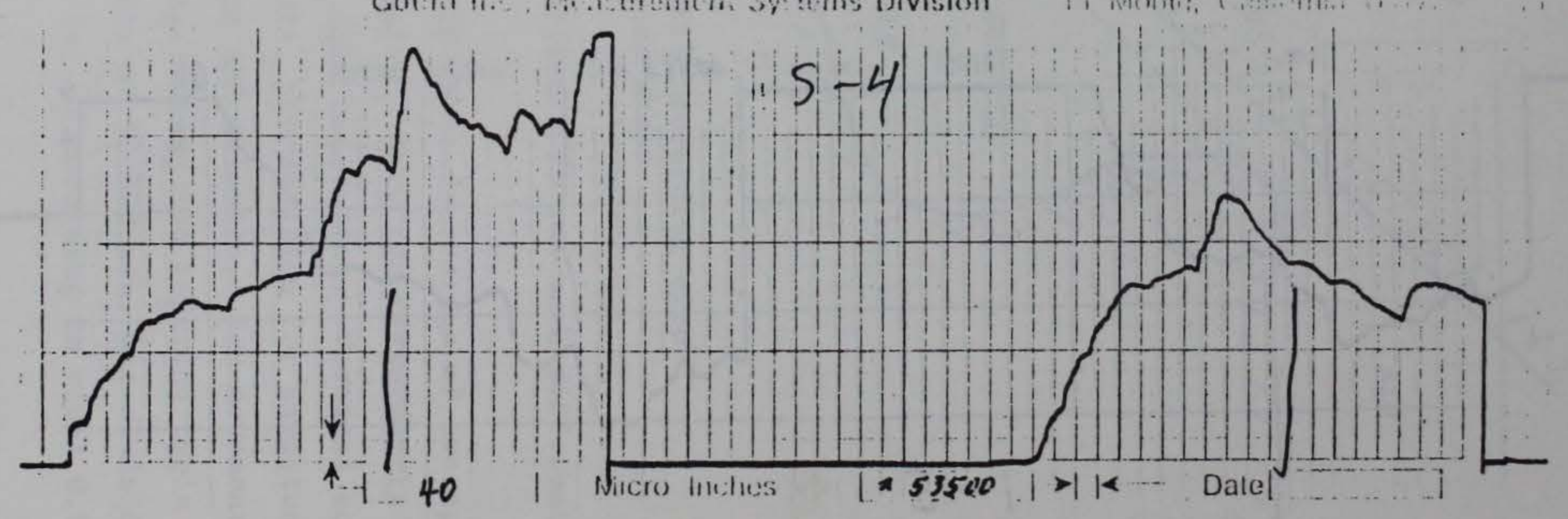

Figure B24. Arithmetic average measurements on sandstone 
Sample No. 5

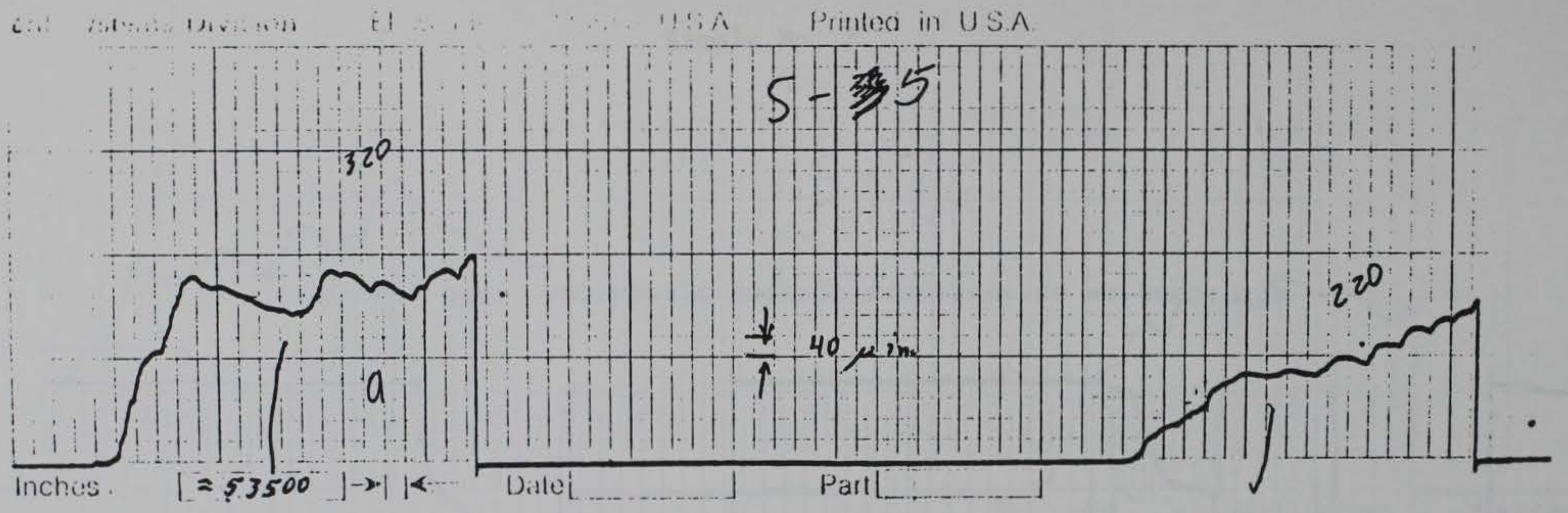

Sample No. 5

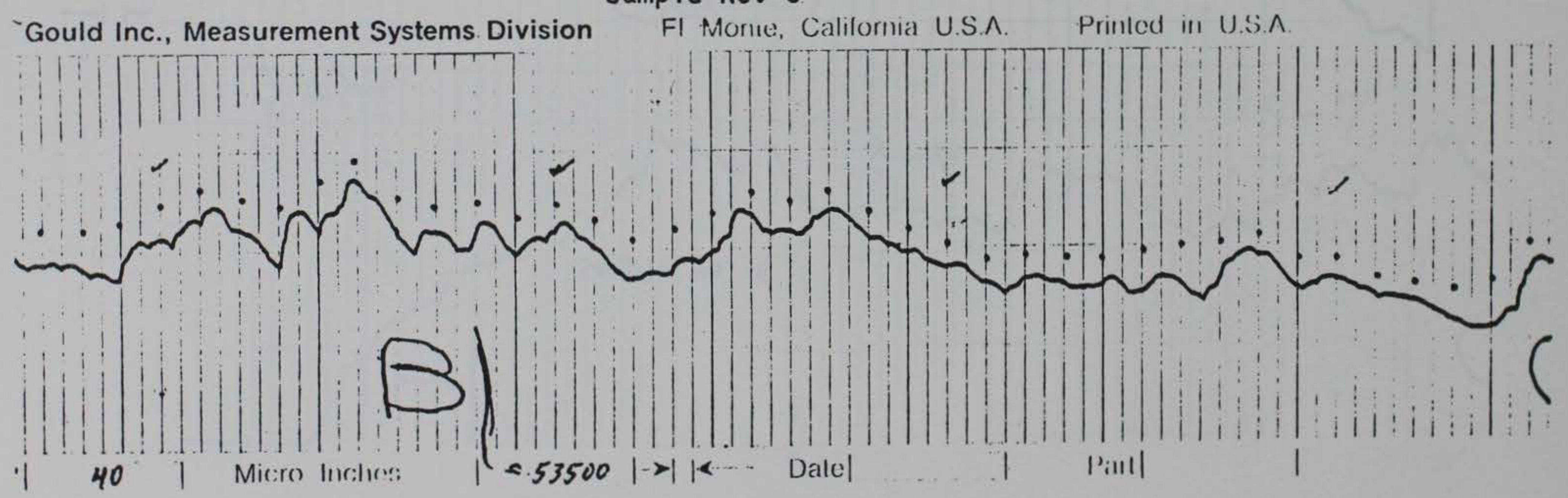

Figure B25. Arithmetic average measurements on sandstone 
Sample No. 6

$\underset{\infty}{\infty}$

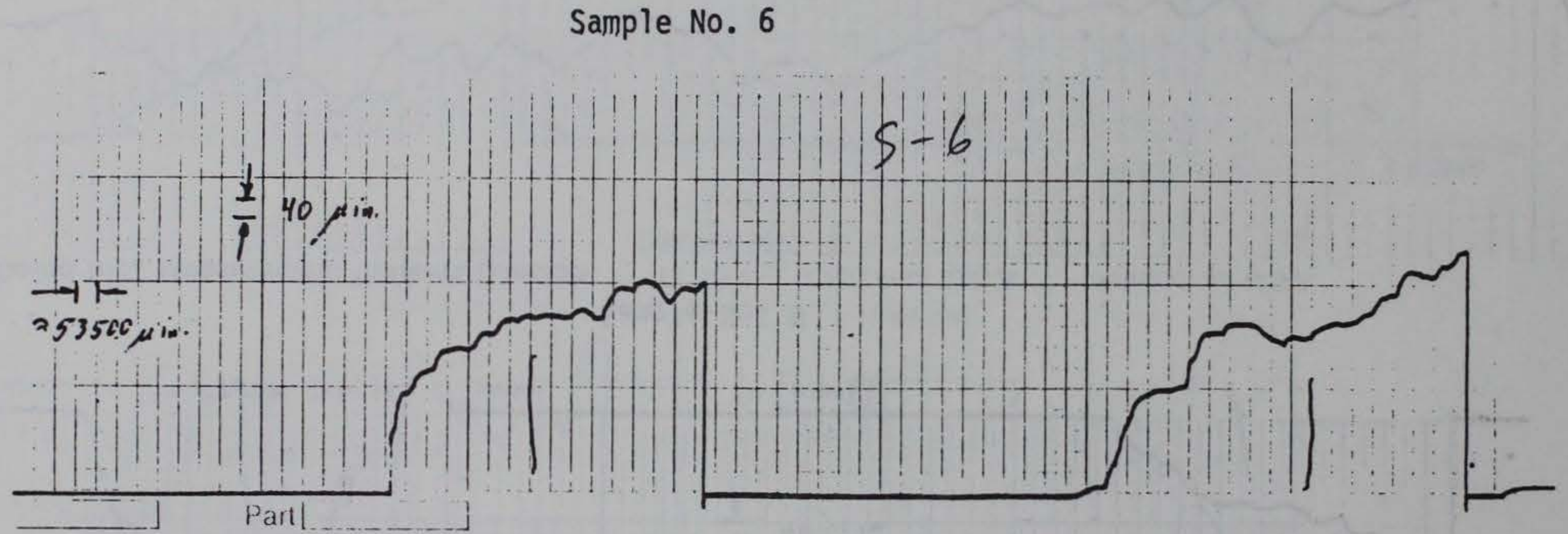

Figure B26. Arithmetic average measurements on sandstone 
Sample No. 7

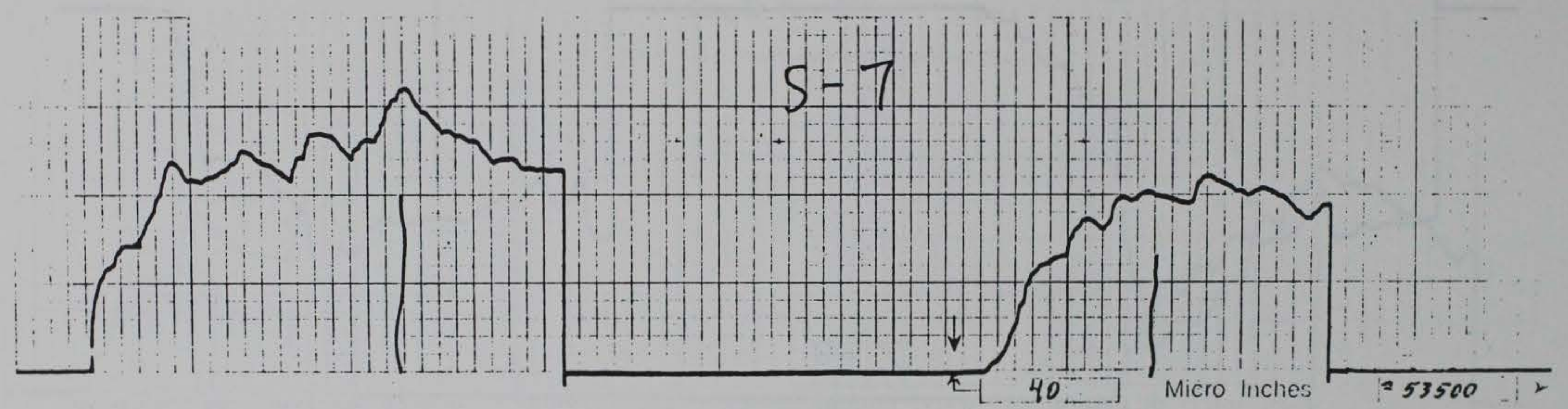

Sample No. 7

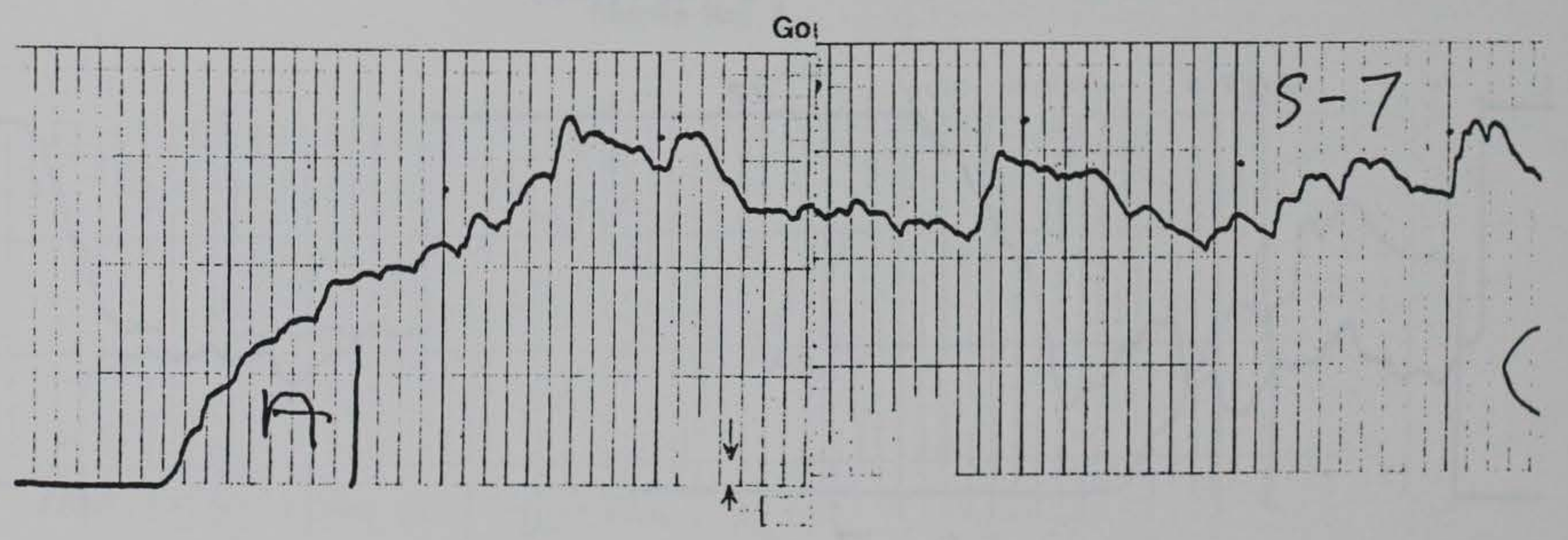

Figure B27. Arithmetic average measurements on sandstone 
Sample No. 1

Could Ine., Hedsurement Systems Dir....

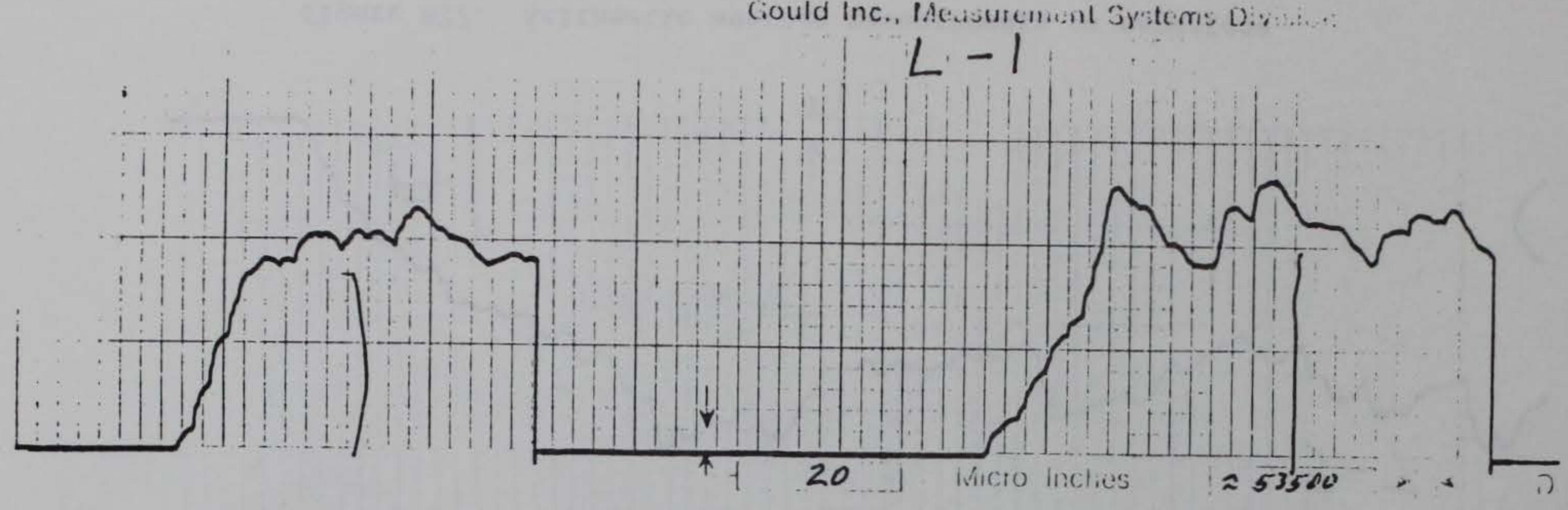

$\underset{\omega}{\infty}$

Sample No. 2

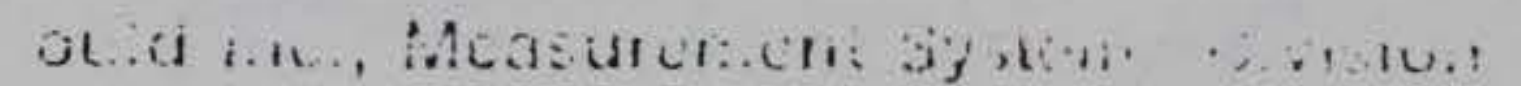

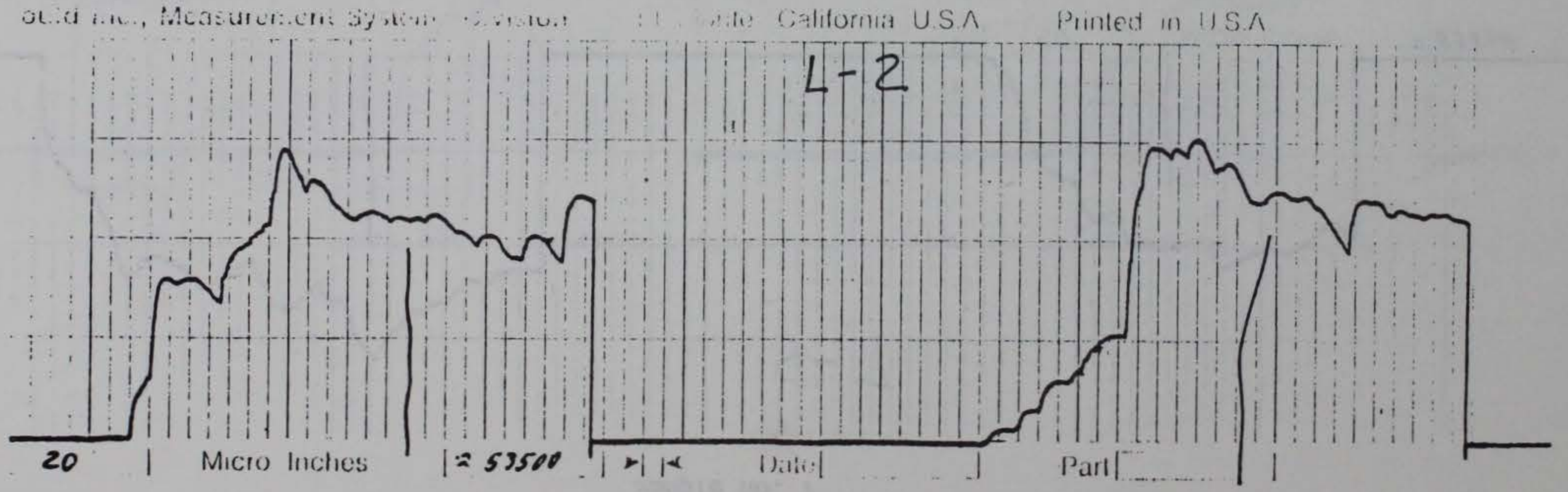

Figure B28. Arithmetic average measurements on limestone 
Sample No. 3

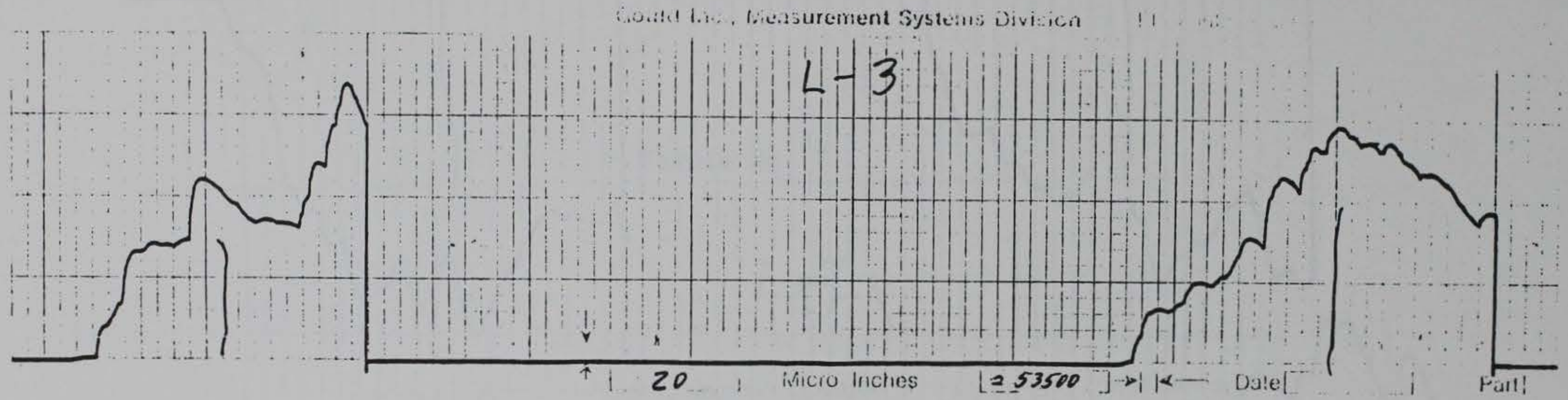

Samnile No. 4

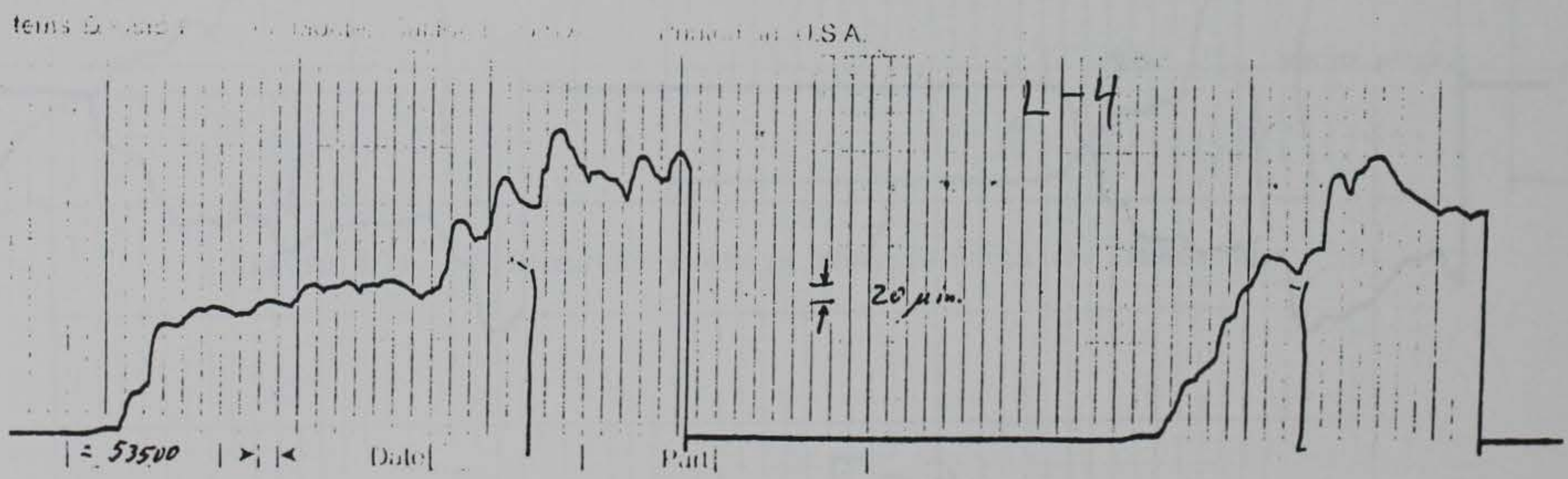

Figure B29. Arithmetic average measurements on limestone 
Sample No. 5

Gould lac., Naser...

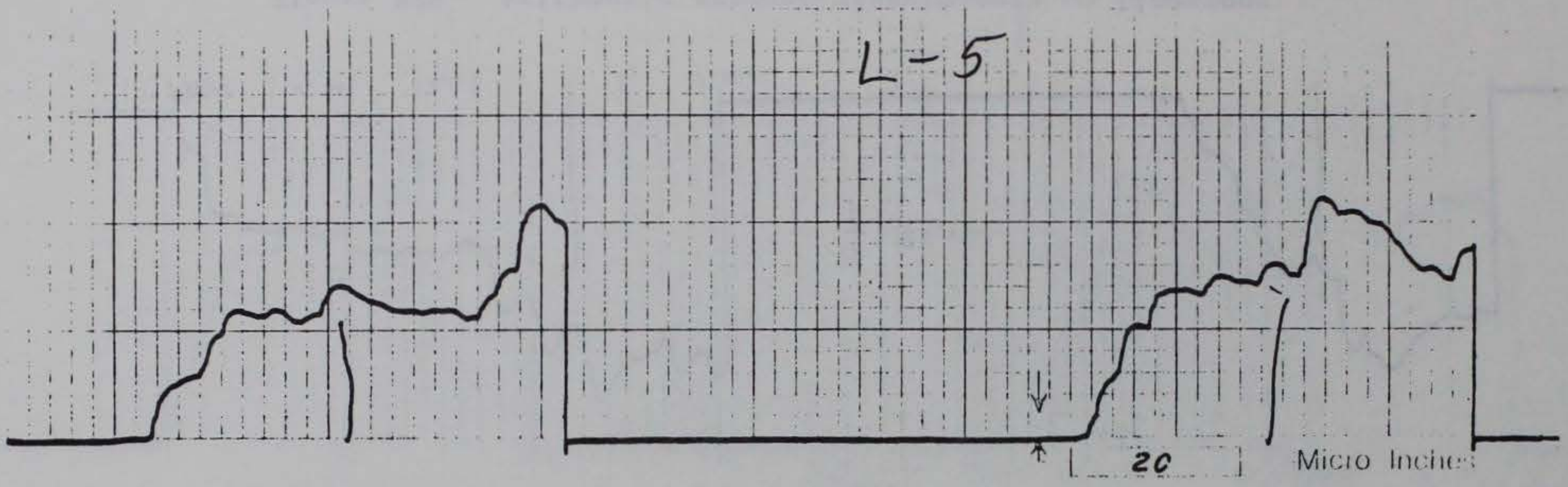

$\underset{\sim}{\varpi}$

Sample No. 6

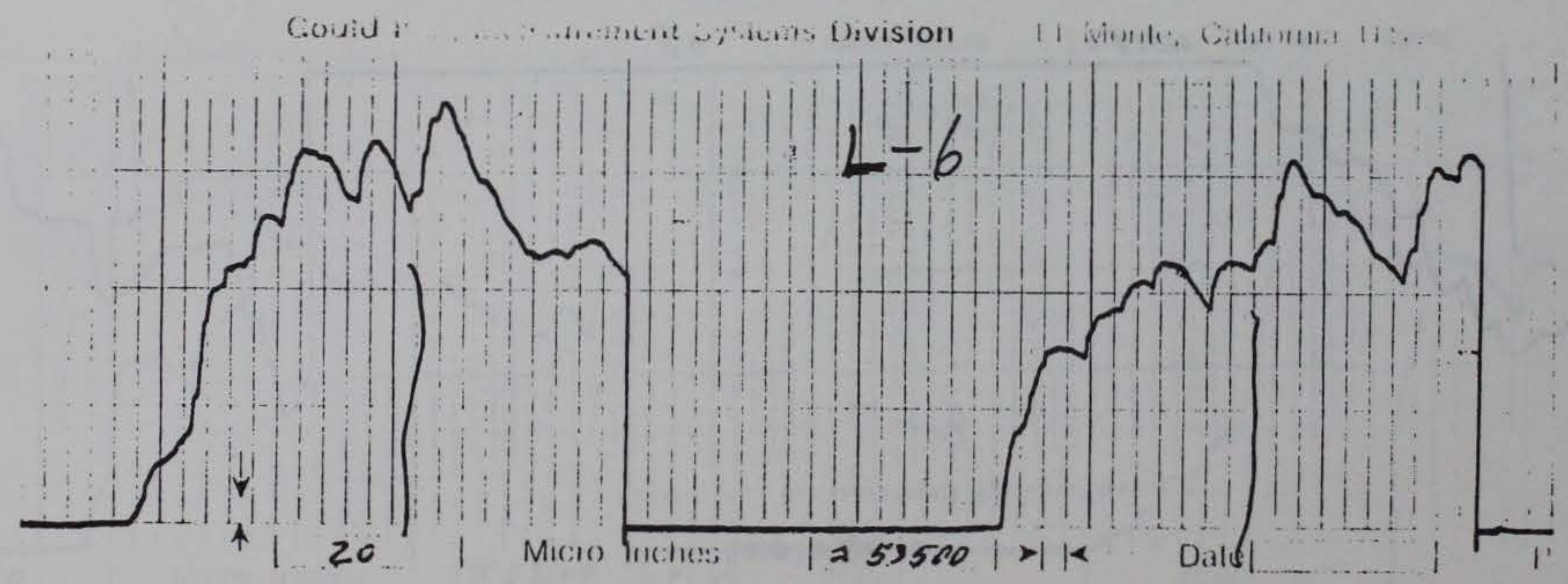

Figure B30. Arithmetic average measurements on limestone 
Sample No. 7

$\underset{\omega}{\varpi}$

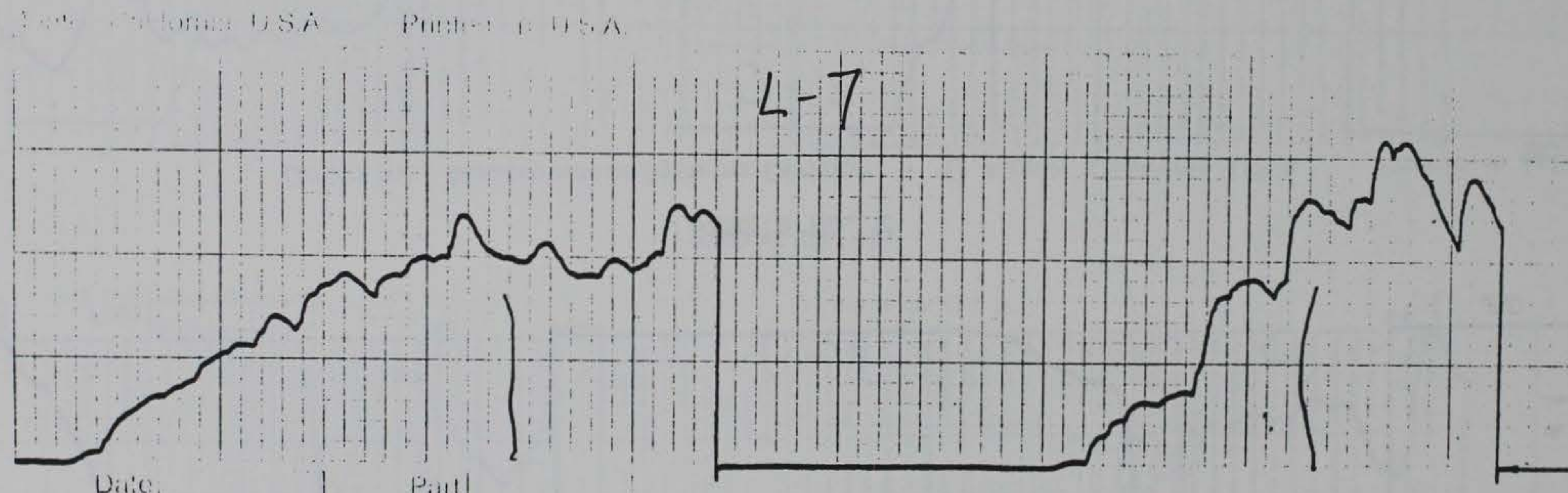

Figure B31. Arithmetic average measurements on limestone 
Sample No. 1

a US.A Printed in U.S.A.

Gould Inc., Nieasurem

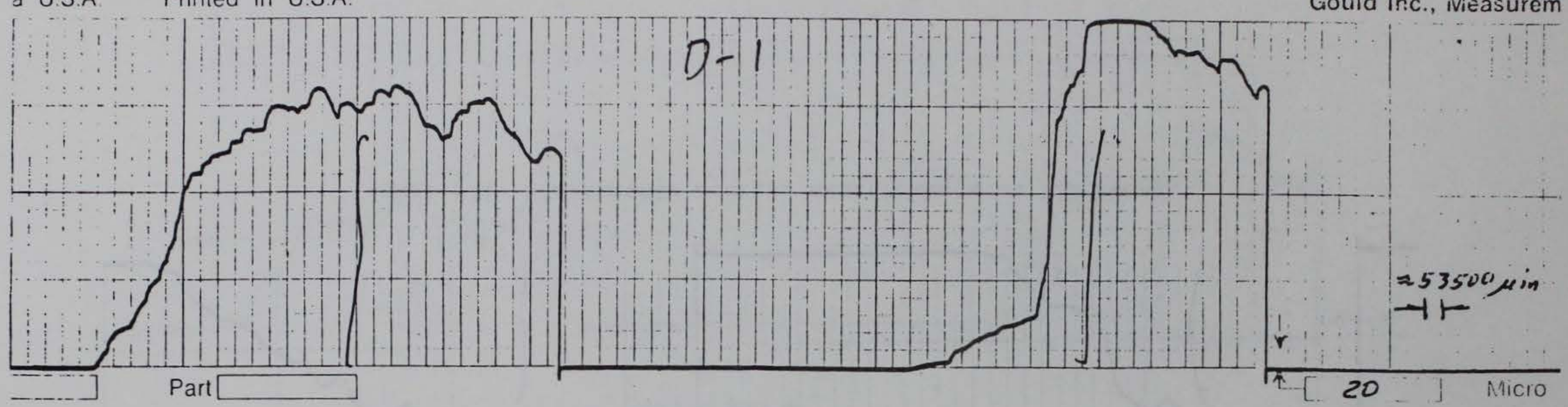

Sample No. 2

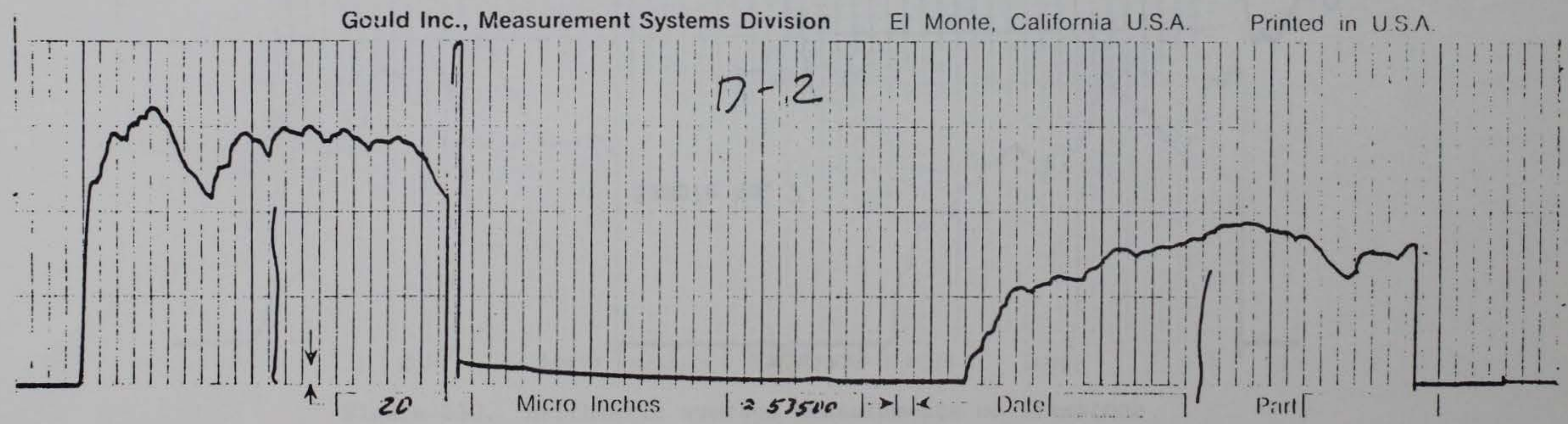

Figure B32. Arithmetic average measurements on dolomite 
Sample No. 3

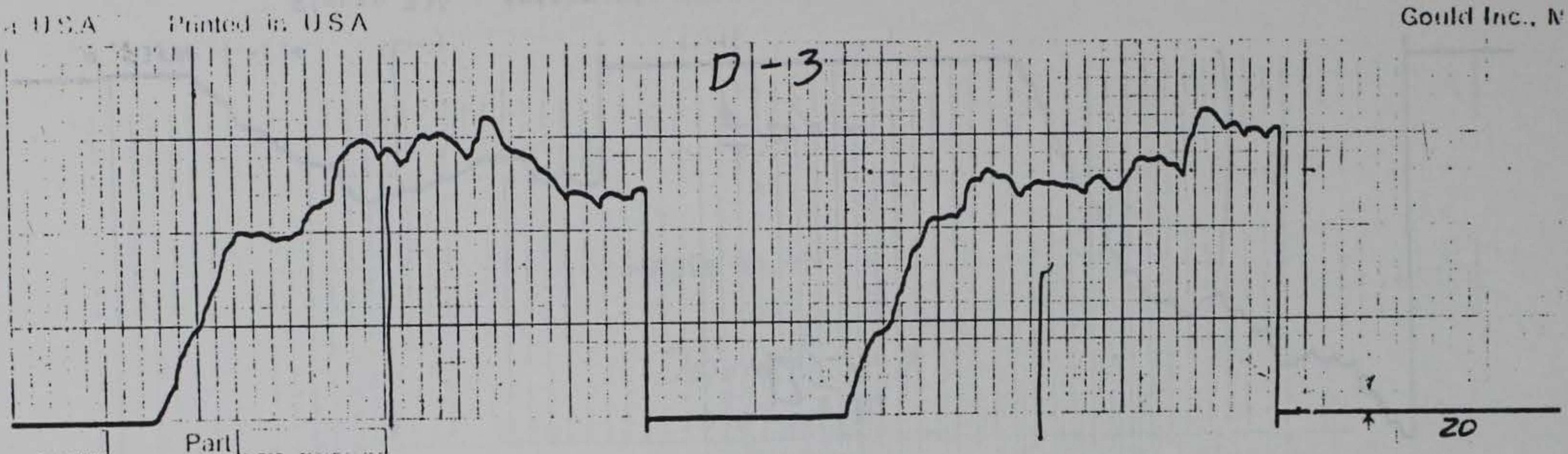

芯

\section{Sample No. 4}

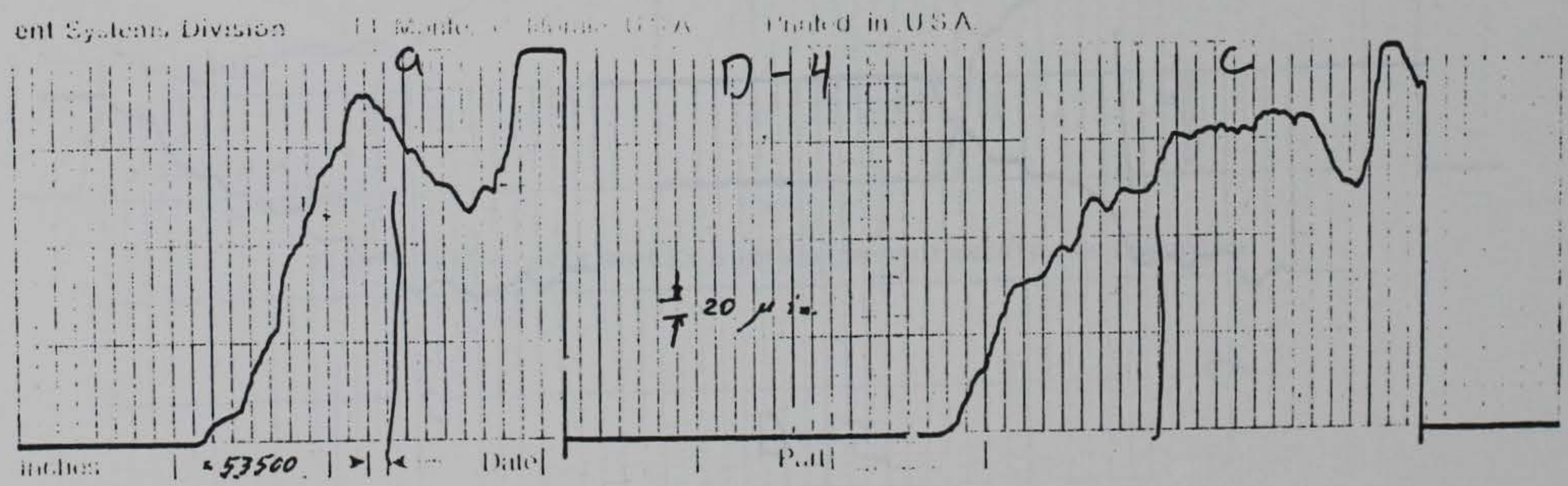

Figure B33. Arithmetic average measurements on dolomite 
Sample No. 5

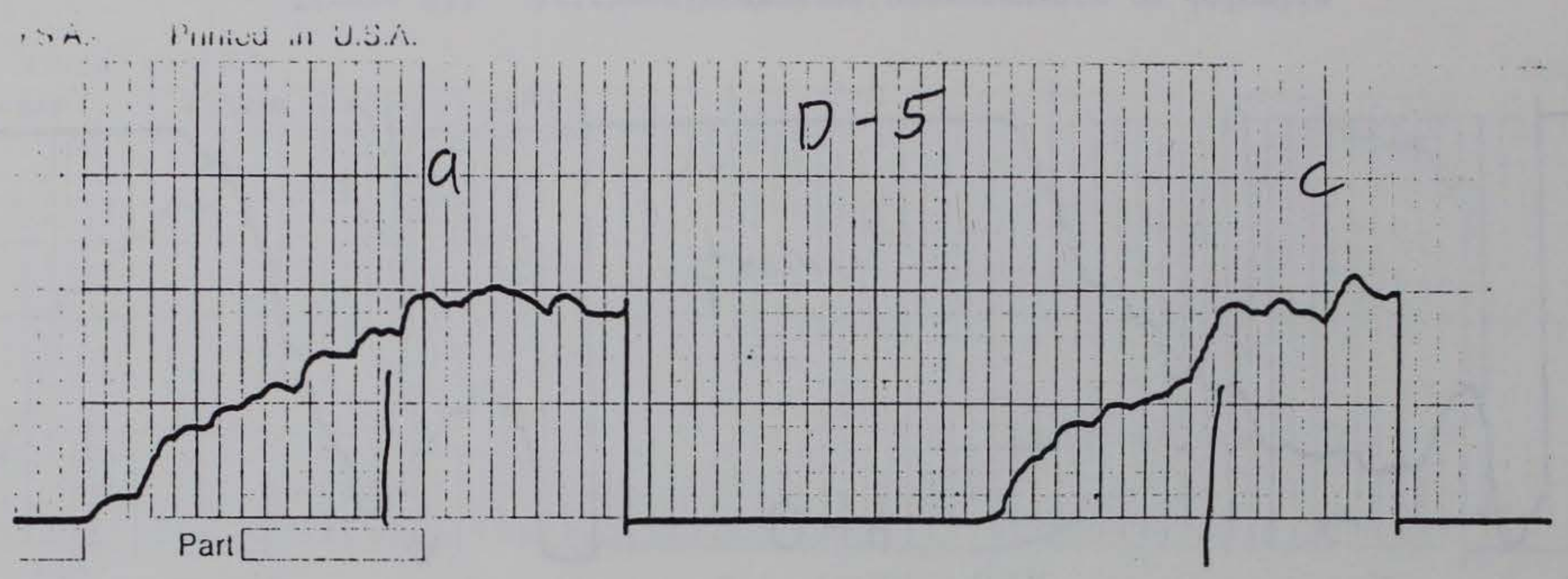

$\underset{\omega}{\omega}$

Sample No. 6

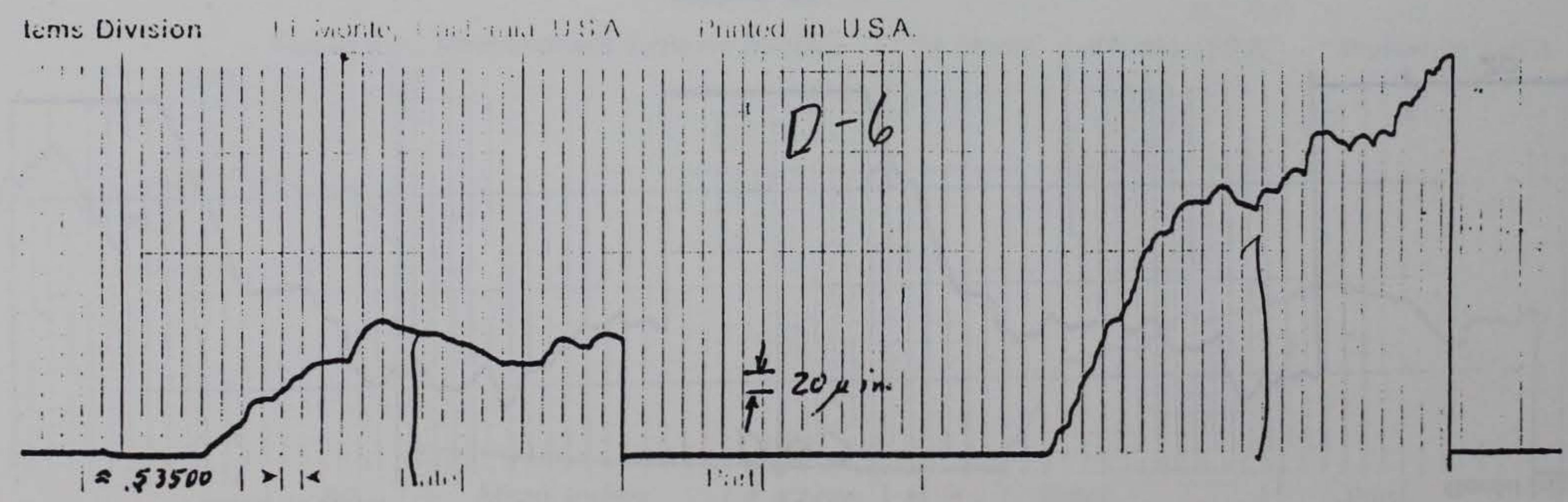

Figure B34. Arithmetic average measurements on dolomite 
Sample No. 7

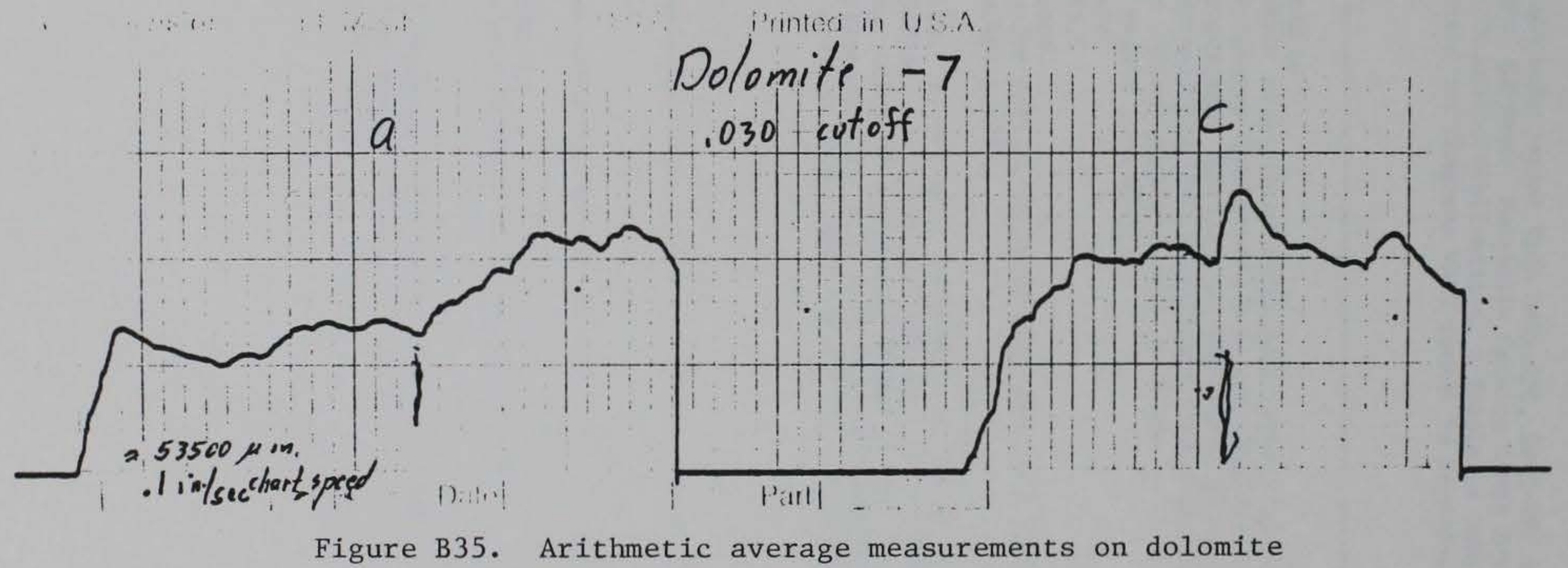

